\title{
Novel insights in the congenital long QT-3 syndrome
}

\author{
Citation for published version (APA):
}

Wehrens, X. H. T. (2002). Novel insights in the congenital long QT-3 syndrome. [Doctoral Thesis, Maastricht University]. Universiteit Maastricht. https://doi.org/10.26481/dis.20020322xw

Document status and date:

Published: 01/01/2002

DOI:

10.26481/dis.20020322xw

Document Version:

Publisher's PDF, also known as Version of record

\section{Please check the document version of this publication:}

- A submitted manuscript is the version of the article upon submission and before peer-review. There can be important differences between the submitted version and the official published version of record.

People interested in the research are advised to contact the author for the final version of the publication, or visit the DOI to the publisher's website.

- The final author version and the galley proof are versions of the publication after peer review.

- The final published version features the final layout of the paper including the volume, issue and page numbers.

Link to publication

\footnotetext{
General rights rights.

- You may freely distribute the URL identifying the publication in the public portal. please follow below link for the End User Agreement:

www.umlib.nl/taverne-license

Take down policy

If you believe that this document breaches copyright please contact us at:

repository@maastrichtuniversity.nl

providing details and we will investigate your claim.
}

Copyright and moral rights for the publications made accessible in the public portal are retained by the authors and/or other copyright owners and it is a condition of accessing publications that users recognise and abide by the legal requirements associated with these

- Users may download and print one copy of any publication from the public portal for the purpose of private study or research.

- You may not further distribute the material or use it for any profit-making activity or commercial gain

If the publication is distributed under the terms of Article $25 \mathrm{fa}$ of the Dutch Copyright Act, indicated by the "Taverne" license above, 
Novel Insights in the Congenital Long QT-3 Syndrome 
(c) Xander H.T. Wehrens MD, MaAstricht 2002

All rights reserved. No part of this book may be translated or reproduced in any form by photo, photoprint, microfilm or any other means without written permission from the publisher.

ISBN 90-9015-470-1

DESICN AND LAYOUT

Maas \& van den Homberg designers, Maastricht

Printine AGency

Scorpio Offset bv 


\section{Novel Insights in the Congenital Long QT-3 Syndrome}

PROEFSCHRIFT

ter verkrijging van de graad van doctor

aan de Universiteit Maastricht

op gezag van Rector Magnificus

Prof. Dr. A.C. Nieuwenhuijzen Kruseman,

volgens het besluit van het College van Decanen,

in het openbaar te verdedigen

op vrijdag 22 maart 2002 om 16.00 uur

door

Xander Hennie Theo Wehrens

geboren te Heerlen 
PROMOTORES

Prof. dr. H.J.J. Wellens

Prof. dr. R.S. Kass (Columbia University, New York)

CO-PROMOTORES

Dr. P.A. Doevendans

Dr. M.A. Vos

BEOORDELINGSCOMMISSIE / ASSESSMENT COMMITTEE

Prof. dr. H.A.J. Struijker Boudier (voorzitter)

Prof. dr. E. Carmeliet (Katholieke Universiteit Leuven, België)

Prof. dr. H.J.G.M. Crijns

Prof. dr. J.P.M. Geraedts

Prof. dr. A.A.M. Wilde (Universiteit van Amsterdam)

Financial support by the Netherlands Heart Foundation for the publication of this thesis is gratefully acknowledged.

ADDITIONAL. FINANCIAL SUPFORT WAS GRANTED BY:

3 M Pharma Nederland BV, ASTA Medica BV, Astra Zeneca BV, Bayer Nederland BV, Bristol-Myerș Squibb BV, Dr. Saal vạn Zwạnenbẹtgștichting. Guidạnt BV,

Medtronic - Bakken Research Center BV, Merck Sharp \& Dohme BV, Novartis Pharma BV, Pfizer BV, Rescar Foundation Maastricht, Roche Nederland BV, Sanofi-Synthélabo BV,

St. Jude Medical Nederland BV, Wijnand M. Pon Stichting, Yamanouchi Pharma BV. 
'Sei allem Abschied voran, als wäre er hinter

dir, wie der Winter, der eben geht.

Denn unter Wintern is einer so endlos Winter,

dab, überwinternd, dein Heiz überhaupt übersteht.'

Rainer Maria Rilke, Sonette an Orpheus, 2/XIII (1922) 



\section{Contents}

CHAPTER 1 Clinical Aspects of the Congenital Long-QT Syndrome

CHAPTER 3 Arrhythmogenic Mechanism of the Di7goG Mutation

of the Human Heart $\mathrm{Na}^{+}$Channel $\alpha$-Subunit

CHAPTER 4 Molecular Pharmacology of the Sodium Channel

Mutation Di7goG Linked to the Long.QT Syndrome

CHAPTER 5 Novel Arrhythmogenic Mechanism Revealed by

a Long-QT Syndrome Mutation in the Cardiac $\mathrm{Na}^{+}$Channel

CHAPTER 6 Heterozygous SCN5A Mutation in the Domain I-II Linker causes Long-QT Syndrome with 2:1 Atrioventricular Block

CHAPTER 7 General Discussion

Summary

Samenvatting

Summarium

Acknowledgments

Curriculum Vitae 


\section{Chapter 1}

Clinical Aspects of the Congenital Long-QT Syndrome

Based on:

WEHRENS XHT, Vos MA, Doevendans PA, Wellens HJ].

Novel Insights in the Congenital Long.QT Syndrome.

Ann Internal Med 2002, in press. 


\section{Abstract}

Purpose. To review new insights in the genetics and cellular electrophysiology, as well as the current understanding of the clinical diagnosis and treatment of the congenital longQT syndrome.

DAtA SOURCEs. Personal databases of the authors and a search of the PubMed database from 1966 to 2001.

StudY SELECTION. Experimental and clinical studies on the congenital long-QT syndrome.

DATA EXTRACTION. From peer-reviewed studies, data were manually extracted, classified, and summarized.

DATA SYNTHESIS. The congenital long-QT syndrome is characterized by abnormally prolonged ventricular repolarization, which predisposes patients to syncope, ventricular arrhythmias and sudden cardiac death. The recent discovery that mutations in genes encoding ion channels are responsible for the manifestation of this disease has improved our understanding of the cellular origin of this condition. Long-QT syndrome may result from inherited defects in cardiac $\mathrm{K}^{+}$and $\mathrm{Na}^{+}$channels, which both result in prolongation of the ventricular action potential. The diagnosis is based on electrocardiographic and clinical criteria. In addition, genetic screening of symptomatic patients or asymptomatic family members may identify patients at risk for life-threatening ventricular arrhythmias. Beta-blocking agents are the mainstay in the treatment. In addition, certain patients may benefit from a pacemaker or implantable cardioverter-defibrillator. Recent studies suggest that in the near future, genotype-specific treatment will become a novel approach to the congenital long-QT syndrome.

CONCLUSIONS. The congenital long-QT syndrome is a potentially life-threatening condition caused by mutations in genes encoding cardiac ion channels. The mechanisms responsible for these conditions are being increasingly better understood, and will guide genotypespecific therapy in the near future. 


\section{Introduction}

Over the past decade, the discovery of mutations in genes encoding ion channels (1) has helped to better understand the mechanism of the congenital long-QT syndrome, an inherited disease characterized by prolonged ventricular repolarization and a propensity for life-threatening ventricular tachyarrhythmias resulting in syncope and sudden death (2). Current estimates suggest that 1 in 10,000 persons are gene carriers, and that long-QT syndrome causes $3000-4000$ sudden deaths in children and young adults each year in the US only (3). The two major clinical syndromes that have been characterized on the basis of the genetic transmission pattern are a more common autosomal-dominant form (RomanoWard syndrome) with a pure cardiac phenotype $(4,5)$ and a rarer autosomal-recessive form (Jervell and Lange-Nielsen syndrome) characterized by the association with congenital neuronal deafness (6). Long-QT syndrome, occurring secondary to electrolyte disturbances or drug-therapy, is called acquired long-QT syndrome (7).

As a consequence of the genetic information, it became clear that what has been classified under the unifying name of the long-QT syndrome, actually represents a variety of different diseases caused by ion channel mutations, all producing alterations in ionic currents, leading to the same end result: prolonged ventricular repolarization (8). In addition, the first ion channel gene mutations and polymorphisms that predispose people to drug-provoked QT-interval prolongation and ventricular arrhythmias have been identified $(9,10)$.

In this review, we A) classify the forms of congenital long-QT syndrome; B) discuss the proposed explanations of the cellular electrophysiology of the syndrome; C) review the clinical characteristics; and D) discuss the identification and management of patierits with congenital long-QT syndrome, including novel approaches such as genotype-specific therapies. 


\section{Historical Remarks on the Congenital Long-QT Syndrome}

The first report of the long-QT syndrome probably dates back to 1856. Meissner related the case of a girl, pupil at the Leipzig School of the Deaf, who collapsed and died while publicly admonished by the Director for a misdemeanor (151). One of her siblings had previously died suddenly after a terrible fright and another after a violent fit of rage (151). In 1901, before the electrocardiogram was widely available, Morquio reported a large Uruguayan family in which several siblings repetitively collapsed and died at a young age (152).

Latham and Munro described in 1937 a family with consanguineous marriage, in which all five children suffered fram congenital deafness in association with spells that were interpreted as epileptic spells. One of these children died unexpectedly (153). In 1953. Herrlin and Möller reported the case of a congenitally deaf boy with frequent episodes of syncope, and described, for the first time, the electrocardiographic (ECG) features of the long-QT syndrome: a prolonged QT-interval, abnormal $T$ waves in the precordial leads, and bradycardia (154).

The case report by Drs. Jervell and Lange-Nielssen, who described the association of congenital deafness with typical ECG abnormalities, in conjunction with fainting attacks and a propensity to sudden death, fully recognized the clinical picture and possible relevance of the disease (G). Soon thereafter, Drs. Romano (4,755), and Ward (5) described independently that fainting attacks and inherited QT-interval prolongation also occurred in the absence of neuronal deafness. The Romano-Ward syndrome (RWS) is now known as the long-QT syndrome with an autosomal-dominant mode of inheritance, although a recessive variant has also been reported recently (19). The Jervell Lange-Nielssen syndrome (JLN), on the other hand, inherits in an autosomal-recessive way $(6,156-160)$. The concomitant neuronal deafness may not always be complete (158), and may be inherited separately from the cardiac defect in certain families (161). 


\section{Methods}

We searched the PubMed database for literature on the congenital long-QT syndrome, focusing on advances in the four specified areas (A-D). From peer-reviewed studies, data were manualily extracted, classified, and summarized.

\section{A. Genetics of the Congenital Long-QT Syndrome}

Genetic linkage mapping of the autosomal-dominant Romano-Ward syndrome has so far identified loci on six chromosomes (LQT-1 to LQT-6) (11-17). The autosomal-recessive variant (Jervell Lange-Nielssen syndrome) arises in individuals who inherit abnormal KCNQ1 (= KvLQT1) or KCNE1 (= minK) alleles from both parents (LQT-1, LQT-5).

The abnormal gene can be the same (usually in consanguineous families) or different (so-called compound heterozygosity) (18). Parents of subjects with Jervell Lange-Nielssen syndrome are heterozygous for long-QT syndrome mutations, but are usually (but not always) asymptomatic (i9). Most long-QT syndrome genes encode $\mathrm{K}^{+}$channels, with the exception of the LQT-3 gene ( $\left.S C N_{5} A\right)$ that encodes the cardiac $\mathrm{Na}^{+}$channel (current indicated by $\left.\mathrm{I}_{\mathrm{Na}}\right)(2 \mathrm{O})$.

Mutations in either the $\alpha$-subunit encoded by KCNQ1 (LQT-1) or the $\beta$-subunit encoded by KCNE1 (LQT-5) can cause defects in the $I_{\mathrm{Ks}}$ current. Similarly, mutations in the LQT-2 $\left(K C N H_{2}=\right.$ HERG $)$ and LQT-6 $\left(K \mathrm{KNH}_{2}=\right.$ MiRP 1$)$ genes encoding the $\alpha$ - and $\beta$-subunit of the rapidly activating delayed rectifier $\mathrm{K}^{+}$channel $I_{\mathrm{K} r}$, respectively, may cause long-QT syndrome (17).

\section{B. Functional Consequences of Long-QT Syndrome Mutations}

The channels carrying the $I_{\mathrm{Ks}}$ and $I_{\mathrm{Kr}}$ potassium currents are multimeric (15,16); a!leles from both parents are thought to contribute to the channel complexes (21). Using 
FICURE 1.1

(A) The ventricular action potential is initiated by current flow through cardiac $\mathrm{Na}^{*}$ channels (depolarization, phase o). Early repolarization (1) is caused by the $\mathrm{K}^{+}$current $\mathrm{I}_{\mathrm{TO}}$

The action potential platean phase (2) is maintained by I Ca,L

$I_{K_{n}}$ and $I_{K_{3}}$ currents, and late repolarization (3) is caused by current flow through $I_{K s}$ and $I_{K}$.

channels. The dotted line represents action potential prolongation as can be observed in the congenital long-QT syndrome.

(B) In case of LQT-3, most mutations in the SC5NA gene cause a small non-inactivating

sodium current that remains active during the action potential plateau phase (dotted) and provides an additional depolarizing current, which prolongs repolarization.

(C) The KCNQ1 gene encodes the slowly activating delayed rectifier

$\mathrm{K}^{+}$channel which conducts the

$I_{K s}$ current. In case of LQT-1, reduced $I_{K s}$ activity leads to action potential prolongation.

(D) The $\mathrm{KCNH}_{2}$ gene encodes

the rapidly activoting delayed rectifier $\mathrm{K}^{+}$channel which conducts the $I_{K r}$ current. in LQT:-2, a reduction of $I_{K_{r}}$ causes prolongation of the repolarization phase (dotted line).
A

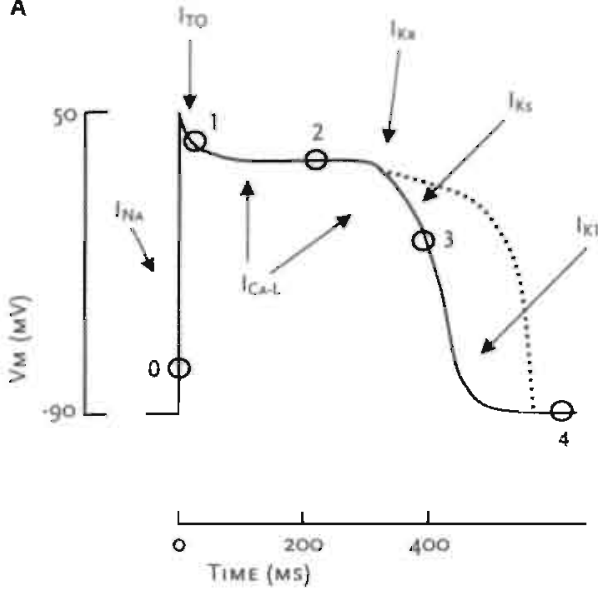

B

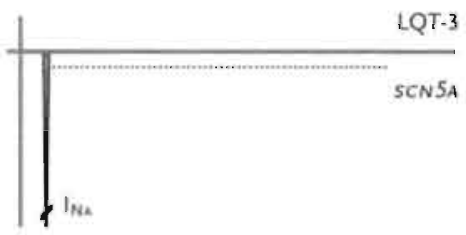

C

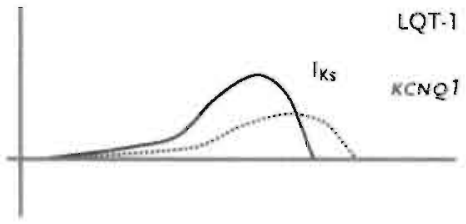

D

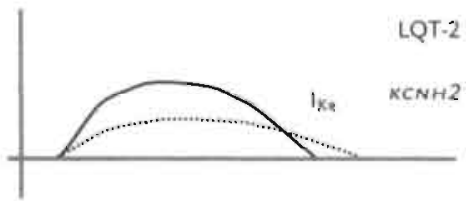

heterologeous expression systems like Xenopus oocytes or mammalian cell lines, mutations in $K C N Q_{1}, K C N E_{1}$, $\mathrm{KCNH}_{2}$, or KCNE2 expressed alone or in combination with wild-type alleles, typically exhibit a 'loss of function' (FICURE 1,1). The total current carried by the defective potassium channel complexes is impaired by reduced gating, modified channel kinetics, or non-expression at the plasma membrane level by deficient transport from the endoplasmatic reticulum. Because potassium channels are tetrameric proteins, there is also the potential for the presence of a single (or more) mutant subunit in a tetramer to disrupt the function of the remaining wildtype subunits (so-called dominant-negative effect) $(22-25)$. Mutations in the cardidc $\mathrm{Na}^{+}$channels linked to LQT-3 generally promote additional $\mathrm{Na}^{+}$channel activity during the plateau phase of the action potential leading to an extra component of inward current $(26,27)$. This additional inward current would be expected to prolong repolarization and hence underlie the phenotype in carriers of these SCN $5 A$ mutations $(8,28)$. However, this gain-of-function persistent $\mathrm{Na}^{+}$current is not observed in all SCN5A mutations (29), which implies that heterogeneity in arrhythmogenic mechanisms exists among $\mathrm{Na}^{+}$channel-related long-QT syndrome. 


\section{Clinical Characteristics}

The International Long-QT Syndrome Registry was started in 1979 to study prospectively epidemiological and genetic characteristics (30-33). In (symptomatic) probands, $50 \%$ had experienced a first cardiac event by the age of 12 years, and by the age of 40 years this had increased to almost $90 \%$ (33). Multivariate analysis identified as independent risk factors for syncope or sudden cardiac death: congenital deafness, history of syncope, female gender, documented torsades de pointes or ventricular fibrillation, age at first episode and the long-QT syndrome gene affected (31-35). The QTC duration was independently associated with the risk of syncope or sudden death during follow-up (33). These results

ECG findings $(1)$
a. QTC (2)
$2480 \mathrm{~ms}^{1 / 2}$ $460-480 \mathrm{~ms}^{1 / 2}$ $450.460 \mathrm{~ms}^{1 / 2}$ (in males)
b. Torsades de pointes (3)
c. T wave alternans
d. Notched T wave in 3 leads
e. Low heart rate for age (4)

Points

3
2
1
2
1
1
0.5

Clinical history
a. Syncope
With stress
Without stress
b. Congenital deafness

Family history (5)

a. Family members with 'definite' long-QT syndrome (6)

b. Unexplained sudden cardiac death < 30 yr among immediate family members
TABLE 2.3

Diagnostic criteria for the long. $Q T$ syndrome:

(1) In the absence of medication or disorders known to affect these electrocardiographic features;

(2) QT calculated with Bazet!'s formulo $(Q T c=Q T / \sqrt{ } R R)$; (3) No points if patient is taking drugs to favor QT prolongation; (4) Resting heart rate below second percentile for age (45); (5) The same family member can not be counted in A and B; (6) 'Definite' long-QT syndrome is defined as long-QT syndrome score of $\geq 4$. SCORING: $\geq 1$ point, low probability of long-QT syndrome; $2-3$ points, intermediate probability. Adapted from: Schwartz PJ et al. 1993 (46). 
are in line with the finding that QT-interval prolongation in an apparently healthy population $(36,37)$ correlates to an increased risk of mortality. The question whether the QTC variability over time correlates with mortality remains to be resolved (38).

\section{The Influence of Age and Gender}

Since the QT-interval duration is shorter in adult males than females, (39-44), a diagnosis of QT prolongation could be made relatively more often in adult females. However, after the introduction of the 1993 diagnostic criteria for long-QT syndrome (TABLE 1.1), that define sex specific criteria for QT duration, such bias leading to a female predominance is less likely. Nevertheless, a female predominance is consistently reported in clinical studies $(32,33,43)$. In males, the risk of first cardiac events is typically higher in childhood, and decreases after puberty, probably due to a regression of QTC duration $(40,42,43,47,48)$.

\section{The Influence of Pregnancy}

Probands with the hereditary long-QT syndrome are at significant risk for cardiac events during the postpartum interval, nearly $10 \%$ of the probands in the study by Rashba et al. (49) experienced their first cardiac event during the postpartum interval. The most important factors contributing to this risk may be related to an increase in sympathetic activity $(2,50)$, or to increased levels of estrogen and progesterone that directly or indirectly influence the number and function of mutant ion channel proteins $(51,52)$. Treatment with $\beta$-blockers can reduce the risk for cardiac events (49).

\section{Identification and Management of Long-QT Syndrome Patients}

Sudden death or a history of unexplained syncope in a child or young adult can bring the patient or family member under the clinician's attention. After informing the patient, an ECC should be recorded, and a detailed family history for syncope and sudden cardiac death should be taken. Many mutation carriers are asymptomatic despite the fact that they display electrocardiographic characteristics of long-QT syndrome. Another group consists of individuals that have been identified as mutation carriers without symptoms or ECG features (21), or they only intermittently display ECC signs. We recommend genetic 
analysis or referral to a specialized combined genetic-cardiology out-patient clinic for all of these patients, as the study of long-QT mutations may aid to better understand the pathophysiology of the disease, and may help to develop mutation-specific therapies in the near future (53). In addition, there is a group of patients that carries ion channel mutations or polymorphisms, predisposing them to drug-induced long-QT syndrome (9).

The following four paragraphs will discuss identification and management of these subgroups of long-QT syndrome patients.

\section{Patients with Symptoms of Congenital Long-QT Syndrome}

\section{Symptoms}

Vertigo, syncopal attacks, cardiac arrest, and unexplained sudden cardiac death among immediate family members, or family members with definite long-QT syndrome point to inheritance of an affected gene. Neurally mediated syncope and epileptic seizures are the most common differential diagnoses (54). A careful history of symptoms and signs can often clarify this diagnostic dilemma. Sudden cardiac death during sleep should also raise suspicion of the long-QT syndrome, particularly the LQT-3 phenotype (55).

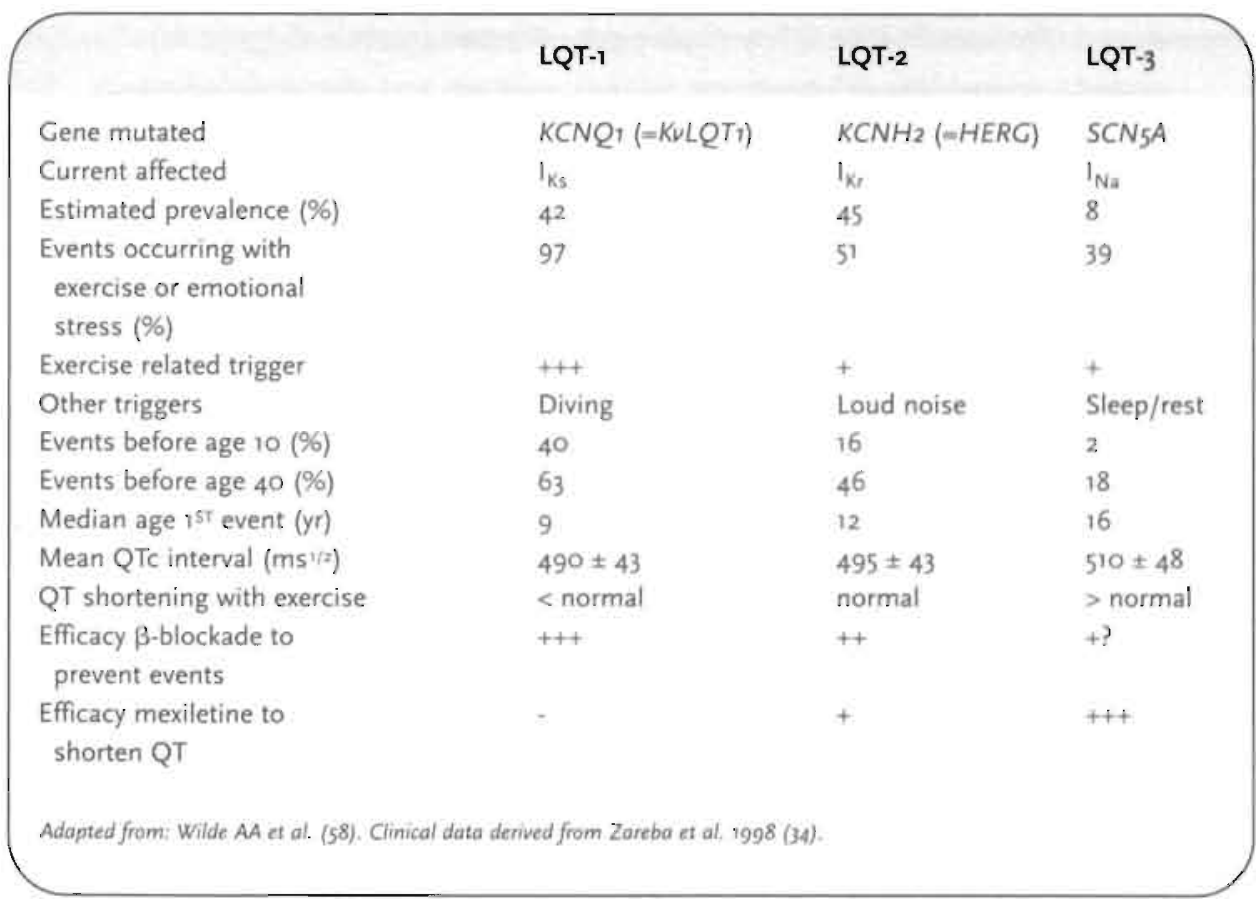

TABLE 1.2

Clinical characteristics in common genotypes of congenital long.QT syndrome. 


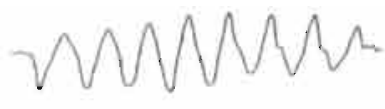

Example of torsades de pointes tachyarrhythmia.
The clinical course of the long-QT syndrome is importantly influenced by the gene affected (34). By age of 15 , almost $60 \%$ of LQT-1 patients have had a cardiac event (syncope, cardiac arrest, or sudden cardiac death), compared to less than $10 \%$ in LQT-3 patients (34,35). The number of cardiac events that occurred till the age of 40 years was also higher among LQT-1 (63\%) or LQT-2. subjects $(46 \%)$ compared to LQT-3 (18\%). In contrast, the likelihood of death during a cardiac event was much higher among LQT-3 (20\%) compared to LQT-1 and LQT-2 (4\%) (36) (TABLE 1.2). Due to the low number of patients, no data are available yet for LQT-4, LQT-5 and LQT-6 patients.

\section{Triggers for Syncopal Events}

Episodes of sudden loss of consciousness are almost always due to TORSADES DE POINTES ARRHYTHMIAS in long-QT patients (57). Torsades de pointes can be defined as a polymorphic ventricular arrhythmia showing a peculiar electrocardiographic pattern characterized by a continuous twisting of the QRS axis around an imaginary baseline (58). An important characteristic of torsades de pointes is its potential for self-termination or deterioration into ventricular fibrillation. This explains why affected patients often survive several syncopal attacks before succumbing to a lethal one.

Recently, it has become evident that triggers for arrhythmic episodes and syncope are also dependent on the specific long-QT syndrome gene affected (TABLE 1.2) (35.59-61).

In $\mathrm{I}_{\mathrm{ks}}$-related long-QT syndrome (LQT-1), exercise- and stress-related events dominate the clinical picture $(48,59,62,63)$, which is related to activation of the $I_{\mathrm{Ks}}$ current by adrenergic stimulation (64). Diving and swimming, as triggers, are almost exclusive for LQT-1 patients $(35,60)$. Patients with LQT-3-associated $\mathrm{Na}^{+}$channel mutations are at particularly high risk at rest or asleep because their QT-interval is prolonged excessively at slow heart rates $(63,65)$. This clear distinction between LQT-1 and LQT-3 with respect to exercise-related triggers does not hold for LQT-2 patients, who tend to display events both at rest and during exercise (59). However, events provoked by auditory stimuli such as an alarm clock or telephone ringing almost exclusively occur in LQT-2 patients $(35.59,60,66,67)$. No data are available yet for LQT-4, LQT-5 and LQT-6 patients.

\section{Treatment Options for Symptomatic Patients}

Symptomatic individuals require treatment $(32,33,68)$. It is important to inform patients and their parents well about the importance of compliance, as noncompliance exposes patients to increased risk of cardiac events. This often requires frequent counseling of young patients to motivate them to continue to take their medication while they are 
asymptomatic. Based on the observations that physical and emotional stress are important triggers for cardiac events in long.QT syndrome (type 1 and 2) patients $(35.59,61)$, nonmedical treatment should also include life-style advice and information on certain drugs that should be avoided because of their potential to prolong QT-intervals. Competitive sports should be generally discouraged, but recreational sports that do not cause sudden increases in heart rate are usually tolerated well. Finally, patients are instructed how to respond to excessive electrolyte loss, e.g. during diarrhea or excessive perspiring. Patients are advised to take drinks that contain minerals such as potassium.

\section{BETA-BLOCKER THERAPY}

Administration of $\beta$-blocking drugs is very effective in preventing ventricular arrhythmias in the long-QT syndrome, although the response is genotype-dependent $(5,69-72)$.

The 10-year mortality rates among symptomatic patients dropped from approximately $50 \%$ when not treated to below $5 \%$ after long-QT syndrome patients were routinely put on $\beta$-adrenergic receptor blocking therapy $(32,33)$. A recent retrospective study by Moss et al. (68) among 869 long-QT syndrome patients revealed a significant reduction in the rate of cardiac events in both probands and affected family members after initiation of betablocking therapy. In patients with aborted cardiac arrest before $\beta$-blocker therapy, the probability of aborted cardiac arrest or sudden death was $6.6 \%$ when using $\beta$-blockers (68). In patients with recurrent cardiac symptoms or aborted cardiac arrest, $\beta$-blocker therapy might not be completely effective in preventing sudden cardiac death, and implantable cardioverter defibrillater (ICD) therapy is warranted for these high-risk patients. An important criticism to this study is the retrospective nature without evidence that patients continued to take their $\beta$-blockers. After it became clear that the long-QT syndrome is caused by ion channel mutations and probably not by IMBALANCE OF THE CARDIAC AUTONOMOUS NERVOUS SYSTEM, the rationale for performing left cardiac denervation has become less obvious.

\section{CARDIAC PACING}

As the onset of torsades de pointes arrhythmias in long-QT syndrome patients has been associated with bradycardia or pauses during sinus rhythm (73-75). permanent cardiac pacing has been recommended as an adjuvant to $\beta$-blocker therapy in patients who also have bradycardia or atrioventricular conduction disturbances (76-81), or in carriers of SCN5A mutations who usually have slow heart rates $(82,83)$. In addition, cardiac pacing can be an important adjuvant therapy in those patients in whom $\beta$-blocking drugs and left 


\section{The Sympathetic Imbalance Theory}

In the seventies and eighties, two opposing hypotheses existed concerning the pathogenetic mechanisms in the congenital long-QT syndrome (LQTS). The 'sympathetic imbalance' theory $(2,50,162)$ and the hypothesis of a 'primary myocardial membrane defect' $(74,75,163)$ were put forward.

The first hypothesis considered a critical role of the autonomic nervous system in the pathogenesis of LQTS on the basis of clinical observations $(162,164)$ and experimental results $(50,165)$. Basically, QT prolongation and T wave altemation could be induced by either left stellate ganglion stimulation or blockade of the right stellate ganglion. These observations suggested that LQTS might have a congenital imbalance between the right and left

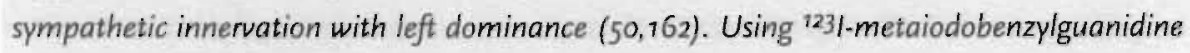
(MIBC) single-photon emission tomography (SPECT) scintigraphy $(766,767)$, some studies demonstrated impaired regional sympathetic innervation in LQTS patients. In contrast, using "C-hydroxyephedrine (HED) positron emission tomography (PET), others showed a normal cardiac sympathetic innervation in LQTS patients (168). Although it is now generally believed that an abnormal distribution of cardiac sympathetic nerves is not a common mechanism in congenital LQTS, it cannot be excluded that the observed MIBG defects might have been regions of enhanced sympathetic activity according to (A) the hypothesis of hyperactivity of left sympathetic nerves (165), and (B) echocardiographic obsenvations of an increased rate of thickening in the posterior wall, possibly related to increased sympathetic activity in this region (169).

Based upon the assumed pathogenesis of the disease, therapy with $\beta$-blockers and surgical left sympathetic denervation was performed (164). The rational of left cardiac sympathetic denervation was to shorten the QT-interval (107), and to protect against ventricular arrhythmias (170). In a world-wide report on 85 patients with left cardiac sympathetic denervation. Schwartz and colleagues reported a decrease in the number of patients with cardiac events, and in the number of cardiac events per patient (171). Although a low five-year mortality rate of $6 \%$ was reported, the study was not designed to allow a conclusive analysis of a possible beneficial effect on mortality. Because few other groups were able to reproduce these findings, left sympathectomy is not a commonly used treatment option anymore for drug-refractory patients. Combination therapy of $\beta$-blockers with a pacemaker, or alternatively, an implantable cardioverter defibrillator are often preferred nowadays (87). 
stellate ganglionectomy have proven inefficacious, even if bradycardia or conduction disturbances are not present (84). Cardiac pacing should be aimed at preventing (A) bradycardia, by using a relatively high lower rate limit ( $\geq 80$ beats $/ \mathrm{min}$ ), and $(B)$ pauses, by using pause-prevention pacing algorithms such as rate-smoothing. Applications of cardiac pacing were reviewed by Viskin (82).

\section{IMPLANTABLE CARDioverter Defibrillators}

Implantable cardioverter defibrillators are increasingly being used in an attempt to prevent sudden cardiac death $(85,86)$. Aborted sudden cardiac death and recurrent symptoms while on combincu $\beta$-blocker and pacemaker therapy are the most frequent indications for ICD implantation (85-87). Since the ICD does not alter the underlying substrate leading to arrhythmias, it is recommended to initiate or continue $\beta$-adrenergic blockade therapy (88).

\section{Towards a Genotype-specific Therapy of Symptomatic Long-QT Patients} The emerging sense that gene-specific therapy might be feasible for some forms of longQT syndrome has recently been supported by clinical and experimental studies. One of the first attempts studies showed that LQT-3 patients shorten their QT-interval more in response to a $\mathrm{Na}^{+}$channel blocker (mexiletine) compared to LQT-1 and LQT-2 patients (89). As most LQT-1 patients experience syncopal events during exercise, competitive sports should be avoided. As diving and swimming are particularly strong triggers for cardiac events in $\mathrm{LQT}^{-1}$ patients, it should be strongly discouraged $(35,60,90)$. LQT-2 patients should be advised to remove sources of loud noise from their direct environment (such as telephone and alarm clocks).

Patients with LQT-I and LQT-2 genotypes typica!ly benefit from $\beta$-blocker therapy $(35,68)$. Because the amplitude of $I_{K r}$ increases when extracellular potassium concentrations are increased $(91,92)$, attempts have beeñ lnidertaken to increase $K^{+}$levels in LQT-2 patients by means of intravenous potassium infusion or administration of the diuretic spironolacton (93). Indeed, QT-intervals have been shown to shorten significantly in LQT-2 (94) but also LQT-1 (95) patients. Potassium supplementation is, however, hindered by difficulties in achieving sufficiently high $\mathrm{K}^{+}$concentrations with chronic oral therapy (96). On the other hand, nicorandil, a $\mathrm{K}^{+}$channel opener, has been shown to normalize repolarization abnormalities induced by epinephrine infusion in LQT-7 patients (97).

A beneficial effect of $\beta$-blocker therapy has not been demonstrated for LQT-3 patients $(35,68)$. Since LQT-3 patients are at higher risk at slow heart rates, they may benefit from pacemaker therapy. Several clinical and experimental studies suggest a. 


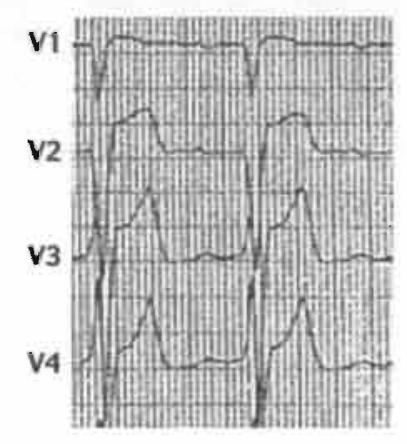

Typical ECC of a patient with Brugada syndrome, showing right precondial ST-segment elevation. beneficial effect of $\mathrm{Na}^{+}$channel blockers such as lidocaine/ mexiletine $(89,98,99)$, tocainide $(98)$, or flecainide $(83)$ in LQT-3 patients, although long-term follow-up data are not available yet. It should be noted, however, that flecainide may cause ECC changes reminiscent of the Brugada-syndrome (familial idiopathic ventricular fibrillation) in a significant number of LQT-3 patients (100). The BRUGADA SYNDROME is characterized by right bundle branch block and ST-segment elevation in the right precordial leads on the ECG, and may lead to ventricular fibrillation and sudden cardiac death (101). The impact of the flecainide-induced changes, which might suggest the introduction of a different arrhythmogenic substrate, is currently unknown. A further therapeutic differentiation on the basis of the specific mutations in the affected gene can be expected in the near future.

\section{Patients Without Symptoms but With Electrocardiographic Characteristics \\ Suggestive of Long-QT Syndrome}

Some individuals are not identified on the basis of their symptoms, but because of typical electrocardiographic features suggestive of long-QT syndrome. The principal diagnostic hallmark of the long-QT syndrome is lengthening of the QT-interval on the 12-lead ECG. As the QTC value is often not sufficiently long to make or exclude the diagnosis in borderline cases, an elaborate point scoring system that goes beyond QTC duration was developed by Schwartz et. al. (46) (TABLE 1.1).

\section{QT Prolongation}

QT-interval prolongation is usually most easily identified in lead $11, V_{1}, V_{3}$, or $V_{5}$, but all 12 leads should be examined to identify the longest QT-interval (104-106). Despite ongoing criticism, Bazett's correction formula (QTC $=$ QT $/ \sqrt{ } R R$ ) for heart rate continues to be useful $(39,46,102,103)$. The 'cut-off value' commonly used was a QTc interval $\geq 440 \mathrm{~ms}$, but more recent genotype-phenotype correlations indicated $>460 \mathrm{~ms}$ to be more appropriate $[35,48)$. Indeed, $40 \%$ of LQT-1 and LQT-2 mutation carriers show QTC, values (410-470 ms) that overlap with non-carriers $(34,43)$. In this QTi range, phenotypic diagnosis from the ECC becomes imprecise and genetic studies may be helpfuil in diagnosing long-QT syndrome. When QTc $\geq 460 \mathrm{~ms}$ is used, the positive predictive accuracy for long-QT syndrome is $96 \%$ in women and $91 \%$ in men; almost $100 \%$ positive predictive accuracy for long.QT syndrome can be achieved at QTc $\geq 470 \mathrm{~ms}$ in males and QTc $\geq 480 \mathrm{~ms}$ in females (50). Finally, QTc intervals tend to be longer in LQT-3 patients than LQT-1 and LQT-2 carriers $(34,35,43)$. 


\section{QT-interval Dispersion}

The second ECG characteristic is QT-interval dispersion, which can be measured as a leadto-lead variability in QT-intervals (105-107). It is debated whether this phenomenon reflects regional differences in ventricular repolarization times $(108,109)$. In normal individuals, the difference between maximal and minimal QT-intervals measured on the standard resting ECG has been reported to vary between $48 \pm 18 \mathrm{msec}(102)$ and $54 \pm 27 \mathrm{msec}(102)$. In patients with the congenital long-QT syndrome, however, regional dispersion of ventricular repolarization times has been reported to vary from $93( \pm 39)$ to $185( \pm 26) \mathrm{msec}$ $(105,106,110,111)$. In long-QT syndrome patients, QT dispersion has been suggested to correlate with the risk for ventricular arrhythmias $(105,112)$, whereas a reduction in dispersion of the QT-interval could be used as a marker of therapeutic efficacy (107).

\section{T Wave Morphology}

In long-QT syndrome patients, not only the duration of repolarization is altered (QTinterval), but also its morphology (113). The most typical presentation of the T wave may be biphasic $(114)$ or notched $(75,114,115)$, and is most prominent in the precordial leads $(174,115)$. In addition, T wave alternans is an infrequently recorded highly arrhythmogenic ECG finding with transient beat-to-beat changes in amplitude, shape, and polarity of the T wave during sinus rhythm without concomitant QRS changes (116-118).

\section{Bradycardia and Sinus Pauses}

Signs of sinus node dysfunction, e.g. sinus bradycardia or sinus pauses $(70,119,120)$, and lower than expected heart rate during exercise have been reported $(33,121-123)$. Slow heart rates are particularly striking in younger children (122). During submaximal exercise testing, many long-QT syndrome patients reach a heart rate level lower than that achieved by healthy controls matched by sex and age $(124,125)$. Sinus pauses, may play a role in the initiation of pause-dependent torsades de pointes arrhythmias $(73,74,126)$. Long-QT syndrome might also be complicated by atrioventricular conduction disturbances, which is generally associated with poor prognosis $(50,81,123)$.

\section{Electrophysiological Testing}

One of the first comprehensive electrophysiological (EP) studies in long-QT syndrome patients was performed by Wellens et al. (127). The absence of inducibility by programmed stimulation indicates that the arrhythmias in long-QT syndrome are probably not the result. of reentrant circuits, but reentry probably plays a role in the perpetuation of torsades de 
FICURE 1.2

Cenotype-specific ECC patterns in the congenital long. QT syndrome.

(A). The two most common LQT-1 ECG patterns:

(a) broad-bosed $T$ wave pattern,

(b) normal-appearing T wave

pattern. (B). The two most frequently encountered LQT-2 ECG manifestation: (a) obvious bifid $T$ waves, (b) subtle bifid $T$ wave with a second component. on top of the T wave in limb and left precordial leads for alternatively the second component on the downslope of $T$ wave; not shown). (C). Most typical LQT-3 ECC patterm:

(a) late-onset peaked/biphasic $T$ wave. Modified from: Zhang et al. 2000 (140).
A a

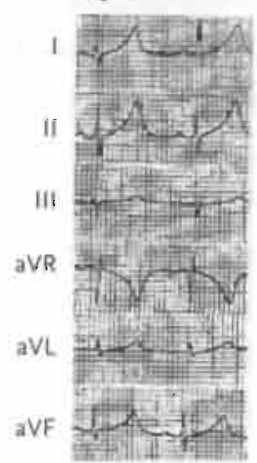

B

àt

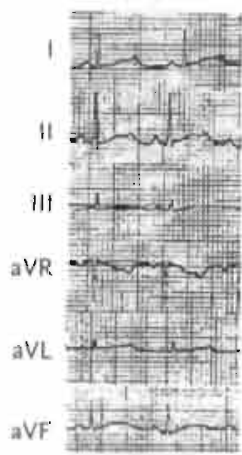

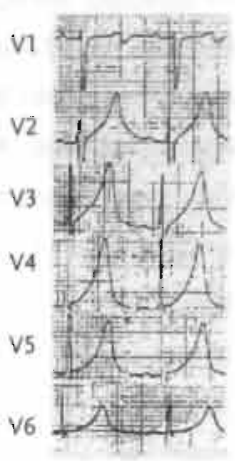

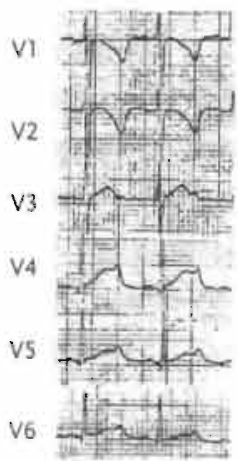

b

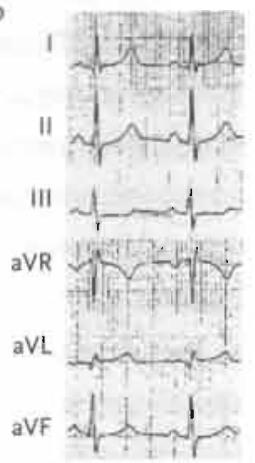

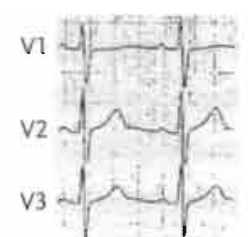

$\sqrt{4}$

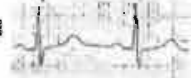

v5 din ar

vol an b

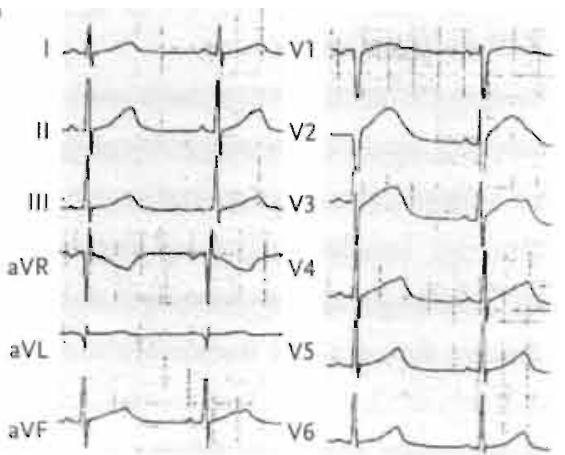

$c$

a

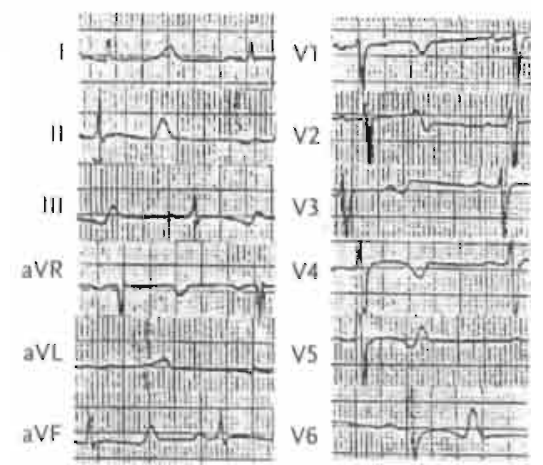


pointes arrhythmias in long-QT syndrome. It is therefore generally believed that EP studies using one or more premature stimuli during ventricular pacing are of limited value in the diagnosis and treatment of patients with the long-QT syndrome $(128,129)$. On the other hand, torsades de pointes might be inducible using short-long-short sequences $(74,130)$. In addition, changes in heart rate provoked by for example the Valsalva maneuver or EP protocols may lead to clear changes in the T wave or ventricular tachycardia (75).

\section{Response to Exercise}

The standard resting ECG as a diagnostic criterion may misclassify members of long-QT syndrome families $(48,131,132)$. Therefore, an exercise test has been suggested to enhance diagnostic accuracy, as shortening of QT-interval was shown to be inadequate in LQTS patients $(4,65,733+736)$. In addition, a submaximal heart rate response during exercise has been reported $(50,124,134)$. In a recent study by Swan et al. (131), a reduced maximum heart rate during exercise was found for LQT-1 patients, whereas this was normal for LQT-2 patients. During recovery from exercise, LQT-1 patients showed an exaggeration of the QT-interval prolongation compared to LQT-2 patients (131). Finally, Schwartz et al. reported that LQT-3 patients display a higher degree of QT-interval shortening in response to increase in heart rate than LQT-2 patients (89) (TABLE 1.2). Holter monitoring may also be useful (137), but well-defined criteria for QTc seperation of long-QT syndrome from normal patients are currently not available. Studies have demonstrated that QT-intervals up to 500 $\mathrm{ms}$ occur in a significant percentage of healthy individuals (138). Therefore, a QTc $>500$ ms, particularly in association with $T$ wave abnormalities, would appear to be necessary to support the diagnosis of long-QT syndrome (54).

\section{Genotype-Specific Electrocardiographic Phenotypes in the Congenital Long-QT Syndrome}

The different time- and voltage-dependence of the ionic currents involved in long-QT syndrome are probably responsible for distinct ECG phenotypes that have been reported for the different genotypes. Initial studies by Moss et al. $(34.139)$ reported an association of certain T wave patterns with LQT-1, LQT-2, and LQT-3. Recently, Zhang et al. (140) recognized 10 typical ST.T wave patterns that are genotype-specific (4 LQT-1, 4 LQT-2, and 2 LQT-3) (see FIGURE 7.2 for the most important ECG patterns). These ECG characteristics, however, cannot be used to diagnose the type of long-QT syndrome, but are rather useful to select which gene should be investigated first when performing genetic analysis. 


\section{Treatment of Asymptomatic Patients with ECG Characteristics of Congenital Long-QT Syndrome}

Treatment of asymptomatic patients is still controversial, because the majority of long-QT syndrome patients will never experience symptoms $(34,35)$ and sudden death during the first syncopal episode is unlikely to occur (34). While waiting for more definitive data, Schwartz recommended to begin treatment for asymptomatic patients only in the following six conditions: in those with congenital deafness; in neonates and for the first year of life because of the enhanced risk during the first months in life; in siblings of children who have already died suddenly; in patients with documented evidence of T wave alternans; when the QTc exceeds $600 \mathrm{~ms}$; and whenever there is manifest anxiety or explicit request for treatment (88).

\section{Mutation Carriers Without Symptoms or Electrocardiographic Characteristics of Long-QT Syndrome}

It is estimated that approximately $10 \%$ of all mutation carriers have a normal Qic interval $<440 \mathrm{~ms}$ (140). However, only $2 \%$ of all long-QT syndrome mutation carriers have a normal ST-T wave pattern with a normal QT-interval. Priori et al. (141) showed that in some families, penetrance of clinical symptoms and QT-interval prolongation may be as low as $25 \%$. This implies that family members considered normal on clinical and electrocardiographic grounds could be silent gene carriers displaying a very mild phenotype (19). They would be unexpectedly at risk of generating affected offspring and perhaps also of developing torsades de pointes arrhythmias if exposed to either cardiac or noncardiac drugs that block potassium channels $(9,10)$. It is therefore recommended to perform molecular screening in all family members of positively genotyped patients (21). Few longQT syndrome patients without ECG abnormalities present with sudden death as their first symptom (103), although preliminary data suggest that sudden death can occur in silent gene carriers (142). Awaiting more definitive data, conservative management of silent gene carriers seems reasonable, as the value of $\beta$-blocker therapy in this group of patients is still unknown.

\section{Patients Carrying Mutations or Polymorphisms Associated With Drug-provoked Long-QT Syndrome}

Some patients carry a predisposition for drug-induced torsades de pointes arrhythmias on the basis of congenital long-QT syndrome-related ion channel mutations $(7,95,143)$.

These patients are usually clinically asymptomatic unitil administration of a drug. A genetic 


\begin{tabular}{|c|c|c|c|c|}
\hline Gene & Channel & Drug & Usage & Reference \\
\hline KCNQ1 & $I_{\mathrm{Ks}}$ & Mefloquine & Antimalarial & $(145)$ \\
\hline KCNQ1 & $\mathrm{I}_{\mathrm{Ks}}$ & Disopyramide & Antiarrhythmic & $(145)$ \\
\hline KCNQ1 & $\mathrm{I}_{\mathrm{Ks}}$ & Terfenadine & Antihistamine & (145) \\
\hline KCNQ7 & $I_{\mathrm{Ks}}$ & Cisapride & Cholinergic antagonist & (10) \\
\hline $\mathrm{SCN}_{5} \mathrm{~A}$. & $\Gamma_{\mathrm{Na}}$ & Halofantrine & Antimalarial & $(146)$ \\
\hline MiRP? & $\mathrm{I}_{\mathrm{Kr}}$ & Clarithromycin & Antibiotic & $(16)$ \\
\hline$M i R P_{1}$ & $\mathrm{I}_{\mathrm{Kr}}$ & Quinidine & Antiarrhythmic & (9) \\
\hline$M i R P_{1}$ & $\mathrm{I}_{\mathrm{K} f}$ & Sulfametoxazole & Antibiotic & (9) \\
\hline MiRPT & $I_{k r}$ & Procainamide & Antiarrhythmic & (9) \\
\hline MiRPT & $I_{K r}$ & Oxatomide & Antihistamine & (9) \\
\hline
\end{tabular}

predisposition to drug-provoked long-QT syndrome torsades de pointes can be caused by mutations in the KCNE2 subunit of the $I_{K r}$ potassium channel $(16,144)$ or a mutation in the KCNQ1 subunit of the $I_{\mathrm{KS}}$ channel $(10,145)$ (TABLE 1.3). In addition, a polymorphism in the KCNE1 gene (147), as well as two relatively common polymorphisms in KCNE2 (allelic frequency in both cases around $1.6 \%$ ) have been associated with quinidine- and erythromycin-induced long-QT syndrome $(9,16)$. Drug-provoked long-QT syndrome has also been linked to mutation in SCN5A (146).

However, it should be noted that in most patients with acquired long-QT syndrome $(>85 \%)$, no ion channel mutations have been identified thus far. In this case, acquired long-QT syndrome is thought to result from electrolyte disturbances, hypertrophy, or treatment: with commonly used medications, including some antiarrhythmic, antihistamine, antibiotic, psychoactive, and gastrointestinal prokinetic agents (148). In patients without ion channel mutations, it is believed that pro-arrhythmia is induced by block of the potassium current $I_{K_{r}}(149,172)$. Recent studies have shed some light on the fact why so many structurally diverse compounds block $\mathrm{KCNH}_{2}$ channels but not other potassium channels. Because the $K_{C N H}$ channel has a unique group of amino acids in the $\mathrm{S} 6$ domain that are not present in other voltage-gated $\mathrm{K}^{+}$channels $\left(\mathrm{K}_{\mathrm{v}} 1-\mathrm{K}_{\mathrm{v}} 4\right)$, many drugs preferentially block $\mathrm{KCNH}_{2}$ channels (9), placing patients at risk for cardiac arrhythmias. It should be noted that acquired long.QT syndrome occurs more often in females (150). 
Genetic diagnostic approaches in patients with acquired long-QT syndrome should be restricted to centers with sufficient experience in the genetic identification of these patients. The relevance of the polymorphisms is not clear yet, and there is no well-defined set of genes that have to be analyzed. A pragmatic approach is to provide a list of compounds that should not be used in the future and should be known to both mutation carriers and patients with long-QT syndrome.

\section{Summary}

The congenital long-QT syndrome is a potentially life-threatening condition characterized clinically by prolonged QT-intervals, syncope, and sudden cardiac death. The abnormally prolonged repolarization is the result of mutations in genes, encoding cardiac ion channels. The diagnosis of long-QT syndrome is based on clinical, electrocardiographic, and genetic criteria. Beta-blocking therapy is important in the treatment of long-QT syndrome, although pacemakers and ICD's are useful in certain categories of patients. In the near future, mutation-specific treatment will probably become a novel approach to this potentially lethal syndrome.

\section{Acknowledgments}

The authors wish to thank Drs. R.S. Kass and A.A. Wilde for sharing with us their expertise. 


\section{References}

r. Wang Q, Shen J, Splawski !, Atkinson D, Li Z, Robinson JL, Moss AJ, Towbin JA, Keating MT. SCN5A mutations associated with an inherited cardiac arrhythmia, long-QT syndrome. Cell 1995:80:805-11.

2. Schwartz PJ, Locati E. The idiopathic long.QT syndrome: pathogenetic mechanisms and therapy. Eur Heart J 1985; 6 Suppl D:103-14.

3. Vincent GM. The molecular genetics of the long-QT syndrome: gẹnes caușing fainting and suddẹn death. Annu Rev Med 1998;49:263-74.

4. Romano C, Gemme G, Pongiglione R. Aritmie cardiache rare dell'eta pediatrica. Clin Pediat. 1963:45:656-83.

5. Ward OC. A new familial cardiac syndrome in children. J Irish Med Assoc 1964;54:103-06.

6. Jervell A, Lange-Nielsen F. Congenital deaf-mutism, functional heart disease with prolongation of the QT-interval, and sudden death. Am Heart j 1957:54:59-68.

7. Roden DM. Mechanisms and management of proarrhythmia. Am J Cardiol 1998;82:49/-57l.

8. Kass RS. Genetically induced reduction in small currents has major impact. Circulation 1997:96:1720-21.

9. Sesti F, Abbott GW, Wei J, Murray KT, Saksena S, Schwartz PJ, Priori SG, Roden DM, George AL Jr, Goldstein SA. A common polymorphism associated with antibiotic-induced cardiac arrhythmia. Proc Natl Acad Sci U S A 2000;97:10613-18.

10. Napolitano C, Schwartz PJ, Brown AM, Ronchetti E, Bianchi L, Pinnavaia A, Acquaro G, Priori SG. Evidence for a cardiac ion channel mutation underlying drug-induced QT prolongation and lifethreatening arrhythmias. J Cardiovasc Electrophysiol 2000;11:691-96.

11. Keating M, Atkinson D, Dunn C, Timothy K, Vincent GM, Leppert M. Linkage of a cardiac arrhythmia, the long-QT syndrome, and the Harvey ras-1 gene. Science 1991;252:704-06.

12. Keating M, Dunn C, Atkinson D. Timothy K, Vincent CM, Leppert M. Consistent linkage of the longQT syndrome to the Harvey ras-1 locus on chromosome 11. Am J Hum Genet 1991;49:1335-39.

13. Jiang C, Atkinson D, Towbin JA, Splawski I, Lehmann MH, Li H, Timothy K, Taggart RT, Schwartz PJ, Vincent GM. Two long-QT syndrome loci map to chromosomes 3 and 7 with evidence for further heterogeneity. Nat Genet 1994;8:141-47.

14. Schott J], Charpentier F, Peltier S, Foley P, Drouin E, Bouhour JB, Donnelly P, Vergnaud G, Bachner L. Moisan JP. Mapping of a gene for long-QT syndrome to chromosome 4q25-27. Am J Hum Genet 1995:57:1114-22.

15. Splawski I, Tristani-Firouzi M, Lehmann MH, Sanguinetti MC, Keating MT. Mutations in the hminK gene cause long-QT syndrome and suppress. I Ks function. Nat Genet 1997:17:338-40.

16. Abbott GW, Sesti F, Splawski I, Buck ME, Lehmann MH. Timothy KW, Keating MT, Goldstein SA. MiRP? forms $I_{\mathrm{Kr}}$ potassium channels with HERG and is associated with cardiac arrhythmia. Cell 1999;97:175-87.

17. Splawski I, Shen J, Timothy KW, Lehmann MH, Priori S, Robinson JL, Moss AJ, Schwartz PJ. Towbin $J A$, Vincent GM, Keating MT. Spectrum of mutations in long-QT syndrome genes. KvLQT1، HERC, SCN5A, KCNE1, and KCNE2. Circulation 2000;102:1178-85.

18. Schulze-Bahr E, Haverkamp W, Wedekind H, Rubie C, Hordt M, Borggrefe M, Assmann G, Breithardt G. Funke H. Autosomal recessive long-QT syndrome (Jervell Lange-Nielsen syndrome) is genetically heterogeneous. Hum Genet 1997;100:573-76. 
19. Priori SG, Schwartz PJ, Napolitano. C, Bianchi L, Dennis A, De Fusco M, Brown AM, Casari G. A recessive variant of the Romano-Ward long-QT syndrome? Circulotion 1998;97:2420-25.

20. Geelen JL, Doevendans. PA, Jongbloed RJ, Wellens HJ, Geraedts JP. Molecular genetics of inherited long-QT syndromes. Eur Heart J 1998;19:1427-33.

21. Priori SG, Napolitano C, Schwartz PJ. Low penetrance in the long-QT syndrome: clinical impact. Circulation 1999;99:529-33.

22. Sanguinetti MC, Curran ME, Spector PS, Keating MT. Spectrum of HERG $\mathrm{K}^{+}$-channel dysfunction in an inherited cardiac arrhythmia. Proc. Natl Acad Sci UI S A 1996;93:2208-12.

23. Barhanin J, Lesage F, Guillemare E, Fink. M, Lazdunski M, Romey G. KvLQT1 and IsK (hminK) proteins associate to form the $\mathrm{I}_{\mathrm{Ks}}$ cardiac potassium current. Nature 1996;384:78-80.

24. Sanguinetti MC, Curran ME, Zou A, Shen J, Spector PS, Atkinson DL, Keating MT. Coassembly of KvLQT 1 and $h \operatorname{minK}$ (IsK) proteins, to form cardiac: I Ks potassium channel. Nature 1996;384:80-83.

25. Chouabe C, Neyroud. N, Guicheney P, Lazdunski M, Romey G, Barhanin J. Properties of KvLQT1 K+ channel mutations in Romano-Ward and Jervell and Lange-Nielsen inherited cardiac arrhythmias. EMBO J 1997; 6:5472-79.

26. Bennett PB, Yazawa K, Makita N, George AL Ir. Molecular mechanism for an inherited cardiac arrhythmia. Nature 1995;376:683-85.

27. Dumaine R, Wang Q, Keating MT, Hartmann HA, Schwartz PI, Brown AM, Kirsch GE. Multiple mechanisms of $\mathrm{Na}^{+}$channel-linked long-QT syndrome. Circ Res 1996;78:916-24.

28. Clancy CE, Rudy Y. Linking a genetic defect to its cellular phenotype in a cardiac arrhythmia. Nature 1999;400:566-69.

29. An RH, Wang XL, Kerem E, Benhorin J, Medina A, Coldmit M, Kass RS. Novel LQT.3 mutation affects $\mathrm{Na}^{+}$channel activity through interactions between $\alpha \cdot$ and $\beta$ 1-subunits. Circ Res 1998;83:947-46.

30. Schwartz PI, Moss AJ. Prolonged Q-T interval: what does it mean? J Cardiovasc Med 1982;7:13:17-30.

31. Schwartz Pj. The idiopathic long-QT syndrome: the need for a prospective registry. Eur Heart $J$ 1983:4:529-31.

32. Moss Al, Schwartz PI. Crampton RS, Locati E, Carleen E. The long-QT syndrome: a prospective international study. Circulation 1985;71:17-21.

33. Moss A, Schwartz PJ, Crampton RS, Tzivoni D, Locati EH, MacCluer I. Hall W], Weitkamp L, Vincent GM, Garson A Jr. The long-QT syndrome. Prospective longitudinal study of 328 families.

Circulation 1997;84:1136-44.

34. Zareba. W, Moss AJ, Schwartz PJ, Vincent GM, Robinson JL, Priori SG, Benhorin J, Locati EH, Towbin JA, Keating MT, Lehmann MH, Hall W/. Influence of genotype on the clinical course of the long-QT syndrome، International Long-QT Șyndrome Registry Research Group. N Engl J Med 1998:339:960-65.

35. Schwartz PJ, Priori SG, Spazzolini C, Moss A), Vincent GMI, Napolitano C, Denjoy i, Guicheney P, Bieithardt G, Keating MT; Towbin JA, Beggs AH, Brink P. Wilde AA, Töivonen L, Zareba W, Robinson IL, Timothy KW, Corfield V, Wattanasirichaigoon D, Corbett C: Haverkamp W, Schulze-Bahr E, Lehmann MH, Schwartz K, Coumel P, Bloise R. Genotype-phenotype correlation in the long-QT syndrome: gene-specific triggers for life-threatening arrhythmias. Circulation 2001;103:89-95.

36. Schouten EG, Dekker JM, Meppelink P, Kok: F), Vandenbroucke fP, Pool J. QT-interval prolongation predicts cardiovascular mortality in an apparently healthy population. Circulation 1991;84:1516-23.

37. de Bruyne MC, Hoes AW, Kors JA, Hofman A, van. Bermmel JH, Grobbee DE. Prolonged. QT-interval predicts cardiac and all-cause mortality in the elderly. The Rotterdam Study. Eur Heare J 1999:20:278-84.

38. Atiga WL, Calkins H, Lawrence JH, Tomaselli GF, Smith JM, Berger RD. Beat-to-beat repolarization lability identifies patients at risk for sudden cardiac death. J Cardiovasc Electrophysiol 1998;9:899-908. 
39. Bazett HC. An analysis of the time-relations of electrocardiograms. Heart 1920;7:353-70.

40. Rautaharju PM, Zhou SH, Wong S, Calhoun HP, Berenson GS, Prineas R, Davignon A.

Sex differences in the evolution of the electrocardiographic QT-interval with age.

Can f Cardiol 1992; 8:690-95:

41. Stramba-Badiale M, Spagnolo D, Bosi G, Schwartz PJ. Are gender differences in QTC present at birth? MISNES Investigators. Multicenter Italian Study on Neonatal Electrocardiography and Sudden Infant Death Syndrome. Am J Cardiol 1995;75:1277-78.

42. Lehmann MH, Timothy KW, Frankovich D, Fromm BS, Keating M, Locati EH, Taggart RT, Towbin JA, Moss Al, Schwartz PJ, Vincent GM. Age-gender influence on the rate-corrected QT-interval and the QT-heart rate relation in families with genotypically characterized long-QT syndrome.

J Am Coll Cardiol 1997;29:93-99.

43. Locati EH, Zareba W, Moss A], Schwartz PI, Vincent GM, Lehmann MH, Towbin IA, Priori SC, Napolitano C, Robinson JL, Andrews M, Timothy K, Hall WJ. Age- and sex-related differences in clinical manifestations in patients with congenital long-QT syndrome: findings from the International LQTS Registry. Circulation 1998;97:2237-44.

44. Merri M, Benhorin J, Alberti M, Locati E, Moss AJ. Electrocardiographic quantitation of ventricular repolarization. Circulation 1989;80:1301-08.

45. Davignon A, Rautaharju B, Boiselle E. Normal ECG standards for infants and children. Pediatr Cardiol 1980;1:123-31.

46. Schwartz PJ, Moss AJ, Vincent GM, Crampton RS. Diagnostic criteria for the long.QT syndrome. An update. Circulation 1993:88:782-84.

47. Hashiba K. Hereditary QT prolongation syndrome in lapan: genetic analysis and pathological findings of the conducting system. Jpn Circ J 1978;42:1133-50.

48. Vincent GM, Timothy KW, Leppert M, Keating M. The spectrum of symptoms and QT-intervals in carriers of the gene for the long-QT syndrome. N Engl] Med 1992;327:846-52.

49. Rashba EJ, Zareba W, Moss AJ, Hall WJ, Robinson J, Locati EH, Schwartz PJ, Andrews M. Influence of pregnancy on the risk for cardiac events in patients with hereditary long-QT syndrome. LQTS Investigators. Circulation 1998;97:451-56.

50. Schwartz. PJ, Periti M, Malliani A. The long-QT syndrome. Am Heart J 1975;89:378-90.

51. Pham TV, Sosunov EA, Gainullin RZ, Danilo P Jr, Rosen MR. Impact of sex and gonadal steroids on prolongation of ventricular repolarization and arrhythmias induced by $\mathrm{I}_{\mathrm{K}}$-blocking drugs.

Circulation 2001;103:2207-12.

52. Tanabe S, Hata T. Hiraoka M. Effects of estrogen on action potential and membrane currents in guinea pig ventricular myocytes. Am J Physiol 1999;277:H826-33.

53. Doevendans PA, Wilde AA (eds.). Cardiovascular Genetics. Dordrecht, Netheriands: Kluwer Academic Publisher 2007.

54. Vincent GM, Timothy K, Fox J, Zhang L. The inherited long-QT syndrome: from ion channel to. bedside. Cardiol Rev 1999:7:44-55.

55. van den Berg MP, Wilde AA, Viersma TJW, Brouwer J, Haaksma J, van der Hout AH, Stolte-Dijkstra I, Bezzina TCR, Van Langen IM, Beaufort-Krol CC, Cornel JH $2^{\text {nd }}$, Crijns HJ. Possible bradycardic mode of death and successful pacemaker treatment in a large family with features of long-QT syndrome type 3 and Brugada syndrome. J Cardiovasc Electrophysiol 2001;12:630-36.

56. Wilde AA, Roden DM. Predicting the long-QT genotype from clinical data: from sense to science. Circulation 2000;102:2796-98.

57. Barlow JB, Bosman CK. Craig Cochrane JW. Congenital cardiac arrhythmias. Lancet 1964;2:531 (letter). 
58. Dessertenne F. La tachycardie ventriculaire à deux foyers opposés variables.

Arch Mal Coeur Vaiss 1966;59:263-72.

59. Wilde AA, Jongbloed RJ, Doevendans PA, Duren DR, Hauer RN, van Langen IM, van Tintelen IP, Smeets HI, Meyer H, Geelen JL. Auditory stimuli as a trigger for arrhythmic events differentiate HERG-related (LQTS2) patients from KvLQT1-related patients (LQTS1).

J Am Coll Cardiol 1999:33:327-32.

6o. Moss AJ, Robinson JL, Gessman L, Gillespie R, Zareba W, Schwartz PJ, Vincent GM, Benhorin J, Heilbron EL, Towbin JA, Priori SG, Napolitano C, Zhang L, Medina A, Andrews ML, Timothy K. Comparison of clinical and genetic variables of cardiac events associated with loud noise versus swimming among subjects with the long-QT syndrome. Am J Cardiol 1999;84:876-79.

61. Ali RH, Zareba W, Moss A], Schwartz PJ, Benhorin \}, Vincent GM, Locati EH, Priori S, Napolitano C, Towbin JA, Hall WJ, Robinson JL., Andrews ML, Zhang L., Timothy K, Medina A. Clinical and genetic variables associated with accute arousal and nonarousal-related cardiac events among subjects with long-QT syndrome. Am J Cardiol 2000;15:457-61.

62. de Jager $T$, Corbett $\mathrm{CH}_{3}$, Badenhorst IC, Brink PA, Corfield VA. Evidence of a long-QT founder gene with varying phenotypic expression in South African families. J Med Genet 1996;33:567-73.

63. Schwartz PJ, Locati E, Napolitano C, Priori SG. The long.QT syndrome. In: Zipes DP, Jalife J (eds.) Cardiac electrophysiology. From cell to bedside. $2^{\text {nd }}$ ed. Philidelphia: WB Saunders 1995: 778-811.

64. Shimizu W, Antzelevitch C. Cellular basis for the ECG features of the $L Q T=1$ form of the long-QT syndrome: effects of beta-adrenergic agonists and antagonists and sodium channel blockers on transmural dispersion of repolarization and torsades, de pointes. Circulation 1998;98:2314-22.

65. Maron BJ, Moller JH, Seidman CE, Vincent GM, Dietz HC, Moss AJ, Towbin JA, Sondheimer HM, Pyeritz RE, McGee G, Epstein AE. Impact of laboratory molecular diagnosis on contemporary diagnoștic çriteria fọr genetiçally trạnșmittẹd cardiovașcular dișeașes: hyperțophic cardiomyopathy; long-QT syndrome, and Marfan syndrome. A statement for healthcare professionals from the Councils on Clinical Cardiology, Cardiovascular Disease in the Young, and Basic Science, American Heart Association. Circulation 1998;98:1460-71.

66. Wellens HI, Vermeulen A, Durrer D. Ventricular fibrillation occurring on arousal from sleep by auditory stimuli. Circulation 1972;46:661-65:

67. Nakajima T, Misu K, Iwasawa K, Tamiya E, Segawa K, Matsuo H, Hada K. Auditory stimuli as a major cause of syncope in a patient with idiopathic long-QT syndrome. Jpn Circ J 1995:59:241-46.

68. Moss AJ, Zareba W, Hall WJ, Schwartz PJ, Crampton RS, Benhorin J, Vincent GM, Locati EH, Priori SG, Napolitano C. Medina A. Zhang L. Robinson JL, Timethy K. Towbin JA, Andrews ML. Effectiveness and limitations of bẹta-bolockẹ therapy in congenițal long-QT syndrome. Circulation 2000;101:616-23.

69. Garza LA, Vick RL, Nora II. MciNamara DG. Heritable Q.T prolongation without deafness. Circulation 1970;41:39-48.

70. James TN. Congenital deafness and cardiac arrhythmias. Am J Cardiol 1967;627:627-43.

71. Johansson BW, Jorming B. Hereditary prolongation of QT-interval. Br Heart J 1972;34:744-51.

72. Grubb BP. The use of oral labetalol in the treatment of arrhythmias associated with the long-QT syndrome. Chest 1991;100:1724-25.

73. Brachmann J, Scherlag BJ, Rosenshtraukh LV, Lazzara R. Bradycardia-dependent triggered activity: relevance to drug-induced multiform ventricular tachycardia. Circulation 1983;68:846-56.

74. Cranefield PF, Aronson RS. Torsade de pointes and other pause-induced ventricular tachycardias: the short-long-short sequence and early afterdepolarizations. Paçing, Clin Electrophysiol 1988;11:670-78. 
75. Jackman WM, Friday KJ, Anderson /L, Aliot EM, Clark M, Lazzara R. The long-QT syndromes: a critical review, new clinical observations and a unifying hypothesis.

Prog Cardiovasc Dis 1988;31:115-72.

76. Ratskin RA, Hunt D, Russell RO, Rackley CE. Q-T interval prolongation, paroxysmal ventricular arrhythmias, and convulsive syncope. Ann Intern Med 1971;75:9:19-24.

77. Roy PR, Emanuel R, Ismail SA, E! Tayit, MH. Hereditary prolongation of the Q-T interval. Genetic observations and management in three families with twelve affected members.

Am J Cardiol 1976;37:237-43.

78. Di Segni E, David D, Katzenstein M, Klein HO, Kaplinsky E, Levy MJ. Permanent overdrive pacing for the suppression of recurrent ventricular tachycardia in a newborn with long-QT syndrome.

$J$ Electrocardiol 1980;13:189-92.

79. Medina-Ravell V, Castellanos A, Portillo-Acosta B, Maduro-Maytin C, Rodriguez-Salas L, HernandezArenas M, La Salle-Toro R, Mendoza-Muịica I, Ortega-Maldonado M, Berkovits BV. Management of tachyarrhythmias with dual-chamber pacemakers. PACE. 1983;6:333-45.

8o. Wilmer $\mathrm{Cl}$, Stein $\mathrm{B}$, Morris DC. Atrioventricular pacemaker placement in Romano-Ward syndrome and recurrent torsades, de pointes. Am J Cardiol 1987:59:171-72.

81. Scott WA, Dick M. Two:one atrioventricular block in infants with congenital long-QT syndrome. Am J Cardiol 1987;60:1409-10.

82. Viskin S. Cardiac pacing in the long-QT syndrome: review of available data and practical recommendations. / Cardiovasc Electrophysiol 2000;11:593-600.

83. Benhorin ), Taub R, Goldmit M, Kerem B, Kass RS, Windman 1, Medina A. Effects of flecainide in patients with new SCNSA mutation: mutation-specific therapy for long-QT syndrome? Circulation 2000;10r:1698-706.

84. Eldar M, Griffin JC, Abbott JA, Benditt D, Bhandari A, Herre JM, Benson DW, Scheinman MM. Permanent cardiac pacing in patients with the long-QT syndrome. J Am Coll Cardiol 1987;10:600-07.

85. Silka MJ, Kron J, Dunnigan A, Dick M. Sudden cardiac death and the use of implantable cardioverterdefibrillators in pediatric patients. The Pediatric Electrophysiology Society. Circulation 1993;87:800-07.

86. Groh WJ, Silka MJ, Oliver RP, Halperin BD, McAnulty JH, Kron J. Use of implantable cardioverterdefibrillators in the congenital long.QT syndrome. Am J Cardiol 1996;78:703-06.

87. Dorostkar PC, Eldar M, Belhassen B, Scheinman MM. Long-term follow-up of patients with long-QT syndrome treated with beta-blockers and continuous pacing. Circulation 1999;100:2431-36.

88. Schwartz PJ. The long-QT syndrome. Armonk, NY: Futura Publishing Company, Inc. 1997.

89. Schwartz PJ, Priori SG, Locati EH, Napolitano C, Cantu F, Towbin JA, Keating MT, Hammoude H, Brown AM, Chen LS. Long-QT syndrome patients with mutations of the SCN5A and HERG genes have differential responses to $\mathrm{Na}^{+}$channel blockade and to increases in heart rate. Implications for gene-specific therapy. Circulation 1995; 92:3381-86.

90. Ackerman MJ, Tester DJ, Porter C). Swimming, a gene-specific arrhythmogenic trigger for inherited long-QT syndrome. Mayo Clin Proc 1999:74:1088-94.

91. Sanguinetti MC, Jurkiewicz NK. Role of external $\mathrm{Ca}^{2+}$ and $\mathrm{K}^{+}$in gating of cardiac delayed rectifier $\mathrm{K}^{+}$currents. Pflugers Arch 1992;420:180-86.

92. Sanguinetti MC, Jiang C, Curran ME, Keating MT. A mechanistic link between an inherited and an acquired cardiac arrhythmia: HERG encodes the $I_{\text {Kr }}$ potasșium channel. Cell 1995;81:299-307.

93. Choy AM, Lang CC, Chomsky DM, Rayos CH, Wilson IR, Roden DM. Normalization of acquired QT prolongation in humans by intravenous potassium. Circulation 1997:96:2149-54. 
94. Compton S), Lux RL, Ramsey MR, Streliçh KR, Sanguinetti MC, Green LS, Keating MT; Mason JW. Genetically defined therapy of inherited long.QT syndrome. Correction of abnormal repolarization by potassium. Circulation 1996:94:1018-22.

95. Kubota T, Shimizu W, Kamakura S, Horie M. Hypokalemia-induced long-QT syndrome with an underlying novel missense mutation in $\mathrm{S}_{4}-\mathrm{S}_{5}$ linker of KCNQ7.

J Cardiovasc Electrophysiol 2000;11:1048-54.

96. Tan HL, Alings M, Van Olden RW, Wilde AA. Long-term (subacute) potassium treatment in congenital HERG-related long-QT syndrome (LQTS2). J Cardiovasc. Electrophysiol 1999:10:229-33.

97. Shimizu W, Kurita T, Matsuo K, Suyama K, Aihara N, Kamakura S, Towbin JA, Shimomura K. Improvement of repolarization abnormalities by a $\mathrm{K}^{+}$channel opener in the LQT-1 form of congenital long-QT syndrome. Circulation 1998;97:1581-88.

98. Rosero SZ, Zareba W, Robinson J, Moss A. Gene-specific therapy for long-QT syndrome: QT shortening with lidocaine and tocainide in patients with mutations of the sodium channel gene. Ann Noninv Electrophys 1997:3:274-78.

99. Sicouri S, Antzelevitch D, Heilmann C. Antzelevitch C. Effects of sodium channel block. with mexiletine to reverse action potential prolongation in in vitro models of the long-QT syndrome. J Cardiovasc Electrophysiol 1997;8:1280-90.

100. Priori SG, Napolitano C, Schwartz PJ, Bloise R, Crotti L, Ronchetti E. The elusive link between LQT-3 and Brugada syndrome : the role of flecainide challenge. Circulation 2000; $702: 945-47$.

101. Brugada P, Brugada J. Right bundle branch block, persistent ST segment elevation and sudden cardiac death: a distinct clinical and electrocardiographic syndrome. A multicenter report. J Am Coll Cardiol 1992;20:1391-96.

102. Cowan JC, Yusoff K, Moore M, Amos PA, Gold AE, Bourke JP, Tansuphaswadikul S, Campbell RW. Importance of lead selection in QT-interval measurement. Am J Cardiol 1988;61:83-87.

103. Garson A]. How to measure the QT-interval - what is normal? Am J Cardiol 1993;72:14B-16B.

104. Morganroth ], Brown AM, Critz S, Crumb W], Kunze DL, Lacerda AE, Lopez H. Variability of the QTe interval: impact on defining drug effect and low-frequency cardiac event. Am J Cardiol 1993:72:26B-31B.

105. Day CP, McComb JM, Campbell RW. QT dispersion: an indication of arhythmia risk in patients with long-QT-intervals. Br. Heart J 1990;63:342-44.

106. Linker NJ, Colonna P, Kekwick CA, Tili J, Camm A, Ward DE. Assessment of QT dispersion in symptomatic patients with congenital long-QT syndromes. Am J Cardiol 1992;69:634-38.

107. Priori SG, Napolitano C. Diehl L, Schwartz PJ. Dispersion of the QT-interval. A marker of therapeutic. efficacy in the idiopathic long-QT syndrome. Circulation 1994:89:1681-89.

108. Wilson FN, MacLeod AG, Barker PS, Johnston FD. The determination and the significance of the areas of the ventricular deflections of the electrocartiogram. Am Heart $J$ 1934:10:46-6r.

108. Malik Mi, Acar B, Gang Y, Yap YG, Hnatkova K. Camm AJ. QIT dispersion does not represent electrocardiographic interlead heterogeneity of ventricular repolarization.

J Cardiovasc Electrophysiol 2000;:11:835-43.

no, Sylven JC, Horacek BM, Spencer CA, Klassen GA, Montague TJ. QT-interval variability on the body surface. J Electrocardiol 1984;17:179-88.

111. Vassallo JA, Cassidy DM, Kindwall KE, Marchlinski FE, Josephson ME. Nonuniform recovery of excitability in the left ventricle. Circulation 1988;78:1365-72.

112. Hii JT, Wyse DG, Gillis AM, Duff Hi), Solylo MA, Mitchell LE. Precordial Q T-interval disperșion as a marker of torsades de pointes. Disparate effects of class IA antiarrhythmic drugs and amiodarone. Circulation 1992;86:1376-82. 
113. Benhorin J, Merri M, Alberti M, Locati E, Moss AJ. Hall WJ, Cui L. Long-QT syndrome. New electrocardiographic characteristics. Circulation 1990;82:521-27.

114. Malfatto G, Beria C, Sala S, Bonazzi O, Schwartz PJ. Quantitative analysis of T wave abnormalities and their prognostic implications in the idiopathic long-QT syndrome.

J Am Coll Cardiol 1994;23:296-301.

115. Lehmann MH, Suzuki F, Fromm BS, Frankovich D, Elko P, Steinman RT, Fresard J, Baga JJ, Taggart RT. T wave "humps" as a potential electrocardiographic marker of the long-QT syndrome. J Am Coll Cardiol 1994;24:746-54.

116. Nearing BD, Huang AH, verrier RL. Dynamic tracking of cardiac vulnerability by complex demodulation of the T wave. Science 1991;252:437-40.

117. Schwartz PJ, Malliani A. Electrical alternation of the T-wave: clinical and experimental evidence of its relationship with the sympathetic nervous system and with the long-QT syndrome.

Am Heart J 1975;89:45-50.

118. Hiejima K, Sano T. Electrical alternans of TU wave in Romano-Ward syndrome.

Br Heart J 1976;38:767-70

119. Schwartz PJ. The long-QT syndrome. In: Kulbertus HE, Wellens HJ (eds.) Sudden death. The Hague: $M$. Nijhoff $1980: 358-78$.

120. Schwartz PJ. Idiopathic long-QT syndrome: progress and questions. Am Heart J 1985;109:399-411.

12.1. Hiejima K, Suzuki F, Satake S, Ishihara K. Electrophysiologic studies of Jervell Lange-Nielsen syndrome. Chest 1981;79:446-48.

122. Vincent GM. The heart rate of Romano-Ward syndrome patients. Am Heart $J$ 1986;112:61-64.

123. Corgels AP, Al Fadley F, Zaman L, Kantoch MJ, Al Halees Z. The long-QT syndrome with impaired atrioventricular conduction: a malignant variant in infants. J Cardiovasc Electrophysiol 1998;9:3225-32.

124. Kugler JD. Sinus nodal dysfunction in young patients with long-QT syndrome. Am Heart J 1991;121:1132-36.

125. Curtiss El, Heibel RH, Shaver JA. Autonomic maneuvers in hereditary Q-T interval prolongation (Romano-Ward syndrome). Am Heart] 1978;95:420-28.

126. Viswanathan PC, Rudy Y, Pause induced early afterdepolarizations in the long-QT syndrome: a simulation study. Cardiovasc Res 1999;42:530-42.

127. Wellens HJ, Lie KI. Ventricular tachycardia: the value of programmed electrical stimulation. In: Krikler DM, Goodwin JF (eds.) Cardiac arrhythmias. W.B. Saunders 1975:182-94.

128. Bhandari AK, Shapiro WA, Morady F, Shen EN, Mason J, Scheinman MM. Electrophysiologic testing in patients with the long-QT syndrome. Circulation 1985;71:63-71.

129. Coumel P, Leclercq JF: Lucet V. Possible mechanisms of the arrhythmias in the long:Cit syndrome. Eur Heart J 1985;6 Suppl D:115.29.

130. Viskin S, Alla SR, Barron HV, Heller K, Saxon L, Kitzis I, Hare GF, Wong MJ, Lesh MD, Scheinman MM. Mode of onset: of torsades de pointes in congenital long-QT syndrome.

J Am Coll Cardiol 1996;28:1262-68.

131. Swan $H$, Viitasalo $M$, Piippo $K$, Laitinen $P$, Kontula $K_{k}$. Toivonen $L$. Sinus node function and ventricular repolarization during exercise stress test in long-QT syndrome patients with $K_{\nu L Q T} T_{7}$ and HERG potassium channel defects. J Am Coll Cordiol 1999;34:823-29.

132. Schwartz SP, De Salo Pool N. Transient ventricular fibrillation. III. The effects of bodily rest, atropine suiphate, and exercise on patients with transient ventricular fibrillation during established auriculoventricular dissociation. A study of the influence of the extrinsic nerves on the idioventricular pacemaker of the heart. Am Heart J 1958;39:361-86. 
133. Phillips J, Ichinose H. Clinical and pathologic studies in the hereditary syndrome of a long-QT. interval, syncopal spells and sudden death. Chest 1970;58:236-43.

134. Vincent, GM, Jaiswal D, Timothy KW. Effects of exercise on heart rate, QT, QTc and QT/QS2 in the: Romano-Ward inherited long-QT syndrome. Am J Cardiol 1991;68:498-503.

135. Shimizu W, Ohe T, Kurita T; Shimomura K. Differential response of QTU interval to exercise, isoproterenol, and atrial pacing in patients with congenital long-QT syndrome.

Pacing, Clin Electrophysiol 1997;14:1966-70.

136. Merri M, Moss A), Benhorin J, Locati EH, Alberti M, Bạdilini F. Relation between ventricular repolarization duration and cardiac cycle length during 24 -hour Holter recordings. Findings in normal patients and patients with long-QT syndrome. Circulation 1992;85:1816-21.

137. Eggeling, T, Osterhues HH, Hoeher M, Gabrielsen FG, Weismueller P, Hombach V. Value of Holter monitoring in patients with the long-QT syndrome. Cardiology 1992;81:107-14.

138. Molnar J, Zhang F, Weiss J, Ehlert FA, Rosenthal JE. Diurnal pattern of QTc interval: how long is prolonged? Possible relation to circadian triggers of cardiovascular events.

J Am Coll Cardiol 1996;27:76-83.

139. Moss AJ, Zareba W, Benhorin J, Locati EH, Hall W], Robinson JL, Schwartz PJ, Towbin JA, Vincent GM, Lehmann MH. ECG T-wave patterns in genetically distinct forms of the hereditary long-QT syndrome. Circulation 1995: 22:2929-34.

140. Zhang L, Timothy KW, Vincent GM, Lehmann MH, Fox J, Giuli LC, Shen J, Splawski I, Priori SG, Compton S1, Yanowitz F, Benhorin J, Moss A), Schwartz PJ, Robinson JL, Wang Q, Zareba W, Keating MT, Towbin JA, Napolitano C, Medina A. Spectrum of ST-T-wave patterns and repolarization parameters in congenital long-QT syndrome: ECG findings identify genotypes.

Circulation 2000;102:2849-55.

141. Priori SG, Barhanin J, Hauer RN, Haverkamp W, Jongsma HJ, Kleber AG, McKenna WJ, Roden DM, Rudy Y, Schwartz K, Schwartz: P). Towbin JA, Wilde AM. Genetic and molecular basis of cardiac arrhythmias: impact: on clinical management parts I and II. Circulation 1999;99:518-28.

142. Vincent GM, Timothy K, Fox J, Zhang L. Long-QT syndrome patients with normal to borderline prolonged QTc intervals are at risk for syncope, cardiac arrest and sudden death.

Circulation 1999:100(185):1245 (abstract).

143. Ackerman M!. The long-QT syndrome: ion channel diseases of the heart. Mayo Clin Proc 1998;73:250-69.

144. Wei J, Abbott GW, Sesti F, Goldstein SA, Schwartz Pl, Saksena S, Murray KT, George AL.. Prevalence of KCNE2 (MiRP) mutations in acquired long-QT syndrome.

Circulation 1999:100(785):1495 (abstract).

145. Donger C, Denjoy I, Berthet M, Neyroud N, Cruaud C, Bennaceur M, Chivoret G, Schwartz K, Coumel P, Guicheney P. KuLQTi C-termina! missense mutation causes a forme fruste long-QT' syndrome. Girculation 1997:96:2778-81.

146. Piippo K, Hotmstrom S, Swan H, Viitasalo M, Raatikka M, Toivonen L. Kontula K. Effect of the antimalarial drug halofantrine in the long-QT syndrome due to a mutation of the cardiac sodium channel gene SCN5A. Am ] Cardiol 2007;87:909-11.

147. Wei j, Yang ICH, Tapper AR, Murray KT, Viswanathan PC, Rudy Y, Bennett PB, Norris K, Balser JR, Roden DM, George AL. KCNE1 polymorphism confers risk of drug-induced long-QT syndrome by altering kinetic properties of $I_{\text {Ks }}$ potassium channels. Circulation 1999:100(785):1495 (abstract).

148. Roden DM. Acquired long-QT syndromes and the risk of proarthythmia.

J Cardiovasc Electrophysiol 2000;11:938-40. 
149. Roden DM, Lazzara R, Rosen M, Schwartz PJ, Towbin J, Vincent. GM. Multiple mechanisms in the long-QT syndrome. Current knowledge, gaps, and future directions. The SADS Foundation Task Force on LQTS. Circulation 1996;94:1996-2012.

150. Lehmann MH, Hardy S, Archibald D, Quart B, MacNeil DJ. Sex difference in risk of torsades. de pointes with d,l-sotalol. Circulation 1996;94:2535-41.

15i. Meissner FL. Taubstummheit und taubstummenbildung. Leipzip/ Heidelberg: C.F. Winter'sche Verlagshandlung, 1856 .

152. Morquio L. Sur une maladie infantil et familiale characterisée par des modifications permanentes du pouls, des attaques epileptiformes et al morte subite. Arch Med Enf 1901;4:467-75.

153. Latham AD, Munro TA. Familial myoclonus epilepsy associated with deaf-mutism in a family showing other psychobiological abnormalities. Ann Eugen Lond 1937:8:166-75.

154. Herrlin KM, Moller T. A case of cardiac syncope. Acta Paediatrica 1953;42:391.

155. Romano C. Congenital cardiac arrhythmias. Lancet 1965; i:658-59.

156. Levine SA, Woodworth CR. Congenital deafmutism, prolonged Q-T interval, syncopal attacks and. sudden death. New Engl J Med 1958;259:412-17.

157. Fraser GR, Forgatt P. James TN. Congenital deafness associated with electrocardiographic abnormalities. Quart J Med 1964;33:367-85.

158. James TN. Congenital deafness and cardiac arrhythmias. Am J Cardiol 1967;627:627-43.

159. Splawski I, Timothy KW, Vincent GM, Atkinson DL, Keating MT. Molecular basis of the long-QT syndrome associated with deafness. N Engl] Med 1997;336:1562-67.

160. Fraser GR, Froggatt P, Murphy T. Genetical aspects of the cardio-auditory syndrome of Jervell and Lange-Nielsen (congenital deafness and electrocardiographic abnormalities).

Ann Hum Genet Lond 1964:28:133-57.

161. Mathews EC, Blount AW, Townsend JI. Q-T prolongation and ventricular arrhythmias, with and without deafness, in the same family. Am J Cardiol 1972;29:702-11.

162. Crampton R. Preeminence of the left stellate ganglion in the long-QT syndrome.

Circulation 1979:59:769-78.

163. Ben-David ), Zipes DP. Differential response to right and left ansae subclaviae stimulation of eariy afterdepolarizations and ventricular tachycardia induced by cesium in dogs.

Circulation 1988;78:124:-50.

164. Moss A], McDonald J. Unilateral cervicothoracic sympathetic ganglionectomy for the treatment of long-QT-interval syndirome. N Engl J Med 1971;285:903-04.

165. Yanowitz F, Preston JB, Abildskov JA. Functional distribution of right and left stellate innervation to the ventricles: production of neurogenic electrocardiographic changes by unilateral alteration of sympathetic tone. Cinc Res $1966 ; 18: 416-28$.

166. Muller KD, Jakob, $H_{1}$ Neuz:ner J, Grebe SF, Schlepper $M_{1}$ Pitschner HF. 1231-metaiodobenzylguanidine scintigraphy in the detection of irregular regional sympathetic innervation in long-QT syndrome. Eur Heart J 1993:143:3:6-25.

167. Gohl K: Feistel H, Weikl A, Bachmann K, Wolf F. Congenital myocardial sympathetic dysinnervation (CMSD) - a structural defect of idiopathic long-Q̣T syndrome.

Pacing Clin Electrophysiol 1997;14:1544-53.

168. Calkins H, Lehmann MH, Allman K, Wieland D, Schwaiger M. Scintigraphic pattern of regional cardiac sympathetic innervation in patients with familial long-QT syndrome using positron emission tomography, Circulation 1993;87:1616-21. 
169. Nador F, Beria G, De Ferrari CM, Stramba-Badiale M, Locati EH, Lotto A, Schwartz PJ. Unsuspected echocardiographic abnormality in the long-QT syndrome. Diagnostic, prognostic, and pathogenetic implications. Circulation 1991;84:1530-42.

170. Schwartz PJ, Verrier RL., Lown B. Effect of stellectomy and vagotomy on ventricular refractoriness in dogs. Circ Res. 1977;40:536-40.

171. Schwartz PJ, Zaza A, Locati E, Moss A). Stress and sudden death. The case of the long-QT syndrome. Circulation 1991;83:1171-80.

172. Mitchesori JS, Chen ), Lin M, Culberson C, Sanguinetti MC. A structural basis for drug-induced long-QT syndrome. Proc Natl Acad Sci U S A 2000:97:12329-33 
Chapter 2

The Cardiac Sodium Channel 


\section{Introduction}

Voltage-gated sodium $\left(\mathrm{Na}^{+}\right)$channels are transmembrane proteins responsible for the rapid upstroke of the cardiac action potential and for rapid impulse conduction through cardiac tissue (for review, see $(1,2)$ ). Mutations in the gene encoding the cardiac $\mathrm{Na}^{+}$ channel $\left(S_{C} N_{5} A\right)$ have been linked to three forms of primary electrical disease: the long-QT syndrome (LQTS) (3), the Brugada syndrome (BrS) (4), and cardiac conduction defects (CCD) $(5,6)$. This chapter will review the physiology, molecular biology, biophysics, pharmacology, modulation and regulation of the cardiac $\mathrm{Na}^{+}$channel, and the relevance to the congenital long-QT syndrome.

\section{Sodium Channel Current}

The upstroke of the action potential of cardiomyocytes and cells of the specialized conduction system is due to a transient increase in membrane permeability to $\mathrm{Na}^{+}$ions. $\mathrm{Na}^{+}$channels can be viewed upon as macromolecular protein tunnels that span the lipid bilayer of the cell membrane, which allow ions to flow in or out the cell in a very efficient fashion (up to $10^{6}$ per second) $(7,8)$. This flow of ions creates electrical currents large enough to produce rapid changes in transmembrane voltage, which is the electrical potential difference between the cell interior and exterior. The very rapid rates of rise of the action potentials in these cells predict that the currents responsible for these voltage changes are rather large (about $1 \mathrm{~mA} / \mathrm{cm}^{2}$ ) (8). Sodium currents were first studied under voltage-clamp in several multicellular cardiac preparations $(9,10)$, but have now also been thoroughly investigated in single cell preparations (11), internally perfused canine cardiac Purkinje cells (12), and embryonic mouse cardiomyocytes (13). Measurements of single sodium channel activity have also been carried out in membranes of rat (14), rabbit (15), canine (12), guinea pig (14), and mouse cardiomyocytes $(16,17)$. Although the role of $\mathrm{Na}^{+}$ channel currents in initiating action potentials and impulse propagation is well known, it has not been as well understood that $\mathrm{Na}^{+}$channel activity can also contribute to the duration of the action potential. A very small fraction of $\mathrm{Na}^{+}$channels fail to enter the inactivated state of the channel and thus create a small persistent current during the action 
potential plateau phase, that has been referred to as 'window current' through $\mathrm{Na}^{+}$ channels (18).

\section{Molecular Architecture of Voltage-gated $\mathrm{Na}+$ Channels}

The tetrodotoxin (TTX)-sensitive $\mathrm{Na}^{+}$channel is a heterotrimeric; voltage-gated ion channel that is highly selective for $\mathrm{Na}^{+}$over other ions (8). The voltage-gated $\mathrm{Na}^{+}$channel consists of three glycoprotein subunits: a principal $\alpha$-subunit of $260 \mathrm{kDa}(19)$, which is associated with a $\beta$-subunit of $36 \mathrm{kDa}(20,21)$, and linked to a $\beta 2$-subunit of $33 \mathrm{kDa}(20,22)$. The primary structure of the $\alpha$-subunit consists of four homologous transmembrane domains (DI-DIV) each containing six membrane-spanning segments (\$1-S6) with a central pore region (23-25). The region between segment 5 and 6 of each of the four domains is called the P-region because it contributes to the pore of the channel (FIGURE 2.1).

In 1992, Gellens et al. (26) cloned and characterized the cardiac sodium channel $\alpha$-subunit gene $\left(S C N_{5} A\right)$. The $S C N_{5} A$ gene consists of 28 exons and sparis approximately $80 \mathrm{~kb}$ on chromosome $3 \mathrm{p}_{21}(27,28)$. The $\mathrm{SCN}_{5}$ A gene encodes $\mathrm{Nav} 1.5 \mathrm{Na}^{+}$channels, that belong to the same family as the neuronal and skeleta! muscle isoforms $(29,30)$. Nav 1.5 channels have been detected in adult heart $\left(h H_{1}\right)(19)$, and in embryonic and denervated muscle ( $h S K M 2$ ) (31). Recent observations indicate that SCN5A is also expressed in the brain $(32,33)$. The expression is localized to the limbic system and certain autonomic structures $(32,33)$, which might implicate the cardiac $\mathrm{Na}^{+}$channel in sudden unexplained death in epilepsy (34).

At least two $\alpha$-subunit mRNA transcripts "Nav 1.1 and Nav 1.5 , have been identified in rat (19) and rabbit heart (35). Nav 1.5 cardiac $\mathrm{Na}^{+}$channels are localized at the cell surface and T-tubular membranes of cardiomycytes, but also at terminal intercalated disk membranes (36). In addition, Nav 1.1 antibody labeling was observed along $Z$ lines in longitudinal sections (37). Whether the subcellular localization of $\mathrm{Na}^{+}$channels may play a role in anisotropic or saltatory conduction, or as a localized voltage-dependent current amplifier, remains to be established (36). 


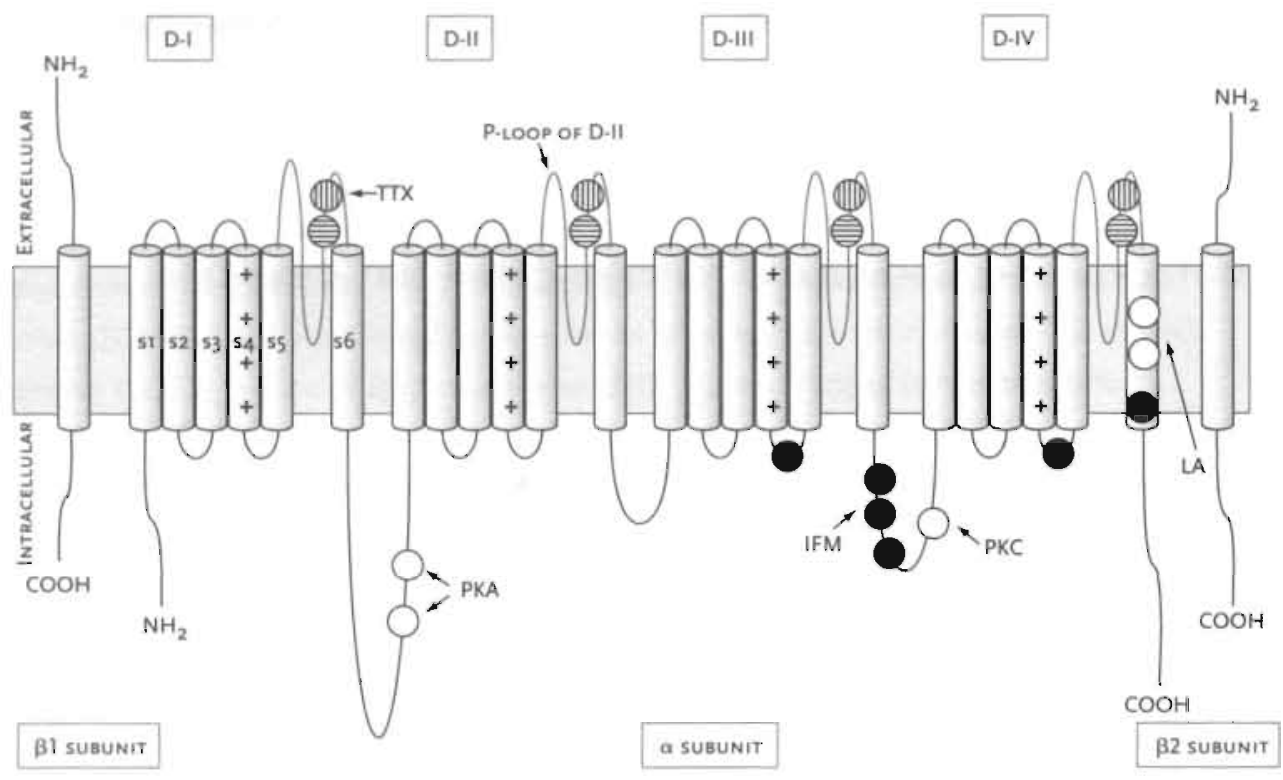

FIGURE 2:?

Structure of the cardiac $\mathrm{Na}^{+}$channel $\alpha$ and $\beta$ subusits. The $\alpha$ subunit consists of four homologous domains, $D-1$ to D-IV. Each domain consists of six transmembrane segments, named S1-56 (indicated in D-1). The voltage-sensors (S4 segments) important for voltage-dependent activation are indicated with '+++'. P-loops (S5-S6) are colored grey (the P-loop of D-II is indicated with an arrow). The circles in the P-loops correspond with residues forming the two rings contributing to the outer pore and selectivity filter, which are also important for tetrodotoxin (TTX) binding to the $\mathrm{Na}^{+}$ channel. Residues important for inactivation, such as the IFM-motif in the III-IV linker, and the docking sites for the fast-inactivation particle, are represented with black circles. The local anesthetic (LA) binding site in DIV- 54 is indicated with two white circles. The PKA (Ser 525, Ser 528) and. PKC (Ser 1503)-binding sites are also shown. The cardiac $\mathrm{Na}^{*}$ channel $\beta_{1}$ and $\beta_{2}$ subunits consist of a single membrane-spanning segment, with a short intracellular $C$-terminus: and a larger extracellular $\mathrm{N}$-terminus. 


\section{Physical Model}

Few studies are available on the actual threedimensional structure of $\mathrm{Na}^{+}$channels. Sato et al. (25) were the first to perform electron microscopy studies on the $\mathrm{Na}^{+}$channel isolated from Electrophorus electricus electroplax (electrical eel). A higher resolution was obtained using helium-cooled cryo-electron microscopy and single-particle image analysis of solubilized $\mathrm{Na}^{+}$channels (38). The channel has a bell-shaped outer surface of $13.5 \mathrm{~nm}$ in height and $10.0 \mathrm{~nm}$ in side length at the square-shaped bottom, and a spherical top with a diameter of 6.5 $\mathrm{nm}$ (FIGURE 2.2). Several inner cavities are connected to four small holes and eight orifices close to the extracellular and cytoplasmic membrane surfaces.
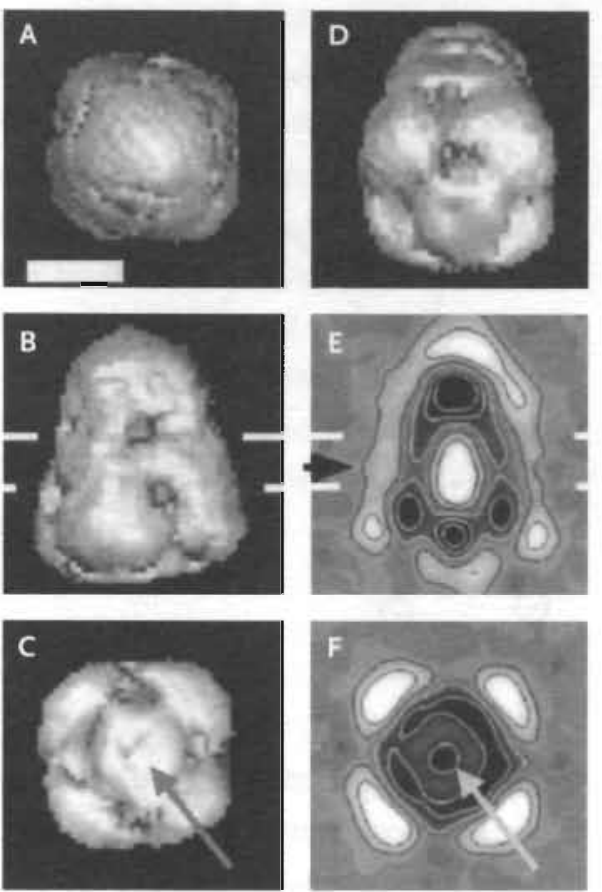

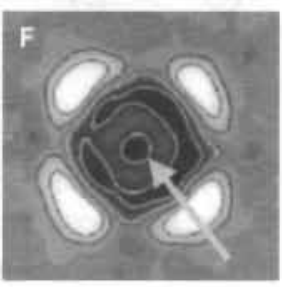

FICURE 2.2

Surface representation of the $\mathrm{Na}^{+}$channel protein (A-D).

(A) Top view, (B) Side view,

(C) Bottom view. (D) View at an oblique angle. Axial section (E) and perpendicular section (F) marked by the black arrow in $\mathrm{E}$. The white arrows in C and F indicate the central pore of the $\mathrm{Na}^{+}$channel. White bars (in $\mathbf{B}$ and $\mathbf{E}$ ) delineate the lipid bilayer. Scale bar, $5.0 \mathrm{~nm}$. Adapted from (38).

\section{$\mathrm{Na}^{+}$Channel Permeation}

The first functional view of the $\mathrm{Na}^{+}$channel was formulated by Hodgkin and Huxley (7) on the basis of voltage-clamp experiments, and provided a rationale for excitability based on the elementary properties of cation permeation (flux through the pore) and gating (dynamic conformational changes in response to membrane potential fluctuations). Although their physical model to explain transient membrane current was revolutionary at the time it was published (FIGURE 2.3), current theory involves a much more complicated scheme of conformational states underlying sodium channel function (39).

The $\mathrm{Na}^{+}$channel pore is the region of the molecule that is specialized to recognize $\mathrm{Na}^{+}$ions and to catalyze their transfer across the membrane. The central ionconduction pore of the $\mathrm{Na}^{+}$channel is lined by the $55-\mathrm{S} 6$ linkers (P-loops) from each of the four domains of the channel. These loops, which are highly conserved among various 
FICURE 2.3

The Hogdkin-Huxiey model of $\mathrm{Na}^{+}$channel gating. The upper trace shows a voltage step and the middle trace, the resulting

membrane current. The lower panel shows a physical model to account for the transient current. In the resting state, the activation gate $(m)$ is in the closed position and the inactivation gate $(h)$ is in the open position. After depolarization, the $m$ gate assumes the open position, sodium ions move into the cell. The $h$ gate then moves into the closed position blocking ion movement. When the membrane is retumed to the resting level, the

$m$ gate moves into the closed position (deactivation). After a variable interval, the $h$ gate moves into the open position (recovery from inactivation) (courtesy of Dr A. Grant (45)).
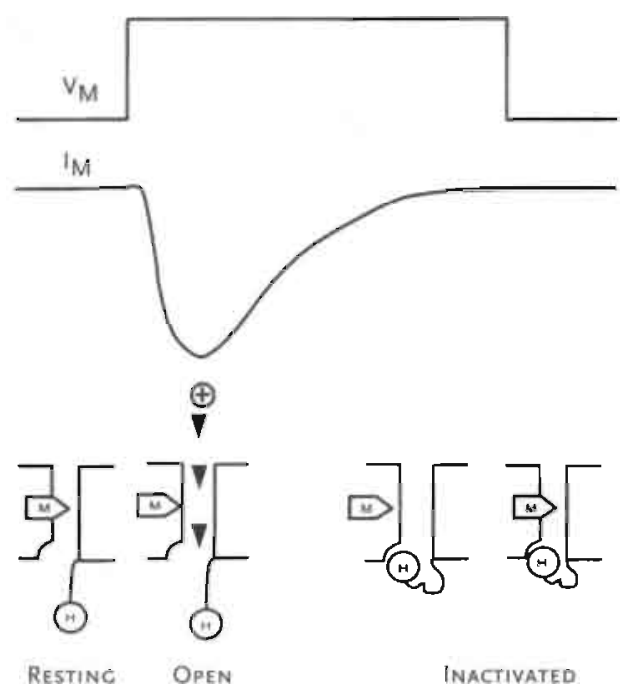

species, determine selectivity and conductance properties of the channel (40). Each of these four P-loop domains has a unique primary structure and a different positioning relative to the permeation pathway (47-43). Cysteine scanning accessibility mutagenesis experiments suggest that the domain II pore loop is most superficial, domains I and III intermediate, and domain IV distinctly deeper, judged by the voltage-dependence of $\mathrm{Cd}^{2+}$ block of the mutated $\mathrm{Na}^{+}$channels (41). Motions in the $\mathrm{Na}^{+}$channel pore were demonstrated by introducing pairs of cysteine residues throughout the pore-lining segment (44). Domains I and II were found to be closely apposed, because of their ability to form disulfide bonds, which implies protein dynamics that allow at least occasional proximity.

\section{Outer Pore and Selectivity Filter}

The segments that line the pore and define the ion selectivity and conductance of the $\mathrm{Na}^{+}$ channel have been identified. The extracellular mouth of the pore plays an important role in $\Pi \mathrm{TX}$ and saxitoxin (STX) binding to the $\mathrm{Na}^{+}$channel (8). These toxins are small rigid molecules of known crystal structure and have been proven crucial in defining the ion conduction pathway of sodium channeis (45). Noda et al. (46) and Terlau et al. (47) identified residues in the ascending limb of the P-loop (the most important one being Glu 387 in brain type II sodium channel) using site-directed mutagenesis that impair affinity for $\Pi \mathrm{X}$. These residues are likely to surround the extracellular opening of the pore and contribute to a receptor site for $\Pi \mathrm{XX}$. 
In addition, a second ring of four amino acids located three residues on the amino terminal site of these is also required for TXX binding (48). The cardiac isoform of the $\mathrm{Na}^{+}$ channel is relatively resistant to $\Pi \mathrm{TX}\left(\mathrm{IC}_{50}\right.$ in $\mu \mathrm{M}$ range) when compared to the brain and skeletal muscle isoforms ( $\mathrm{IC}_{50}$ in $\mathrm{nM}$ range). A cysteine at position 373 in the cardiac isoform (in the P-loop of domain I) is responsible for this phenomenon (49) (FIGURE 2.1) . The same amino-acid difference is also responsible for the susceptibility of the heart isoform to $\mathrm{Cd}^{2+}$ block, compared to the relatively insensitive neuronal and skeletal muscle isoforms (50). In addition, mutation of only one amino-acid in the P-loop of domain III ( $\mathrm{K}_{1419}$ in SCN5A) is sufficient to confer $\mathrm{Ca}^{2+}$-channel-like properties to the $\mathrm{Na}^{+}$channel (40). Mutations of the tetrad WDGL. (amino-acids 1713-1716 in SCN5A) in the D-IV P-loop affect selectivity among monovalent cations (41).

\section{$\mathrm{Na}+$ Channel Gating}

\section{Voltage-dependent Activation}

Activation of the voltage-gated $\mathrm{Na}^{+}$channel is thought to result from a voltage-driven conformational change that opens a transmembrane pore through the protein. The voltage-dependence of activation of the $\mathrm{Na}^{+}$channel derives from the OUTWARD MOVEMENT OF GATING CHARCES in response to changes in the electrical field $(7,51)$. Recent studies indicate that approximately 12 electronic charges in the $\mathrm{Na}^{+}$channel protein move across the membrane electric field during activation (52). Because sequence analysis of the $\mathrm{Na}^{+}$channel $\alpha$-subunit, revealed that the fourth transmembrane segment $\left(\mathrm{S}_{4}\right)$ in each of the four domains coritained repeated motifs of a positively charged residue followed by two hydrophobic residues, it was postulated that the $\mathrm{S}_{4}$ segment might serve as the key voltage-sensor that underlies channel activation $(53,54)$, which was subsequently confirmed by mutagenesis studies $(55-57)$. Changes in transmembrane potential exert a force on these gating charges, and initiate conformational changes in each domain of the channel protein that lead to activation.

In the process of activation, severa! charged residues in each 54 . segment actually transverse the membrane through a narrow tunnel formed by other, not yet identified regions of the channel $(58,59)$. The sliding helix $(60)$ or helical screw $(61)$ models of gating propose that these positively charged amino residues are stabilized in the transmembrane. 
environment by forming ion pairs with negatively charged residues in adjacent transmembrane segments. Depolarization of the membrane was proposed to release the $\mathrm{S}_{4}$ segments to move outward along a spiral path, initiating a conformational change that opens the pore. Although this model was quite speculative when it was proposed, its major features have now received direct experimental support from work on both sodium and potassium channels $(58,59,62)$.

\section{Fast Inactivation}

Voltage-dependent inactivation of $\mathrm{Na}^{+}$channels is a consequence of the voltage-dependent activation $(51,63)$. Inactivation is characterized by at least two distinguishable kinetic components, an initial rapid component (fast inactivation) and a slower component (slow inactivation). Using site-directed mutagenesis $(55,64)$ and peptide-specific antibodies $(65)$, the cytoplasmic linker between domains III and IV of the $\mathrm{Na}^{+}$channel $\alpha$-subunit has been identified as a key structural component that contributes to fast inactivation. This cytoplasmic linker serves as the inactivation gate that occludes the $\mathrm{Na}^{+}$channel pore from the cytoplasmic side of the membrane during maintained depolarization (so-called 'balland-chain' model) (51). The residues that form a hydrophobic triplet (IFM) in the III-IV linker are involved in inactivation gating (64). The IFM motif has been suggested to function as a 'latch' that holds the inactivation gate shut. A cysteine scanning study of the residues $1_{4} 85, \mathrm{~F}_{14} 86$, and $\mathrm{M}_{748} 7$ in the human cardiac $\mathrm{Na}^{+}$channel revealed that these amino-acids contribute to stabilizing the fast-inactivation particle in analogy to the brain $\mathrm{Na}^{+}$channel (66-68). However, peptide-binding studies suggest that inactivation may not involve simple occlusive block of the inner mouth of the pore (69). Glycine and proline residues that flank the IFM motif may serve as molecular hinges to allow closure of the inactivation gate like a hinged lid ('hinged-lid model') $(64,70)$.

Mutagenesis studies have identified a number of additional residues that reside in cytoplasmic loci consistent with 'docking sites' for the inactivation gate. Residues on S6 segment of domain IV form part of the intracellular mouth of the pore, and are thought to form part of the hydrophobic receptor site for the inactivation gate (71) or may stabilize the inactivated state through an indirect mechanism (72). Residues in cytoplasmic loops proximal to the III-IV linker including the domain III (73) and domain IV $54-5$ loops also may form part of the 'docking site' $(69,74-76)$ (FIGURE 2.1).

\section{Slow Inactivation}

In most published SCHEMES OF THF CARDIAC NA+ CHANNEL, slow inactivation follows fast 
(65), and therefore likely to be an independent gating process. It has been shown that transposition of all four cardiac isoform P-loops into the human skeletal muscle isoform ( $h \mathrm{SKM}_{1}$ ) backbone conferred heart isoform-like slow inactivation properties on the chimeric construct, suggesting a role for the P-loops in slow inactivation $(79,80)$. Changes in flexibility of the P-loops may affect slow inactivation (81). Recently, a single residue in the D-II P-loop of the cardiac $\mathrm{Na}^{+}$channel (1891) has been shown to regulate the steady-state ability of slow inactivation (82). It is suggested that slow inactivation in $\mathrm{Na}^{+}$channels involves conformational changes in the outer pore in a fashion analogous to $\mathrm{C}$-type inactivation in $\mathrm{K}^{+}$channels $(83-85)$. On the other hand, it has been suggested that other voltage-dependent structures play a role in slow inactivation. A region near the midpoint of the $\mathrm{S}_{4}$ segment of D-IV has been shown to play an important role in slow inactivation $(86,87)$, and suggests a role of $\mathrm{S}_{4}$ segments in slow inactivation.

\section{Coupling of Activation to Inactivation}

In neuronal tissue, sodium channel inactivation derives most of its voltage-dependence from coupling to the activation process driven by transmembrane movements of the $\mathrm{S}_{4}$ voltage sensors $(51,197)$. In heart tissue, however, the thesis has always been defended that the coupling between activation and inactivation is relatively weak. While channels can inactivate from a closed state, inactivation is facilitated by previous opening of the channel (39). There is accumulating evidence that outward movement of the $\mathrm{S}_{4}$ segment in domains III and IV is the signal to initiate fast inactivation of the sodium channel by closure of the intracellular inactivation gate $(68,88-90)$. An alternative mechanism based on physical interaction between regions on the $\mathrm{S}_{4}-\mathrm{S}_{5}$ linker of DIV and the DIII-DIV inactivation particle has also been proposed $(75,76)$. Such an association could be sensitive to changes in the conformation of $\mathrm{S}_{4}-\mathrm{S}_{5}$ of DIV, which are the result of movement of the voltage sensor of that domain during activation. This could lead to a change in the position of the inactivation gate relative to its docking sites.

\section{Inner Pore and Local Anesthetic Binding Site}

Class I antiarrhythmic drugs such as lidocaine, quinidine, and flecainide $(91,92)$ act by inhibiting ionic currents through $\mathrm{Na}^{+}$channels. Tertiary amine local anesthetics, such as procaine and etidocaine, which are chemically related to lidocaine, act in a similar manner.
Markov model of the sodium channel (39). Ceclosed state; $O$-open state; IF-fast-inactivated state; IS-slow-inactivated state. Inactivation can also occur from the closed state in the absence of channel opening (so-called closedstate inactivation $(\mathrm{r} \rightarrow \mathrm{F})$. 


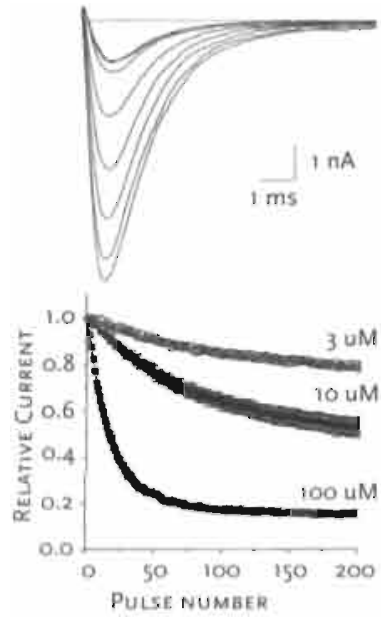

Development of use-dependent lidocaine-block upon repetitive depolarizations; note the gradual decrease in $\mathrm{Na}^{+}$channel amplitude (top). Time course of UDB in the presence of 3,10 , and $100 \mu \mathrm{M}$ lidocaine (bottom).
The efficacy of these drugs stems from their ability to selectively inhibit $\mathrm{Na}^{+}$channels during abnormal membrane depolarizations and rapid bursts of action potentials that characterize cardiac and neuronal pathologies (93).

It is thought that the selectivity of local anesthetics (LA) and antiarrhythmic drugs for depolarized $\mathrm{Na}^{+}$channels results from the preferential binding of these drugs to open and/or inactivate channel states that predominate at depolarized membrane potentials, rather than the resting chaninel states that predorninate at more hyperpolarized membrane potentials. The state-dependent drug action can be explained by an allosteric model in which a modulated drug receptor is in a low affinity conformation when the channel is resting, and converts to a high affinity conformation when the channel is open and/or inactivated $(93,94)$. This concept is often being referred to as, the 'modulated receptor model' $(93,94)$, and attributes the complex time- and voltage-dependent effects of LA and antiarrhythmics to distinct binding, affinities for the three putative gated conformational states of the $\mathrm{Na}^{+}$channel (closed - opened - inactivated) (7). Mild suppression of $\mathrm{Na}^{+}$ current cluring, isolated, brief depolarizations is attributed to low affinity binding for the closed channel conformation (tonic block), while far greater current suppression during repetitive depolarization, also known as USE-DEPENDENCE (95), is attributed to binding to states occupied during depolarization (either open or inactivated). Importantly, this model implies not only distinct high and low affinity drug-receptor sites, but also a complex interrelationship between channel gating and drug action. Lipid-soluble drug forms are thought to reach the receptor via a hydrophobic region of the membrane, while charged and less lipid-soluble forms pass via a hydrophylic region (inner channel mouth). The hydrophilic pathway is open only when the sodium channel opens.

Hille (94) has proposed that the binding site for both neutral and charged drugs that are used as local anesthetics and antiarrhythmic agents lies between the channel gates and the selectivity filter. Starmer et al. (96) have attempted to simplify and formalize some of these concepts mathematically. Thus, in their 'guarded receptor model', the binding site is guarded by the channel gates; a drug can bind to its receptor (and inhibit current) only after the gate is open and the receptor is unguarded.

Local anesthetics and related anti-arrhythmic drugs are thought to bind to a receptor site on the $\mathrm{Na}^{+}$channel that is accessible only from the intracellular side of the membrane, and is more accessible when the $\mathrm{Na}^{+}$channel is open $(8,97)$. Mutagenesis experiments of $\mathrm{Na}^{+}$channels revealed that the local anesthetic receptor is confined to the DIVS6 segment $\{98,99\}$. High-affinity binding of local anesthetics to the inactivated state of the $\mathrm{Na}^{+}$channel requires two critical amino acid residues, Phe-1764 and Tyr-1771, 
located in the DIVS6 transmembrane segment in the brain IIA channel (corresponding to $\mathrm{F}_{1760}$ and $\mathrm{Y}_{1767}$ in SCN $5 A$ ) (99). The current concept is that the tertiary amino group of local anesthetics interact with Phe-1764, which is located deeply in the pore, and that the aromatic moiety of the local anesthetics interact with Tyr-1771, which is located nearer to the intraceliular side of the pore (99) (see FIGURE 2.4). It is noteworthy that at least one of the residues implicated in LA block (F1764) importantly affects inactivation gating $(71,72)$. While it is likely that DIVS6 forms part of the local anesthetic receptor, the fact that mutations in this location also influence inactivation gating makes it difficult to exclude the possibility that some of the mutational effects on drug action are indirect. In support: of this observation, recent studies have shown that mutations in the outer pore, C-terminal to the selectivity filter and putative LA binding site, alter inactivation and LA block $(100,101)$.

\section{Modulation by Auxiliary $\beta$-subunits}

Auxiliary $\beta$-subunits do not form the ion-conducting pore but rather modulate channel $\mathrm{Na}^{+}$ gating and cell surface expression levels, and interact with extracellular matrix and cell adhesion molecules (103). Although no mutations in $\beta$-subunits have been linked to one of the inherited arrhythmogenic syndromes, a mutation in the $\beta_{1}$ gene $\left(S \mathrm{CN}_{1} B\right)(104,105)$ has been implicated to play a role in febrile seizures and generalized epilepsy (34).

Brain sodium channels are composed of a single pore-forming $\alpha$-subunit, noncovalently bound to a $\beta_{1}$-subunit, and linked to the $\beta_{2}$-subunit by a disulfide bond, in a 1:1:1 stoichiometry $(20,22,62,106)$. Expression of the $\mathrm{Na}^{+}$channel $\alpha$-subunit alone resulted
FIGURE 2.4

Proposed orientation of amino acids in the sixth transmembrane segment of DIV of the $\mathrm{Na}^{+}$ channel with respect to bound local anesthetic molecule in the conduction pore. The DIV pore loop, which probably aiso contributes to the receptor site. is shown as well. Amino acid positions 1760, 1764, and 1771 are shown facing the pore lumen. From: (102). 
in functional sodium channels (65). Co-expression studies of brain $\mathrm{Na}^{+}$channel $\alpha$-subunits with the $\beta$ 1-subunit have demonstrated larger peak $I_{\mathrm{Na}}$ amplitude, acceleration of activation and inactivation, and a more negative voltage-dependence of steady-state. inactivation than the $\alpha$-subunit expressed alone $(21,104,107-110)$.

The subunit structure of cardiac sodium channels has been controversial for a long time. Recently, however, Malhotra et al. (37) determined that cardiac. $\mathrm{Na}^{+}$channels in rat and mouse cardiac myocytes are composed of $\alpha$-, $\beta_{1}$ - and $\beta_{2}$-subunits. In addition, a $\beta_{3}$-subunit has been identified in human and rat heart (111), and a splice-variant of the $\beta$ 1-subunit $\left(\beta_{1} A\right)$ has been identified in rat heart (112). Their functional roles in modulating cardiac sodium channels, however, remain to be determined.

$\mathrm{Nav} 1.5 \mathrm{Na}^{+}$channel and $\beta 1$ co-expression has been studied in heterologous. expression systems with variable and conflicting results $(104,108,110,113-115)$. When expressed in Xenopus oocytes, Nav 1.5 channels alone show gating and blocking, properties: comparable to native $\mathrm{Na}^{+}$channels (49). While studies consistently show that $\beta$-subunit coexpression in Xenopus oocytes enhances the current magnitude, studies differ in regard to whether gating effects are present: (110) or absent: (116). Some groups have reported that $\beta 1$ has no observable effects on $N a v 1.5$ functional expression $(104,108)$, while other reported modulation of channel sensitivity to lidocaine block and subtle changes in channel kinetics and gating properties in response to $\beta_{1}$ expression $(37,114,115)$. The recent study by Malhotra et al. (37) showed that in HEK cells, co-expression with $\beta 1$ shifts the voltage-dependence of inactivation, whereas $\beta 2$. does not. The voltage-dependence of activation is not modified by $\beta$-subunit coexpression (37). A possible explanation for the inconsistent results reported in previous studies is that some HEK cell lines express endogenously the $\beta 1 \alpha$-subunit, which could confound the electrophysiological measurements ( 117$)$. Finally, rat: Nav $1,1 \alpha$-subunits are also modulated by $\beta_{11}$ - and $\beta_{2}$ subunits when expressed in oocytes (118).

Structural correlates for the noncovalent $\alpha-\beta 1$ subunit interaction are thought: to reside on the extracellular and intramembraneous domains of the $\beta$ 1-subunit (119-121) and domain I and IV P-loops within the $\alpha$-suburit $(80,120,122)$. McCormick (121) showed that the immunoglobulin (lg)-fold of the $\beta$ 1 extracellular domain serves as a scaffold that presents charged residues or interaction with the $\alpha$-subunit. In addition, the cytoplasmic. C-terminal domain of the $\alpha$-subunit has been implicated to play a yet unknown role in the interaction with the B1-subunit $(115,120)$.

Cardiac $\beta$-subunits, which are type I topology membrane proteins (123), are characterized by one large extracellular domain at the aminoterminus, a single 
transmembrane region, and a shorter intracellular C-terminal domain (124). A surprising finding from determination of the primary structures of the $\beta$ r and $\beta 2$-subunits $(21,22)$ was their close relationship to the large family of cell adhesion molecules of the immunoglobulin superfamily (125). No other auxiliary subunits of ion channels have related structures (62). Both $\beta$-subunits interact with extracellular matrix molecules and participate in homophilic cell adhesion, resulting in cellular aggregation and recruitment. of ankyrin to the plasma membrane at point of cell-cell contact (103). The presence of $\beta$-subunits in cardiac myocytes may facilitate sodium channel localization and clustering to discrete functional domains via cell-adhesive interactions. Interestingly, the putative cytoplasmic region of both $\beta_{1}$ and $\beta_{3}$ contains a sequence YLAI 16 amino acids from the end of the predicted transmembrane sequence. The position and sequence of this motif fits the consensus for an internalization signal recognized by clathrin-coated pits, suggesting a possible role for $\beta$-subunits in the movement of sodium channels between cellular compartments (111).

Ankyrins are a family of spectrin-binding proteins associated with the cytoplasmic surface of the plasma membrane in many cell types. Ankyrins associate via their membrane binding domains with several ion channels (126). Sodium channels in ankyrin ${ }_{B^{\circ}}$ knockout mice display a reduced current density and abnormal $\mathrm{Na}^{+}$channel kinetics that lead to action potential prolongation and abnormal QT-rate adaptation (17), suggesting that a proper functional localization of $\mathrm{Na}^{+}$channels is essential. In line with these results, Undrovinas et al. (127) have demonstrated that breakup of the actin-based cardiomyocyte cytoskeleton with cytochalasin $\mathrm{D}$ produced late $\mathrm{Na}^{+}$current at hyperpolarizing test potentials, and suggested a role for the cytoskeleton in regulating $\mathrm{Na}^{+}$channel gating.

\section{Transcriptional and Posttranslational Modification of $\mathrm{Na}^{+}$Channel Expression}

\section{Transcriptional Control of $\mathrm{Na}^{+}$Channel Gene Expression}

Control of excitability can occur at the genomic level by transcriptional regulation of ion channel genes. The expression of $\mathrm{Na}^{+}$channels is developmentally regulated (13) and tissue restricted. Patterns of certain electrical activity can also influence transcriptional activity, e.g. seizures alter $\mathrm{Na}^{+}$gene expression in the brain (128). Denervation induces the 
expression of the cardiac isoform of the $\mathrm{Na}^{+}$channel in skeletal muscle, while transiently suppressing the expression of the mature skeletal muscle isoform (31). Chronic exposure to antiarrhythmic drugs which block $\mathrm{Na}^{+}$channels can increase the steady-state levels of $\mathrm{Na}^{+}$mRNA, which would counteract the effects of channel blockade (129). In addition, chronic treatment with n-3 polyunsaturated fatty acids, which are known to prevent fatal ventricular arrhythmias (130), reduced mexiletine-induced increase in cardiac $\mathrm{Na}^{+}$charnel expression in cultured neonatal cardiac myocytes (131). Finally, an increased expression of neuronal subtype $\mathrm{Na}^{+}$channels was identified in post myocardial infarction remodeled myocardium, with a reversion toward the fetal phenotype (132).

\section{Post-translational Modification of $\mathrm{Na}^{+}$Channel Expression}

All $\mathrm{Na}^{+}$channel subunits are modified by glycosylation. The $\beta_{1}, \beta_{2}$, and brain and muscle $\alpha$-subunits are heavily glycosylated $(25-40 \%)(133,134)$, whereas the cardiac $\alpha$-subunit is composed by $5 \%$ carbohydrates (135). Sialic acid is a prominent component of the $\mathrm{N}$-linked carbohydrate of the $\mathrm{Na}^{+}$channel. Neurominidase treatment to remove sialic acid from expressed skeletal muscle channels produces a depolarizing shift of steady-state inactivation (136). Local surface charge is also importantly influenced by charged amino acid residues that stud the outer mouth of the pore, although the predominant effects in this case are on permeation rather than gating $(41,47)$. Recently, it has been shown that incomplete glycosylation during post-translational processing may contribute to $\mathrm{Na}^{+}$ channel-dependent arrhythmogenesis in mice, with heart failure (137).

\section{Regulation of the $\mathrm{Na}^{+} \mathrm{Channel}$}

There is evidence that the cardiac $\mathrm{Na}^{+}$channel may be the target of modulation by CAMPdependent protein kinase $A$ (PKA) and protein kinase $C$ (PKC), although the experimerital evidence for modulation of this channel is not as well established as it is for other ion channels. Cyclic nucleatide-dependent phosphorylation sites have been mostly studied in the $\alpha$-subunit of the voltage-gated brain sodium channel type: IIA (138"140). Within the intracellular linker region between D156 and D2S1 (ID 1-2) of the $\alpha$-subunit of the rat brain I!A sodium channel five sites matching PKA consensus sequences, are found (141), four of which have been shown biochemically to be involved in PKA phosphorylation of the 


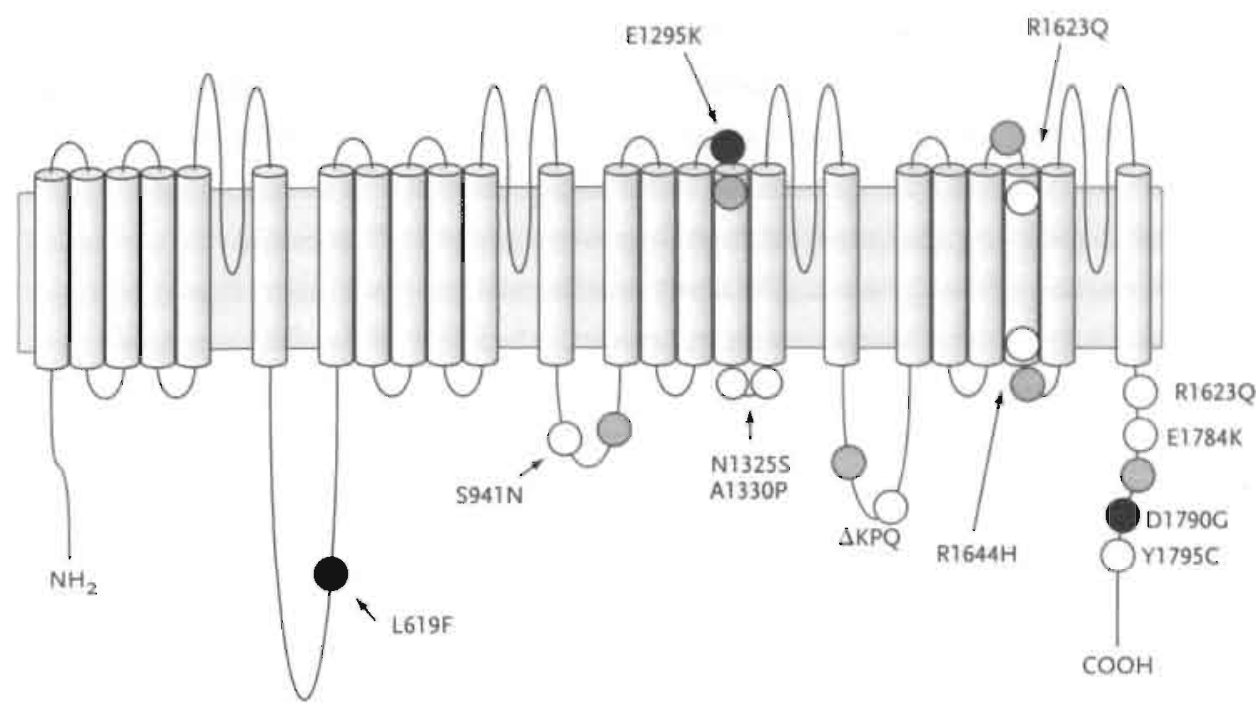

channel $(119,140)$. Phosphorylation at the second PKA site (Ser 537) is necessary and sufficient to diminish amplitude in brain $\mathrm{Na}^{+}$channels (141).

The cardiac sodium channel has eight candidate consensus PKA phosphorylation sites of the form KRXXS*, RXXS*, or RXS* in the I-II linker, all of which are distinct from the neuronal channel. In vitro studies of expressed rat cardiac $\mathrm{Na}^{+}$channels demonstrated CAMP-dependent phosphorylation of only two of these serines (Ser 526 and Ser 529. corresponding with Ser 525 and Ser 528 in the human isoform) (142). Phosphorylation by PKA at these sites augments the $\mathrm{Na}^{+}$current (142-144), by increasing the number of $\mathrm{Na}^{+}$ channels in the plasma membrane $(145,146)$. Modulation of cardiac $\mathrm{Na}^{+}$channel gating has also been demonstrated, including changes in the voltage-dependence of channel activation and inactivation (146-149).

The effects of upstream receptor-activated stimulation are less clear, with both increases. and decreases in current being reported after treatment with CAMP-elevating agents or membrane-permeant CAMP analogs (148). In addition to the indirect pathway mediated by $\mathrm{G}$-proteins acting through second messenger cascades, a direct membranedelimited G-protein regulatory pathway involving direct interaction of the stimulatory G-protein $\alpha$-subunit with the cardiac $\mathrm{Na}^{+}$channel has been proposed $(144,145,147,148,150)$. Protein kinase $C$ (PKC) also modulates cardiac $\mathrm{Na}^{+}$channels, both reducing the maximal conductance of the channel and altering gating. Both effects are largely attributable to
FICURE 2.5

Structure of the cardiac $\mathrm{Na}^{+}$ channel a-subunit. Indicated with. the circles are long.QT syndrome mutations with the respective amino-acid substitutions or deletions. The white circles represent mutations that have been characterized electrophysiologically. grey circles have not been characterized yet, and black circles represent mutotions characterized in this thesis. 
phosphorylation of a serine residue in the III-IV linker that is conserved in the neuronal and cardiac isoform (151). Interestingly, while PKC phosphorylation of this residue reduces $\mathrm{Na}^{+}$ current in both isoforms, the gating defects diverge. Phosphorylation of Serine 1503 in the cardiac isoform induces a negative shift in the voltage-dependence of steady-state inactivation (implying stabilized inactivation), while in brain $\mathrm{Na}^{+}$channels, phosphorylation of the same residues slows and destabilizes inactivation $(64,151)$. Because the III/IV linker sequences are conserved, interaction of the phosphorylated serine with other domains may differ for the two isoforms.

\section{Slip-mode Conductance of the Cardiac $\mathrm{Na}^{+}$Channel}

Nav $1.5 \mathrm{Na}^{+}$channels can become permeable to $\mathrm{Ca}^{2+}$ after activation of protein kinase: $\mathrm{A}$ (152). This slip-mode conductance of the $\mathrm{Na}^{+}$channel only occurs in transfected cells in the presence of both $\beta_{1}$ and $\beta_{2}$-subunits (153). The $\mathrm{Ca}^{2+}$ flux through this pathway can increase subcellular $\mathrm{Ca}^{2+}$ and thereby activate sarcoplasmatic reticulum (SR) $\mathrm{Ca}^{2+}$ release, $\mathrm{Ca}^{2+}$ sparks, and the $\mathrm{Ca}^{2+}$ transient. This is an intriguing finding, as, consensus PKA sites are remote from the pore and selectivity filter. Yel: sympathetic stimulation results in a dramatic change in the calciurn selectivity of the sodium channel. The mechanism involved in this potentially physiologically important phenomenon remains to be further established.

\section{Long-QT Syndrome $\mathrm{Na}+$ Channel Mutations}

Mutations in the cardiac $\mathrm{Na}^{+}$channel $\alpha$-subunit gene SCN5A were linked to LQTS by a candidate gene approach and positional cloning (3). First, the LQT-3 locus was mapped to chomosome 3p21-24 (154). Subsequently, the SCN5A gene was mapped to chromosome 3P21 (28), and mutations in SCN5A were linked to type 3 LQTS (3).

Seventeen distinct mutations associated with LQT-3 (see F!GURE 2.5) have been reported to date. The first mutation discovered was a 3 -amino acids deletion (residues 1505-1507) in the cytoplasmic linker region between DIII and DIV of the $\mathrm{Na}^{+}$channel $\alpha$-subunit ( $\triangle K P Q$ mutation). Other mutations involve amino acid substitutions $(n=15)$ and a deletion ( $n=1$ ) (TABLE 2.1). In this thesis, the biophysical properties of D1790G, and the novel E1295 $\mathrm{K}$ and L619F mutant LQT-3 $\mathrm{Na}^{+}$channels will be described (FICURE 2.5; and CHAPTERS. 3, 5, and 6). 
The first functional phenotype reported, and hence the 'prototypical LQT-3 phenotype' is caused by the $\triangle \mathrm{KPQ}$ mutation $(28,64)$. Using two-electrode voltage-clamp recordings from Xenopus laevis oocytes, a TTX-sensitive persistent $\mathrm{Na}^{+}$current of less than $5 \%$ of the peak inward current was identified during prolonged repolarizations (28). In addition, time constants for current decay were decreased in the $\triangle \mathrm{KPQ}$ mutant, and there was a $-6 \mathrm{mV}$ shift of the potential at which half of the current is inactivated (28). At the single channel level, brief dispersed reopenings and infrequent long-lasting bursts of openings were responsible for the macroscopic non-inactivating $\mathrm{Na}^{+}$current $(28,165,166)$. $\triangle K P Q$ mutant $\mathrm{Na}^{+}$channels were also studied in human embryonic kidney (HEK) cells using whole-cell patch-clamp analysis $(158,166,167)$. The presence of a non-inactivating $\mathrm{Na}^{+}$current during prolonged depolarizations was confirmed. In HEK cells, current inactivation was speeded, recovery from inactivation faster, and the voltage-dependence of inactivation shifted towards more negative potentials $(i 58,166)$.

\begin{tabular}{|c|c|c|c|c|c|}
\hline $\begin{array}{l}\text { Nucleotide } \\
\text { change }\end{array}$ & $\begin{array}{l}\text { Aminoacid } \\
\text { substitution }\end{array}$ & $\begin{array}{l}\text { Channel } \\
\text { domain }\end{array}$ & Exon & $\begin{array}{l}\text { No of RW } \\
\text { families }\end{array}$ & Reference \\
\hline $\mathrm{AA}_{2971 T C}$ & $\mathrm{~S}_{941 \mathrm{~N}}$ & DII/DIII & 16 & 1 & (155) \\
\hline$G_{3340 A}$ & $\mathrm{D} m{ }_{4} \mathrm{~N}$ & DI/DII & 18 & $\mathrm{~T}$ & $(156)$ \\
\hline$C_{3911 T}$ & $\mathrm{~T}_{3} 0_{4} \mathrm{M}$ & $\mathrm{Dili} / \mathrm{S}_{4}$ & 22 & 1 & (157) \\
\hline$A_{3974 G}$ & $\mathrm{~N}_{1325 \mathrm{~S}}$ & Dill/S4-5 & 23 & I & $(158)$ \\
\hline$G_{4138} \mathrm{~A}$ & A1330P & $\mathrm{D} 11 ! / \mathrm{S}_{4-5}$ & 23 & 1 & (159) \\
\hline $\mathrm{C}_{4501 G}$ & Lișiv & Dill/DIV & 26 & 1 & $(156)$ \\
\hline del $4517-4519$ & del1505-1507 & DIII/DIV & 26 & 4 & (3) \\
\hline del $4850-4852$ & delfifi7 & $\mathrm{DIV} / \mathrm{S}_{3}-4$ & 28 & 1 & $(156)$ \\
\hline $\mathrm{G}_{4868 \mathrm{~A}}$ & $\mathrm{R}: 523 \mathrm{Q}$ & $\mathrm{DIV} / \mathrm{S}_{4}$ & 28 & 2 & $(156,160)$ \\
\hline$G_{4868 T}$ & $\mathrm{R}_{1623 \mathrm{~L}}$ & $\mathrm{DIV} / \mathrm{S}_{4}$ & 28 & $!$ & $(156)$ \\
\hline$\sigma_{4931 A}$ & $\mathrm{R} 1644 \mathrm{H}$ & DIV/S4 & 28 & 2 & $(156,158)$ \\
\hline$G_{4934} T^{\top}$ & T1645M! & $\mathrm{OIV} / \mathrm{S}_{4}$ & 28 & 1 & (157) \\
\hline$G_{53} 29 \mathrm{~A}$ & V $1777 \mathrm{M}^{\mathrm{M}}$ & C-terminus & 28 & $y$ & $(161)$ \\
\hline$G_{5349 A}$ & Ei784K & C-terminus & 28 & 2 & $\{15,6,162\}$ \\
\hline $\mathrm{G}_{5360 \mathrm{~A}}$ & Si78;iv & C-terminus & 28 & 1 & $\{156)$ \\
\hline A5359G & Di79oG & C-terminus & 28 & $i$ & $(163)$ \\
\hline $\mathrm{A}_{53} 8{ }_{4} \mathrm{C}$ & Yi795C & C-terminus & 28 & 1 & $(164)$ \\
\hline
\end{tabular}

TABLE 2..1

Summary of all published SCIVSA mutations. 


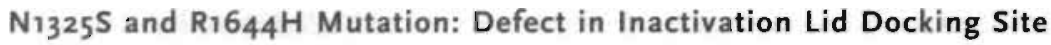

The $\mathrm{N}_{1325} \mathrm{~S}$ mutation occurs in the $\mathrm{S}_{4}-\mathrm{S}_{5}$ region of domain $1 ! \mathrm{I}, \mathrm{R} 1644 \mathrm{H}$ near the cytoplasmic end of the $\mathrm{S}_{4}$ segment of domain IV. Both regions are highly conserved between the cardiac, skeletal muscle, and brain !la. isoforms suggesting their importance $(26,53,168)$. Both the N1325S and $\mathrm{R} 1644 \mathrm{H}$ mutations lead to persistent, non-inactivating $\mathrm{Na}^{+}$current $(158,165)$. The $\mathrm{N} 1325 \mathrm{~S}$ mutation also causes a negative shift in the voltagedependence of inactivation and slower recovery from inactivation $(158,165)$. Interestingly, mutation $\mathrm{T}_{1645} \mathrm{M}$ (directly adjacent to residue $\mathrm{R}_{1644}$ ) in the first cytoplasmic residue of the $\mathrm{S}_{4}$-S5 linker in domain IV has also been associated with LQT-3 (157).

\section{S941N Mutation: Sudden Infant Death Syndrome}

The sporadic SCN 5 A mutation $\mathrm{S}_{94} 1 \mathrm{~N}$ was identified in a 44 -day old infant with congenital LQTS, resuscitated from ventricular fibrillation. The aspartate at amino-acid position 941 (Asp94.1) is located in the highly conserved intracellular loop between the second and third transmembrane domains of SCN5A (27). When expressed in Xenopus oocytes, this mutation was characterized by a late sodium current of $1.8-2.5 \%$ (155). The mechanism by which a substitution in this part of the channel protein leads to a persistent inward current is not yet understood.

\section{R1623Q Mutation: Uncoupling of Activation-inactivation}

The de novo missense mutation $\mathrm{R}_{1} 623 \mathrm{Q}$ was identified in a Japanese girl severely affected by a sporadic form of the long.QT syndrome (169). The positively charged R1623 is the outermost residue of the $\mathrm{S}_{4}$ segment of domain IV. When expressed heterologously in Xenopus oocytes, a small non-inactivating current was found at the end of the $100 \mathrm{~ms}$ depolarizations (<.3\% of peak current) (170), comparable to previously described LQT-3 mutations. Striking difference between $R_{1} 623 Q$ and $W / T$ current was a slowed rate of macroscopic current decay, a unique feature not observed in other mutations reported in fạmilial LQTS mutations $(28,158,165)$.

During single channel recordings, the Ri623Q exhibited multiple, prolonged openings early in the depolarization period, which give rise to the slow decay. The ability of open channels to inactivate is impaired $(160,170)$. The underling mechanism may involve uncoupling activation from inactivation $(59,171)$. In addition, Kambouris et al. (172) reported that the voltage-dependence of availability of $I_{\mathrm{Na}}$ was shifted to more negative potentials when expressed in Xenopus oocytes, indicating that inactivation from closed states is increased. A slowing of open-state inactivation with co-existent enhancement of 
closed-state inactivation for this SCN5A mutation is consistent with gating phenotypes reported for mutations in the domain IV-S4 segment of the human skeletal muscle $\mathrm{Na}^{+}$ channel (hSkM1) linked to paramyotonia congenita $(171,173)$. The precise mechanism of impaired inactivation of the R1623Q mutation may be a functional defect in activationinactivation coupling of the $\mathrm{Na}^{+}$channel that has been previously reported in the paramyotonia congenita mutations R1448 H/C (65).

Genetic analysis of LQTS families, enrolled in the International Long-QT Registry has indicated that the C-terminus of the SCN 5 A gene is a hot-spot for LQT-3i mutations (156). Approximately $30 \%$ of all LQT-3 mutations have been identified in this part of the $\mathrm{Na}^{+}$channel.

\section{Ei784K Mutation: C-terminal Mutation}

The E.784 K mutation occurs in a highly conserved acidic domain immediately following the $\mathrm{D}_{4} / \mathrm{S} 6$ segment, within the carboxy terminus of the cardiac $\mathrm{Na}^{+}$channe! (162). Electrophysiological analysis of E1784 K channels in Xenopus oocytes (162) and HEK. cells (174) revealed a $2-4 \%$ maintained $\mathrm{Na}^{+}$current, a $-12 \mathrm{mV}$ negative shift in the $\mathrm{V}_{1 / 2}$ of steadystate inactivation, and a faster recovery from inactivation. These results suggest a destabilization of the inactivated state of the $\mathrm{Na}^{+}$channel. Additional mutagenesis experiments in the early C-terminus domain suggest that the biophysical mechanism may be allosteric rather than caused by direct interference with channel-gating properties (162). The early part of the C-terminus (adjacent to DIV-S6) of the human cardiac $\mathrm{Na}^{+}$channel has clusters of negatively charged amino acid residues (162). Little research has been performed as to the function of this highly conserved segment of the $\mathrm{Na}^{+}$channel. The accentuation of the functional defect by the $\beta_{1}$-subunit, was observed in the E1784K and the nearby Di79oG mutations. It is, however, difficult to reconcile these findings with the work of other groups demonstrating that the cytoplasmic domain of the $\beta$ 1-subunit might not be required for its functional effects on mammalian sodium channels (119-121).

\section{Dı790G Mutations: Impaired $\alpha$ - $\beta 1$ Subunit Interaction}

The Di790C (negatively charged aspartic acid to a neutral glycine) mutation is also located in the C-terminal part of the channel (163). In contrast to most other LQT-3 mutations, it does not lead to a sustained $\mathrm{Na}^{+}$current when studied in a heterologous expression system (115). Although a disturbed interaction between the $\alpha$ and $\beta_{\text {i }}$-subunit of the cardiac $\mathrm{Na}^{+}$channel were suggested to cause the $\mathrm{D} 1790 \mathrm{G}$ phenotype, the exact mechanism by which this mutation may lead to an arrhythmogenic phenotype remained to be established. 
Andrel Andreyevich Markov was a graduate of Saint Petersburg University (1878), where he began as a professar in 7886. Markov's early work was mainly in number theory and analysis, continued fractions, limits of integrals, approximation theory and the convergence of series. Markov is particularly remembered for his study of Markov chains, sequences of random variables in which the future variable is determined by the present variable but is independent of the way in which the present state arose from its predecessors. This work launched the theory of stochastic processes.
In CHAPTER 3 of this thesis, novel insights in the electrophysiological consequences of this mutation will be described.

Interestingly, the mutation E1784K (negatively charged glutamic acid to positively charged lysine), located only 6 aminoacids away from D1790G, does lead to sustained inward current. In contrast, the mutation E1784D (a mutation conserving the negative charge) was indistinguishable from wild-type current with respect to sustained current (174). This implies that subtle changes in amino-acid charges in the early carboxyterminal domain may have profound effects on gating of the cardiac $\mathrm{Na}^{+}$channel.

\section{Arrhythmogenic Mechanism of the Non-inactivating $\mathrm{Na}^{+}$Current}

The fact that several LQTS $\mathrm{Na}^{+}$channel mutations spanning nearly the entire $\alpha$-subunit, modify fast inactivation suggests that $\mathrm{Na}^{+}$channel inactivation depends upon complex ensembled interactions among many structural domains. Incomplete inactivation leading to persistent inward current has been shown to be a common consequence of most of the identified SCNSA mutations $(28,158,160,162,165-167,170)$. This resultant non-inactivating component of $\mathrm{Na}^{+}$channel current exceeds the physiological leveis of $\mathrm{Na}^{+}$current during the action potential plateau phase $(18,175)$.

Using a single-channel based MARKOVIAN computational model, Clancy and Rudy (39) were able to demonstrate elegantly that sustained $\mathrm{Na}^{+}$current during the plateau phase of the action potential may lead to arrhythmogenic consequences at the cellular level. Although the amplitude of the persistent current is very small, only $1 \%$ of the peak $I_{\mathrm{Na}}$, it is sufficient to shift the delicate balance of currents that exists during the action potential plateau (176-179). The additional current carried by sodium acts in opposition to repolarizing outward currents and prolongs the APD (39).

\section{Molecular Pharmacology of LQT-3 $\mathrm{Na}^{+}$Channel Mutations}

The precise identification of genetic defects that cause different forms of LQTS opened up the possibility of discovering new therapeutic approaches to the management of this disorder based on the molecular pharmacology of the mutant ion channels encoded by the. specific gene defects (180). Because it is possible to investigate the functional properties of the mutant genes using heterologous expression systems, in vitro tests can be carried out 
to identify unique drug-channel interactions that may occur as a consequence of the interrupted gene defect: and that may be exploited to devise novel pharmacological approaches to disease management (CHAPTER 4).

Class IB antiarrhythmics, such as lidocaine and mexiletine, are drugs that block $\mathrm{Na}^{+}$channels in a voltage-dependent manner. As discussed previously, channel block depends on the state of the channel in a complex manner, being influenced by the relative number of resting, open, and/or inactivated channels $(93,94,181)$. Because certain $\mathrm{Na}^{+}$ channel mutations that underlie LQT-3 have been shown to modify inactivation (28), it is very likely that these mutant. $\mathrm{Na}^{+}$channels will be modified in a unique manner by local anesthetic drugs.

There have been several reports indicating that such a specific interaction is indeed clinically relevant. Experiments carried out in transfected HEK cells (180) and Xenopus oocytes $(182)$ revealed that maintained $\mathrm{Na}^{+}$current through non-inactivating mutant channels was more sensitive to local anesthetic block than peak inward current. This suggests that $\mathrm{Na}^{+}$channel current that underlies impulse conduction (peak current) will be less sensitive to class IB drugs than currents that underlie QT prolongation in carriers of LQT-3 gene mutations. This observation has been reinforced in preliminary clinical pharmacological studies $(183,184)$. Schwartz et al. showed that the class IB agent mexiletine effectively shortens the QT-interval of patients identified as carriers of the SCN5A gene mutations $\triangle K P Q$ and $\mathrm{R}_{1644} \mathrm{H}$ (183). In addition, Rosero et al. (184) reported QT-interval shortening in two $\triangle K P Q$ carriers by short-term intravenous lidocaine and longterm oral tocainide therapy.

When more LQT-3 $\mathrm{Na}^{+}$channels were characterized electrophysiologically, it became clear that class IB Na+ channel blockers might not constitute a universal approach to LQT-3. As predicted on the basis of the absence of maintained current in Di79oG mutant $\mathrm{Na}^{+}$channels (115), lidocaine did not correct QT-interval prolongation in two patients with the Di790G mutation (185). However, the class IC antiarrhythmic agent: flecainide did shorten QT-intervals and other repolarization parameters in Di7goG mutation carriers significantly (185). The molecular basis of this observation is the subject of CHAPTER 4 in this thesis. 


\section{Other Arrhythmogenic Syndromes Caused by $\mathrm{Na}^{+} \mathrm{Channel}$ Mutations}

$\mathrm{Na}^{+}$channel mutations can also cause the Brugada syndrome, a hereditary cardiac disease characterized by right bundle-branch, block (RBBB), an elevation of the ST segment in leads $V_{1}$ through $V_{3}$ on the electrocardiogram, and ventricular fibrillation that can lead to sudden cardiac death (186). In patients with Brugada syndrome, missense mutations T1620M (4), R1512W (174), A1924T (187), splice-donor, and frameshift. mutations have been identified in $\mathrm{SCN}_{5} \mathrm{~A}(4)$. For further information on the electrophysiological phenotypes of these $\mathrm{Na}^{+}$channel mutations, the reader is referred to the reviews by Bezzina et al. (2) and Vatta et: al. (i88).

Although LQTS and Brugada syndrome are known as distinct disorders, a recent study reported a mutation in the SCN 5 A gene that causes both syndromes (189). An inframe insertion of three nucleotides in the carboxyterminal region resulting in an additional aspartate at: position 1795 was found to be responsible for this 'overlap syndrome'. Subsequent reports described the biophysical phenotype of this $\mathrm{Na}^{+}$channel mutation (190,191).

Progressive slowing of cardiac conduction is a common electrophysiological manifestation of the progressive fibrosis in the conduction system of elderly patients (192). Progressive cardiac conduction disease (PCCD) or Lev-Lenegre syndrome, was first: recognized as șuch by Drs. Lev (193) and Lenegre (194), and is characterized by progressive impairment of cardiac conduction through the His-Purkinje system leading to right or left bundle tranch block. This may deteriorate into complete atrioventricular block, causing syncope and sudden death. Surprisingly, Schott et al. (5) demonstrated that a single nucleotide deletion at position 5280 in SCN5A causes early-onset. PCCD in a Dutch family. Deletion of $G_{5280}$ is predicted to lead to a frame-shift resulting in a stop-codon. The resulting truncated channels might contribute to an overall reduced $\mathrm{Na}^{+}$current density, which might explain slow conduction in these: patients.

Tan et al. (6) reported a SCN5A mutation that causes a sustained sinoatrial and atrioventricular conduction defect with pathologrical slowing of the cardiac rhythm in the absence of other cardiac abnormalities. The missense mutation $\mathrm{C}_{514} \mathrm{C}$ was identified in the channel protein. The gating defects of this mutation are likely to cause slow myocardial conduction, but do not provoke rapid cardiac arrhythmias associated with LQTS and Brugada syndrome (6). A previous study reported linkage of an isolated cardiac conduction 


\section{Aim of This Thesis}

The identification and study of SCN5A mutations related to the congenital long-QT syndrome may serve several purposes (TABLE 2.2). Common techniques to characterize functional defects related to mutations in the cardiac sodium channel included heterologous expression studies in Xenopus laevis oocytes (28) and human embryonic kidney (HEK) cells (115). More recently, transgenic mice have been used to study the functional consequences of sodium channel mutations on the cellular and whole organism level (195).

Although considerable progress has been made in terms of the biophysical characterization of long-QT syndrome-related $\mathrm{Na}^{+}$channel mutations, few of the mechanisms so far are really fully understood. For example, the Di7goG mutation was the first $\mathrm{Na}^{+}$channel mutation identified, that did not lead to non-inactivating current upon proloriged depolarization (175). Although it was initially suggested that defective $\alpha-\beta$ r subunit interactions underlie the channel defect (115), is was not obvious from these data how this might prolong cellular action potentials. In CHAPTER 3 , we extended these findings by incorporated whole-cell patch-clamp data of the D1790C mutation into the Luo-Rudy computer model of the ventricular action potential.

Motivations to Identify and Characterize $S C N_{5} A$ Mutations

1. Identification of patients with symptoms of the long-QT syndrome mutation

2. Screening of (asymptomatic) family members of long-QT syndrome patients

3. Study of structure-function relationship of the sodium channel

4. Study of molecular pharmacology

\section{Methods to Characterize SCN5A Mutations}

1. Heterologous expression studies in Xenopus laevis oocytes

2. Heterologous expression studies in HEK cells

3. Transgenic mice
TABLE 2.2

The rationale and methods of studying SCN5A mutations. 
A recent clinical study by Benhorin et al. (185) showed that in carriers of the Di790C mutation, class IB sodium channel blockers were ineffective, whereas class IC blocker flecainide significantly shortened all heart rate-corrected repolarization parameters. In CHAPTER 4, we investigated the molecular pharmacological basis of this intriguing clinical observation. Other clinical studies support the idea that, considerable heterogeneity exists in carriers of long.QT syndrome related ion channel mutations $(183,196)$. In an attempt to assess whether this was also true for carriers of different $\mathrm{Na}^{+}$charınel mutations, we studied two novel SCN5A mutations, E1295K (CHAPTER 5) and L619F (CHAPTER 6).

Finally, after describing several novel mechanisms by which $\mathrm{Na}^{+}$channel mutations may prolong ventricular action potentials, and thus the QT-interval on the electrocardiogram, we summarize current concepts regarding the LQT-3 phenotypes. We discuss these data in perspective of the structure-function relationship of the cardiac $\mathrm{Na}^{+}$channel, and review the implications of our findings for the mutation-specific treatment of the long.QT syndrome type 3 . 


\section{References}

1. Balser JR. Structure and function of the cardiac sodium channels. Cardiovasc Res 1999;42:327-38.

2. Bezzina $C R$, Rook MB, Wilde AA. Cardiac sodium channel and inherited arrhythmia syndromes. Cardiovasc Res 2001;49:257-77.

3. Wang Q, Shen J, Splawski I, Atkinson D, Li Z, Robinson JL, Moss Al, Towbin JA, Keating MT. SCN5A mutations associated with an inherited cardiac arrhythmia, long-QT syndrome. Cell 1995;80:805-11.

4. Chen Q, Kirsch GE, Zhang D, Brugada R, Brugada J, Brugada P, Potenza D, Moya A, Borggrefe M, Breithardt G, Ortiz-Lopez R, Wang Z, Antzelevitch C, O'Brien RE, Schulze-Bahr E, Keating MT, Towbin JA, Wang Q. Genetic basis and molecular mechanism for idiopathic ventricular fibrillation. Nature 1998;392:293-96.

5. Schott JI, Alshinawi C, Kyndt F, Probst V, Hoorntje TM, Hulsbeek M, Wilde AA, Escande D, Mannens MM, Le Marec H. Cardiac conduction defects associate with mutations in SCN5A.

Nat Genet 1999;23:20-21.

6. Tan HL, Bink-Boelkens MT, Bezzina CR, Viswanathan PC, Beaufort-Krol GC, van Tintelen PJ, Van den Berg MP, Wilde AA, Balser JR. A sodium-channel mutation causes isolated cardiac conduction disease. Nature 2007;409:1043-47.

7. Hodgkin AL, Huxley AF. A quantitative description of membrane current and its application to conduction and excitation in nerve. J Physiol 1952;117:500-44.

8. Hille B. Ionic channels of excitable membranes. (2 $2^{\text {nd }}$ ed). Sunderland, MA: Sinauer Associates, 1992

9. Colatsky T). Voltage clamp measurements of sodium channel properties in rabbit cardiac Purkinje fibres. J Physiol 1980;305:215-34.

10. Ebihara L, Johnson EA. Fast sodium current in cardiac muscle. A quantitative description. Biophys J 1980;32:779-90.

11. Brown AM, Lee KS, Powell T. Sodium current in single rat heart muscle cells. J Physiol 1981;318:479-500.

12. Makielski JC, Sheets MF, Hanck DA, January CT: Fozzard HA. Sodium current in voltage clamped internally perfused canine cardiac Purkinje cells. Biophys J 1987:52:1-11.

13. Davies MP, An RH, Doevendans P, Kubalak S. Chien KR, Kass RS. Developmental changes in ionic channel activity in the embryonic murine heart. Circ Res 1996;78:15-25.

14. Kunze DL, Lacerda $A E$, Wilson DL, Brown $A M$. Cardiac $\mathrm{Na}^{+}$currents and the inactivating, reopening, and waiting properties of single cardiac Na channels. J Gen Physiol 1985;86:697-799.

15. Grant AO, Starmer CF, Strauss HC. Unitary sodium channels in isolated cardiac myocytes of rabbit. Cifc Res 1983:53:823-29.

16. Benndorf K. Properties of single cardiac Na* channels at 35 degrees C. J Gen Physiol 1994:704:801-20.

17. Chauhan VS, Tuvia S, Buhusi M, Benriett V, Grant AO. Abnormal cardiac Na* channel properties and QT heart rate adaptation in neonatal ankyrin(B) knockout mice. Circ Res 2000;86:441-47.

18. Attwell D, Cohen I, Eisner D, Ohba M, Ojeda C. The steady state TDX-sensitive ("window") sodium current in cardiac Purkinje fibres. Pflugers Arch 1979:379:137-42.

19. Rogart RB, Cribbs LL, Muglia LK, Kephart DD, Kaiser MW. Molecular cloning of a putative tetrodotoxin-resistant rat heart $\mathrm{Na}^{+}$channel isoform. Proc Notl Acad Sci U S A 1989;86;8170-74.

20. Hartshorne RP, Messner DJ, Coppersmith JC, Cattera!l WA. The saxitoxin receptor of the soclium channel from rat brain. Evidence for two nonidentical beta subunits. J Biol Chem 1982;257:13888-91. 
21. Isom LL, De Jongh KS, Patton DE, Reber BF, Offord ], Charbonneau H, Walsh K, Goldin AL, Catterall WA. Primary structure and functional expression of the $\beta$ 1-subunit of the rat brain sodium channel. Science 1992;256:839-42.

22. Isom LL, Ragsdale DS, De Jongh KS, Westenbroek RE, Reber BF, Scheuer T, Catterall WA. Structure and function of the $\beta 2$-subunit of brain sodium channels, a transmembrane glycoprotein with a CAM motif. Cell 1995;83:433-42.

23. Catterall WA. Structure and function of voltage-gated ion channels.

Annu Rev Biochem 1995:64:493-531.

24. Fozzard HA, Hanck DA. Structure and function of voitage-dependent sodium channels: comparison of brain II and cardiac isoforms. Physiol Rev 1996;76:887-926.

25. Sato $C$, Sato M, Iwasaki A, Doi T, Engel A. The sodium channel has four domains surrounding a central pore. J Struct Biol 1998;121:314-25.

26. Gellens ME, George AL Jr, Chen LQ, Chahine M, Horn R, Barchi RL, Kallen RG. Primary structure and functional expression of the human cardiac tetrodotoxin-insensitive voltage-dependent sodium channel. Proc Natl Acad Sci U S A 1992;89:554-58.

27. Wang Q, Li Z, Shen I, Keating MT. Genomic organization of the human SCN5A gene encoding the cardiac sodium channel. Genomics 1996;34:9-16.

28. Bennett: PB, Yazawa K, Makita N, George AL Jr. Molecular mechanism for an inherited cardiac arrhythmia. Nature 1995;376:683-85.

29. Goldin AL. Diversity of mammalian voltage-gated sodium channels. Ann N Y Acad Sci 1999:868:38-50.

30. Goldin AL, Barchi RL, Caldwell JH, Hofmann F, Howe JR, Hunter JC, Kallen RG, Mandel G, Meisler MH, Netter YB, Noda M, Tamkun MM, Waxman SG, Wood JN, Catterall WA. Nomenclature of voltage-gated sodium channels. Neuron 2001;28:365-68.

31. Kallen RG, Sheng ZH, Yang J, Chen LQ, Rogart RB, Barchi RL. Primary structure and expression of a sodium channel characteristic of denervated and immature rat skeletal muscle. Neuron 1990;4:233-42.

32. Hartmann HA, Colom LV, Sutherland ML, Noebels JL. Selective localization of cardiac SCN5A sodium channels in limbic regions of rat brain. Nat Neurosci 1999;2:593-95.

33. Donahue LM, Coates PW, Lee VH, Ippensen DC, Arze SE, Poduslo SE. The cardiac sodium channel mRNA is expressed in the developing and adult rat and human brain. Brain Res 2000;887:335-43.

34. Wallace RH, Wang DW, Singh. R, Scheffer IE, George AL Jr, Phillips HA, Saar K, Reis A, Johnson EW, Sutherland GR, Berkovic SF, Mulley JC. Febrile seizures and generalized epilepsy associated with a mutation in the $\mathrm{Na}^{+}$channel 31 -subunit gene. SCN1B. Nat Genet 1998;19:366-70.

35. Baruscotti M, Westenbroek R, Catterall WA, DiFrancesco D, Robinson RB. The newborn rabbit sinoatrial node expresses a neuronal type I-like $\mathrm{Na}^{+}$channel. J Physiol 1997;498:641-48.

36. Cohen SA. Immunocytochemical localization of $r \mathrm{H}_{1}$ sodium channel in adult rat heart atria and ventricle. Presence in terminal intercalated disks. Circulation 1996;94:3083-86.

37. Malhotra JD, Chen C, Rivolta I. Abriel H, Malhotra R, Mattei LN, Brosius FC, Kass RS, Isom LL. Characterization of sodium channel $\alpha$ and $\beta$-subunits in rat and mouse cardiac myocytes. Circulation 2007;103:1303-10.

38. Sato C, Ueno Y, Asai K, Takahashi K, Sato M, Engel A, Fujiyoshi Y. The voltage-sensitive sodium channel is a bell-shaped molecule with several cavities. Nature 2001;409:1047-51.

39. Clancy CE, Rudy Y. Linking a genetic defect to its cellular phenotype in a cardiac arrhythmia. Noture 1999:400:566-69

40. Heinemann SH, Terlau H, Stuhmer W, Imoto K. Numa S. Calcium channel characteristics conferred on the sodium channel by single mutations. Nature 1992;356:441-43.

41. Chiamvimonvat $N_{\text {" }}$ Perez-Garcia MT, Ranjan R, Marban E, Tomaselli GF. Depth asymmetries of the 
pore-lining segments of the $\mathrm{Na}^{+}$channel revealed by cysteine mutagenesis. Neuron 1996;16:1037-47.

42. Perez-Garcia MT, Chiamvimonvat N, Ranjan R, Baiser JR, Tomaselli GF, Marban E. Mechanisms of sodium/calcium selectivity in sodium channels probed by cysteine mutagenesis and sulfhydryi modification. Biophys J 1997:72:989-96.

43. Yamagishi T, Janecki M, Marban E, Tomaselli GF. Topology of the $P$ segments in the sodium channel pore revealed by cysteine mutagenesis. Biophys J 1997;73:195-204.

44. Benitah JP, Ranjan R, Yamagishi T, Janecki M, Tomaselli GF, Marban E. Molecular motions within the pore of voltage-dependent sodium channels. Biophys $J$ 1997:73:603-13.

45. Grant AO. Molecular biology of sodium channels and their role in cardiac arrhythmias. Am J Med 2001;110:296-305.

46. Noda M, Suzuki H, Numa S, Stuhmer W. A single point mutation confers tetrodotoxin and saxitoxirı insensitivity on the sodium channel II. FEBS Lett 1989;259:213-16.

47. Terlau H, Heinemann SH, Stuhmer W, Pusch M, Conti F, Imoto K, Numa S. Mapping the site of block by tetrodotoxin and saxitoxin of sodium channel II. FEBS Lett 1991;293:93-96.

48. Catterall WA. Structure and function of voltage-gated ion channels. Trends Neurosci 1993:16:500-06.

49. Satin J, Kyle JW, Chen M, Rogart RB, Fozzard HA. The cloned cardiac $\mathrm{Na}^{+}$channel $\alpha$-subunit expressed in Xenopus oocytes show gating and blocking properties of native channels.

J Membr Biol 1992;130:11-22.

50. Backx PH, Yue DT, Lawrence JH, Marban E, Tomaselli GF. Molecular localization of an ion-binding site within the pore of mammalian sodium channels. Science 1992;257:248-51.

51. Armstrong CM. Sodium channels and gating currents. Physiol Rev 1981;6r:644-83.

52. Hirschberg B, Rovner A, Lieberman M, Patlak J. Transfer of twelve charges is needed to open skeletal muscle $\mathrm{Na}^{+}$channels. J Cen Physiol 1995;106:1053-68.

53. Noda M, Ikeda T, Suzuki H, Takeshima H, Takahashi T, Kuno M, Numa S. Expression of functional sodium channels from cloned cDNA. Nature 1986;322:826-28.

54. Catterall WA. Structure and function of voltage-sensitive ion channels. Science 1988;24:50-6\%.

55. Stuhmer W, Conti F, Suzuki H, Wang XD, Noda M, Yahagi N, Kubo H, Numa S. Structural parts involved in activation and inactivation of the sodium channel. Nature 1989;339:597-603.

56. Kontis KJ, Rounaghi A, Goldin AL. Sodium channel activation gating is affected by substitutions of voltage sensor positive charges in all four domains. I Gen Physiol 1997;110:391-401.

57. Mitrovic N, George AL, Horn R. Independent versus coupled inactivation in sodium channels. Role of the domain $2 \mathrm{~S}_{4}$ segment. / Gen Physiol 1998;111:451-62.

58. Yang $\mathrm{N}$, Horn R. Evidence for voltage-dependent $\mathrm{S}_{4}$ movement in sodium channels. Neuron 1995: 15:213-18.

59. Yang $N_{1}$ George AL, Horn R, Molecular basis of charge movement in vaitage-gated sodium channeis. Neuroni 1996;16:113:22.

6o. Catterall WA, Schmidt JW, Messner DJ, Feller DI. Structure and biosynthesis of neuronal sodium channels. Ann N Y Acad Sci 1986;379:186-203.

61. Guy HR, Seetharamulu P. Molecular model of the action potential sodium channel. Proc Natl Acad Sci U S A 1986;83:508-12.

62. Dock W. Transitory ventricular fibrillation as a cause of syncope and its prevention by quinidine sulphăte. Am Heart J 1929;4:709-14.

63. Aldrich RW, Corey DP, Stevens CF. A reinterpretation of mammalian sodium channel gating based on single channel recording. Nature 1933;306:436-41.

64. West JW, Patton DE, Scheuer T, Wang Y, Goldin AL, Catterall WA. A cluster of hydrophobic amino acid residues required for fast $\mathrm{Na}^{+}$channel inactivation. Proc Natl Acad Sci U S A 1992;89:10910-14. 
65. Vassilev P, Scheuer T, Catteral! WA. Inhibition of inactivation of single sodium channels by a sitedirected antibody. Proc Natl Acad Sci U S A 1989;86:8147-51.

66. Hartmann HA, Tiedeman AA, Chen SF, Brown AM, Kirsch GE. Effects of III-IV linker mutations on human heart $\mathrm{Na}^{+}$channel inactivation gating. Circ Res 1994;75(1):114-22.

67. Deschenes I, Trottier E, Chahine M. Cysteine scanning analysis of the IFM cluster in the inactivation gate of a human heart sodium channel. Cardiovasc: Res 1999;42:521-29.

68. Sheets MF, Kyle JW, Hanck DA. The role of the putative inactivation lid in sodium channel gating current immobilization. J Gen Physiol 2000;115:609-20.

69. Tang L, Kallen RG, Horn R. Role of an $\mathrm{S}_{4}-\mathrm{S}_{5}$ linker in sodium channel inactivation probed by mutagenesis and a peptide blocker. J Gen Physiol 1996;108:89-104.

70. Kellenberger S, Scheuer T, Catterall WA. Movement of the $\mathrm{Na}^{+}$channel inactivation gate during inactivation. J Biol Chem 1996;271:30971-79.

71. McPhee IC, Ragsdale DS, Scheuer $T$, Catterall WA. A mutation in segment IVS 6 disrupts fast inactivation of sodium channels. Proc Natl Acad Sci U.S A 1994;91:12346-50.

72. McPhee $\mathrm{JC}$, Ragsdale DS, Scheuer T, Catterall WA. A critical role for transmembrane segment IVS 6 of the sodium channel $\alpha$-subunit in fast inactivation. J Biol Chem 1995:270:12025-34.

73. Smith MR, Goldin AL. Interaction between the sodium channel inactivation linker and domain III S4-55. Biophys J 1997:73:7885-95.

74. McPhee JC, Ragsdale DS, Scheuer T, Catterall WA. A critical role for the $\mathrm{S}_{4}$-S 5 intracellular loop in domain IV of the sodium channel $\alpha$-subunit in fast inactivation. J Biol Chem 1998;273:1121-29.

75. Lerche H, Peter W, Fleischhauer R, Pika-Hartlaub U, Malina T, Mitrovic N, Lehmann-Horn F. Role in fast inactivation of the IV/S4-S5 loop of the human muscle $\mathrm{Na}^{+}$channel probed by cysteine mutagenesis. J Physiol 1997;505:345-52.

76. Tang L, Chehab N, Wieland SJ, Kallen RG. Glutamine substitution at alanine 1649 in the $\mathrm{S}_{4}-\mathrm{S}_{5}$ cytoplasmic loop of domain 4 , removes the voltage sensitivity of fast inactivation in the human heart sodium channel. J Gen Physiol 1998;111:639-52.

77. Schwartz SP, Jezer $A$. The action of quinine and quinidine of patients with transient ventricular fibrillation. Am Heart J 1934:9:792-801.

78. Rudy B. Slow inactivation of the sodium conductance in squid giant axons. Pronase resistance. J Physiol 1978;283:7-21.

79. Balser JR, Nuss HB, Chiamvimonvat N, Perez-Garcia MT, Marban E, Tomaselli GF. External pore residue mediates slow inactivation in mu i rat skeleta! muscle sodium channels.

J Physiol 1996;494:431-42.

80. Vilin YY, Makita N, George AL, Ruben PC. Structural determinants of slow inactivation in human cardiac and sketetal muscle sodium channels. Biophys J 1999;77:1384-93.

81. Benitah JP: Chen Z, Balser IR, Tomaselli GF, Marban E. Moleçiar dynamics of the sodium channel pore vary with gating: interactions between P-segrnent motions and inactivation.

J Neurosci 1999;19:1577-85.

82. Vilin YY, Fujimoto E. Ruben PC. A single: residue differentiates between human cardiac and skeletal muscle $\mathrm{Na}^{+}$channel slow inactivation. Biophys \} 2001;80:2227-30.

83. Hoshi T, Zagotta WN, Aldrich RW. Two types of inactivation in Shaker $K^{+}$channels: effects of alterations in the carboxy-terminal region. Neuron 1991;7:547-56.

84. Townsend C, Horn R. Effect of alkali metal cations on slow inactivation of cardiac $\mathrm{Na}^{+}$channels. J Gen Physiol 1997;110:23-33.

85. Todt H, Dudley SC, Kyle /W, French RJ, Fozzard HA. Ultra-slow inactivation in $\mathrm{mLI}_{1} \mathrm{Na}^{+}$channels is produced by a structural rearrangement of the outer vestibule. Biophys ] 1999;76:1335-45. 
86. Vedantham V, Cannon SC. Rapid and slow voltage-dependent conformational changes in segment IVS6 of voltage-gated $\mathrm{Na}^{+}$channels. Biophys J 2000;78:2943-58.

87. Mitrovic N, George AL, Horn R. Role of domain 4 in sodium channel slow inactivation. I Gen Physiol' 2000;115:707-18.

88. Chen LQ, Santareili V, Horn R, Kallen RG. A unique role for the $\mathrm{S}_{4}$ segment of domain 4 in the inactivation of sodium channels. J Gen Physiol 1996;108:549-56.

89. Sheets MF, Kyle JW, Kallen RG, Hanck DA. The Na ${ }^{+}$channel voltage sensor associated with inactivation is localized to the external charged residues of domain IV, S4. Biophys J 1999;77:747-57.

9o. Cha A, Ruben PC, George AL, Fujimoto E, Bezanilla F. Voltage senșors in domains III and IV, but not I and II, are immobilized by $\mathrm{Na}^{+}$channel fast inactivation. Neuron 1999:22:73-87.

91. Vaughan Williams EM. A classification of antiarrhythmic actions reassessed after a decade of new drugs. J Clin Pharmacol 1984:24:129-47.

92. Harrison DC. Antiarihythmic drug classification: new science and practical applications. Am J Cardiol 1985:56:185-87.

93. Hondeghem LM, Katzung BC. Time- and voltage-dependent interactions of antiarrhythmic drugs with cardiac sodium channels. Biochim Biophys Acto 1977:472:373-98.

94. Hille B. Local anesthetics: hydrophilic and hydrophobic pathways for the drug-receptor reaction. J Gen Physiol 1977;69:497-515.

95. Courtney KR. Mechanism of frequency-dependent inhibition of sodium currents in frog myelinated nerve by the lidocaine derivative CEA.J Pharmacol Exp Ther 1975:195:225-36.

96. Starmer CF, Grant AO, Strauss HC. Mechanisms of use-dependent block of sodium channels in excitable membranes by local anesthetics. Biophys $\int 1984 ; 46: 15-27$.

97. McCormack K, Tanouye MA, Iverson LE, Lin JW, Ramaswami M, McCormack. T。 Campanelli JT, Mathew MK, Rudy B. A role for hydrophobic residues in the voltage-dependent gating of Shaker $\mathrm{K}^{+}$ channels. Proc Natl Acad Sci U S A 1991;88:2931-35.

98. Ragsdale DS, MCPhee IC, Scheuer T, Catterall WA. Molecular determinants of state-dependent block of $\mathrm{Na}^{+}$channels by local anesthetics. Science 1994;265:1724-28.

99. Ragsdale DS, MCPhee $1 C$, Scheuer T, Catterall WA. Common molecular determinants of local anesthetic, antiarrhythmic, and anticonvulsant block of voltage-gated $\mathrm{Na}^{+}$channels.

Proc Natl Acad Sci U S A 1996:93:9270-75.

100. Kambouris NG, Hastings LA, Stepanovic S. Marban E. Tomaselli GF, Balser JR. Mechanistic link between lidocaine block and inactivation probed by outer pore mutations in the rat $\mu 1$ skeletal muscle sodium channel. I Physiol 1998;512:6937705.

101. Li RA, Tsushima RG, Himmeidirk K. Dime DS, Backx PH. Local anesthetic anchoring to cardiac sodium channels. Implications into tissue-selective drug targeting. Circ Res 1999:85:88-98.

102. Grant AO, Whalley DW, Wendt DJ. Pharmacology of the cardiac sodium channels. In: Zipes DP, Jalife J (eds). Cardiac electrophysiology. From cell to bedside. Philadelphia: WB, Saunders, 2000:133-41.

103. Isom LL. Sodium channel $\beta$-subunits: anything but auxillary. Neuroscientist 2001:7:42-54.

104. Makita N, Bennett PB, George, AL. Voltage-gated $\mathrm{Na}^{+}$channel $B$ 1-subunit mRNA expressed in adult human skeletal muscle, heart, and brain is encoded by a single gene. J Biol Chem 1994;269:7571-78.

105. Makita N, Sloan-Brown K, Weghuis DO, Ropers HH, George AL. Genomic organization and chromosomal assignment of the human voltage- gated $\mathrm{Na}^{+}$channel $\beta$ 1-subunit gene (SCN1B). Genomics 1994:23:628-34.

106. Hartshorne RP, Catterall WA. The sodium channel from rat brain. Purification and subunit composition.J Biol Chem 1984;259:1667-75. 
107. McClatchey Al, Cannon SC, Slaugenhaupt SA, Gusella JF. The cloning and expression of a sodium channel $\beta$ r-subunit cDNA from human brain. Hum Mol Genet 1993;2:745-49.

108. Yang JS, Bennett PB, Makita N, George AL, Barchi RL. Expression of the sodium channel B1-subunit in rat skeletal muscle is selectively associated with the tetrodotoxin-sensitive $\alpha$-subunit isoform. Neuron 1993:11:915-22.

109. Patton DE, Isom LL, Catterall WA, Goldin AL. The adult rat brain $\beta_{1}$-subunit modifies activation and inactivation gating of multiple sodium channel alpha subunits. J Biol Chem 1994:269:17649-55.

110. Nuss HB, Chiamvimonvat N, Perez-Garcia MT, Tomaselli GF, Marban E. Functional association of the $\beta 1$-subunit with human cardiac $\left(h H_{1}\right)$ and rat skeletal muscle $(m u 1)$ sodium channel $\alpha$-subunits expressed in Xenopus oocytes. J Gen Physiol 1995;106:1171-91.

111. Morgan K, Stevens EB, Shah B, Cox Pl, Dixon AK, Lee K, Pinnock RD, Hughes I, Richardson PJ, Mizuguchi K, !lackson AP. Beta 3: an additional auxiliary subunit of the voltage-sensitive sodium channel that modulates channel gating with distinct kinetics.

Proc Natl Acad Sci U S A 2000;97:2308-13.

112. Kazen-Gillespie KA, Ragsdale DS, D'Andrea MR, Mattei LN, Rogers KE, Isom LL. Cloning, localization, and functional expression of sodium channel $B$ iA-subunits.

$\int$ Biol Chem 2000;275:1079-88.

113. Qu Y, Isom LL, Westenbroek RE, Rogers IC, Tanada TN, McCormick KA, Scheuer T, Catterall WA. Modulation of cardiac $\mathrm{Na}^{+}$channel expression in Xenopus oocytes by $\beta$ 1-subunits.

J Bioi Chem 1995:270:25696-701.

114. Makielski JC, Limberis JT, Chang SY, Fan Z, Kyle JW. Coexpression of $\beta 1$ with cardiac sodium channel

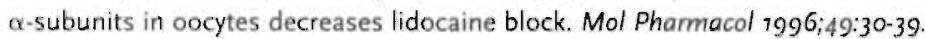

115. An RH, Wang XL, Kerem B, Benhorin J, Medina A, Coldmit M, Kass RS. Novel LQT-3 mutation affects $\mathrm{Na}^{+}$channel activity through interactions between $\alpha$ - and $\beta 1$-subunits. Circ Res 1998;83:141-46.

116. Qu Y, Rogers 1, Tanada T, Scheuer T, Catterall WA. Molecular determinants of drug access to the receptor site for antiarrhythmic drugs in the cardiac $\mathrm{Na}^{+}$channel.

Proc Natl Acad Sci U S A 1995:92:11839-43.

117. Moran O, Nizzari M, Conti F. Endogenous expression of the B1A sodium channe! subunit in HEK-293 cells. FEBS Lett 2000;473:132-34.

118. Smith RD, Goldin AL. Functional analysis of the rat I sodium channel in Xenopus oocytes. INeurosci 1998:18:811-20.

119. Chen C, Cannon SC. Modulation of $\mathrm{Na}^{+}$channel inactivation by the $\beta_{1}$-subunit: a deletion analysis. Pflugers Arch 1995;431:186-95.

120. Makita N, Bennett PB, George AL. Molecular determinants of $\beta 1$-subunit-induced gating modulation in voltage-dependent $\mathrm{Na}^{+}$channels. J Neurosci 1996;16:7117-27.

121. McCormick KA, Isom LL, Ragsdale D, Smith D, Scheuer T, Catterall WA. Molecular determinants of $\mathrm{Na}^{+}$channel function in the extracellular domain of the $\beta$ 1-subunit. J Biol Chem 1998;273:3954-62.

122. Qu Y, Rogers JC, Chen SF, McCormick KA, Scheuer T, Catterall WA. Functional roles of the extracellular segments of the sodium channel $\alpha$-subunit in voltage-dependent gating and modulation by Br-subunits. J Biol Chem 1999;274:32647-54.

123. Wickner WT, Lodish HF. Multiple mechanisms of protein insertion into and across membranes. Science 1985;230:400-07.

124. Eubanks J, Srinivasan j, Dinulos MB, Disteche CM, Catterall WA. Structure and chromosomal localization of the $\beta z$-subunit of the human brain sodium channel. Neuroreport 1997;8:2775-79.

125. Isom. LL, Catterall WA. Na+ channel subunits and Ig domains. Nature 1996;383:307-08.

126. Malhotra JD, Kazen-Gillespie K, Hortsch M, Isom LL. Sodium channel $\beta$-subunits mediate 
homophilic cell adhesion and recruit ankyrin to points. of cell-cell contact.

J Biol Chem 2000;275:11383-88.

127. Undrovinas AI, Shander CS, Makielski JC. Cytoskeleton modulates gating of voltage-dependent sodium channel in heart. Am J Physiol 1995;269:H203-14.

128. Gastaldi M, Robaglia-Schlupp A, Massacrier A, Planells R, Cau P. mRNA coding for voltage-gated sodium channel $\beta 2$-subunit in rat central nervous system: cellular distribution and changes following kainate-induced seizures. Neurosci Lett 1998;249:53-56.

129. Duff HJ, Offord J, West J, Catterall WA. Class I and IV antiarrhythmic drugs and cytosolic calcium regulate mRNA encoding the sodium channel $\alpha$-subunit in rat cardiac muscle.

Mol Pharmacol 1992;42:570-74.

130. Kang IX, Leaf A. Antiarrhythmic effects of polyunsaturated fatty acids. Recent studies. Circulation 1996;94:1774-80.

131. Kang IX, Li Y, Leaf A. Regulation of sodium channel gene expression by class I antiarrhythmic drugs and $n-3$ polyunsaturated fatty acids in cultured neonatal rat cardiac myocytes.

Proc Natl Acad Sci U S A 1997;94:2724-28.

132. Huang B, El Sherif T, Gidh-Jain M, Qin D, el Sherif N. Alterations of sodium channel kinetics and gene expression in the postinfarction remodeled myocardium.

J Cardiovasc Electrophysiol 2001;12:218-25.

133. Roberts $\mathrm{RH}_{1}$ Barchi RL. The voltage-sensitive sodium channel from rabbit skeletal muscle. Chemical characterization of subunits. J Biol Chem 1987:262:2298-303.

134. James WM, Agnew WS. Alpha- $(2 \rightarrow 8)$-polysialic acid immunoreactivity in voltage-sensitive sodium channel of eel electric organ. Proc R Soc Lond B Biol Sci 1989:237:233.45.

135. Cohen SA, Levitt LK. Partiai characterization of the $\mathrm{rH}$ 1 sodium channel protein from rat heart using, subtype-specific antibodies. Circ Res 1993:73:735-42.

136. Bennett E, Urcan MS, Tinkle SS, Koszowski AG, Levinson SR. Contribution of sialic acid to the voltage dependence of sodium channel gating. A posssible electrostatic mechanism.

J Gen Physiol 1997:109:327.43.

137. Ufret-Vincenty CA, Baro DJ, Lederer W], Rockman HA, Quinones LE, Santana LF. Role of sodium channel deglycosylation in the genesis of cardiac arrhythmias in heart failure.

J Biol Chem 2001;276:28197-203.

138. Gershon E, Weigl L, Lotan I, Schreibmayer W, Dascal N. Protein kinase A reduces voltage-dependent $\mathrm{Na}^{+}$current in Xenopus oocytes. J Neurosci 1992; $; 2: 3743$-52.

139. Li M, West JW, Lai Y, Scheuer T, Catterall WA. Functional modulation of brain sodium channels by CAMP-dependent phosphorylation. Neuron 1992;8:1157-59.

140. Li M, West JW, Numann R, Murphy BJ, Scheuer T, Catterall WA. Convergent regulation of sodium channels by protein kinase $C$ and CAMP- dependent protein kinase. Science 1993;261:1439-42.

141. Smith RD, Goldin AL. Phosphorylation at a single site in the rat brain sodium charmel is necessary and sufficient for current reduction by protein kinase A. J Neurosci 199\%;7:6086-03.

142. Murphy BJ, Rogers J. Perdichizzi AP, Colvin AA, Catterall WA. CAMP-dependent phosphorylation of two sites in the $\alpha$-subunit of the cardiac sodium channel. J Biol Chem 1996:271:28837-43.

143. Schreibmayer W, Frohnwieser B, Dascal N, Platzer D, Spreitzer B, Zechner R, Kallen RG, Lester HA. Beta-adrenergic modulation of currents produced by rat cardiac. $\mathrm{Na}^{+}$channels expressed in Xenopus laevis oocytes. Receptors Channels 1994:2:339-50.

144. Frohnwieser B, Chen LQ, Schreibmayer W, Kallen RG. Modulation of the human cardiac sodium channel $\alpha$-subunit by CAMP-dependent protein kinase and the resiponsible sequence domain. J Physiol 1997:498:309-18. 
145. Lu T, Lee HC, Kabat JA, Shibata. EF. Modulation of rat cardiac sodium channel by the stimulatory G protein $\alpha$-subunit. J Physiol 1999;518:371-84.

146. Zhou J, Yi J, Hu N, George. AL Jr, Murray KT. Activation of protein kinase A modulates trafficking of the human cardiac, sodium channel in Xenopus oocytes. Circ Res 2000;87:33-38.

147. Ono K, Fozzard HA, Hanck DA. Mechanism of CAMP-dependent modulation of cardiac sodium channel current kinetics. Circ Res 1993;72:807-15:

148. Schubert B, VanDongen AM, Kirsch GE, Brown AM. Beta-adrenergic inhibition of cardiac sodium channels by dual G-protein pathways. Science 1989;245:516-19.

149. Gintant GA, Liu DW. Beta-adrenergic modulation of fast inward sodium current in canine myocardium. Syncytial preparations versus isolated myocytes. Circ Res 1992;70:844-50.

150. Matsuda JJ, Lee H, Shibata EF. Enhancement of rabbit cardiac sodium channels by beta-adrenergic stimulation. Circ. Res 1992;70:199-207.

15\%. Qu Y, Rogers JC, Tanada TN, Catterall WA, Scheuer T: Phosphorylation of S1505, in the cardiac Na+ channel inactivation gate is required for modulation by protein kinase $C$.

J Gen Physiol 1996;108:375-79.

152. Santana LF, Gomez AM, Lederer W]. $\mathrm{Ca}^{2+}$ flux through promiscuous cardiac $\mathrm{Na}^{+}$channels: slip-mode conductance. Science 1998;279:1027-33.

153. dos Santos Cruz I, Santana LF, Frederick CA, Isom LL, Malhotra JD, Mattei LN, Kass RS, Xia ), An RH, Lederer WJ. Whether 'slip-mode conductance' occurs. Science 1999;284:716a-23a.

154. Jiang C, Atkinson D, Towbin JA, Splawski I, Lehmann MH, Li H, Timothy K, Taggart RT, Schwartz PJ, Vincent GM. Two long-QT syndrome loci map to chromosomes 3 and 7 with evidence for further heterogeneity. Nat Genet 1994;8:141-47.

155. Schwartz Pl, Priori SG, Dumaine R, Napolitano C, Antzelevitch C, Stramba-Badiale M, Richard TA, Berti MR, Bloise R. A molecular link between the sudden infant death syndrome and the long-QT syndrome. N EnglJ Mied 2000;343:262-67.

156. Splawski I, Shen /, Timothy KW, Lehmann MH, Priori S, Robinson !L, Moss A], Schwartz PJ, Towbin IA, Vincent GM, Keating. MT. Spectrum of mutations in long-QT syndrome genes. KuLQT1, HERG, SCN5A, KCNE1, and KCNE2: Circulation 2000;102:1178-85.

157. Wattanasirichaigoon D, Vesely MR, Duggal P, Levine JC, Blume ED, Wolff GS, Edwards SB, Beggs AH. Sodium channel abnormalities are infrequent in patients with long-QT syndrome: identification of two novel SCN 5A mutations. Am J Med Genet 1999;86:470-76.

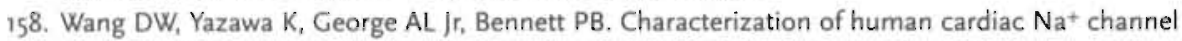
mutations in the congenital long-QT syndrome. Proc Natl Acad Sci U S A 1996;93:13200-05.

159. Wedekind $H$, Smits JP, Schulze-Bahr E, Arnold R, Veldkamp MW, Bajanowșki T, Borggrefe M, Brinkmann B, Warnecke I, Funke $H_{*}$, Bhuiyan ZA, Wilde AA, Breithardt C. Haverkamp W. De novo mutation in the SCN 5 A gene associated with early onset of sudden infant death.

Circulation 2001;104:1158-64.

160. Makita N, Shirai N, Nagashima M, Matsuoka R, Yamada Y, Tohse N, Kitabatake A. A de novo missense mutation of human cardiac $\mathrm{Na}^{+}$channel exhibiting novel molecular mechanisms of long-QT syndrome. FEBS Lett 1998;423:5-9.

161. Lupoglazoff JM, Cheav T, Baroudi G, Berthet M, Denjoy I, Cauchemez B, Extramiana F, Chahine M, Guicheney P. Homozygous SCNSA mutation in long-QT syndrome with functional two-to-one atrioventricular block. Circ Res 2001;89:E16-21.

162. Wei J, Wang DW, Alings M, Fish F. Wathen M, Roden DM, George AL Jr. Congenital long-QT syndrome caused by a novel mutation in a conserved acidic domain of the cardiac $\mathrm{Na}^{+}$channel. Circulation 1999;99:3165-71. 
163. Benhorin J, Goldmit M, MacCluer JW, Blangero J, Goffen R, Leibovitch A, Rahat A, Wang Q, Medina A, Towbin J, Kerem B. Identification of a new SCN5A mutation, D1840G, associated with the long-QT syndrome. Hum Mutat 1998;12:72.

164. Rivolta I, Abriel H, Tateyama M, Liu H, Memmi M, Vardas P, Napolitano C, Priori SG, Kass RS. Inherited Brugada and LQT-3 syndrome mutations of a single residue of the cardiac sodium channel confer distinct channel and clinical phenotypes. J Biol Chem 2001;276:30623-30.

165. Dumaine R, Wang Q, Keating MT, Hartmann HA, Schwartz PJ, Brown AM, Kirsch GE. Multiple mechanisms of $\mathrm{Na}^{+}$channel-linked long-QT syndrome. Circ Res 1996;78:916-24.

166. Chandra R, Starmer CF, Grant AO. Multiple effects of $\triangle K P Q$ deletion mutation on gating of human cardiac: $\mathrm{Na}^{+}$channels expressed in mammalian cells. Am J Physiol 1998;274:H1643-54.

167. Nagatomo T, Fan Z, Ye B, Tonkovich GS, January CT, Kyle JW, Makielski JC. Temperature dependence of early and late currents in human cardiac wild-type and long QT $\triangle K P Q \mathrm{Na}^{+}$channels. Am J Physiol 1998;275:H2016-24.

168. George AL, Komisarof J, Kallen RG, Barchi RL. Primary structure of the adult human skeletal muscle voltage-dependent sodium channel. Ann Neurol 1992;31:131-37.

169. Yamagishi H, Furutani M, Kamisago M, Morikạwạ Y, Koj̣ima Y, Hino Y, Furutani Y, Kimura M.

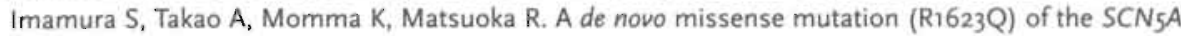
gene in a lapanese girl with sporadic long-QT sydrome. Hum Mutat 1998;11:481.

170. Kambouris NG, Nuss HB, Johns DC, Tomaselli GF, Marban E, Balser JR. Phenotypic characterization of a novel long-QT syndrome mutation ( $\mathrm{R}_{1623} \mathrm{Q}$ ) in the cardiac sodium channel.

Circulation 1998;97:640-44.

171. Chahine M, George AL, Zhou M, Ji S, Sun W, Barchi RL, Horn R. Sodium channel mutations in paramyotonia congenita uncouple inactivation from activation. Neuron $>994 ; 12: 281-94$.

172. Kambouris NG, Nuss HB, Johns DC, Marban E, Tomaselli GF, Balser IR. A revised view of cardiac sodium channel "blockade" in the long-QT syndrome. J Clin Invest 2000;105:1133-40.

173. Ji S, George AL, Horn R, Barchi RL. Paramyotonia congenita mutations reveal different roles for segments $S_{3}$ and $S_{4}$ of domain $D_{4}$ in hSkM1 sodium channel gating. J Gen Physiol 1996:107:183-94.

174. Deschenes I, Baroudi G, Berthet M, Barde I, Chalvidan T, Denjoy I, Guicheney P, Chahine M. Electrophysiological characterization of SCN5A mutations causing long-QT (E1784 K) and Brugada (R1512W and Ri432G) syndromes. Cardiovasc Res 2000;46:55-65.

175. Kiyosue T, Arita M. Late sodium current and its contribution to action potential configuration in guinea pig, ventricular myocytes. Circ Res 1989;64:389-97.

176. Lua CH, Rudy Y. A dynamic model of the cardiac ventricular action potential. I. Simulations of ionic currents and concentration changes. Circ Res, 1994:74:1071-96.

177. Lua CH, Rudy Y. A dynamic model of the cardiac ventricular action potential. II. Afterdepolarizations, triggered activity, and potentiation. Circ Res 1994:74:1097-13.

1778. Zeng J, Rudy Y. Early afterdepola rizations in cardiac myocytes: mechanism and rate dependence. Biophys [ 1995:68:949-64.

179. Zeng J, Laurita KR, Rosenbaum DS, Rudy Y. Two components of the delayed rectifier $\mathrm{K}^{+}$current in ventricular myocytes of the guinea pig type. Theoretical formulation and their role in repolarization. Circ Res 1995;77:140-52.

180. An RH, Bangalore R, Rosero SZ, Kass RS. Lidocaine block of LQT-3 mutant human $\mathrm{Na}^{+}$channels. Circ: Res 1996;79:103-08.

181. Starmer CF. Theoretical characterization of ion channel blockade. Competitive binding to periodically accessible receptors. Biophys J 1987;52:405-12. 
182. Wang DW, Yazawa K, Makita N, George AL Jr, Bennett PB. Pharmacological targeting, of iong-QT mutant sodium channels. J Clin invest 1997;99:1714-20.

183. Schwartz PJ, Priori SC, Locati EH, Napolitano C, Cantu F, Towbin JA, Keating MT, Hammoude H, Brown AMl, Chen LS. Long.QT syndrome patients with mutations of the SCN5A and HERG genes have differential responses to $\mathrm{Na}^{+}$channel blockade and to increases in heart rate. Implications for gene-specific therapy. Circulation 1995;92:3381-86.

184. Rosero: SZ, Zareba W, Robinson \}, Moss A. Gene-specific therapy for long-QT syndrome: QT shortening with lidocaine and tocainide in patients with mutations of the sodiumi channel gene. Ann Noninvasive Electrocardiol 1997;3:274-78.

385. Benhorin J, Taub R, Goldmit M, Kerem B, Kass RS, Windman I, Medina A. Effects of flecainide in patients with new SCN 5 A mutation: mutation-specific therapy for long-QT syndrome? Circulation 2000;107:1698-706.

186. Brugada P, Brugada J. Right bundle branch block, persistent ST segment elevation and sudden cardiac death: a distinct clinical and electrocardiographic syndrome. A multicenter report. J Am Coll Cardiol 1992;20:1391-96.

187. Rook MB, Alshinawi CB, Groenewegen WA, Van Gelder IC, Van Ginneken AC, Jongsma HI, Mannens MM, Wilde AA. Human SCN5A gene mutations alter cardiac sodium channel kinetics and are associated with the Brugada syndrome. Cardiovasc Res 1999;44:507-17.

188. Vatta M, Li H, Towbin JA. Molecular biology of arrhythmic syndromes. Curr Opin Cardiol 2000;75:12-22.

189. Bezzina C, Veldkamp MW, Van den Berg MP, Postma AV, Rook MB, Viersma JW, van Langen IM, Tan-Sindhunata $G$, Bink-Boelkens MT, Van der Hout AH, Mannens MM, Wilde AA. A single $\mathrm{Na}^{+}$ channel mutation causing both long.QT and Brugada syndromes. Circ Res 1999:85:1206-13.

19a. Veldkamp MW, Viswanathan PC, Bezzina C, Baartscheer A, Wilde AA, Balser JR. Two distinct congenital arrhythmias evoked by a multidysfunctional $\mathrm{Na}^{+}$channel. Circ Res 2000;86:E91-97.

191. Baroudi $G$, Chahine M. Biophysical phenotypes of SCNSA mutations causing long-QT and Brugada syndromes. FEBS Lett. 2000;487:224-28.

192. Taneja T, Mahnert BW, Passman R, Goldberger J, Kadish A. Effects of sex and age on electrocardiographic and cardiac electrophysiological properties in adults.

Pacing Clin Electrophysiol 2001;24:16-21.

193. Lev M, Kinare SC, Pick A. The pathogenesis of atrioventricular block in coronary disease. Circulation 1970;42:409-25.

194. Lenegre ), Moreau P. Le bloc auriculo-ventriculaire chronique. Etude anatomique, clinique et histologique. Arch Mal Coeur Vaiss 1963:56:867-88.

195. Nuyens D , Steng| $M$, Dugarmaa $S$, Rossenbacker $T$, Compernolle $V, R u d y ~ Y$, Smits JF, Flameng W, Clancy CE, Moons L. Vos MA, Dewerchin M, Benndorf K, Collen D, Carmeliet E, Carmeliet P. Abrupt rate accelerations or premature beats cause life-threatening arrhythmias in mice with long-QT3 syndrome. Nat Med 2001;7:1027-27.

196. Schwartz PJ, Priori SG, Spazzolini C, Moss A], Vincent GM, Napolitano C, Denjoy I, Guicheney P, Breithardt $C$, Keating MT, Towbin JA, Beggs AH, Brink P, Wilde AA, Toivonen L, Zareba W, Robinson JL, Timothy KW, Corfield V, Wattanasirichaigoon D, Corbett C, Haverkamp W, Schulze-Bahr E, Lehmann MH, Schwartz. K, Coumel P, Bloise R. Genotype-phenotype correlation in the long-QT syndrome: gene-specific triggers for life-threatening arrhythmias. Circulation 2001;103:89-95.

197. Aldrich RW, Stevens CF. Voltage-dependent gating of single sodium channels from mammalian neuroblastoma cells. I Neurosci 1987:7:418-31. 
Chapter 3

Arrhythmogenic Mechanism of the D179oG Mutation of the Human Heart $\mathrm{Na}^{+}$Channel $\alpha$-Subunit

\section{Based on:}

Wehrens XHT, Abriel H, Cabo C, Benhorin J, Kass RS.

Arrhythmogenic Mechanism of an LQT-3 Mutation of

the Human Heart $\mathrm{Na}^{+}$Channel $\alpha$-Subunit - A Computational Analysis.

Circulation 2000;102:584-90. 


\section{Abstract}

BACKGROUND. Di790G, a mutation of SCN5A, the gene that encodes the human $\mathrm{Na}^{+}$channel $\alpha$-subunit, is linked to one form of the congenital long-QT syndrome (LQT-3). In contrast to other LQT-3-linked SCN5A mutations, D179oC does not promote sustained $\mathrm{Na}^{+}$channel activity but instead alters the kinetics and voltage-dependence of the inactivated state.

METHODS AN D ResUlts. We modeled the cardiac ventricular action potential (AP) using parameters and techniques described by Luo and Rudy as our control. On this background, we modified only the properties of the voltage-gated $\mathrm{Na}^{+}$channel according to our patchclamp analysis of Di790C channels. Our results indicate that D1790G-induced changes in $\mathrm{Na}^{+}$channel activity prolong APs in a steeply heart rate-dependent manner not directly due to changes in $\mathrm{Na}^{+}$entry through mutant channels but instead to alterations in the balance of net plateau currents by modulation of calcium-sensitive exchange and ion channel currents.

Conclusions. We conclude that the Di79oG mutation of the $\mathrm{Na}^{+}$channel $\alpha$-subunit can prolong the cardiac ventricular AP despite the absence of mutation-induced sustained $\mathrm{Na}^{+}$channel current. This prolongation is calcium-dependent, is enhanced at slow heart rates, and at sufficiently slow heart rate triggers arrhythmogenic early afterdepolarizations. 


\section{Introduction}

The congenital long-QT syndrome (LQTS) is an inherited cardiac disorder that is defined in part by prolonged ventricular repolarization, an association with recurrent syncope, a propensity to polymorphous ventricular tachycardia (torsades de pointes), and sudden death $(1,2)$. Multiple genes that encode ion channel subunits have now been shown to be linked to LQTS (3) and in most cases, the functional properties of the mutant gene products are consistent with the disease phenotype, i.e., increase of inward or decrease of outward plateau current $(4,5)$.

LQT-3 is linked to the gene encoding the $\alpha$-subunit of the cardiac voltage-gated sodium channel (SCN5A on chromosome 3) (6). Functional analysis of initially reported SCN5A mutations revealed mutant $\mathrm{Na}^{+}$channels that fail to inactivate completely on prolonged depolarization $(7,8)$ and produce a small but functionally important enhancement of inward plateau current sufficient to delay repolarization and increase vulnerability of the heart to arrhythmias (9). All subsequently reported LQT-3 mutations with the exception of Di79oG (DG) promote sustained $\mathrm{Na}^{+}$current and are expected to prolong repolarization through this common mechanism (9-14).

The purpose of the present study was to use a computational approach to determine whether or not the biophysical properties of $\mathrm{DG}$ mutant $\mathrm{Na}^{+}$channels might affect the cellular action potential (AP) through mechanisms other than a direct contribution to maintained $\mathrm{Na}^{+}$channel plateau current. We modeled the cardiac ventricular AP using parameters and techniques described by Luo and Rudy (15) as our control and modified only the properties of the voltage-gated $\mathrm{Na}^{+}$channel according to our patch-clamp analysis of DG channels. Our results indicate that the DG mutation can prolong AP duration (APD) despite the absence of mutation-induced inward $\mathrm{Na}^{+}$channel current during the plateau phase. Instead, the mutation indirectly affects other electrogenic pathways, which have a common interdependence on altered cellular calcium homeostasis. The computations predict DG mutation-induced AP prolongation, which is heart ratedependent and driver by subsequent changes in the intracellular calcium transient. These results are important not only for the novel fundamental insight into the mechanistic basis of inherited arrhythmias but also because they suggest novel targets (i.e., calcium-handling proteins) as therapeutic agents. 


\section{The Luo-Rudy Model of the Ventricular Action Potential}

The simulations in this chapter were conducted using the Luo-Rudy (LRd) model, a theoretical dynamic model of a mammalian ventricular action potential (FIGURE 3.S1). The model is based mostly on guinea pig experimental data; it includes membrane ionic channel currents that are formulated mathematically using the Hodgkin-Huxley approach, as well as ionic pumps and exchangers. The model also accounts for processes that regulate intracellular concentration changes of $\mathrm{Na}^{+}, \mathrm{K}^{+}$and $\mathrm{Ca}^{2+}(9,29,30)$. Intracellular processes represented in the model include $\mathrm{Ca}^{2+}$ uptake and $\mathrm{Ca}^{2+}$ release by the sarcoplasmic reticulum (SR) as well as $\mathrm{Ca}^{2+}$ buffering by calmodulin and troponin (in the myoplasm) and calsequestrin (in the SR). As it was shown that reduced density of $I_{K_{5}}$ can result in electrical and pharmacological properties that are very similar to those of $M$ cells (31), consistent with experimental data by Liu et al. (32), M-cell properties were formulated by lowering $I_{\mathrm{Ks}}$ density while keeping $I_{\mathrm{Kr}}$ constant.

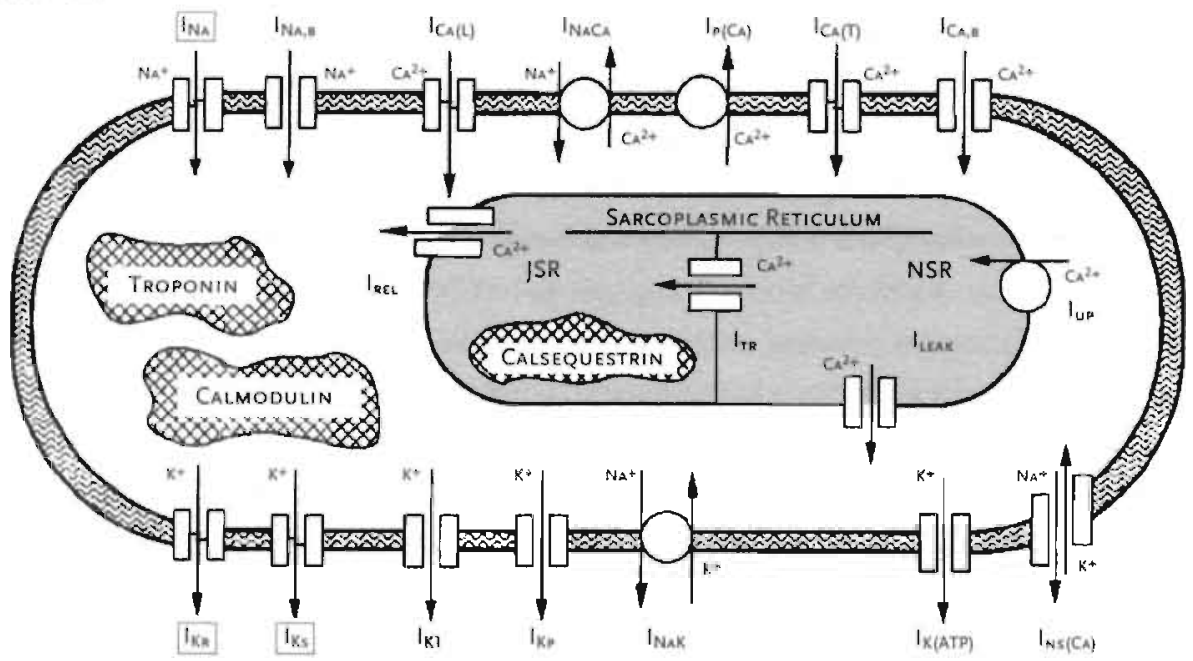

FIGURE 3.S1 Schematic diagram of the LuO-Rudy mammalian ventricular cell model. I ${ }_{\mathrm{No}}$, fast $\mathrm{Na}^{+}$curtent: $\mathrm{I}_{\mathrm{Ca}(\mathrm{L})} \mathrm{Ca}^{2+}$ current through the L-type $\mathrm{Ca}^{2+}$ chonnel; I $\mathrm{Ca}(\mathrm{T})$. $\mathrm{Ca}^{2+}$ current through the T-type $\mathrm{Ca}^{2+}$ channel; $I_{\mathrm{Kr}}$ fost component of the delayed rectifier $K^{+}$current; $I_{K_{s}}$, slow component of the delayed rectifier $K^{*}$ current; $I_{K=}$, inward rectifier $\mathrm{K}^{+}$current; $I_{K p}$, plateau $\mathrm{K}^{+}$current; $I_{K(\mathrm{ATP})}$. ATP sensitive $\mathrm{K}^{+}$current; $I_{\mathrm{NaK}}, \mathrm{Na} a^{+} \mathrm{K}^{+}$pump; $I_{\mathrm{NaCa}}, \mathrm{Na}^{+}-\mathrm{Ca}^{2+}$ exchange current; $I_{p\{\mathrm{Ca},} \mathrm{Ca}^{2+}$ pump in the sarcolemma; $I_{\mathrm{Nab}} \mathrm{Na}^{+}$background current; $\mathrm{ICab}_{\mathrm{C}} \mathrm{Ca}^{2+}$ background

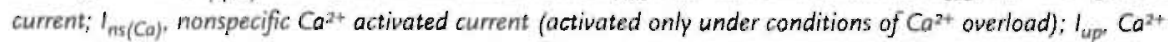
uptake from the myoplasm to network sarcoplasmic reticulum (NSR); $I_{\text {rei }}$. $\mathrm{Ca}^{2+}$ release from the junctional sarcoplasmic reticulum (JSR); $1_{\text {eak }}$. Ca $a^{2+}$ leakage from NSR to myoplasm; $1_{t r}, \mathrm{Ca}^{2+}$ translocation from NSR to JSR: Calmodulin and Troponin, myoplasmic $\mathrm{Ca}^{2 *}$ buffers; Calsequestrin, SR $\mathrm{Ca}^{2+}$ buffer. 


\section{Methods}

\section{Computer-generated AP Reconstruction}

The AP was calculated by solving the differential equation $I_{i o n}=-C_{m}\left(d V_{m} / d t\right)$, where $I_{\text {ion }}$ is the total transmembrane ionic current $\left(\mu \mathrm{A} / \mathrm{cm}^{2}\right), C_{m}$ is the specific capacitance of the membrane $\left(\mu \mathrm{F} / \mathrm{cm}^{2}\right)$, and $V_{m}$ is the transmembrane potential $(\mathrm{mV})$. All ionic currents were formulated according to THE LUO-RUDY MODEL OF THE VENTRICULAR AP (15), except that the sodium current was formulated to reproduce our patch-clamp experiments in HEK 293 cells. The differential equation was solved numerically with a discretization time step of $10 \mu \mathrm{s}$.

Experimental parameters used in the model were determined from experimental data for voltage-dependence of steady-state activation and inactivation and the kinetics of the onset and recovery from inactivation. Parameters for Boltzmann relationships and time constants were extracted as previously described (76). Rate constants were adjusted with temperature, assuming $Q_{10}$ factors (the factor is usually between 2 and 3 for rate constants between different states in ionic channels).

To simulate wild-type (WT) channels, we used $m_{x}=1 /\left\{1+\exp \left[-\left(V_{m}+32.5\right) / 9\right]\right\}$ and $h_{x}\left(=1 /\left\{1+\exp \left[\left(V_{m}+57.87\right) / 7\right]\right\}\right.$. To simulate DG channels, $m_{x}\left(=1 /\left\{1+\exp \left[-\left(V_{m}+29\right) / 10.5\right]\right\}\right.$ and $h_{s o}\left(=1 /\left\{T+\exp \left[\left(V_{m}+74.3\right) / 6.5\right]\right\}\right.$ were used. In the DG channels, the time constants of onset of inactivation (h) and the slow inactivation gate (j) were half of those used in the WT channels. The maximum sodium conductance was $27 \mathrm{mS} / \mathrm{cm}^{2}$. In all simulations, the maximum conductance of the slow component of the delayed rectifier potassium current, $I_{K s}$, was reduced by $40 \%$ to uncover AP differences between cells with WT and DG channels. These APs thus simulate endocardial or M-cell activity $(5,17-20)$. APs were: initiated by intracellular $0.5 \mathrm{~ms}$ current pulses $\left(100 \mu \mathrm{A} / \mathrm{cm}^{2}\right)$. Initial conditions were established by stimulating cells with WT and DG channels once per second for a 3 minute period. Cells were stimulated 20 times at a constant cycle length $(500-4000 \mathrm{~ms})$.

\section{Expression of Recombinant $\mathrm{Na}^{+}$Channels}

$\mathrm{Na}^{+}$channels were expressed in HEK 293 cells as previously described (11). Transfections were carried out with equal amounts of $\mathrm{Na}^{+}$channel $\alpha$-subunit cDNA (WT or DG;. respectively), with $h \beta_{1}$ - and/or $h \beta 2$-subunit cDNA subcloned individually into the pcDNA3 (Invitrogen) vector (total cDNA $2.5 \mu \mathrm{g}$ ). Control experiments (data not shown) indicated no significant differences in channel activity for these subunit combinations. 


\section{Electrophysiology}

Membrane currents were measured with whole-cell patch-clamp procedures (21) with Axopatch $200 B$ amplifiers (Axon Instruments) as previously described (11). Unless noted otherwise, recordings were made at room temperature $\left(22^{\circ} \mathrm{C}\right)$ with previously published solutions (11). Data acquisition and analysis were carried out with pClamp ? (Axon Instruments), Excel (Microsoft), and Origin (Microcal Software). Steady-state inactivation was determined after application of 500 ms conditioning pulses applied once every 2 seconds. Recovery from inactivation was measured in paired pulse experiments, with a test pulse applied at variable times after a $100 \mathrm{~ms}$ conditioning pulse to $-10 \mathrm{mV}$. Holding potentials were $-80 \mathrm{mV}$.

\section{Results}

\section{Biophysical Properties of DG Mutant Channels: Computational Parameter Set} FICURE 3.1 shows families of experimental records of WT and DG mutant channels expressed in HEK 293 cells as well as analysis of the experimentally determined voltagedependence of the time constants of the onset of inactivation. As illustrated in FICURE 3.TA, we compared experimental recordings of WT and DG channels at $22^{\circ} \mathrm{C}$ (top) and $29^{\circ} \mathrm{C}$ (bottom). Clearly, increasing temperature speeds the kinetics of both WT and DG mutant channels, as expected (22) but it neither changes the relationship between WT and DG mutant channel time constants nor promotes DG-induced sustained inward current. FIGURE 3.18 summarizes time constants obtained by fitting experimental records with functions containing one exponential component. Although in a limited number of experiments, we previously reported no effect of the DG mutation on the !netics of the onset of inactivation, in a more complete analysis we have found that, in fact, this mutation speeds the onset of inactivation (FIGURE 3.1) and slightly alters the voltagedependence of activation (FICURE 3.3). Using these data, we extrapolated the temperature coefficient $\left(Q_{10}\right)$ of 2.1 for inactivation kinetics for both WT and DG mutant channels to compute the effects of the mutation on APs at physiological temperatures.

FICURE 3.2 shows the simulated changes in $\mathrm{Na}^{+}$channel currents and the time constants of the onset of inactivation generated by the computer-based model. As is the case for the experimental data, the simulated currents reflect the speeding of the onset of inactivation as a function of membrane potential but do not exhibit enhanced sustained current. 
WT
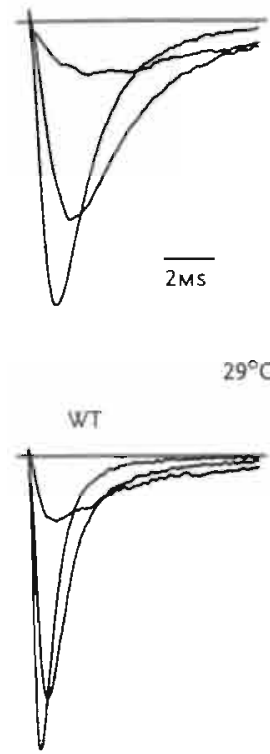

D17906
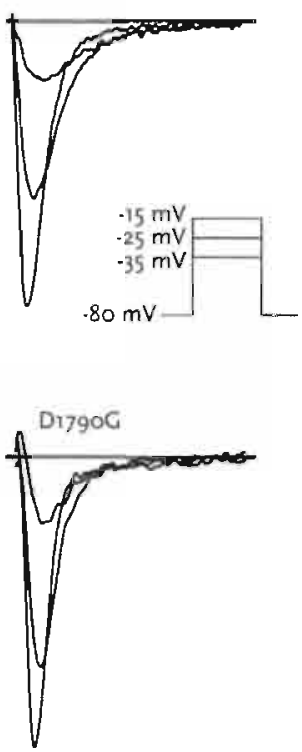

B
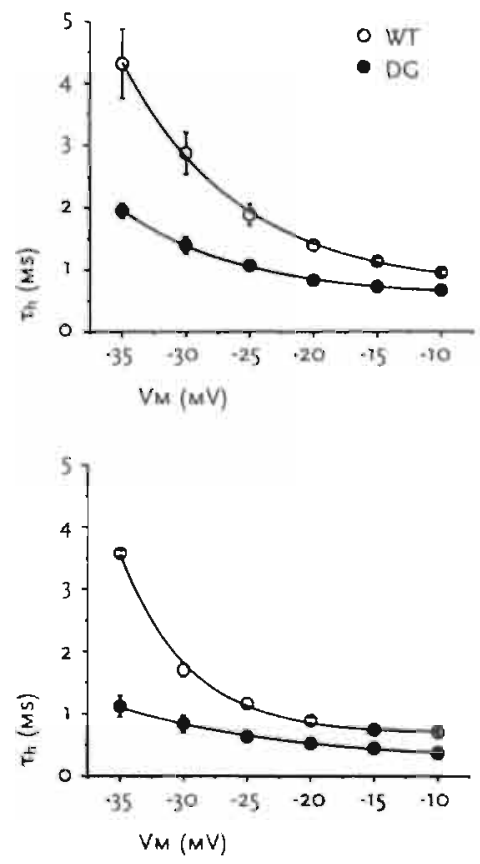

B

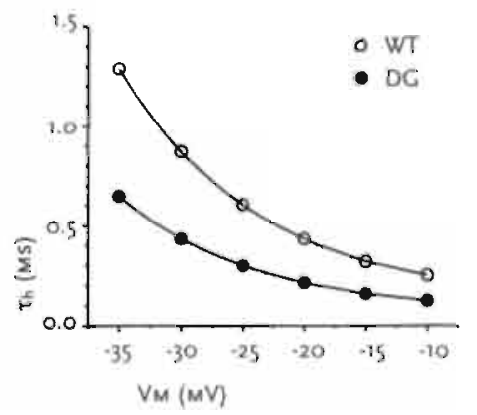

\section{FICURE 3.7}

DG mutatian speeds onset of inactivation at $22^{\circ} \mathrm{C}$ (top) and $29^{\circ} \mathrm{C}$ (bottom). A, Representative current traces evoked by $20 \mathrm{~ms}$ pulses to voltages indicated in inset for cells expressing WT or DG mutant $\mathrm{Na}^{+}$channels.

Maximum currents have been normalized to facilitate comparison of WT and DG current. traces, B. Time constants (mean \pm SEM, $n=3$ to $>$ for each data point) determined from bestfit single exponential functions to data, plotted us test-pulse potential for WT (o) and DG (•) chonnels.

FICURE 3.2

Effects of DG mutation on simulated $\mathrm{Na}^{+}$channel currents. A, Effects of calculated time constants on computed families of WT and DC currents. B, Voltage-depemdence of time corstants of inativation for WT and DC channels. Current traces for WT and DC. $\mathrm{Na}^{+}$channel currents are simulated at $37^{\circ} \mathrm{C}$. 
FICURE 3.3

Experimentally determined (A)

and simulated (B) effects of

DG mutation on channel

properties. Each panet shows

steady-stote inactivation and activation (top) and recovery from inactivation (bottom) for WT (o) and DC (•) channels. Theoretical cunves (B) generated with parameters obtained in $\mathbf{A}$ in Luo and Rudy model (note that recovery from inactivation is modeled as a single exponential function) as follows: $T=25.2 \mathrm{~ms}$ for $W T ; T=12.6 \mathrm{~ms}$ for $D G$.
A
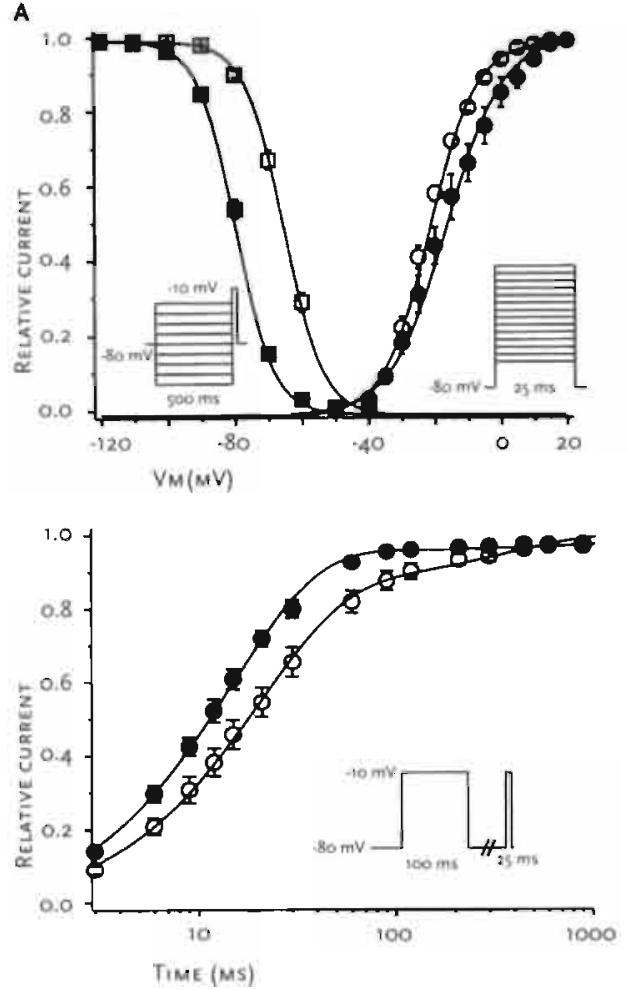

B
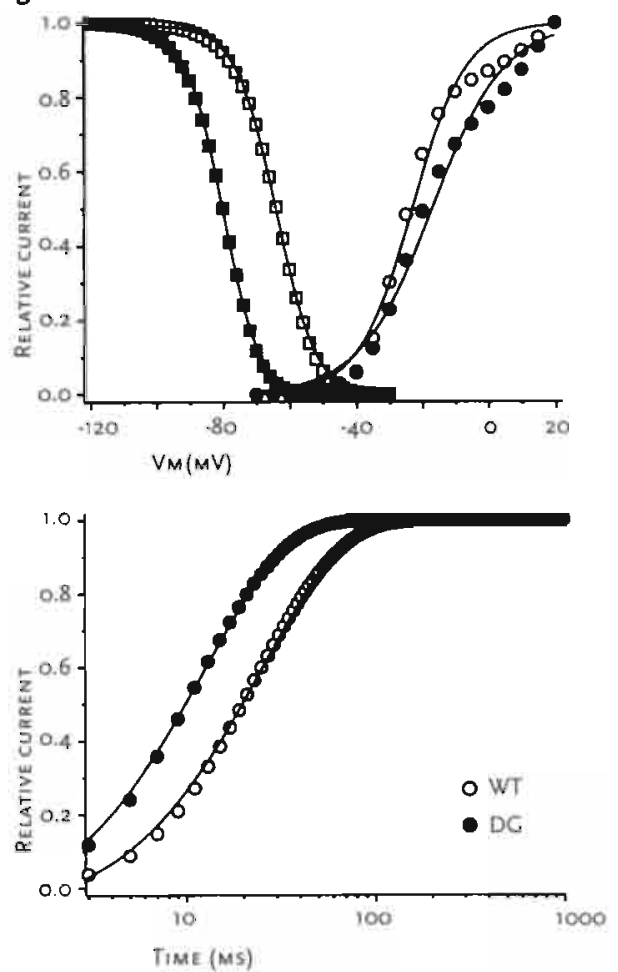

FIGURE 3.3 illustrates experimental and computational data showing the effects of the DC mutation on the voltage-dependence of steady-state inactivation and activation and on the time course of recovery from the inactivated state. For activation, peak currents (measured in $30 \mathrm{mmol} / \mathrm{L}\left[\mathrm{Na}^{+}\right]_{0}$ ) were normalized to driving force to determine conductance. The mutation causes a marked negative shift of the voltage-dependence of inactivation (WT, DG: $V_{1 / 2}-64,-79 \mathrm{mV} ; \mathrm{k} 5.9 .5 .5 ; n=13$ ) with relatively minor changes in the voltage-dependence of activation, (WT, DG: $V_{1 / 2}-23,-17 ; K: 6.9,9.2(n=6)$, as we previously reported (11). The mutation also causes a small but significant speeding of the recovery process (averaged experimental time constants and relative weights are $W T(0)$ : $\tau_{\text {fast }}=20.4 \mathrm{~ms}, a_{\text {fast }}=0.87, \tau_{\text {slow }}=351 \mathrm{~ms}, a_{\text {slow }}=0.13$; and for DC $(\bullet): \tau_{\text {fast }}=14.9 \mathrm{~ms}$, $a_{\text {fast }}=0.97, \tau_{\text {slow }}=2149 \mathrm{~ms}, a_{\text {slow }}=0.03$ ). The results obtained in experiments (A) were incorporated into the simulated channels (B). 

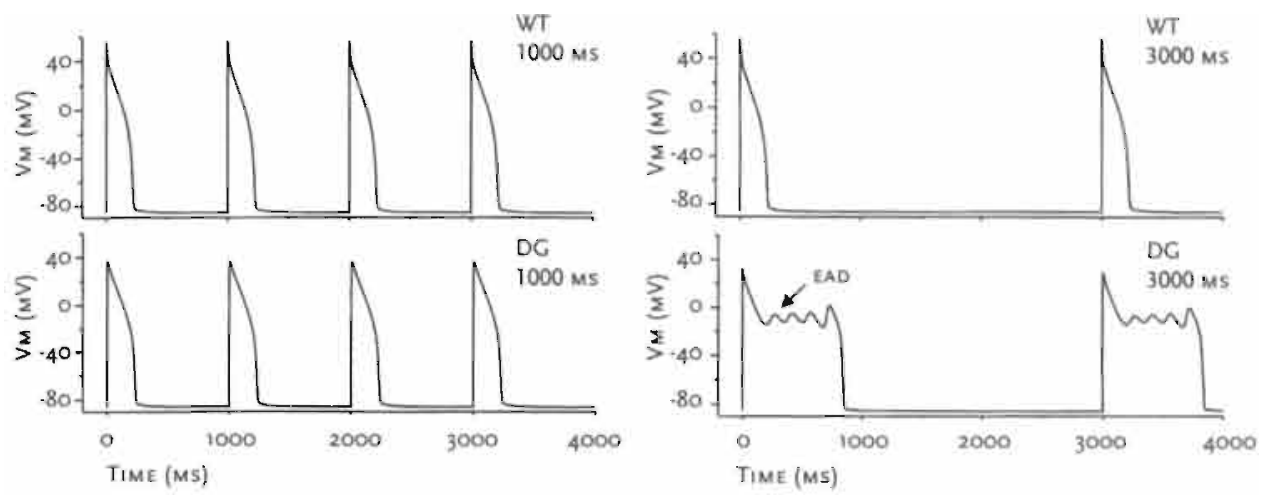

\section{Simulation of Cellular Electrical Activity:}

\section{AP Prolongation That Is Heart Rate-dependent}

FIGURE 3.4 shows the consequences of these mutation-induced changes in channel properties on cellular electrical activity that is predicted by the computer-generated model. At a basic cycle length $(B C L)$ of $1000 \mathrm{~ms}$, there is little effect of the $D G$ mutation despite a significant $A P D$ prolongation. At a $B C L$ of $3000 \mathrm{~ms}$, however, it causes dramatic $A P D$ prolongation, which results in the generation of early afterdepolarizations (EADs). The results of similar calculations repeated over a series of $B C L S$ are summarized in FICURE 3.5, in which APD is plotted versus BCL for both WT and DG channels.

The expression of mutant DC channels markedly alters this relationship. FICURE 3.5 shows that even at moderately long BCLs (1000 to $2000 \mathrm{~ms}$ ), the DG mutation prolongs APs compared with cells expressing WT channels. This effect becomes very pronounced (note change in vertical scale) as heart rate slows further, and at a $\mathrm{BCL}$ of $3000 \mathrm{~ms}$, as illustrated above, the mutationinduced action prolongation is sufficient to induce EADs (arrow). Similarly, the DG mutation induces EADs after pauses in AP activity (FIGURE 3.6).

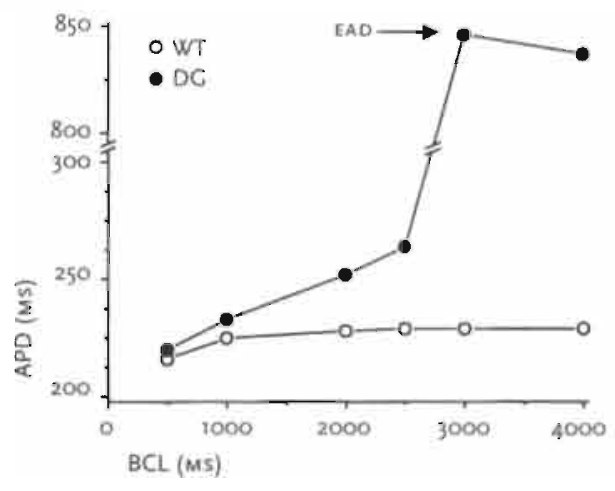

FICURE 3.4

Effect of pacing frequency on $A P D$ and development of EADs for DG cells. First 4 (left 2 rows) and first 2 (right 2 rows) APs after trains of 20 APs at BCLs of 1000 $m s$ (left 2 rows) and $3000 \mathrm{~ms}$ (right 2 rows) simulated for cells expressing WT and DC $\mathrm{Na}^{+}$channels.
FICURE 3.5

DG-induced AP prolongation is steeply heart rate-dependent. Plotted is relationship between $A P D$ and $B C L$. At $B C L$ of $3000 \mathrm{~ms}$, mutation-induced action prolongation is sufficient to induce EADs (arrow) at $B C L>2500 \mathrm{~ms}$. 
FICURE 3.6

Effect of DC mutation on pauses in stimulation. Last 2 APs in a train of 20 at $B C L$ of $500 \mathrm{~ms}$ followed by $1500 \mathrm{~ms}$ pause and postpause AP. Pause in activity induces an EAD (orrow) in cells expressing DC but not WT channels.

\section{FICURE 3.7}

Effects of DC mutation on $\mathrm{Na}^{+}$ channel activity during AP and AP upstroke: ( $B C L$ of $3000 \mathrm{~ms}$ ). Membrane potential (top) and computed $\mathrm{Na}^{+}$channel currents (bottom) for cells expressing WT (dotted lines) and DC (solid lines) channels.

A, Slow time base recording: note obsence of sustained inward $\mathrm{Na}$ c current and reduction of AP overshoot (arrow).

B. Expanded time base. DG mutation reduces contribution of $\mathrm{N}^{+}$channel activity and slows initial upstroke of AP.
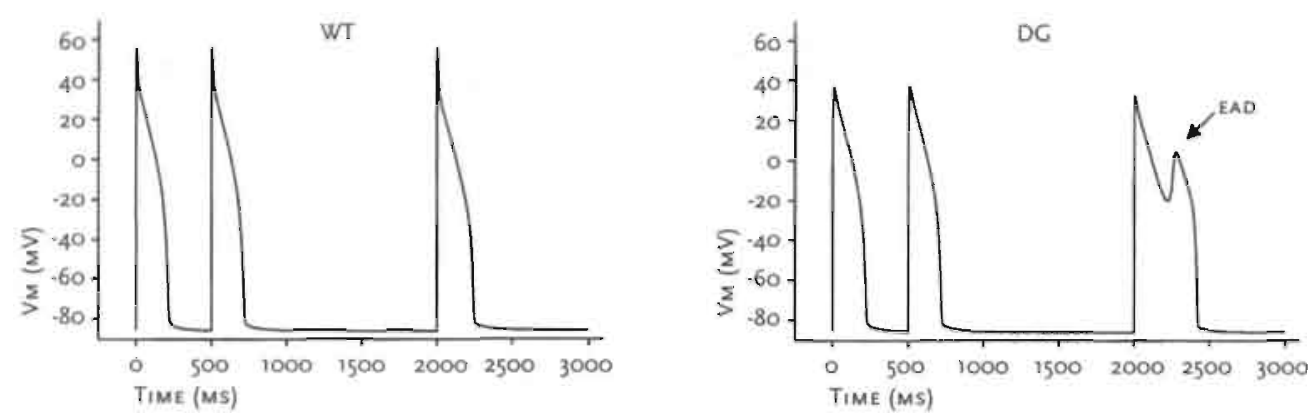

A

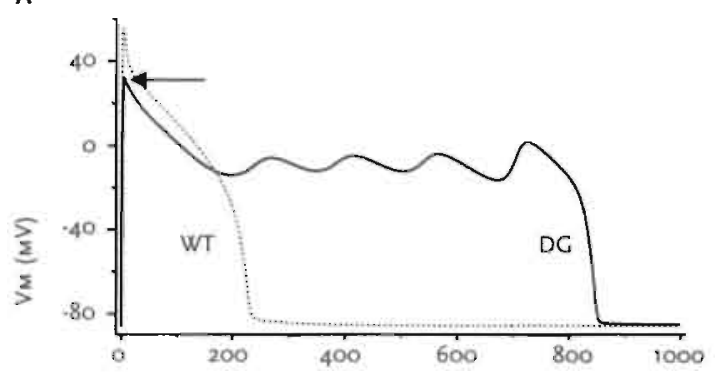

B
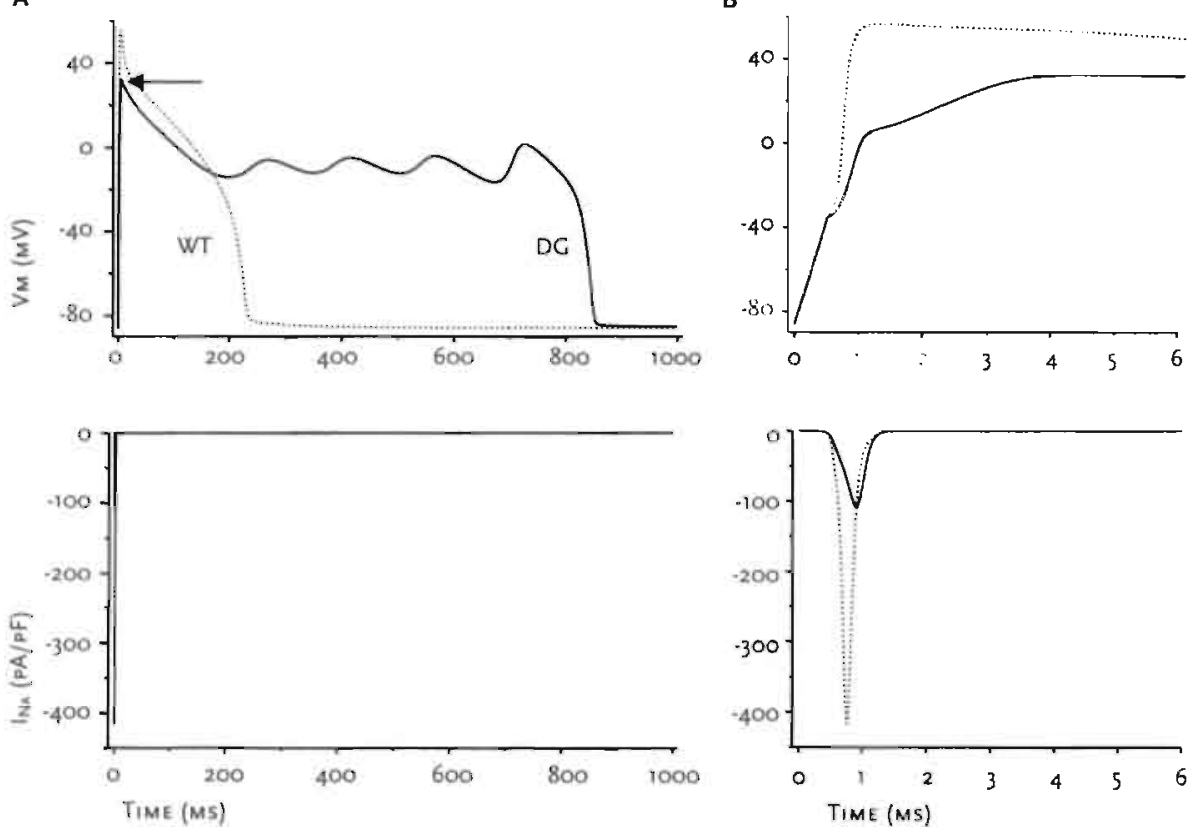
Ionic Basis of DG Cellular Phenotype: A Role for $\left[\mathrm{Cal}^{2+}\right]_{\mathrm{i}}$

FICURES 3.7 and 3.8 show the effects of the DC mutation on several key ionic pathways underlying the computed APs. These computations reflect s.teady-state conditions during a $B C L$ of $3000 \mathrm{~ms}$, but the patterns revealed are the same as those that occur in DG-induced pause-dependent AP prolongation (data not shown). FICURE 3.7 focuses on computed $\mathrm{Na}^{*}$ channel currents and illustrates current during the AP plateau (A) as well as, on an expanded time scale, during the upstroke (B). As predicted by the voltage-clamp data, the DG mutation does not promote sustained inward $\mathrm{Na}^{+}$current that would account for AP prolongation ( $A$, lower row). In fact, the computations show that the overall effect of this mutation is to reduce the contribution of $\mathrm{Na}^{+}$channel activity to the initial upstroke and overshoot (arrow) of the AP. FIGURE 3.8 illustrates DG mutation-induced changes in other pathways that occur during the duration of the AP. The computations reveal an increase in $\mathrm{Ca}^{2+}$ influx through L-type $\mathrm{Ca}^{2+}$ channels, an increase in the magnitude of the transient change in $[\mathrm{Ca}: \cdot]_{i}$, changes in $\mathrm{Na}^{+} / \mathrm{Ca}^{2+}$ exchange current, and an initial reduction followed by prolonged activation of the slowly activating $\mathrm{K}^{+}$ channel current, $I_{K s}$.
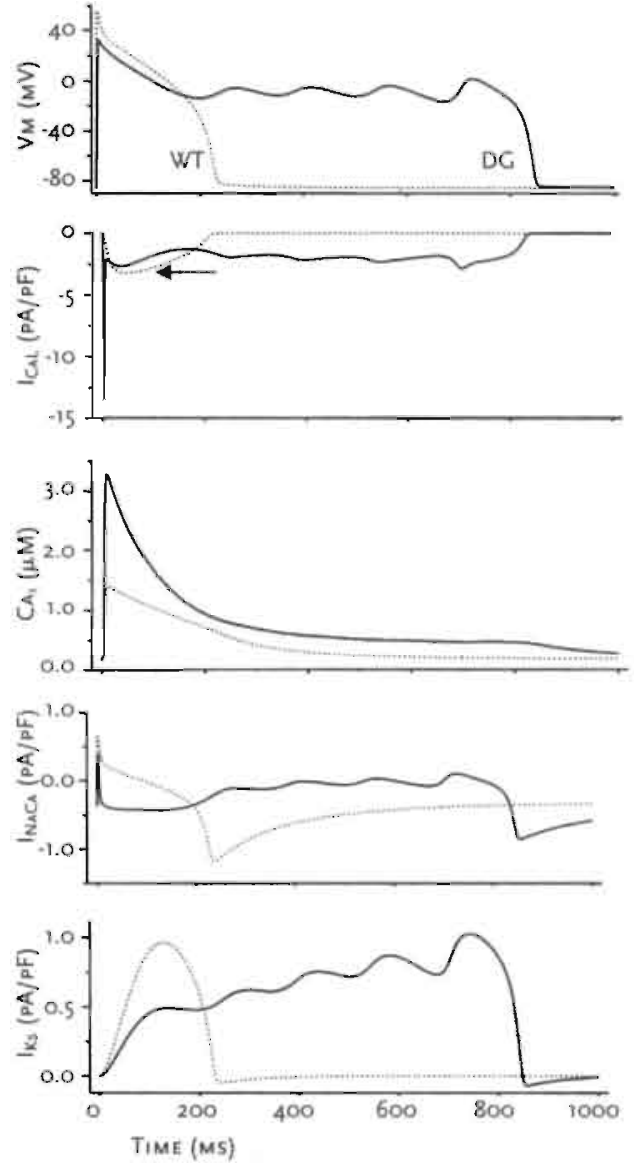

FICURE 3.8

DG mutation affects $\mathrm{Ca}^{2+}$. sensitive pathways. Simufation of effects of DC mutation on APs and key underlying pathways that occur ot BCL of $3000 \mathrm{~ms}$. Shown are following computations for cells expressing WT (dotted lines) and DG (solid lines) $\mathrm{Na}^{+}$channeis (top to bottom): membrane potential; L-type $\mathrm{Ca}^{2+}$ channel currents; intracellular free $\mathrm{Ca}^{2+} ; \mathrm{Na}^{*} / \mathrm{Ca}^{2+}$ exchange current; and delayed rectifier current, $I_{K s}$ Arrow in second row indicates peak $\mathrm{Ca}^{3+}$ influx with WT channel. 


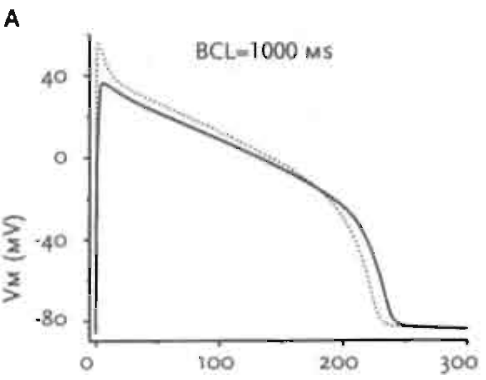

\section{$\mathbf{B}$}

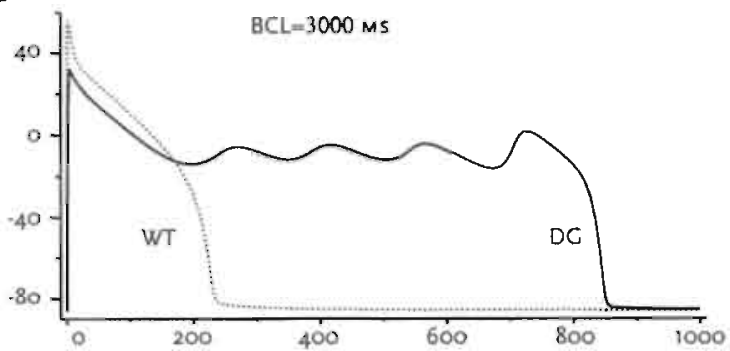

FIGURE 3.9

DG-induced changes in $\mathrm{Ca}^{2+}$ transient are heart rate. dependent. Computed APs (top) and free calcium transients (bottom) shown for $1000 \mathrm{~ms}$ (A) and $3000 \mathrm{~ms}$ (B) BCLs.
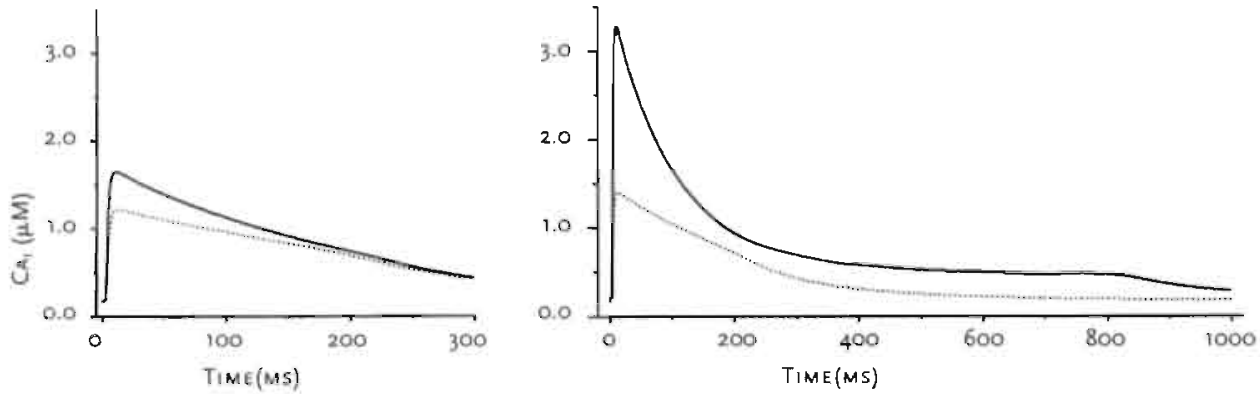

DG-Induced Changes in $\left[\mathrm{Ca}^{2+}\right]_{i}$ Determine Frequency-dependent ADP Prolongation Perhaps the most prominent feature of the DG cellular phenotype predicted from these computations is the marked dependence of APD on heart rate (FIGURE 3.5).

FIGURE 3.9 shows marked DG mutation-induced changes in the calcium transient that are steeply frequency-dependent. At low stimulation frequencies (long BCLs), the calcium transient in cells expressing DG $\mathrm{Na}^{+}$channels is increased in both amplitude and duration. At faster heart rates (BCLs on the order of $1000 \mathrm{~ms}$ ), there is little difference between calcium transients of WT and DG-expressing cells (A). The computations thus suggest a complex calcium-dependent pathway regulating APD that becomes altered, as described above, by DG-induced changes in calcium entry. Because the effects of these changes on the calcium transient are predicted to be steeply frequency-dependent, the calculations suggest a strong interdependence on the filling and subsequent emptying of intracellular calcium stores in this process. 


\section{Discussion}

\section{Sustained $\mathrm{Na}^{+}$Channel Current Is Not Necessary to Prolong the Ventricular AP}

The major finding reported in this study is the fact that biophysical properties of DC mutant $\mathrm{Na}^{+}$channel $\alpha$-subunits prolong computer-simulated ventricular APs, even though this mutation does not promote sustained $\mathrm{Na}^{+}$channel current during the AP plateau phase. This study thus extends our understanding of the molecular basis of the disease phenotype, the prolonged QT-intervals, and confirms the importance of computational studies in bridging information relating functional changes in individual ion channel subunits to predictions of cellular and even system phenotypes.

The plateau phase of the cardiac ventricular AP is maintained by a delicate balance between inward and outward movement of ions, and even very small changes in ionic currents during the plateau are expected to have marked effects on $\operatorname{APD}(4,23)$. The functional properties of channels encoded by DG mutant $\alpha$-subunits have defied interpretation within a framework that requires direct mutation-dependent increase in $\mathrm{Na}^{+}$channel current during the AP plateau, because this mutation does not promote sustained $\mathrm{Na}^{+}$channel activity in the face of cellular depolarization (11). Instead, the most prominent characteristics of DG channels are a negative shift in channel availability as a function of membrane potential and a speeding of the kinetics of the onset of inactivation. However, our computations reveal the importance of these biophysical changes in channel properties to events that determine the duration of the AP and show that events that occur during the initial $5 \mathrm{~ms}$ of the AP can have profound effects on electrical activity that occurs during the following several hundred milliseconds.

\section{DG.Induced Decrease in $\mathrm{Na}^{+}$Channel Activity Leads to an Increase in the $\left[\mathrm{Ca}^{2+}\right]_{i}$ Transient}

FIGURES $3.7,3.8$, and 3.9 provide insight into the mechanism(s) by which the DC mutation delays AP repolarization. Because of the changes in $\mathrm{Na}^{+}$channel kinetics, fewer channels are available for activation at the cellular resting potential, and once opened, these channels inactivate faster than WT channels. This results in a reduced $\mathrm{Na}^{+}$channel current, slower upstroke, and more importantly, a less positive overshoot of the AP (FIGURE 3.7, arrow). The change in $\mathrm{dV} / \mathrm{dt}$ and overshoot occurs during the very early stages. of ventricular depolarization, as seen in FIGURE 3.8, and in turn causes an increase of $\mathrm{Ca}^{2+}$ entry via L-type $\mathrm{C}_{3}{ }^{2+}$ channels during this crucial period of electrical activity. The primary, 
mechanism underlying this effect is not a change in gating parameters for $\mathrm{Ca}^{2+}$ channel activation and inactivation, but the effect: of the DC mutation on the AP overshoot and subsequent change in the driving force for $\mathrm{Ca}^{2+}$ entry via L-type $\mathrm{Ca}^{2+}$ channels (not illustrated). With this alteration in $\mathrm{Ca}^{2+}$ entry, the model predicts that the subsequent $\mathrm{Ca}^{2+}$ transient will be altered in both time and magnitude, and as a result, all $\left[\mathrm{Ca}^{2+}\right]_{i}$-dependent processes will subsequently be altered (FICURE 3.8). Two important ionic pathways, the $\mathrm{Na}^{+} / \mathrm{Ca}^{2+}$ exchanger (24) and the slowly activating delayed $\mathrm{K}^{+}$channel current, $\mathrm{I}_{\mathrm{Ks}}(25)$ are affected (FIGURE 3.8). The result is a net increase of inward plateau current and corresponding increase in APD. The fundamental difference between the generation of the cellular phenotype in the case of the DG mutation compared with previously described LQT-3 mutations is that the increase of inward current does not come from a direct contribution of altered $\mathrm{Na}^{+}$channel activity but rather from other pathways.

The computations also reveal a critical role of $\mathrm{I}_{\mathrm{Ks}}$ in the DG-induced cellular phenotype (FICURE 3.8) as a result of the reduction in this current that occurs as a consequence of mutation-induced changes in $V_{m}$. Thus, although the disease-linked mutation is in the SCN5A gene, the cellular phenotype is due in part to changes in activity of channels encoded by LQT-1-and LQT-5-linked genes $(26,27)$.

\section{Relationship Between Cellular and Clinical Phenotypes}

The work presented here is the result of incorporation of biophysical properties of human WT and DG mutant $\mathrm{Na}^{+}$channels expressed in a mammalian cell line into a computational model that integrates experimental data obtained from a variety of cell types and species (15). Extrapolation of these results to a precise understanding of human pathophysiology is not possible and goes beyond the scope of this study. Qualitative, but not quantitative, conclusions may be drawn from this work. Nevertheless, comparison to appropriate clinical parameters that have been measured for carriers of the DG mutation is important, and in fact, a stringent test of the validity of the methodology.

The model suggests that under steady-state pacing conditions, the $\mathrm{Na}^{+}$current is smaller in myocytes expressing DG mutant channels next to WT channels. This will most likely lead to a reduced rate of rise of the AP upstroke $(\mathrm{dV} / \mathrm{dt}$ ) as predicted for the cellular model, and this, in turn, would be expected to be reflected in a widening of the QRS complex on the ECG of mutation carriers. Indeed, DG carriers tend to have wider QRS complexes than control patients (28). The computational work clearly indicates that for this mutation, bradycardia will potentiate APD prolongation. It is interesting to note that heart rates of DG carriers have been found to be slower than those of noncarriers (10). In fact, 
in several members of the DG family that have been studied, sinus slowing and even arrest may have been as significant as APD prolongation. This raises the interesting and important question as to a causal relationship between pacing and the DC mutation, a question that certainly is beyond the scope of the present study.

\section{Role of $\mathrm{I}_{\mathrm{TO}}$ in Modulating the Effect of the DG Mutation on APD}

In the computations that we have carried out and reported, we have not included a contribution of the transient outward current $\left(1_{\text {TO }}\right)$. We did, however, test for its effects in calculations, which we have not illustrated. We find, as might be expected, that if expressed at sufficiently high levels, this current will tend to offset the effects of the DG mutation and modify its influence on APD. Thus, cells expressing $1_{\text {TO }}$ at the highest densities (epicardial cells) would be expected to have substantially shorter APDs than cells in which TO $_{\text {is }}$ expressed at the lowest densities (endocardial cells), because the additional contribution of DG mutant channels would then follow the same anatomic pattern (20). This pattern of channel expression would thus be expected to favor enhanced $T$ wave dispersion (19) which, interestingly, is what is observed in carriers of the DG mutation (28). Heterogeneity in the expression of ion channel genes, no doubt, remains an important area of investigation that will be needed to provide a causal link between expression of specific gene mutations and generation of the systemic disease phenotype.

\section{Novel Therapeutic Strategies for LQT-3}

Our analysis has revealed that beat-dependent changes in intracellular calcium that occur as a consequence of the DG LQT-3 mutation should be considered major factors in generating the disease phenotype (delayed ventricular repolarization) in carriers of this gene defect. This work therefore strongly suggests that a therapeutic strategy that includes inhibition of L-type calcium channel activity may be beneficial for carriers of the DG gene defect.

In summary, our computations show that the biophysical properties of DG mutant channels are sufficient to account for a cellular phenotype consistent with LQT-3: prolongation of the ventricular AP. This occurs despite the absence of mutation-induced sustained $\mathrm{Na}^{+}$current. This finding not only is a necessary step in understanding the molecular basis of QT prolongation in carriers of the DG mutation but also raises the possibility that previously overlooked functional properties of other LQT-3 SCN 5 A mutations may also contribute to the disease phenotype and may require further 
investigation. Furthermore, our work suggests that novel therapeutic strategies may include modulation of calcium as well as sodium channel activity.

\section{Acknowledgments}

This work was supported by US Public Health Service grant Ro1-HL-568105-02 (Dr Kass). Dr Abriel was supported the Swiss National Foundation for Fellowships in Medicine and Biology, Dr Wehrens by the Dutch foundation De Drie Lichten, and Dr Cabo in part by a research grant of the Whitaker Foundation. 


\section{References}

1. Moss AJ, Schwartz P], Crampton RS, Tzivoni D, Locati EH, MacCluer J, Hall WJ, Weitkamp L, Vincent GM, Garson A Jr. The long-QT syndrome: prospective longitudinal study of 328 families. Circulation 1991;84:1136-44.

2. Schwartz PJ, Periti M, Malliani A. The long-QT syndrome. Am Heart J 1975;89:378-90.

3. Yan GX, Antzelevitch C. Cellular basis for the Brugada syndrome and other mechanisms of arrhythmogenesis associated with ST-segment elevation. Circulation 1999;100:1660-66.

4. Kass RS. Ionic basis of electrical activity in the heart. In: Sperelakis $\mathbf{N}$ (ed.) Physiology and pathophysiology of the heart. Nonwell, Mass. Kluwer Academic 1995:77-90.

5. Viswanathan PC, Rudy Y. Pause induced early afterdepolarizations in the long-QT syndrome: a simulation study. Cardiovase Res 1999;42:530-42.

6. Wang Q, Shen J, Splawski I, Atkinson D, Li Z, Robinson JL, Moss A), Towbin JA, Keating MT. $S C N_{5}$ A mutations associated with an inherited cardiac arrhythmia, long-QT syndrome. Cell 1995:80:805-17.

7. Bennett PB, Yazawa K, Makita N, George AL Jr. Molecular mechanism for an inherited cardiac arrhythmia. Nature 1995;376:683-85.

8. Wang DW, Yazawa K, George AL Ir, Bennett PB. Characterization of human cardiac $\mathrm{Na}^{+}$channel mutations in the congenital long-QT syndrome. Proc Nat/ Acad Sci U S A 1996;93:13200-05.

9. Clancy CE, Rudy $Y$. Linking a genetic defect to its cellular phenotype in a cardiac arrhythmia. Noture 1999:400:566.69.

10. Benhorin J, Coldmit M, MacCluer JW, Blangero J, Goffen R, Leibovitch A, Rahat A, Wang Q, Medina $A_{1}$ Towbin J, Kerem B. Identification of a new SCN5A mutation associated with the long-QT syndrome. Hum Mutat 1998;12:72.

11. An RH, Wang XL, Kerem B, Benhorin 1, Medina A, Goldmit M, Kass RS. Novel LQT-3 mutation affects $\mathrm{Na}^{+}$channel activity through interactions between $\alpha$ - and $\beta$ 1-subunits. Circ Res 1998;83:147-46.

12. Wei J, Wang DW, Alings $M$, Fish $F$, Wathen $M$, Roden DM, George AL Jr. Congenital long-QT syndrome caused by a novel mutation in a conserved acidic domain of the cardiac $\mathrm{Na}^{+}$channel. Circulation 1999:99:3165-71.

13. Kambouris NG, Nuss HB, Johns DC, Tomaselli GF, Marban E, Balser JR. Phenotypic characterization of a novel long-QT syndrome mutation (R1623Q) in the cardiac sodium channel.

Circulation 1998;97:640-44.

14. Makita $N$, Shirai $N$, Nagashima M. Matsuoka $\bar{R}$, Yamada $Y$, Tohse $N$, Kitabatake A. A, de novo. missense mutation of human cardiac $\mathrm{Na}^{+}$channel exhibiting novel molecular mechanisms of long-QT syndrome. FEBS Leil 1998;423:5-9.

15. Luo CH, Rudy Y. A dynamic model of the cardiac ventricular action potential, II: aftẹrdepolarizations. triggered activity, and potentiation. Circ Res 1994:74:1097-113.

16. An RH, Bangalore R, Rosero SZ, Kass RS. Lidocaine block of LQT-3 mutant human $\mathrm{Na}^{+}$channels. Circ Res 1996;79:703-08.

17. Viswanathan $P C$. Shaw RM, Rudy $Y$. Effects of $I_{K r}$ and $I_{K s}$ heterogeneity on action potential duration and its rate dependence: a simulation study. Circulation 1999:99:2466-74.

18. Antzelevitch $C$. Ion channels and ventricular arrhythmias: cellular and ionic mechanisms underlying the Brugada syndrome. Curr Opin Cardiol 1999;14:274-79. 
19. Antzelevitch C, Shimizu W, Yan GX, Sicouri S. Cellular basis for QT dispersion. J Electrocardiol 1998;30(suppl):168-75.

20. Antzelevitch C, Sicouri S, Litovsky SH, Lukas A, Krishnan SC, Di Diego JM, Gintant CA, Liu DW. Heterogeneity within the ventricular wall: electrophysiology and pharmacology of epicardial, endocardial, and M cells. Circ Res 199;;69:1427-49.

21. Hamill OP, Marty A, Neher E, Sakmann B, Sigworth FJ. Improved patch-clamp techniques for highresolution current recording from cells and cell-free membrane patches. Pflugers Arch 1981;391:85-100.

22. Nagatomo T, Fan Z, Ye B, Tonkovich CS, January CT, Kyle JW, Makielski JC. Temperature dependence: of early and late currents in human cardiac wild-type and long-QT $\triangle K P Q \mathrm{Na}^{*}$ channels.

Am J Physiol 1998;275:H2016-24.

23. Weidmann S. Effect of current flow on the membrane potential of cardiac muscle.

J Physiol 1951;115:227-36.

24. Blaustein MP, Lederer WJ. Sodium/calcium exchange: its physiological implications Physiol Rev 1999:79:763-854.

25. Toshe N. Calcium-serisitive delayed rectifier potassium current in guinea pig ventricular cells. AmJ Physiol 1990;258:H1200-07.

26. Splawski I, Tristani-Firouzi M, Lehmann MH, Sanguinetti MC, Keating MT. Mutations in the hmink gene cause long-QT syndrome and suppress $I_{K s}$ function. Nat Genet 1997:17:338-40.

27. Wang Q, Curran ME, Splawski I, Burn TC, Millholland JM, VanRaay TJ, Shen I, Timothy KW, Vircent CM, de Jager T, Schwartz PJ, Toubin JA, Moss AJ, Atkinson DL, Landes GM, Connors TD, Keating MT. Positional cloning of a novel potassium channel gene: KVLQT1 mutations cause cardiac arrhythmias. Nat Genet 1996;12:17-23.

28. Benhorin J, Taub R, Goldmit M, Kerem B, Kass RS, Windman I, Medina A. Effects of flecainide in patients with new SCNSA mutation: mutation-specific therapy for long-QT syndrome?

Circulation 2000;101:3698-706.

29. Luo $\mathrm{CH}$, Rudy Y. A dynamic model of the cardiac ventricular action potential. I. Simulations of ionic currents and concentration changes. Circ Res 1994:74:1071-96.

3a. Zeng J, Laurita KR, Rosenbaum DS, Rudy Y. Two components of the delayed rectifier $\mathrm{K}^{+}$current in ventricular myocytes of the guinea pig type. Theoretical formulation and their role in repolarization. Circ Res 1995:77: 140-52.

31. Viswanathan PC, Shaw RM, Rudy $Y$. Effects of $I_{K r}$ and $I_{K s}$ heterogeneity on action potential duration and its rate dependence: a simulation study. Circulation 1999;99:2466-74.

32. Liu DW: Antzelevitch $C$. Characteristics of the delayed rectifier current $\left(I_{K_{r}}\right.$ and $\left.I_{K s}\right)$ in canine ventricular epicardial, midmyocardial, and endocardial myocytes. A weaker $\mathrm{I}_{\mathrm{Ks}}$ contributes to the longer action potential of the M cell. Circ Res 1995:76:357-65. 


\section{Chapter 4}

Molecular Pharmacology of the Sodium Channel Mutation Di7goG Linked to the Long-QT Syndrome

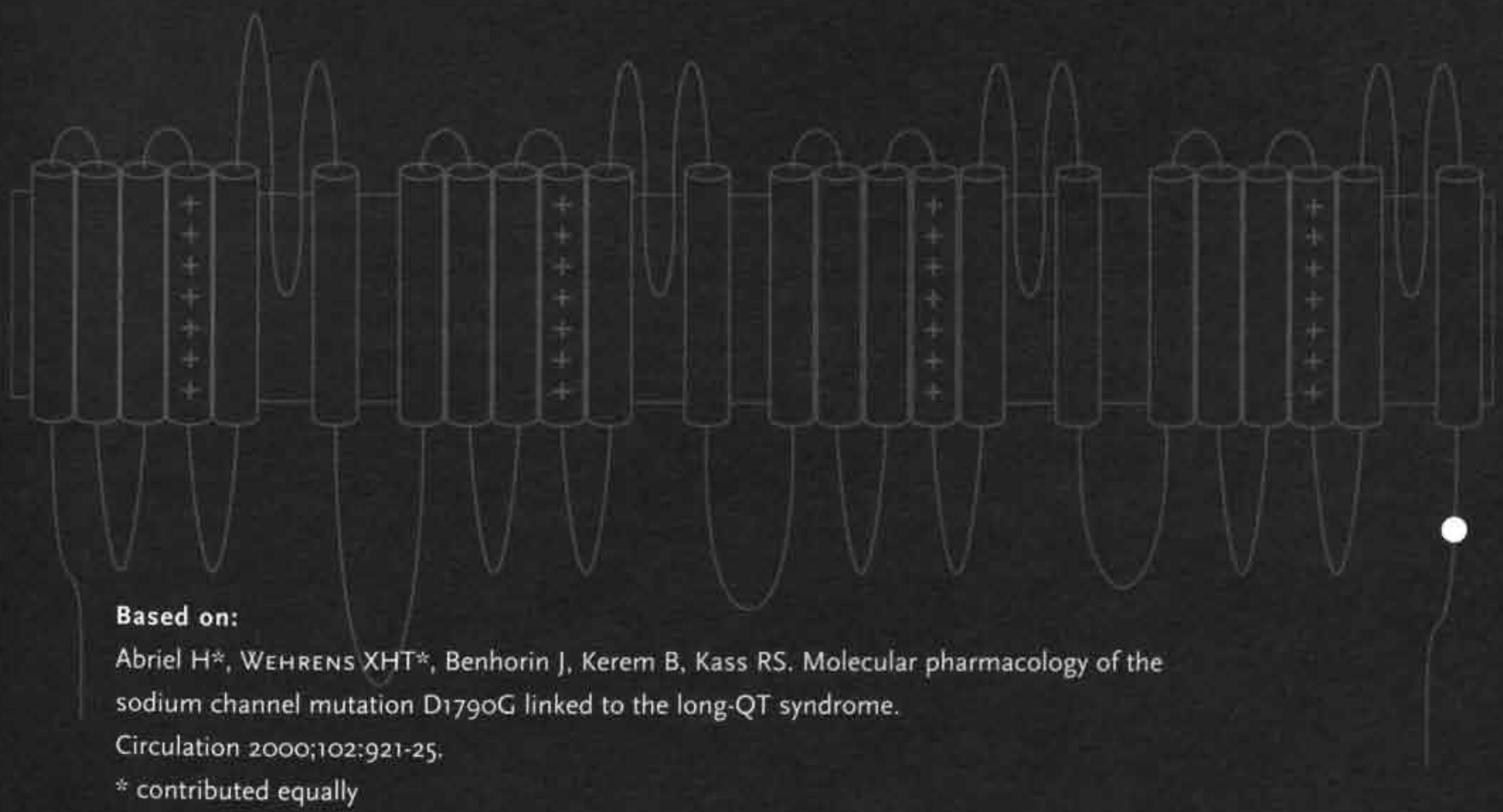




\section{Abstract}

BACKGROUND. Multiple mutations of SCN5A, the gene that encodes the human $\mathrm{Na}^{+}$channel $\alpha$-subunit, are linked to one form of the congenital long-QT syndrome (LQT-3). Di7gaG (DG), an LQT-3 mutation of the C-terminal region of the $\mathrm{Na}^{+}$channel $\alpha$-subunit, alters steady-state inactivation of expressed channels but does not promote sustained $\mathrm{Na}^{+}$channel activity. Recently, flecainide, but not lidocaine, has been found to correct the disease phenotype, delayed ventricular repolarization, in DG carriers.

METHODS AND RESULTS. To understand the molecular basis of this difference, we studied both drugs using wild-type (WT) and mutant $\mathrm{Na}^{+}$channels expressed in $\mathrm{HEK}^{\prime} 293$ cells. The DG mutation conferred a higher sensitivity to lidocaine $\left(E C_{5,0}, W T=894\right.$ and $D G=205$ $\mu \mathrm{mol} / \mathrm{L}$ ) but not flecainide tonic block in a concentration range that is not clinically relevant. In contrast, in a concentration range that is therapeutically relevant, $D C$ channels are blocked selectively by flecainide $\left(E C_{50}, W T=11.0\right.$ and $\left.D G=1.7 \mu \mathrm{mol} / \mathrm{L}\right)$, but not lidocaine $\left(E_{5,0}, W T=318\right.$ and $\left.D G=176 \mu \mathrm{mol} / L\right)$ during repetitive stimulation.

CONCLusions. These results (1) demonstrate that the DG mutation confers a unique pharmacological response on expressed channels; (2) suggest that flecainide usedependent block of DG channels underlies its therapeutic effects in carriers of this gene mutation; and (3) suggest a role of the $\mathrm{Na}^{+}$channel $\alpha$-subunit $\mathrm{C}$-terminus in the flecainide/channel interaction. 


\section{Introduction}

The congenital long-QT syndrome is an inherited cardiac disorder defined by prolonged ventricular repolarization, recurrent syncope, a propensity to polymorphous ventricular tachycardia (torsades de pointes), and sudden death $(1,2)$. Molecular genetic studies have identified defects in the $\alpha$-subunit of the cardiac voltage-gated ion channel (SCN 5 A) that are linked to one form of the disease: LQT-3 (3). Initial functional analysis of most SCN5A mutations has revealed mutant $\mathrm{Na}^{+}$channels that fail to inactivate completely on prolonged depolarization (4-8), a property sufficient to delay repolarization of the ventricular action potential and increase vulnerability of the heart to arrhythmias ( 9 ). In contrast, the D1790G (DG) SCN5A mutation (10), located in the cytoplasmic region of the $\alpha$-subunit $C$-terminus, causes a marked negative shift in the relationship between channel availability and membrane potential and alters inactivation kinetics of mutant channels (11) but does not promote sustained inward current (7).

Pharmacological analysis of LQT-3 mutant channels expressed heterologously has provided evidence that sodium channel blockers that interact with either the inactivated or open state of the channel $(12,13)$ effectively block maintained current conducted by mutant. channels (14-20), shorten action potential duration in cellular studies $(21,22)$, and in preliminary studies correct QT prolongation in patients $(22,23)$.

Because the biophysical properties of the DC mutation do not promote maintained current during the action potential plateau phase, it had been suggested that agents such as lidocaine would not be effective in correcting the disease phenotype linked to this mutation (7). Clinical studies (24) have confirmed this prediction but, in addition, have shown that flecainide, which preferentially blocks open but not inactivated channels (25), is effective in correcting DG-induced QT prolongation in patients carrying the DG gene defect. However, the mechanism underlying this mutation-specific therapeutic efficacy has not yet been determined.

Here, we report the pharmacological profile of DC channels expressed in a mammalian cell line and show that this point mutation confers a flecainide sensitivity that is distinct from wild type (WT) and at least one other LQT-3 mutant channel (2O). Our results reveal marked drug-specific differences in channel modulation that are consistent with the clinical efficacy of both lidocaine and flecainide and suggest that over concentration ranges that are used clinically, it is the marked difference in flecainide's usedependent block (UDB) of DG compared with WT channels that underlies its therapeutic 
efficacy. The results of this study' provide further support for the approach of mutationspecific pharmacology as a basis for the management of inherited cardiac arrhythmias.

\section{Materials and Methods}

\section{Expression of Recombinant $\mathrm{Na}^{+}$Channels}

HEK 293 cells (Cold Spring Harbor Laboratories) were grown under culture conditions and transfected with equal amounts of $\mathrm{Na}^{+}$channel $\alpha$ - (WT or DC, respectively), $h \beta_{1-\text {, and/or }}$ $\mathrm{h} \mathrm{B}_{2}$-subunit cDNAs subcloned individually into the pCDNA3 (Invitrogen) vector (Lotal CDNA, $2.5 \mu \mathrm{g}$ ) by a lipofection procedure previously described by us (7). Control experiments (data not shown) indicated no significant differences in channel activity with or without drug for these subunit combinations. $\beta$-Subunit cDNAs were gifts of Drs L. Isom (University of Michigan, $h \beta_{2}$ ) and A. George (Vanderbilt University, h $\beta_{1}$ ), and the DC mutation was constructed as previously described (7).

\section{Electrophysiology}

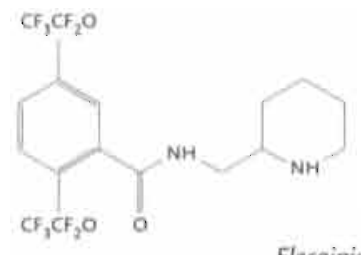

Flecainide

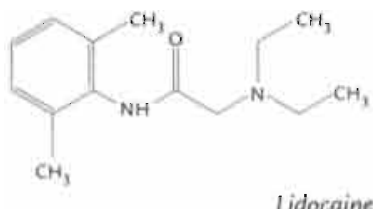

Membrane currents were measured by whole-cell patch-clamp procedures (26) with Axopatch $200 \mathrm{~B}$ amplifiers (Axon Instruments) and the following solutions (mmol/L): internal: $\mathrm{CsCl} 60$, aspartic acid 50, $\mathrm{CaCl}_{2}, \mathrm{MgCl}_{2}$ 1.2, HEPES 10, EGTA 11, and $\mathrm{Na}_{2}$ ATP 5; $\mathrm{pH}$ corrected to 7.2 with $\mathrm{CsOH}$; external: $\mathrm{NaCl} 130, \mathrm{CsCl}_{5}, \mathrm{CaCl}_{2} 2, \mathrm{MgCl}_{2}$ 1.2, HEPES 10, and glucose $5 ; \mathrm{pH}$ corrected to 7.4 with $\mathrm{CsOH}$. Drug (Sigma Chemical $\mathrm{Co}$.) solutions were made from $10 \mathrm{mmol} / L$ (FLECAINIDE) or $100 \mathrm{mmol} / \mathrm{L}$ (LIDOCAINE) stock solutions in $\mathrm{H}_{2} \mathrm{O}$. Experiments were carried out with pClamp7 software (Axon Instruments), and data were analyzed with Origin software (Microcal Software). Unless otherwise specified in the figure legends, experiments were carried out at room temperature $\left(22^{\circ} \mathrm{C}\right)$. Measurements at higher temperature were performed with a solution heater (In-line Heater $\mathrm{SH}-27 \mathrm{~B}$, Warner Instrument $\operatorname{Corp}$ ) warming the superfusate to $37^{\circ} \mathrm{C}$. Recordings were made during $25 \mathrm{~ms}$ test pulses to $-10 \mathrm{mV}$ from $-100 \mathrm{mV}$ holding potentials. Tonic block (TB) was measured at $0.033 \mathrm{~Hz}$ after steady-state was achieved in the presence of drug (1 minute for lidocaine and 2 to 4 minutes for flecainide). Steady-state inactivation was measured with 5 second conditioning pulses followed by a test pulse $(-10 \mathrm{mV})$, with an interpulse interval of 30 seconds. Steady-state UDB was reached in response to trains of variable numbers of 
pulses $(100$ to $600,-10 \mathrm{mV}$ ) at frequencies indicated in the figure legends. UDB was measured as block induced by pulse trains relative to TB for a given drug concentration. UDB data were normalized to currents recorded with the same protocols but in the absence of drug.

Data are represented as mean \pm SEM. Two-tailed Student's t-test was used to compare means; a value of $\mathrm{P}<0.05$ was considered statistically significant.

\section{Results}

\section{TB of WT and Mutant Channels}

Because the DG mutation alters the voltage-dependence of steady-state inactivation of expressed channels (7), we first tested for differences between the interactions of lidocaine and flecainide with the inactivated state of WT and DC channels. FICURE 4.1 shows that lidocaine, but not flecainide, induces marked hyperpolarizing shifts in the steady-state inactivation relationship for both WT and DG channels. Furthermore, the effects of lidocaine on inactivation are approximately the same for WT and DC channels.

The lidocaine-selective shift in inactivation predicts greater TB of DC versus WT channels by lidocaine, but not flecainide, at physiologically relevant holding potentials. This prediction is confirmed in the experiments summarized in FIGURE 4.2 However, at clinically relevant concentrations (27) of lidocaine $(30 \mu \mathrm{mol} / \mathrm{L})$ and flecainide $(3 \mu \mathrm{mol} / \mathrm{L})$, neither drug discriminates between WT and DG channels on the basis of TB.

\section{UDB: Distinctions Between WT and DC Channels}

Therefore, we next compared block that accumulates with repetitive activity when DC mutant and WT channels are exposed to lidocaine and flecainide (FIGURE 4.3). Again at clinically relevant concentrations $(30 \mu \mathrm{mol} / \mathrm{L})$, there is no difference between lidocaine block of WT and DC channels (FICURE 4.3A). In contrast, there is a statistically significant $(P<0.001)$ difference between flecainide UDB of DC and WT channels at the clinically relevant concentration of $3 \mu \mathrm{mol} / \mathrm{L}$. This difference is evident over a broad concentration range: $\mathrm{EC}_{50}$ for flecainide UDB of DG channels is roughly 5 times lower than for block of WT channels (FIGURE 4.3B). In contrast, UDBs of WT or DG channels by lidocaine are 
A
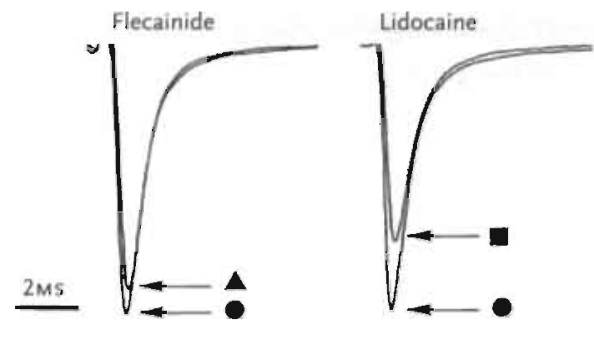

C

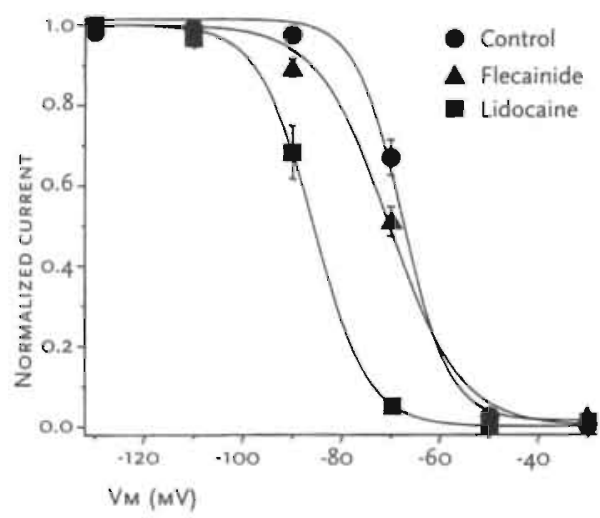

B D1790C. $.110 \mathrm{MV}$

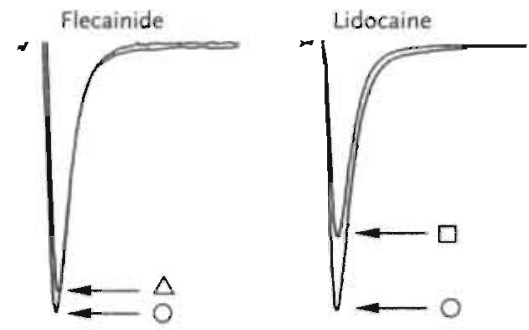

D

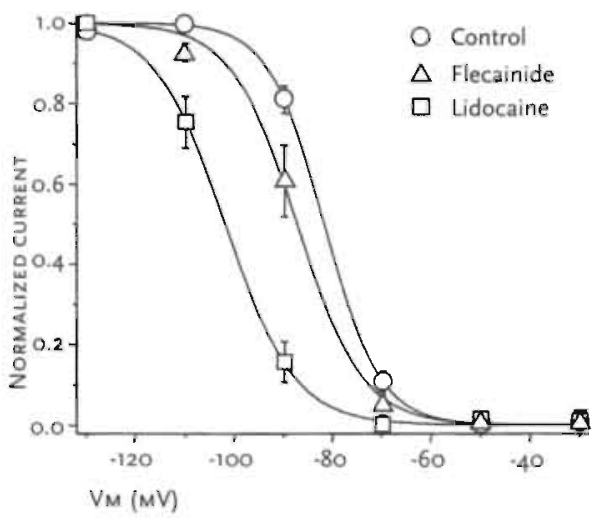

F!CURE 4.1

Effects of flecainide and lidocaine on steady-state inactivation of WT and DG channe/s. Steady-state availability of channels was measured (Methods) in absence and presence of each drug. A and B, Current traces, normalized to peak drug-free currents, illustrate effects of lidocaine $(300 \mu \mathrm{mol} / \mathrm{L})$ and flecainide (30 $\mathrm{mmol} / \mathrm{L})$. Arrows indicate drug. induced changes in peak currents for each condition. C and D, Averaged steady-state availability curves are shown in

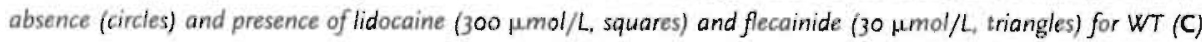
and DG (D) channels. Na+ currents elicited by $-10 \mathrm{mV}$ test pulses were normalized to largest currents obtained in control conditions from hyperpolarized holding potentials. Graphs show normalized current plotted against conditioning pulse voltage. Smooth lines are according to $1 /\left\{1+\exp \left[\left(V_{c}-V_{1 / 2}\right) / k\right]\right\}$, where $V_{c}$ is conditioning potential, $V_{1 / 2}$ is voltage for which half the channels are not available, and $k$ is the slope factor. $V_{1 / 2}(\mathrm{mV})$ for WT is $-66.2 \pm 0.9$ for control, $-69.8 \pm 0.9$ with flecainide, and $-85.7 \pm 1.4$ with lidocaine; $V_{1 / 2}(m V)$ for $D C$ is $-81.8 \pm 7.4$ for contral, $-87.3 \pm 2.4$ with flecainide, and $-102.5 \pm 2.7$ with lidocaine; $n=4$ cells per condition. 
A LIDOCAINE $300 \mu \mathrm{MOL} / \mathrm{L}$

WT

C
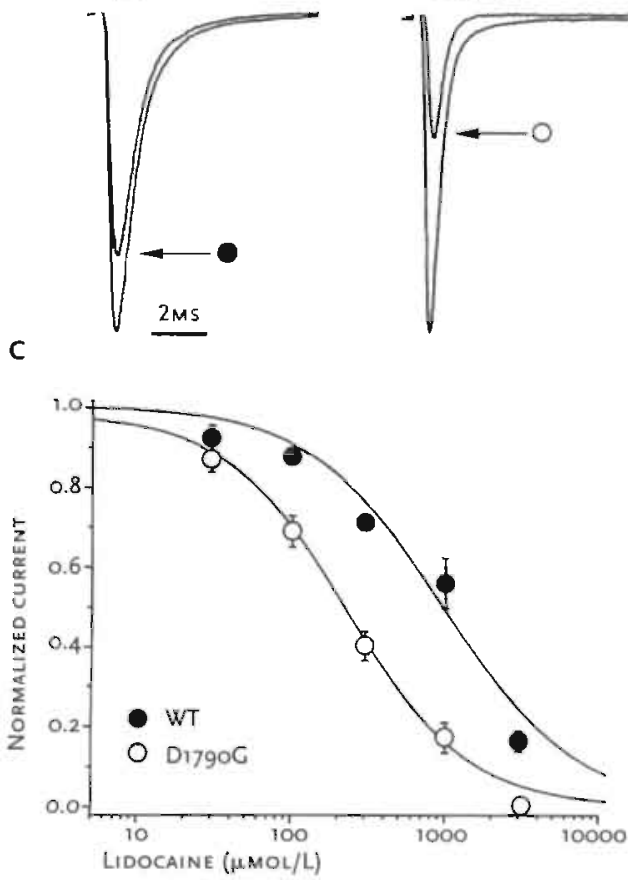

B FLECAINIDE $30 \mu \mathrm{MOL} / \mathrm{L}$
Di7goC

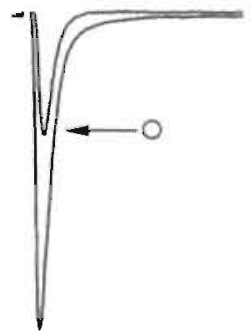

WT
D1790G

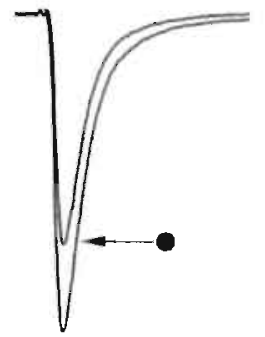

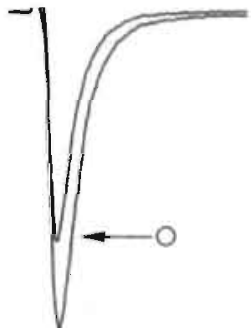

D

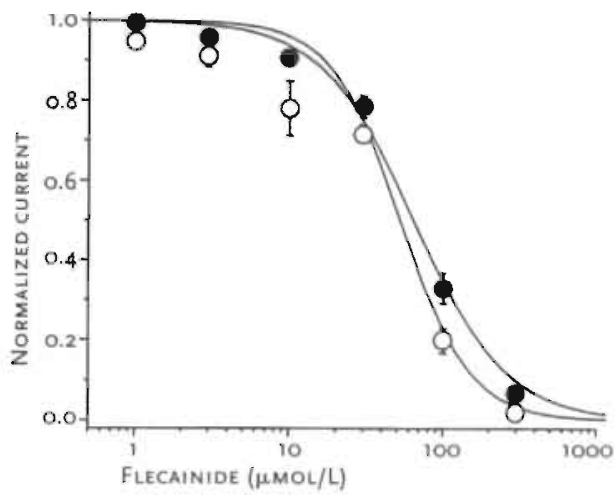

FICURE 4.2

TB of WT and DG mutant $\mathrm{Na}^{+}$channels. $\mathrm{A}$ and $\mathbf{B}$, Inhibition of $\mathrm{Na}^{+}$current elicited in HEK cells expressing WT of DG channels with lidocaine (A) or flecainide (B). Traces show currents in control solution and after steady-state TB was attained (arrows) 2 to 4 minutes after cell superfusate was changed to one containing lidocaine (300 $\mu \mathrm{mol} / \mathrm{L}$ )

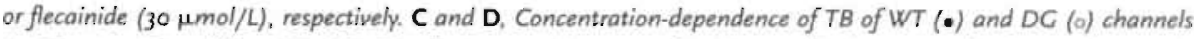
by lidocaine (C) and flecainide (D). Graph shows peak current after drug application, normalized to peak current in absence of drug, plotted as a function of drug concentration. Smooth lines are according to $1 /\left(1+[d r u g] / E C_{50}\right)^{n}$. $E C_{50}$ for lidocaine is 894 (WT) and 205 (DG): $E C_{50}$ for flecainide is 59-3 (WT) and 48.2 (DC); $n=3$ to 6 cells per condition. 

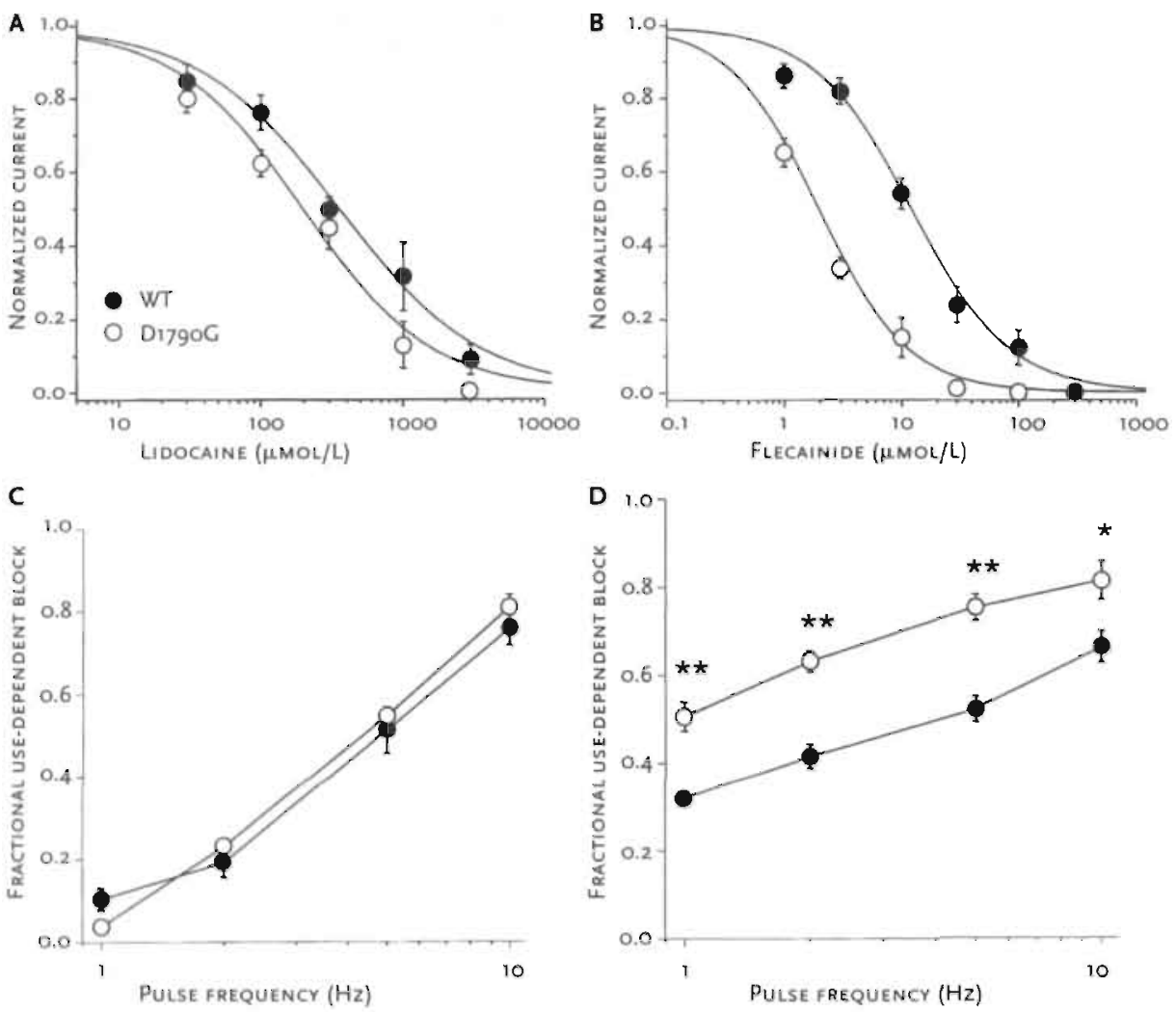

FIGURE 4.3

DG mutation increases sensitivity of channels to UDB by flecainide but not lidocaine. Concentration dependence of UDB of WTT (•) and DC (o) channels by lidocaine (A) and flecainide (B). Currents were evoked by pulses applied at a frequency of $5 \mathrm{~Hz}$ in presence of drugs until steady-state UDB was achieved and normalized to TB ievels before high-frequency train protocol was started. Smooth lines are according to $1 /\left(1+\left[\text { drug } / / E_{50}\right)^{n}\right.$. EC-so for lidocaine is $318(W T)$ and 176 (DG); $E C_{50}$ for flecainide is $11.0(W T)$ and 1.7 (DG); $n=3$ to 6 cells per condition.

$\mathbf{C}$ and $\mathbf{D}$, Frequency-dependence of lidocaine and flecainide block of $W T(\bullet)$ and $\overline{D G}(0)$ channels at fixed drug concentrations. Trains of 100 to 600 pulses were applied at various frequencies in presence of lidocaine (300 $\mu \mathrm{mol} / \mathrm{L}, \mathrm{C})$ or flecainide (10 $\mu \mathrm{mol} / \mathrm{L}, \mathrm{D})$. Graphs show peak current during steady-state UDB normalized to peak current during first pulse of train plotted against stimulus frequency; $n=4$ cells per condition. $\$ P<0.05$, $\# \geqslant P<0.0$. 
approximately the same over all concentrations tested. In addition, the distinction in usedependent drug action between WT and DC channels is retained when the frequency range of pulse application is extended to a broader frequency range (FIGURE 4.3C AND 4.3D).

\section{Effect of DG Mutation on Recovery From Flecainide Block}

Block that accumulates as a consequence of repetitive channel activity (UDB) is caused by a balance between the time course of the onset of block (during depolarization) and the recovery from block (during repolarization) $(12,13)$. To understand the marked sensitivity of DC channels to UDB, we next investigated the time course of the recovery from UDB. Here, we focused only on the effects of flecainide, because there was little difference between WT and DG channels in response to UDB by lidocaine (FIGURE 4.3A and 4.3C).

In these experiments, we applied a "conditioning" train of pulses (to $-10 \mathrm{mV}$, from a -100 mV holding potential) for a fixed duration $(25 \mathrm{~ms})$ and frequency $(25 \mathrm{~Hz})$ to induce flecainide block of channels. Test pulses were then imposed after variable recovery intervals at holding potential. Currents were normalized to steady-state current levels during slow pacing (once every 30 seconds). Normalized current is plotted against recovery interval. As illustrated in FIGURE 4.4 , in the absence of the drug, DG channels tend to recover faster from inactivation that occurs as a consequence of the conditioning train. In the presence of flecainide, repriming of channels is very different: now DG channels recover very slowly. Even after 10 seconds at the holding potential $(-100 \mathrm{mV})$ under pulse-free conditions, only a small fraction of the flecainide-blocked current recovers. This result suggests that the flecainide-bound DC channel is very stable and that infrequent pulsing can still be very effective at accumulating block because once blocked, channels remain nonconducting for tens of seconds.

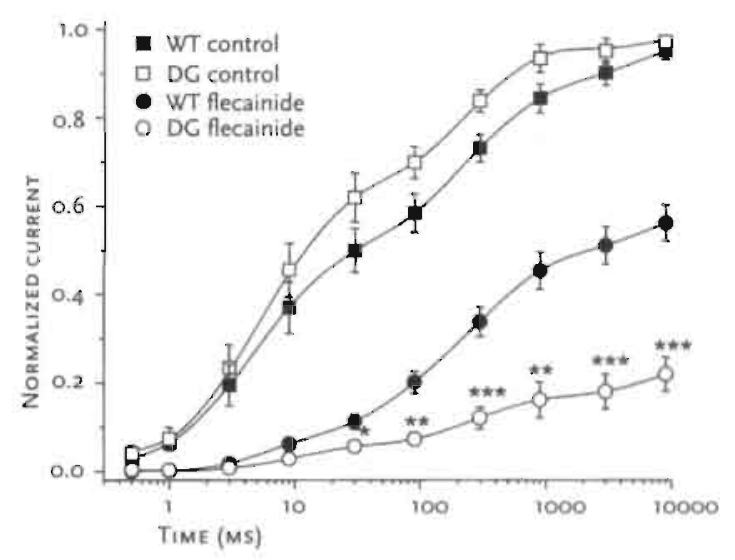

FICURE $4 \cdot 4$

Effect of DG mutation on time course of recovery from inactivation and flecainide block. UDB of WT (solid symbols) and DG (open symbols) mutant channel's was induced before (squares) and after (circles) application of $10 \mu \mathrm{mol} / \mathrm{L}$ flecainide; $n=4$ cells per condition. $* P<0.0$, * $\Rightarrow P<0.01$, \#*\# $P<0.001$. 
A
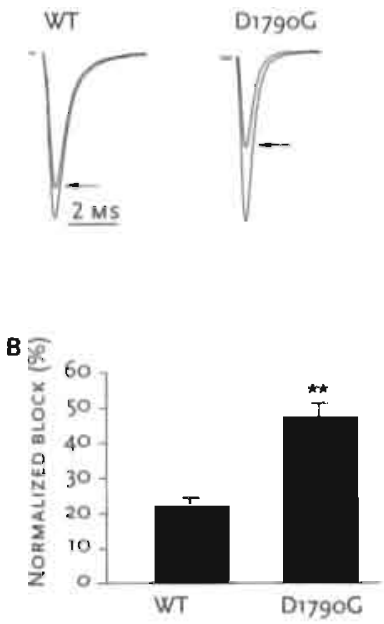

FICURE 4.5 Preferential flecoinide block of DC vs WT channeis under physiological conditions.

A. Current traces before and after steady-state UDB (arrows). Shown are superimposed records of first and 10oth $^{\text {th }}$ traces in trains applied to WT (left) and DC (right) channeis. B, Bar graphs summarize steady-state UDB plotted as fraction of current blocked in response to the pulse train: $n=6$ cells per condition. औth $\mathrm{P}<0.01$.
Clinical Efficacy of Flecainide: Distinctions Between UDB of WT and DG Channels The dramatic slowing of flecainide unblock caused by the DG mutation (FICURE 4.4) has important implications for the clinical usefulness of this compound in the treatment of LQT-3 in carriers of the DG mutation. Because use-dependent flecainide block discriminates between WT and DG mutant channels (FIGURE 4.3), it is important to demonstrate UDB of DG channels under conditions that more closely resemble those encountered in the heart. Thus, we tested for differences between WT and DG channeis in the response to flecainide ( $3 \mu \mathrm{mol} / \mathrm{L}$ ), when longer pulses ( $400 \mathrm{~ms}$ ), which mimic the duration of action potentials in LQT-3 patients, are applied at a physiological frequency $\left(\mathrm{Hz}\right.$ ) and temperature $\left(37^{\circ} \mathrm{C}\right.$ ). These experiments (FICURE 4-5) confirm that, even under these conditions, the extremely slow recovery from flecainide block of DG channels is sufficient to cause significantly greater block of DC versus WT channels.

\section{Discussion}

\section{Molecular Basis for Mutation-specific Pharmacology:}

\section{Implications for a Role of C-Terminus in Inactivation and Drug Activity}

The principal finding of this study is that a LQT-3-linked mutation of the heart $\alpha$-subunit of the $\mathrm{Na}^{*}$ channel dramatically and specifically changes the manner by which channels encoded by the mutant gene interact with sodium channel-blocking drugs. The mutation confers a higher sensitivity to UDB by flecainide, but not lidocaine, over a clinically relevant concentration range. Flecainide TB is not affected by the DG mutation. Our findings thus illustrate the importance of investigating mutation-induced changes not only in channel function but also in channel pharmacology.

Voltage-dependent block of $\mathrm{Na}^{+}$channel currents by antiarrhythmic drugs is a consequence of distinct interactions with different states of the voltage-gated $\mathrm{Na}^{+}$channel. Lidocaine and flecainide differ in their modes of action in that lidocaine interacts preferentially with inactivated channels, and drug block is not necessarily dependent on channel openings $(25,28)$, whereas flecainide requires channels to open and is not dependent on channels entering the inactivated state to promote block $(25,29)$.

We observed that the DC mutation does not influence the interaction of lidocaine with the $\mathrm{Na}^{+}$channel, even if TB was greater than for mutant channels (FICURE 4.2).

Novel Insights in the Congenital Long QT-3 Syndrome | PAGE 100 
Indeed, this effect is explained by the fact that lidocaine shifts the steady-state inactivation curve by the same amount for WT as for the DG mutant channel, but the DG mutation by itself already shifts this curve by $-20 \mathrm{mV}$ in the absence of drug. Because flecainide has a much weaker effect on the inactivation curve (FIGURE 4.1), there is little difference between flecainide-induced TB of WT and DG channels. In contrast, the DG mutation markedly increases flecainide UDB of channels, in large part because of the pronounced slowing of the repriming of DC channels in the presence of the drug (FICURE 4.4).

This specific alteration of the sensitivity to UDB by flecainide is not a general property of all LQT-3 mutant channels. Recently, Nagatomo et al. (20) found that LQT-3 $\triangle K P Q$ mutant channels have an intrinsically higher affinity than WT channels to flecainide, but in the case of this mutation, sensitivity to both TB and UDB is increased. Thus, our data indicate that the DG point mutation causes a unique pharmacological response of the expressed channels, which is distinct not only from WT but also from $\triangle K P Q$ mutant channels.

The DG mutation is a nonconservative change from an aspartic acid to a glycine only 18 amino acids away from transmembrane segment $\mathrm{S} 6$ in the C-terminus of the $\mathrm{Na}^{+}$ channel $\alpha$-subunit, a region of the channel not previously considered to play a maior role in the molecular interactions of flecainide (30). Our data clearly show that this is not the case and raise the possibility that other residues of the C-terminus may also be important in determining pharmacological responses of $\mathrm{Na}^{+}$channels. Importantly, one other nonconservative C-terminus LQT-3 mutation ( $\mathrm{E}_{1784} \mathrm{~K}$ ) has been reported recently (6), and a C-terminus insertion mutation (1795ins D) has been linked to both Brugada's syndrome and LQT-3 (31). Our work strongly suggests that these mutations may also modify the interactions of the encoded channels by flecainide (and probably other drugs), raising the possibility of pharmacological targeting of a broad range of mutation-induced phenotypes. As has been shown for $\triangle K P Q$ and DG channels, however, determination of the pharmacological profile must be carried out systematically on a mutation-by-mutation basis before this would be possible.

\section{Relationship Between Molecular Pharmacology and Therapeutic Efficacy}

Our data on recombinant human $\mathrm{Na}^{+}$channels complement those of Benhorin et al. (24), which have shown that flecainide, but not lidocaine, significantly decreased the QTC interval in DC carriers by $10 \%$ but was without effect in control patients. This difference was even more striking when the effect of flecainide on the marked repolarization 
heterogeneity seen in DG carriers was considered. Our experiments, indicate that over the clinically relevant drug concentration range and under physiological conditions, flecainide discriminates between WT and DC primarily because of the pronounced effect of the DG mutation on flecainide UDB. The correlation between the clinical results and our data strongly suggests that it is this mechanism of action that underlies the therapeutic usefulness of flecainide compared with lidocaine in the treatment of carriers of the DG mutation. Interestingly, flecainide has also recently been shown to be very effective in treating carriers of the $\triangle K P Q$ LQT-3 mutation (A.J. Moss, personal communication), even though, as discussed above, the interactions of flecainide with $\triangle K P Q$ and DC mutant channels differ. In the case of both channel defects, however, recovery from the drugblocked state is markedly slowed compared with WT channeis, and it may be this common mode of action that makes this drug so useful as a therapeutic tool in the treatment of carriers of these gene defects.

In summary, we have found that the LQT-3 DG mutation changes the pharmacological response of encoded channels in a manner that differs not only from WT but also from other LQT-3 mutant channels. The pharmacological profile of DC channels shows distinct changes that occur over a therapeutically relevant concentration range. Our data provide further support for the usefulness of a mutation-specific pharmacological approach for the management of distinct inherited ion channel defects.

\section{Acknowledgments}

This work was supported by US Public Health Service grant Ro1-HL-568105-02 (Dr Kass).

Dr Abriel was supported by the Swiss National Foundation for Fellowships in Medicine and Biology, and Dr Wehrens by the Dutch foundation De Drie Lichten. 


\section{References}

1. Moss AJ, Schwartz PJ, Crampton RS, Tzivoni D, Locati EH, MacCluer J, Hall WJ, Weitkamp L, Vincent GM, Garson A Jr. The long-QT syndrome: prospective longitudinal study of 328 families. Circulation 1991;84:1136-44.

2. Schwartz PJ, Periti M, Malliani A. The long.QT syndrome. Am Heart J 1975;89:378-90.

3. Wang Q, Shen J, Splawski I, Atkinson D, Li Z, Robinson IL, Moss AJ), Towbin JA, Keating MT. SCN5A mutations associated with an inherited cardiac arrhythmia, long QT-syndrome. Cell 1995;80:805-11.

4. Bennett PB, Yazawa K, Makita N, George AL. Jr. Molecular mechanism for an inherited cardiac arrhythmia. Nature 1995:376:683-85.

5. Wang DW, Yazawa K, George AL Jr, Bennett PB. Characterization of human cardiac $\mathrm{Na}^{+}$channel mutations in the congenital long QT-syndrome. Proc Nat/ Acad Sci U S A 1996;93:13200-05.

6. Wei J, Wang DW, Alings M, Fish F, Wathen M, Roden DM, George AL Jr. Congenita! long-QT syndrome caused by a novel mutation in a conserved acidic domain of the cardiac $\mathrm{Na}^{+}$channel. Circulation 1999;99:3165-71.

7. An RH, Wang XL, Kerem B, Benhorin /, Medina A, Goldmit M, Kass RS. Novel LQT-3 mutation affects $\mathrm{Na}^{+}$channel activity through interactions between $\alpha$ - and $\beta 1$-subunits. Circ Res 1998;83:147-46.

8. Kambouris NG, Nuss HB, Johns DC, Tomaselli GF, Marban E, Balser JR. Phenotypic characterization of a novel long-QT syndrome mutation (R1623Q) in the cardiac sodium channel. Circulation 1998; 97 : 640-44.

9. Clancy CE, Rudy $Y$. Linking a genetic defect to its cellular phenotype in a cardiac arrhythmia. Nature 1999:400:566.69.

10. Benhorin J, Coldmit M, MacCluer JW, Blangero J, Coffen R, Leibovitch A, Rahat A, Wang Q, Medina A, Towbin J, Kerem B. Identification of a new SCN5A mutation associated with the long. QT syndrome. Hum Mutat 1998;12:72.

11. Wehrens XHT, Abriel H, Cabo C, Benhorin 1, Kass RS. Arrhythmogenic mechanism of an LQT-3. mutation of the human heart $\mathrm{Na}^{+}$channel $\alpha$-subunit: a computational analyșis.

Circulation 2000;102:584-90.

12. Hille B. Local anesthetics: hydrophilic and hydrophobic pathways for the drug-receptor reaction. J Gen Physiol 197\%,69:497-515.

13. Hondeghem LM, Katzung BC. Time- and voltage-dependent interactions of antiarshythmic drugs, with cardiac sodium channels. Biochim Biophys Acta 1977:472:373-98.

14. An RH, Bangalore R, Rosero SZ, Kass, RS. Lidocaine block of LQT-3 mutant human $\mathrm{Na}^{+}$channels. Circ Res 1996:79:103-08.

15. Compton S], Lux RL, Ramsey MR, Strelich KR, Sanguinetti MC, Green LS, Keating MT; Mason JW. Genetically defined therapy of inherited long-QT syndrome: correction of abnorma! repolarization by potassium. Circulation 1996;94:1018-22.

16. Dumaines R, Wang Q. Keạting MT, Hạrțạnn HA, Schwartz PI, Brown AM, Kirsch CE. Multiple mechanisms of $\mathrm{Na}^{+}$channel linked long-QT syndrome. Circ Res 1926;78:916-24.

17. Priori SG, Napolitano C, Cantui F, Brown AM, Schwartz PJ. Differential response to $\mathrm{Na}^{+}$channel blockade, $\beta$-adienergic stimulation, and rapid pacing in a cellular model mimicking the $S C N_{5} \mathrm{~A}$ and HERC defects present in the long-QT syndrome. Circ Res 1996:78:1009-15: 
18. Wang DW, Yazawa K, Makita N, George AL Jr, Bennett PB. Pharmacological targeting of long-QT mutant sodium. j Clin Invest 1997;99:1714-20.

19. Dumaine R, Kirsch GE. Mechanism of lidocaine block of late current in long-QT mutant $\mathrm{Na}^{+}$ channels. Am J Physiol 1998;274:H477-87.

20. Nagatomo T, january CT, Makielski JC. Preferential block of late sodium current in the LQT-3 $\triangle K P Q$ mutant by the class IC antiarnythmic flecainide. Mol Pharmacol 2000;57:101-07.

21. Shimizu W, Antzelevitch C. Sodium channel block with mexiletine is effective in reducing dispersion of repolarization and preventing torsades de pointes in LQT-2 and LQT-3 models of the long-QT syndrome. Circulation 1997:96:2038-47.

22. Schwartz PJ, Priori SG, Locati EH, Napolitano C, Cantu F, Towbin JA, Keating MT, Hammoude H, Brown AM, Chen LS. Long-QT syndrome patients with mutations of the SCN5A and HERC genes have differential responses to $\mathrm{Na}^{+}$channel blockade and to increases in heart rate: implications for gene-specific therapy. Circulation 1995:92:3381-86.

23. Zareba W, Moss A], Rosero SZ, Hajj-Ali R, Konecki J, Andrews M. Gene-specific therapy for longQT syndrome: QT shortening with lidocaine and tocainide in patients with mutation of the sodium channel gene. Ann Nonimas Electrocardiol 1997;2:274-78.

24. Benhorin 1, Taub R, Goldmit M, Kerem B, Kass RS, Windman I, Medina A. Effects of flecainide in patients with new SCN5A mutation: mutation-specific therapy for long-QT syndrome?

Circulation 2000;701:1698.706.

25. Ragsdale DS, MCPhee JC, Scheuer T, Catterall WA. Common molecular determinants of local anesthetic, antiarrhythmic, and anticonvulsant block of voltage-gated $\mathrm{Na}$ " channels.

Proc Notl Acad Sci U S A 1996;93:9270-75.

26. Harnill OP, Marty A, Neher E, Sakmann B, Sigworth FJ. Improved patch-clamp techniques for high-resolution current recording from cells and cell-free membrane patches. Pflugers Arch 1981:397:85-100.

27. Marcus. Fl, Opie LH. Antiarrhythmic agents. In: Opie LH (ed.) Drugs for the heart. Philadelphia, PA: WB Saunders; 1997:207-47.

28. Bean BP, Cohen $C_{\text {, }}$, Tsien RW. Lidocaine block of cardiac sodium channels. J Gen Physiol 1983:81:613-42.

29. Anno T, Hondeghem LM. Interactions of flecainide with guinea pig cardiac sodium channels: importance of activation unblocking to the voltage dependence of recovery. Circ Res 1990;66:789-803.

30. Catterall WA. Molecular properties of sodium and calcium channels. J Bivenerg Biomembr 1996:28:219-30.

31. Bezzina C, Veldkamp MW, Van den Berg MP, Postma AV, Rook MB, Viersma JW, Van Langen IM, Tan-Sindhunata G, Bink-Boelkens MT, Van der Hout AH, Mannens MM, Wilde AA. A single $\mathrm{Na}^{+}$channel mutation causing both long-QT and Brugada syndromes. Circ Res 1999;85:1206-13. 


\section{Chapter 5}

Novel Arrhythmogenic Mechanism Revealed by a Long-QT Syndrome Mutation in the Cardiac $\mathrm{Na}^{+}$Channel

Based on:

Abriel H, Cabo C, Wehrens XHT, Rivolta I, Motoike HK, Memmi M, Napolitano C, Priori SG, Kass RS. Novel Arrhythmogenic Mechanism Revealed by a Long-QT Syndrome Mutation in the Cardiac $\mathrm{Na}^{+}$Channel. Circ Res 2001;88:740-45. 
Variant 3 of the congenital long-QT syndrome (LQT-3) is caused by mutations in the gene encoding the $\alpha$-subunit of the cardiac $\mathrm{Na}^{+}$channel. In the present study, we report a novel LQT.3 mutation, E1295K (EK), and describe its functional consequences when expressed in HEK293 cells.

The clinical phenotype of the proband indicated QT-interval prolongation in the absence of $T$ wave morphological abnormalities and a steep QT/R-R relationship, consistent with an LQT-3 lesion. However, biophysical analysis of mutant channels indicates that the EK mutation changes channel activity in a manner that is distinct from previously investigated LQT.3 mutations.

The EK mutation causes significant positive shifts in the half-maximal voltage $\left(V_{1 / 2}\right)$ of steady-state inactivation and activation $(+5.2$ and $+3.4 \mathrm{mV}$, respectively). These gating changes shift the window of voltages over which $\mathrm{Na}^{+}$channels do not completely inactivate without altering the magnitude of these currents. The change in voltage dependence of window currents suggests that this alteration in the voltage dependence of $\mathrm{Na}^{+}$channel gating may cause marked changes in action potential duration because of the unique voltage-dependent rectifying properties of cardiac $\mathrm{K}^{+}$channels that underlie the plateau and terminal repolarization phases of the action potential. $\mathrm{Na}^{+}$channel window current is likely to have a greater effect on net membrane current at more positive potentials (E.K channels) where total $\mathrm{K}^{+}$channel conductance is low, than at more negative potentials (wild-type channels), where total $\mathrm{K}^{+}$channel conductance is high. These findings, suggest a fundamentaily distinct mechanism of arrhythmogenesis for congenital LQT-3. 


\section{Introduction}

Electrical activity in the heart is the result of a complex interaction of a large number of ion channels, pumps, and exchange mechanisms that serve unique physiological roles in anatomically distinct regions $(1,2)$. The action potential duration (APD) of ventricular cells is determined by a long-lasting (hundreds of milliseconds) depolarization or plateau phase that is controlled by a fine balance between small inward and outward ionic currents and during which there is little change in membrane potential (3). Key to an energetically favorable maintenance of depolarization are the voltage-dependent rectification properties of at least two types of potassium channel currents, $I_{k_{r}}$ and $I_{k_{r}}$, which restrict outward movement of potassium during the plateau but permit large outward currents during the terminal phases of repolarization as the membrane potential becomes more negative $(4,5)$.

Physiological insight into the roles of ion channels in the control of the human cardiac action potential (AP) plateau phase has grown rapidly during the past 5 years from studies of the congenital long-QT syndrome (LQTS), an inherited cardiac arrhythmia, which is clinically characterized by prolongation of the ECG QT-interval, syncope, and sudden death (6-12). The unexpected importance of $\mathrm{Na}^{+}$channel activity to the control of QT-intervals has been revealed by studies of LQT-3, which is caused by mutations in the SCN 5 A gene, which codes for the $\alpha$-subunit of the cardiac $\mathrm{Na}^{+}$channel $(8,10,13)$.

Expression of LQT-3 mutant channels in heterologous systems has revealed mutation-induced channel activity that either directly $(14,-6)$, or indirectly $(17-20)$ causes. a small increase in net inward current over the voltage range and time course of the AP plateau. Computational analysis has shown that this increase in inward current is sufficient to explain the cellular phenotype of APD prolongation $(17,21)$. Nevertheless, not all LQT-3 mutations alter $\mathrm{Na}^{+}$channel functional properties in the same manner, and distinction in mutation-induced changes in channel properties is important to document, not only because of the possibility of mutation-specific clinical phenotypes but also because such changes may have implications for therapeutic intervention.

In the present study, we report the biophysical consequences of a novel LQT-3. mutation that change a conserved negative into a positive amino acid (E1295K [EK]) in a region immediately adjacent to the extracellular portion of the $\mathrm{S}_{4}$ segment of channel domain III (DIIIS4). Expression of mutant channels in a mammalian cell line indicates that the primary effect of this mutation is to cause small positive shifts in the valtage. dependence of both activation and inactivation gating of the channel, which, in turn, shift 
the window of voltages over which noninactivating $\mathrm{Na}^{+}$channel activity can be measured (22-24). These small changes in the voltage dependence of $\mathrm{Na}^{+}$channel gating occur over the plateau range of membrane potentials for which two cardiac $\mathrm{K}^{+}$channel currents, $I_{K Y}$ and $I_{K r}$, show strong inward rectification $(4,25-32)$. Window current that flows during the terminal phase of repolarization (wild-type [WT] channels), where rectification of $I_{K}$ and $I_{K r}$ is being relieved, is likely to be less effective than window current that flows over more positive voltages (EK channels) where the conductance of these two channels is minimal. The linkage of these small changes in $\mathrm{Na}^{+}$channel gating to delay in ventricular repolarization through LQT-3 confirms the important principle of balance of currents necessary to maintain the AP plateau phase and the role of membrane input impedance in determining the effects of small changes in ion channel currents on cellular electrical activity (3). Thus, our findings are important because they further support the concept of phenotypic heterogeneity of LQT-3 that has to be taken into account when developing new therapeutic strategies for this disorder.

\section{Materials and Methods}

\section{Molecular Screening}

Genomic DNA was extracted from peripheral blood lymphocytes by standard techniques. The coding region of the $S C N_{5} A$ gene encoding the cardiac $\mathrm{Na}^{+}$channel was screened using single-strand conformation polymorphism (SSCP) on polymerase chain reaction (PCR)-amplified genomic DNA samples. The abnormal conformers were directly sequenced using an $\mathrm{ABI}_{3} 10$ genetic analyzer or cloned (TOPO-TA cloning, Invitrogen) and sequenced using plasmid-specific oligonucleotides. SSCP shifts were also checked against a panel of genomic DNA from 300 ( 600 chromosomes) healthy reference individuals. The presence of a second mutation in the remaining LQTS-related genes (i.e., KCNQ1, HERG, KCNE1, and KCNE2) was excluded by molecular analysis.

\section{Mutagenesis and Expression of Recombinant $\mathrm{Na}^{+}$Channels}

The Ei295K mutation of SCN5A was engineered into WT CDNA cloned in pcDNA3.1 (Invitrogen) by overlap extension using mutation-specific primers and Quik Change ${ }^{\top \mathrm{T}}$ SiteDirected Mutagenesis Kit (Stratagene). The presence of the mutation was confirmed by 
sequence analysis. WT and mutant $\mathrm{Na}^{+}$channels were expressed in $\mathrm{HEK} 293$ cells. Briefly, transient transfections were carried out with equal amounts of $\mathrm{Na}^{+}$channel $\alpha$-subunit, with $h \beta_{1}$ and/or $h \beta_{2}$ subunits CDNA subcloned individually into the pcDNA3.1 (Invitrogen) vector (total cDNA $2.5 \mu \mathrm{g}$ ) using a previously described procedure (17). Control experiments (data not shown) indicated no significant differences in channel activity for these subunit combinations. We found no difference in the properties of expressed channels with or without cotransfection of $h \beta 2$.

\section{Electrophysiology}

Membrane currents were measured using whole-cell patch-clamp procedures, with Axopatch 200 B amplifiers (Axon Instruments, Foster City, CA). Recordings were made at room temperature $\left(22^{\circ} \mathrm{C}\right)$ using an internal solution containing ( $\mathrm{mmol} / \mathrm{L}$ ) $\mathrm{CsCl} 60$, cesium aspartate 80, EGTA 11, $\mathrm{MgCl}_{2} 1, \mathrm{CaCl}_{2} 1$ (effective free calcium $100 \mathrm{nmol} / \mathrm{L}$ ), HEPES ro, and $\mathrm{Na}_{2}$ ATP $5, \mathrm{pH}$ adjusted to 7.2 with $\mathrm{CsOH}$. In experiments recording $\mathrm{I} / \mathrm{V}$ curves, external $\mathrm{Na}^{+}$was reduced to $30 \mathrm{mmol} / \mathrm{L}$ using $\mathrm{n}$ methyl-glucamine as a $\mathrm{Na}^{+}$substitute.

The use of these solutions in our experiments allowed us to make very stable recordings with minimal time-dependent changes in voltage-parameters of activation and inactivation.

We have carried out control experiments for both voltage-dependence of activation and inactivation. After an initial time of 1 to 2 minutes, we determined that there are no significant changes in the voltage-dependence of activation or inactivation for periods at least as long as 12 minutes (FIGURE 5.1). However, in order
A
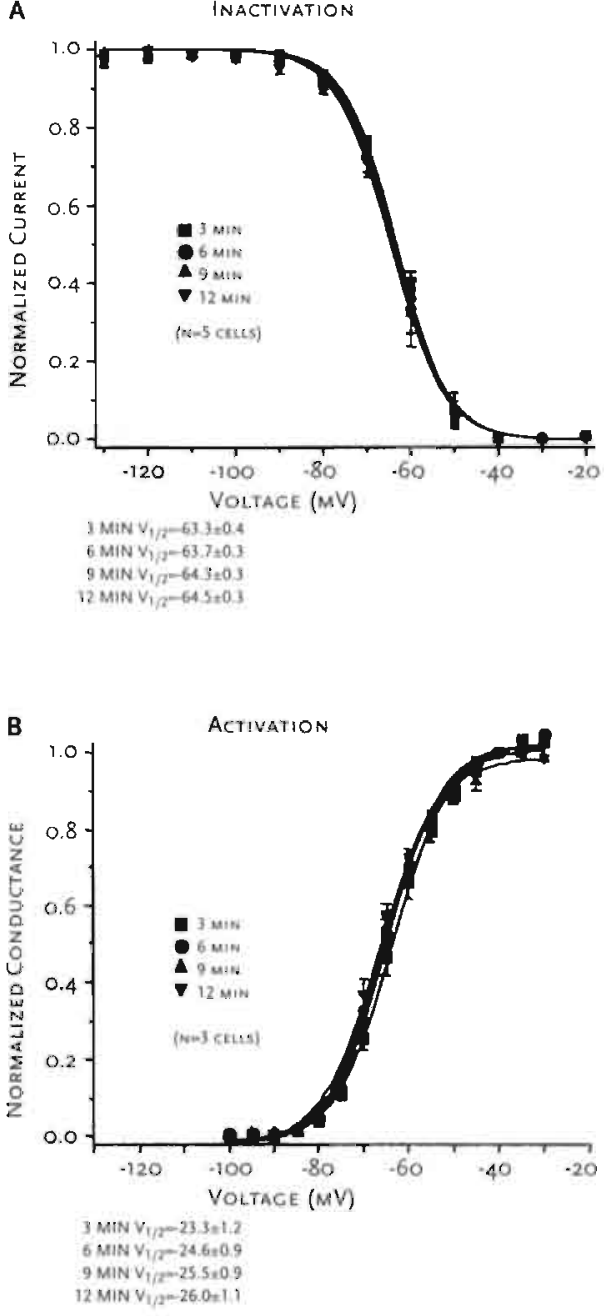

FIGURE 5.1

Stability of recordings with intracellular solution used in this study. Inactivation (A) and activation (B) curves recorded at the indicated times. We detect no significant change in the voltage. dependence of inactivation or activation over the recording periods used in this study. 
to ensure reproducibility, we systematically timed each experiment and thus restrict recording, times between $3 \mathrm{~min}$ and $8 \mathrm{~min}$ after rupturing the membrane to establish whole-cell conditions. pClamp 7 (Axon Instruments, Foster City, CA); EXCEL (Microsoft, Seatle, WA); and Origin (Microcal Software, Northampton, MA) were used for data acquisition and analysis. Protocols used have been described previously by us $(14,17)$. Holding potentials were $-80 \mathrm{mV}$ unless otherwise indicated. Control experiments of voltage-dependence of activation and inactivation with $-100 \mathrm{mV}$ holding potentials did not yield significantly different values. Data are represented as mean \pm SEM. Two-tailed Student's $t$-test was used to compare means; $\mathrm{P}<0.05$ was considered statistically significant.

\section{Results}

\section{Description of a New LQT-3 Mutation in a Patient with QTc Prolongation}

The patient, an 18 -year-old white man, was referred to us because of the documentation of QT-interval prolongation at medical checkup. No history of syncope and cardiac arrest was present. Family history was negative for syncope and sudden death. The 12-lead ECC showed normal sinus rhythm and normal atrioventricular and intraventricular conduction; a QT-interval prolongation (QTc D2: $480 \mathrm{~ms}$ ), in the absence of T wave morphological abnormalities, was aiso observed. No ventricular ectopies were found at 24 -hour Holter recording or elicited at the exercise stress test. Interestingly, QTc interval was shorter during relative tachycardia (both at Holter and exercise stress test, FICURES 5.2A and 5.2B), indicating a steep QT/R-R relationship. FIGURE 5.2C, which compares the relationship between $Q T$ and $R-R$ intervals for this proband and a noncarrier indicates almost a doubling of the QT/R-R slope for the proband. These data show an increased propensity to excessive QT prolongation at slow heart rate for the carrier of the EK mutation and suggest increased risk of arihythmia during bradycardia. This abnormal adaptation of the QT interval has been reported in carriers of LQT-3 mutations (33) but not in carriers of LQT-1 or LQT-2 mutations or in control subjects $(33.34)$. Thus, the clinical phenotype suggested the possibility of an LQT-3 lesion.

Analysis of the DNA of the proband by SSCP in fact revealed an abnormal conformer in the exon 22 of the SCN5A gene. Subsequent DNA sequence analysis of this 


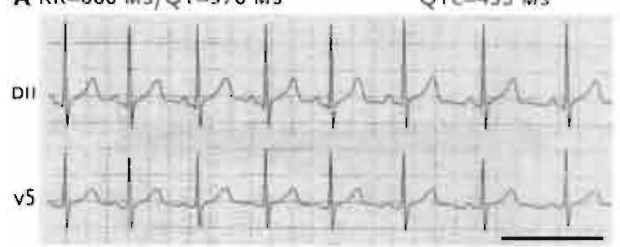

B RR $=1440 \mathrm{MS} / \mathrm{QT}=580 \mathrm{MS}$

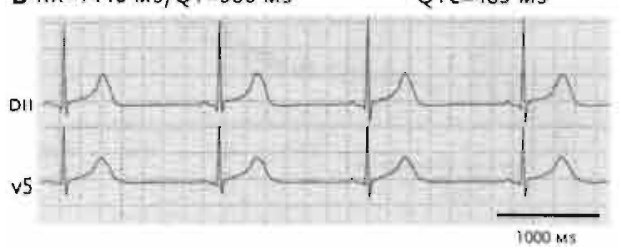

C

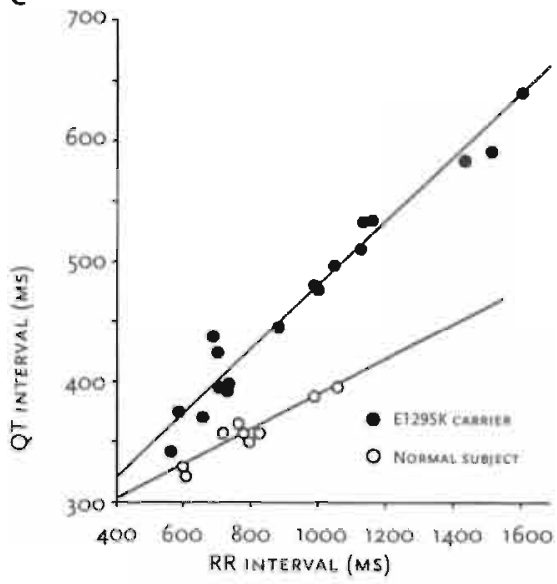

FIGURE 5.2

ECG recordings of the EK carrier during relative tochycardia (A) and bradycardia (B), showing the increase of QT corrected for heart rate with Bazett's formula (QTC) at slower heart rates. C, Analysis of the QT versus R-R interval relationship in the EK carrier measured in lead D2 during 12-lead Holter recording for the mutation carrier and for a healthy control subject the mother of the proband). The QT/R.R slopes were 0.254 and 0.145 for the EK patient and the control subject, respectively.

exon with specific primers for the regions of introns 21 and 22 flanking exon 22 showed a single nucleotide transition from $C$ to $A$ at the first base of the codon 1295 leading to the missense mutation Glu1295Lys, changing the charge at this location from negative to positive. Because this change in charge occurs close to the extracellular extremity of DIIIS4, a critical contributor to channel gating, we next sought to determine whether functional changes accompany this amino acid change.

\section{Biophysical Characterization of the EK Mutation in HEK293 Cells}

We performed a detailed characterization of mutant EK channels to look for biophysical properties that may explain the observed clinical phenotype. HEK293 cells transiently transfected with EK CDNA expressed $\mathrm{Na}^{+}$currents similar in amplitude and time course to WT channels (FIGURE 5.3A). Mean peak current density was not different in cells expressing WT or EK channels: $254 \pm 21 \mathrm{pA} / \mathrm{pF}(n=13)$ and $259 \pm 31 \mathrm{pA} / \mathrm{pF}(n=10)$, respectively. FICURE 5.3B shows that, in contrast to most of the previously reported LQT-3 mutations, we did not measure any mutation-induced increase in sustained current in response to voltage pulses applied near the expected peak of the I/V relationship $(-10 \mathrm{mV})$. The measured fractional tetrodotoxin (TTX)-sensitive current after $50 \mathrm{~ms}$ was $0.29 \pm 0.09 \%$ $(n=9)$ of peak current with WT channels and $0.24 \pm 0.07 \%(n=5)$ with mutant channels. We next fitted the time course of the onset of current inactivation with a monoexponential decay function, because it is possible that changes in inactivation kinetics may contribute to control of APD. In some cells, this fit could be slightly improved 
FICURE 5.3

A. Representative $\mathrm{Na}^{+}$currents in

HEK293 cells transiently transfected with WT and EK cDNAs. The currents were evoked by $25 \mathrm{~ms}$ pulses to voltages ranging from -80 to $\div 70 \mathrm{mV}$ (5 $\mathrm{mV}$ steps) with a $30 \mathrm{mmol} / \mathrm{L}$ $\mathrm{Na}^{+}$extracellular solution.

B. TX-sensitive current (30 $\mu \mathrm{mol} / L$ ) evoked by a test pulse to -10 $\mathrm{mV}$ (traces are average of 10 sweeps). Traces were normalized for comparison (peak $W T=5.5 n A$ and $E K=7.1 n A)$. Insets, same recordings but with expanded scale.
A

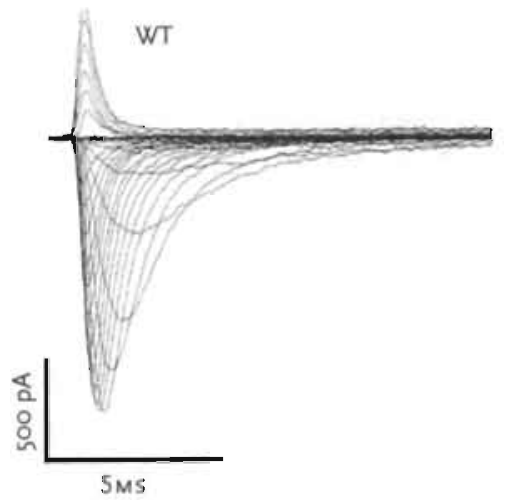

B
WT

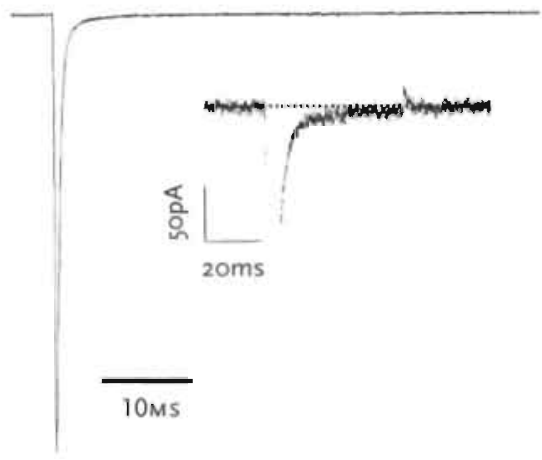

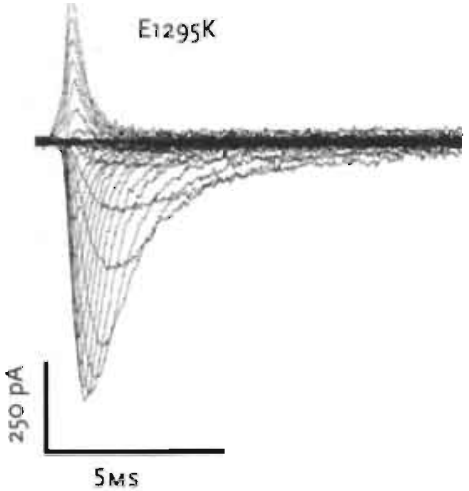

E1295K

when a biexponential function was used, but in these fits, the slower component of inactivation never exceeded $10 \%$ of the total weight (data not shown). Therefore, we used a monoexponential model for simplicity. The effect of the EK mutation on kinetics was restricted to the voltage range between -35 and $-20 \mathrm{mV}$ where it significantly slowed the onset of inactivation (FIGURE 5.4A). We then measured the time course of recovery from inactivation (RFI) (after a $100 \mathrm{~ms}$ conditioning pulse to $-10 \mathrm{mV}$ ) and observed a mutationinduced speeding of this process (FICURE 5.4B). Time constants and relative weights on the averaged data are as follows: $W T(0): \tau_{\text {fast }}=20.1 \mathrm{~ms}, a_{\text {fast }}=0.87, \tau_{\text {slow }}=446 \mathrm{~ms}$, $a_{\text {slow }}=0.13$; EK $(\bullet): \tau_{\text {fast }}=11.6 \mathrm{~ms}, a_{\text {fast }}=0.90, \tau_{\text {slow }}=464 \mathrm{~ms}, a_{\text {slow }}=0.10$. Time of halfrecovery $\left(T_{1 / 2}\right)$ from inactivation was significantly faster with EK channels than with WT channels when this parameter was determined for each individual cell: WT $T_{1 / 2}=18.2 \pm 4.0 \mathrm{~ms}(n=6)$ and $E K T_{1 / 2}=9.6 \pm 1.6 \mathrm{~ms}(n=8) ; P<0.05$. 
A

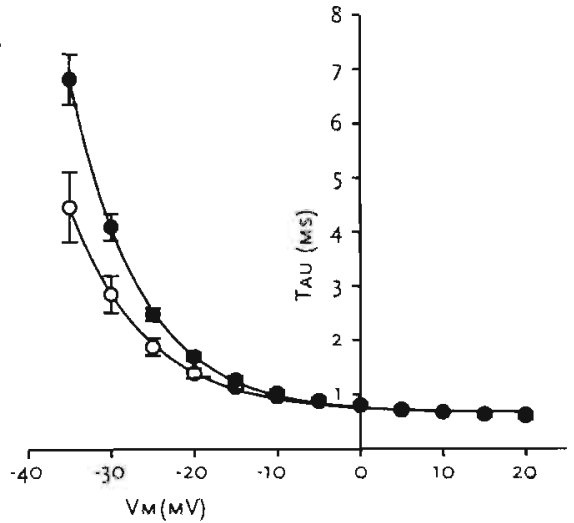

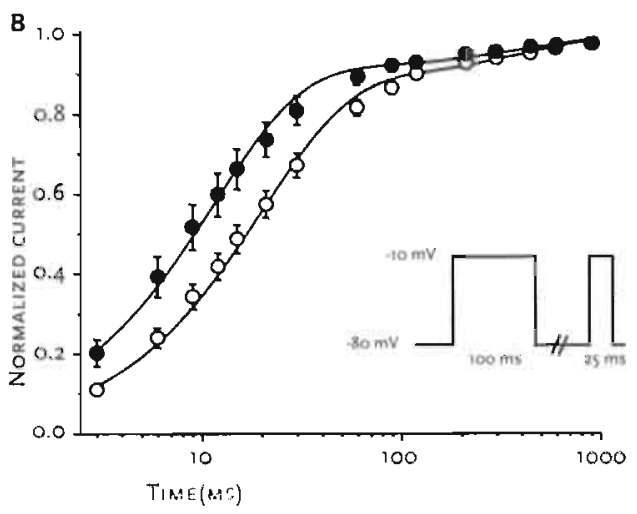

FIGURE: $5 \cdot 4$

A. Time constant of onset of inactivation of WT and EK channels fitted with a monoexponential decay versus command membrane voltage ( $n=6$ for $W T$ and $n=7$ for $E K$ )

B, Recovery from inactivation was fitted with a biexponential function (see results).

We next evaluated the effects of the EK mutation on the voltage dependence of steady-state activation and inactivation. Activation was determined from $I / V$ relationships by normalizing peak current to driving force and maximal current and plotting normalized conductance versus voltage (FIGURE 5.5). This analysis showed small but consistent positive shifts in activation. We detected a larger mutation-induced positive shift in the voltage dependence of inactivation that is also illustrated in FICURE 5.5. Boltzmann relationships were fitted to steady-state activation and inactivation data, and we obtained the following results. Slope factors of inactivation and activation were not different. For inactivation, $V_{1 / 2}:-65.2 \pm 0.2,-60.0 \pm 0.2 ; k: 6.1 \pm 0.2,6.1 \pm 0.1 \quad(n=13$ for $W T$ and $n=10$ for EK); for activation: $V_{1 / 2}:-21.5 \pm 0.3,-18.6 \pm 0.3 ; k: 6.9 \pm 0.3,6.7 \pm 0.2(n=6$ for $W T$ and $n=7$ for $E K$ ). All differences between inactivation and activation $V_{1 / 2}$ are statistically significant at $\mathrm{P}<0.01$.

\section{Mutation-induced Shift}

\section{in Window Current}

Are these effects on the voltage dependence of activation and inactivation related to the cellular phenotype: APD prolongation? Close inspection of the effects of the $E K$ curves in FIGURE 5.5 suggests that the mutation changes the window of voltages where these two curves overlap. To test for this, we used a slow-voltage ramp protocol

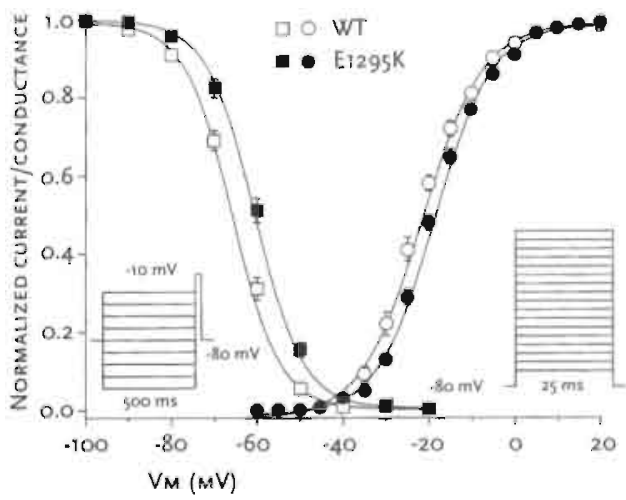

FICURE 5.5

Steady-state activation and inactivation relationships were measured with protocols presented in the insets. For pctivation measurements, peak currents were normalized to driving force to determine conductance. Fits to experimental data yielded the resulting Boltzmann parameters (see results). 
FICURE 5.6

Currents with WT, EK, and $\triangle K P Q$ channels elicited with a ramp protocol ranging from -100 to + $50 \mathrm{mV}$ in 2 seconds. Recordings shown are scaled for comparison and are TTX-subtracted (30 $\mu \mathrm{mol} / \mathrm{L})$. to measure window currents. Such slowly rising; voltage ramps promote inactivation of transient currents and have proven useful in the measurement of the voltage dependence of noninactivating $\mathrm{Na}^{+}$current for other LQT-3 mutations (35). We applied this protocol before and after the application of $30 \mu \mathrm{mol} / \mathrm{L} \Pi \mathrm{XX}$ to first measure and then subtract background currents. As illustrated in FICURE 5.6, we measured small $\mathrm{Na}^{+}$channel window current for WT and EK channels. Current density of the window current was not modified by the mutation (WT $=0.54 \pm 0.21 \mathrm{pA} / \mathrm{pF}(n=8) ; E K=0.40 \pm 0.12 \mathrm{pA} / \mathrm{pF}(n=10) ; N S)$. However, the peak: of the window current is shifted. The average voltage of the peak was shifted by about $+10 \mathrm{mV}$ by the EK mutation: $W T=$ $-44.5 \pm 1.3 \mathrm{mV}(\mathrm{n}=8)$ and $E K=-35.5 \pm 1.0 \mathrm{mV}$ $(n=10) ; P<0.001$. The $I / V$ relationship obtained from this protocol indicates a very restricted range of voltages over which noninactivating $\mathrm{Na}^{+}$current is expressed for the EK channel, a range of voltages that coincides only with the window of overlap between the two gating curves (FIGURE 5.5). Furthermore, this voltage dependence distinguishes; the activity of EK mutant channels from other LQT-3 mutant channels that conduct sustained channel activity over a broader voltage range and have a fundamentally distinct response to voltage-ramp protocols as illustrated by the $\triangle K P Q$ mutation $(\pi 6,35,36)$ in fIGURE 5.6. Moreover, note that peak $\triangle K P Q$ channel currents evoked with this protocol were on average 6 to 8 times larger than window currents $(3.44 \pm 0.84 \mathrm{pA} / \mathrm{pF}$; peak voltage $-15.0 \pm 0.6 \mathrm{mV} ; n=4)$, again pointing to a fundamental different mechanism underlying mutation-induced gating changes.

\section{Discussion}

\section{Novel Mechanism of APD Prolongation Linked to the LQT-3 Syndrome}

The main findings of this study are that a novel SCN5A mutation, which is linked to a clinical phenotype of LQT-3 (33), changes the biophysical properties of expressed 
channels in a manner that is distinct from previously reported LQT-3 mutations. In contrast with other previously investigated LQT-3 mutations such as the $\triangle K . P Q$ mutation, the EK mutation promotes sustained channel activity only over a very narrow window of voltages that differs from $W T$ channels only in the voltage range of the window. To significantly alter net membrane current, the mutation-induced window current must flow when currents through repolarizing channels are small.

\section{Heterogeneity in the Pathological Mechanisms in LQT-3}

Thus far, seven mutations linked with LQT-3 have been functionally studied $(18,20,35,37$ $40)$. Most of these mutations alter the fast inactivation properties of the channel-inducing sustained $\mathrm{Na}^{+}$current on prolonged membrane depolarization over a wide range of plateau voltages. Such a defect is consistent with an increase in inward current during the entire plateau phase of the AP, which consequently prolongs the APD. This is not the only mechanism by which LQT-3-linked $\mathrm{Na}^{+}$channel mutations are able to prolong cellular APD. Recent studies $(17,18)$ showed that an LQT-3 mutation in the carboxy-terminus region of the channel (D1790G), which does not produce persistent current different from WT channels, prolongs APD indirectly through effects on other ion channels. In the present work, we report yet a third mechanism by which an LQT-3 mutation is likely to prolong the cellular AP.

\section{Roles of $\mathrm{K}^{+}$Channel Rectification in EK Channel Cellular Phenotype}

It has been known for almost 50 years that the plateau phase of the cardiac AP is a period in which the cellular input impedance is maximal (3). Consequently, during this plateau, small changes in net ionic current will cause large changes in membrane potential. Repolarization of the AP normally begins when outward current through delayed rectifier $\left(I_{K s}\right.$ and $\left.I_{K r}\right)$ channels is sufficient to just balance and eventually exceed the total flow of inward current across the membrane. As repolarization begins, the cellular membrane potential reenters the voltage range for which $W T \mathrm{Na}^{+}$channels may again open to contribute as window current. This voltage range, however, coincides with voltages at which rectification of inward rectifier $\left(I_{K_{1}}\right)$ and HERG channels $(32,41,42)$ is relieved. Consequently, the effect of WT $\mathrm{Na}^{+}$channel window current is minimal. In the case of cells expressing EK channels, the range of voltages over which window current can flow is more positive, and the contribution of these channels is more pronounced because window current through them is activated over a voltage range in which rectification of $\mathrm{I}_{\mathrm{K}_{1}}$ and $\mathrm{I}_{\mathrm{Kr}}$ channels minimizes their contribution to total membrane current. 
Note that because the functional effects of this mutation are most pronounced when background $\mathrm{K}^{+}$channel currents are minimized, it is likely that the cellular (and hence systemic) effects of the mutation may be more pronounced in cells with smaller outward repolarizing current such as $M$ cells (43). If one assumes heterogeneity of repolarizing current across the ventricular wall (44), then it is likely that the effect of the EK mutation will be blunted in cells with higher density of outward currents. A difference between repolarization in different cell types might therefore exacerbate heterogeneity in APD within the myocardial wall and increase the likelihood of an arrhythmic event (45).

\section{Structure-function Relationship}

Glutamic acid (E1295), mutated into a positively charged lysine in this patient, is found in a 4-amino acid extracellular loop connecting DIIIS3 with DIIIS4. E1295 is the amino acid closest to DIIIS4, which is one of the voltage sensors for activation gating process of the channel (46). The presence of a negative residue just external to the DIIIS 4 segment is not only conserved among cardiac channels of different species but also among all different isoforms of the $\mathrm{Na}^{+}$channel. We postulate that this mutation-induced change in charge alters the voltage dependence of activation and/or inactivation gating sensor and that this is reflected by the recorded shifts in steady-state activation and inactivation curves. Window currents are found at voltages where there is overlap of the activation and inactivation curves, and as there is a concomitant shift of both, window currents are shifted accordingly (FICURE. 5.6). The EK mutation hastens the RFI after a $100 \mathrm{~ms}$ inactivating pulse. This observation is consistent with recent observations $(47,48)$ showing that movement of DIIIS 4 and DIVS 4 is coupled to fast inactivation. These changes in channel kinetics may also have to be taken into account when considering the basis of frequency-dependent changes in cellular electrical activity induced by the EK mutation.

\section{Clinical and Therapeutic Implications}

This study provides a further illustration that the LQT-3 type of LQTS is aggravated by bradycardia (FICURE 5.2). Beta-blockers are the mainstay in the management of the LQTS; however, the efficacy of this treatment in LQT-3 patients has been questioned (49) mainly because the decrease in heart rate that accompanies this treatment can enhance QT prolongation in LQT-3 carriers. Because the present study provides evidence that bradycardia markedly aggravates the phenotype (prolonged QT) in the case of the EK mutation, our results predict that beta-blockers may worsen the phenotype carriers of this 
mutation by slowing heart rate. Clearly, our results emphasize the importance of identifying the genotype of LQTS patients in general and LQT-3 patients in particular, before an optimum therapeutic regimen can be planned. For example, in the case; of the EK mutation, alternative strategies such as pacing (which prevents bradycardia) or administration of mexiletine (which by shifting the inactivation curve to more negative voltages may normalize the voltage dependence of the window current) might prove to be more effective in preventing arrhythmias.

\section{Implications for Drug-induced LQTS}

Our investigation into the functional consequence of the EK mutation on $\mathrm{Na}^{+}$activity provides one more example of the delicate interplay of small inward and outward currents that control the plateau phase of the cardiac AP. In the case of the EK mutation, there is no net increase in the magnitude of inward current flowing through $\mathrm{Na}^{+}$channels; instead, there is a shift in the voltages over which channels can reopen. Such small changes in the voltage-dependent properties of inward $\mathrm{Na}^{+}$channel current can have marked effects on APD only if they occur in the presence of a highly nonlinear background of outward $\mathrm{K}^{+}$channel currents (50). By inference, these results suggest that alteration in background $\mathrm{K}^{+}$channel activity against different patterns of $\mathrm{Na}^{+}$channel activity would be expected to have distinct effects on APD. It is interesting to speculate that subtle changes in $\mathrm{Na}^{+}$channel gating caused by coding changes in the $\alpha$-subunit, insufficient to cause substantial changes in cellular APD by themselves, may lead to excessive changes in APD in the face of inhibition of one of these key $\mathrm{K}^{+}$channels and thus contribute to some forms of drug-induced LQTS. Experiments are underway to test for this possibility.

\section{Acknowledgments}

This work was supported by United States Public Health Service Grant Rol-HL-56810-04 (to R.S.K.). H.A. was supported by the Swiss National Foundation for Fellowships in Medicine and Biology. 


\section{References}

1. Kass RS. ionic basis of electrical activity in the heart. In: Sperelakis N (ed). Physiology and pathophysiology of the heart. Norwell, Mass: Kluwer Academic 1984:83-96.

2. Antzelevitch C. Shimizu W, Yan GX, Sicouri S, Weissenburger J, Nesterenko WV, Burashnikov A, Di Diego J, Saffitz J. Thomas. GP. The M cell: its contribution to the ECG and to normal and abnormal electrical function of the heart. J Cardiovasc Electrophysiol 1999:10:1124-52.

3. Weidmann S. Effect of current flow on the membrane potential of cardiac muscle. J Physiol 1951:115:227-36.

4. Sanguinetti MC, Zou A. Molecular physiology of cardiac delayed rectifier $\mathrm{K}^{+}$chaninels. Heart Vessels 1997; Suppl 12:170-72.

5. Kass RS. Delayed potassium channels in the heart: regulatory and molecular properties. In: Morad M, Ebashi S, Trautweiin W, Kurachi Y (eds). Molecular physiology and pharmacology' of cardiac ion channels and transporters. Boston, Mass: Kluwer Academic Publishers 1994:74-82.

6. Moss A J, Robinson $\mathrm{LL}$. The long-QT syndrome: genetic considerations. Trends Cardiovasc Med 1993;2:81-83.

7. Moss AJ, Robinson J. Clinical features of the idiopathic long-QT syndrome. Circulation 1992;85(Suppl I):/140-44.

8. Priori SG, Barhanin ), Hauer RN, Haverkamp W, Jongsma HJ, Kleber AG, McKenna WJ, Roden DM, Rudy Y, Schwartz K, Schwartz P), Towbin JA, Wilde AA. Genetic and molecular basis of cardiac arrhythmias; impact on clinical management. Study group on molecular basis of arrhythmias of the working group an arrhythmias of the European Society of Cardiology. Eur Heart J 1999;20:174-95.

9. Schwartz PI, Locati EH, Napolitano C, Priori SG. The long-QT syndrome. In: Zipes DP, Jalife ! (eds.) Cardiac electrophysiology: from cell to bedside. New York, NY: WB Saunders; 1994:597-6its.

10. Keating MT, Sanguinetti MC. Pathophysiology of ion channel mutations. Curr Opin Genet. Dev 1996:6:326-33.

11. Sanguinetti MC, Spector PS. Potassium channelopathies. Neuropharmacology 1997;36:755-62.

12. Kameyama M, Kakei M, Sato R, Shibasaki T, Matsuda H, Irisawa $\mathrm{H}$. Intracellular $\mathrm{Na}^{+}$activates ai $\mathrm{K}^{+}$channel in mammalian cardiac cells. Nature (Lond) 1984:309:354:56.

13. Roden DM, Kupershmidt S. From genes to channels: normal mechanisms. Cardiovasc Res 1999;42:318-26.

14. An RH, Bangalore R, Rosero SZ, Kass RS. Lidocaine block of LQT-3 mutant human $\mathrm{Na}^{+}$channels. Circ Res 7996:79:103-08.

15. Wang DW: Yazawa K, Makita N, George AL, Bennett PB. Pharmacological targeting of long-QT mutant sodium channels. f Clin Invest 1997:99:1714-20.

16. Bennett $\mathrm{PB}$, Yazawa K, Makita N, George AL. Molecular mechanism for an inherited cardiac arrhythmia. Nature (Lond) 1995:376:683-85.

17. Wehrens XHT, Abriel H, Cabo C, Benhorin J, Kass RS. Arrhythmogenic mechanism of an LQT-3 mutation of the human heart $\mathrm{Na}^{+}$channe! $\alpha$-subunit: a computational analysis. Circulation 2000;102:584-90.

18. An RH, Wang XL, Kerem B, Benhorin !, Medina A, Goldmit M, Kass RS. Novel LQT-3 mutation affects $\mathrm{Na}^{+}$channel activity through interactions between $\alpha$ - and $\beta$ 1-subunits. Circ Res 1998;83:147-46.

19. Abriel H, Wehrens XHT, Benhorin 1, Kerem B, Kass RS. Molecular pharmacology of the sodium channel mutation Di79oG linked to the long-QT syndrome. Circulation 2000;102:921-25. 
20. Makita N, Shirai N, Nagashima M, Matsuoka R, Yamada Y, Tohse N, Kitabatake A. A de novo missense mutation of human cardiac $\mathrm{Na}^{+}$channel exhibiting novel molecular mechanisms of long. QT syndrome. FEBS Lett 1998;423:5-9.

21. Clancy $C E$, Rudy $Y$. Linking a genetic defect to its cellular phenotype in a cardiac arrhythmia. Nature (Lond) 1999;400:566-69.

22. Attwell D, Cohen I, Eisner D, Ohba M, Ojeda C. The steady state TX-sensitive ("window") sodium current in cardiac Purkinje fibres. Pflugers Arch 1979:379:137-42.

23. Hirano $Y$, Moscucci A, January CT. Direct measurement of L-type $\mathrm{Ca}^{2+}$ window current in heart cells. Circ Res 1992;70:445-55.

24. Wasserstrom /A, Salata J). Basis for tetrodotoxin and lidocaine effects on action potentials in dog, ventricular myocytes. Am J Physiol 7988;254:Hirs;-66.

25. Sakmann B, Trube G. Conductance properties of single inwardly rectifying potassium channels in ventricular cells from guinea-pig heart. J Physiol (Lond) 1984:347:641-57.

26. Backx PH, Marban E. Background potassium current active during the plateau of the action potential in guinea pig ventricular myocytes. Circ Res 1993:72:890-900.

27. Kass RS. Genesis of cardiac arrhythmias: roles of calcium and delayed potassium channels in the heart. In: Andreoli T, Fambrough D, Hoffman J, Welsh M, Schultz S, Brown AM (eds). Molecular biology of membrane transport disorders. New York, NY: Plenum 1994:595-604.

28. Barry DM, Nerbonne JM. Myocardial potassium channels: electrophysiological and moleculat diversity. Annu Rev Physiol 1996;58:363-94.

29. Schonherr R, Heinemann SH. Molecular determinants for activation and inactivation of HERC, a human inward rectifier potassium channel. J Physiol (Lond) 7996;493:635-42

30. Smith PL, Baukrowitz T, Yellen G. The inward rectification mechanism of the HERG cardiac potassium channel. Nature (Lond) 1996;379:833-36.

31. Sanguinetti MC, Jurkiewicz NK. Two components of cardiac delayed rectifier $\mathrm{K}+$ current: differential sensitivity to block by class III antiarrhythmic agents. J Gen Physiol 1990;96:195-215.

32. Sanguinetti $M C_{\text {, Jiang }} C_{1}$ Curran $M E$, Keating $M T$. A mechanistic link between an inherited and an acquired cardiac arrhythmia: HERG encodes the $\mathrm{I}_{\mathrm{Kr}}$ potassium channel. Cell 1995;81:299-307.

33. Schwartz PJ, Priori SG, Locati EH, Napolitano C, Cantu F, Towbin JA, Keating MT, Hammoude H, Brown AM, Chen LSK, Colatsky TJ. Long-QT syndrome patients with mutations of the SCNSA and $H E R C$ genes have differential responses to $\mathrm{Na}^{+}$channel blockade and to increases in heart rate: implications for gene-specific therapy. Circulation 1995;92:3381-86.

34. Swan H, Viitasalo M, Piippo K, Laitinen P, Kontula K, Toivonen L. Sinus node function and ventricular repolarization during exercise stress test in long-QT syndrome patients with KVLQT and HERG potassium channel defects. J Am Coll Cardiol 1999;34:823-29.

35. Wang DW, Yazawa K, Ceorge AL Jr, Bennett PB. Characterization of human cardiac $\mathrm{Na}^{+}$channel mutations in the congenital long-QT syndrome. Proc Nat/ Acad Sci U S A 1996,93:13200-05.

36. Wang Q, Shen J, Splawski I, Atkinson D, Li Z, Robinson JL, Moss AJ, Towbin JA, Keating: MT. SCNSA mutations associated with an inherited cardiac arrhythmia, long-QT syndrome. Cell 1995;80:805-11.

37. Dumaine R, Wang Q, Keating MT, Hartmann HA, Schwartz. PI, Brown AM, Kirsch GE. Multiple mechanisms of $\mathrm{Na}^{+}$channel linked long-QT syndrome. Circ Res 1996;78:916-24.

38. Kambouris NC, Nuss HB, Johns DC, Tomaselli GF, Marban E, Balser JR. Phenotypic characterization of a novel long-QT syndrome mutation (R1623Q) in the cardiac sodium channel.

Circulation 1998;97:640-44. 
39. Bezzina C, Veldkamp MW, Van Den Berg MP, Postma AV, Rook MB, Viersma JW, Van Langen IM, Tan-Sindhunata G, Bink-Boelkens MT, Der Hout AH, Mannens MM, Wilde AA. A single $\mathrm{Na}^{+}$channel mutation causing both long-QT and Brugada syndromes. Circ Res 1999;85:1206-13.

40. Wei J, Wang DW, Alings M, Fish F, Wathen M, Roden DM, George AL Jr. Congenital long-QT syndrome caused by a novel mutation in a conserved acidic domain of the cardiac $\mathrm{Na}^{+}$channel. Circulation 1999;99:3165-71.

41. Spector PS, Curran ME, Zou A, Keating MT, Sanguinetti MC. Fast inactivation causes rectification of the I $\mathrm{K}_{\mathrm{r}}$ channel. I Gen Physiol 1996;107:611-19.

42. Kass RS, Sanguinetti MC. Calcium channel inactivation in the cardiac Purkinje fiber: evidence for voltage-and calcium-mediated mechanisms. J Cen Physiol 1984;84:705-26.

43. Liu DW, Antzelevitch C. Characteristics of the delayed rectifier current $\left(I_{\mathrm{Kr}}\right.$ and $\left.I_{\mathrm{Ks}}\right)$ in canine ventricular epicardial, midmyocardial, and endocardial myocytes: a weaker $I_{K_{s}}$ contributes to the longer action poteritial of the M cell. Circ Res 1995;76:357-65.

44. Antzelevitch C. The M cell. J Cardiovasc Pharmacol Ther 1997;2:73-76.

45. Antzelevitch C. Electrical heterogeneity, cardiac arrhythmias, and the sodium channel. Circ Res 2000;87:964-65.

46. Catterall WA. From ionie currents to molecular mechanisms: the structure and function of voltagegated sodium channels. Neuron 2000;26:13-25.

47. Cha A, Ruben PC, George AL Jr, Fujimoto E, Bezanilla F. Voltage sensors in domains III and IV, but not I and II, are immobilized by $\mathrm{Na}^{+}$channel fast inactivation. Neuron 1999;22:73-87.

48. Sheets MF, Kyle JW, Hanck DA. The role of the putative inactivation lid in sodium channel gating current immobilization. J Gen Physiol 2000;115:609-20.

49. Moss Al, Zareba W, Hall W], Schwartz PJ, Crampton RS, Benhorin J, Vincent GM, Locati EH, Priori SC, Napolitano C, Medina A, Zhang L, Robinson JL, Timothy K, Towbin JA, Andrews ML. Effectiveness and limitations of beta.blocker therapy in congenital long.QT syndrome. Circulation 2000;101:616-23.

50. Noble D. lonic mechanisms in normal cardiac activity. In: Jalife J, Zipes DP (eds). Cardiac Electrophysiology. Philadelphia, Pa: WB Saunders 1990. 


\section{Chapter 6}

\section{tía}

Heterozygous SCN5A Mutation in the Domain 1-11 Linker causes Long-QT Syndrome with 2:1 Atrioventricular Block
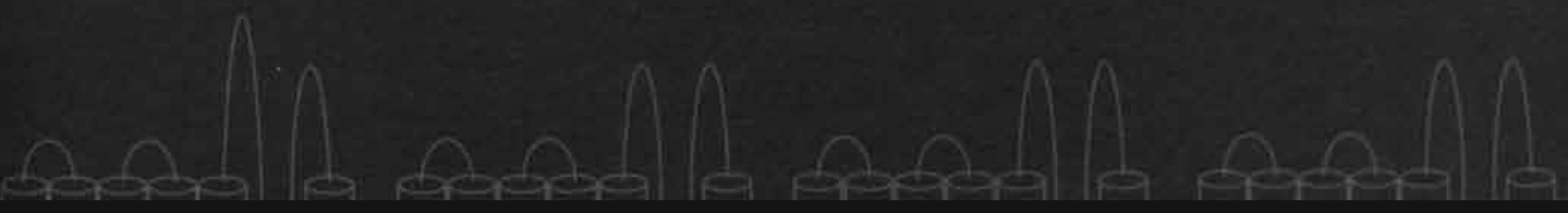

\section{Based on:}

WeHrens XHT, Rossenbacker T, Jongbloed Rf, Gewillig M, Heidbüchel H,

Doevendans PA, Vos MA, Wellens HJ\}, Kass RS. Submitted. 


\section{Abstract}

BACKGROUND. Congenital long-QT syndrome type 3 (LQT-3) is caused by mutations in the gene encoding the $\alpha$-subunit of the cardiac $\mathrm{Na}^{+}$channel (SCN5A). Previous studies have linked homozygous mutations in SCN5A and the $\mathrm{K}^{+}$channel gene KCNH2 (HERG) to congenital long-QT syndrome with functional 2:1 atrioventricular block (AVB), a severe phenotype with a particularly bad prognosis.

METHODS AND RESULTS. In an infant with 2:1 AVB and major QTC prolongation $\left(657 \mathrm{~ms}^{1 / 2}\right)$, mutational analysis identified a heterozygous missense mutation ( $\mathrm{L619F}$ ) in the domain I-II linker of the cardiac $\mathrm{Na}^{+}$channel. Whole-cell patch-clamp analysis of recombinant $\mathrm{L}_{61 \mathrm{~g}} \mathrm{~F}$ mutant channels expressed in HEK293 cells showed a mutation. induced increase in persistent TTX-sensitive inward sodium current (WT: 0.26 \pm 0.06 ; L619F: $0.79 \pm 0.17 \mathrm{pA} / \mathrm{pF} ; \mathrm{P}<0.01$ ). In addition, a $5.8 \mathrm{mV}$ positive shift in the voltagedependence of inactivation caused a shift in the peak voltage (WT: $-44.3 \pm 0.7 ; \mathrm{L6} 19 \mathrm{~F}$ : $-40.7 \pm 0.9 \mathrm{mV} ; \mathrm{P}<0.05)$, and an increase in the amplitude of $\mathrm{Na}^{+}$channel 'window-current' (WT: $0.58 \pm 0.12 ; \mathrm{L}$ 619F: $1.07 \pm 0.17 \mathrm{pA} / \mathrm{pF} ; \mathrm{P}<0.05$ ).

Discussion. This study provides the first evidence that a heterozygous missense mutation in SCN5A may cause LQT-3 with functional 2:1 AVB in an infant. The L619F mutation promotes an increase in sustained (non-inactivating) current as well as an increase in $\mathrm{Na}^{+}$channel window-current, two mechanisms which are expected to delay ventricular repolarization. The defective inactivation imposed by the L619F mutation implicates a novel role for the domain $\mathrm{I}-1 \mathrm{l}$ linker in the $\mathrm{Na}^{+}$channel inactivation process. 


\section{Introduction}

Congenital long-QT syndrome (LQTS) is an inherited disorder characterized by prolonged ventricular repolarization and a propensity to sudden cardiac death caused by polymorphous ventricular tachycardia (torsades de pointes; TdP). LQTS is considered a pure 'electrical disease', and is usually not associated with congenital heart, disease or acquired cardiac disabilities $(1,2)$. The symptoms of L.QTS may surface at any age as episodic dizziness, syncope, epileptic seizures, and sudden cardiac death. LQTS may also be involved in some cases of sudden infant death syndrome (3).

Long-QT syndrome in association with two-to-one atrioventricular block (AVB) typically occurs in fetuses, neonates and young infants, and is probably the result of a severely prolonged action potential duration in association with a relatively long effective refractory period of the His-Purkinje system and/or the ventricular myocardium $(4,5)$. It has been suggested that LQTS resulting in AVB in the neonatal period has a particularly poor prognosis $(6,7)$. Despite traditional management with beta-adrenergic blockade and/or cardiac pacing, a large proportion of infants may not survive childhood (6).

Recently, three reports described the association of homozygous mutations in the KCNH2 (HERG) $(8,9)$ and SCN5A genes (10) with a severe cardiac phenotype involving marked prolongation of the QT-interval and 2:1 AVB. In contrast, heterozygous carriers were free of symptoms, and had normal or marginally prolonged QTc intervals. In the present study, we describe the first case of an LQTS patient with functional 2:1 AVB due to a heterozygous mutation of the SCN 5 A gene. Biophysical characterization of the $S C N_{5} A$ mutation $\mathrm{L} 619 \mathrm{~F}$ revealed a novel combination of enhanced non-inactivating $\mathrm{Na}^{+}$channel activity during prolonged depolarization with increased $\mathrm{Na}^{+}$channel window current, two channel properties that, by themselves, would be expected to delay repolarization and prolong the QT-interval (11). Moreover, the location of the $\mathrm{L} 619 \mathrm{~F}$ mutation in the domain I-II linker suggests a novel role of this region in $\mathrm{Na}^{+}$channel inactivation. 


\section{Materials and Methods}

\section{Clinical Data}

The study was performed according to a protocol approved by the Leuven University ethics committee and informed consent was obtained. The patient studied was the second child of asymptomatic, non-consanguineous Western European parents.

\section{Mutation Analysis}

Genomic DNA was extracted from peripheral blood lymphocytes using standard techniques. The entire coding regions of the known LQTS genes were amplified using PCR. Denaturing high performance liquid chromatography (D-HPLC; Wave Transgenomics) was performed to analyze the KCNQ1, KCNH 2 and $K C N E_{2}$ genes. The KCNE1 and $S_{1} C N_{5} A$ gene were analyzed by sequence analysis of the complete coding region by the Big-Dye terminator ready reaction kit (PE Applied Biosystems) on an ABI-3100 genetic analyzer (PE Applied Biosystems). The mutation L619F was excluded in a control panel of 150 (300 alleles) healthy individuals.

\section{Construction and Expression of Recombinant $\mathrm{Na}^{+}$Channels}

The mutant $h_{1} H_{1} \mathrm{C}_{1855}$ T was engineered using the QuikChange-XLTM site-directed mutagenesis kit (Stratagene, La Jolla, CA) using the following mutagenic sense and antisense primers: 5'-CC.CCA.CGA.AGC.CAC.CTC.ITC.CGC.CCT.GTG.ATG.CTA.G-3' 5'-C.TAC.CAT.CAC.AGG.GCG.GAA.GAG.GTG.GCT.TCC.TCG.GG-3'

$\mathrm{Na}^{+}$channels were expressed in HEK293 cells. Transient transfections of wild-type (WT) and $\mathrm{L}_{619} \mathrm{~F}$ mutant $\mathrm{Na}^{+}$channels were carried out with equal amounts of $\mathrm{Na}^{+}$channel $\alpha$-subunit, $\beta 1$-subunit, and CD-8 antigen CDNA subcloned individually into the pCDNA3.1 (Invitrogen) vector (total CDNA $2.5 \mathrm{mg}$ ) using a previously-described procedure (12). Transfected cells were identified by light microscopy and the use of anti-CD8-coated beats (Dynabeads M 450 CD8).

\section{Electrophysiology}

Membrane currents were measured ușing whole-cell patch-clamp procedures, with Axopatch $200 \mathrm{~B}$ amplifiers (Axon Instruments, Foster City, CA). Recordings were made at room temperature $\left(22^{\circ} \mathrm{C}\right)$ using an internal solution containing $(\mathrm{mmol} / \mathrm{L}) \mathrm{CsCl} 6 \mathrm{O}$, cesium aspartate 80, EGTA $11, \mathrm{MgCl}_{2}, \mathrm{CaCl}_{2}$, (effective free calcium $100 \mathrm{nmol} / \mathrm{L}$ ), HEPES 10, 
and $\mathrm{Na}_{2}$ ATP $5, \mathrm{pH}$ adjusted to 7.2 with $\mathrm{CsOH}$. In experiments recording I/ $\mathrm{V}$ curves, external $\mathrm{Na}^{+}$was reduced to $30 \mathrm{mmol} / \mathrm{L}$ using $\mathrm{n}$-methyl-glucamine as a $\mathrm{Na}^{+}$substitute. The use of these solutions in our experiments allowed us to make very stable recordings with minimal time-dependent changes in voltage-parameters of activation and inactivation (13). Protocols to analyze mutant channel gating have been described previously $(13,14)$.

\section{Statistical Analysis}

Data were collected and analyzed with pClamp8 (Axon Instruments, Foster City, CA); Excel (Microsoft, Seattle, WA); and Origin (Microcal Software, Northampton, MA). Data are represented as mean \pm SEM. Two-tailed Student $t$-test was used to compare means; $P<0.05$ was considered statistically significant.

\section{Results}

\section{Clinical Characteristics}

The mother of the index patient was referred at a gestational age of 27 weeks for ultrasound evaluation because of fetal bradycardia and a large perimembraneous ventricular septal defect. Echography at 35 weeks revealed AVB with ventricular bradycardia: of $72 \mathrm{bpm}$. Maternal serum was negative for anti-SSA/Ro antibodies.

A female baby, weighing 2840 gram, was born prematurely at 36 weeks of gestation by uneventful vaginal delivery. Initial ECG after birth showed sinus rhythm of 139 bpm, normal atrioventricular conduction, signs of pre-excitation, and a prolonged QTC interval of $538 \mathrm{~ms}^{1 / 2}$ (FICURE 6.1A). Serum levels of potassium, magnesium, and calcium were within normal limits. No evidence of impaired hearing was found. In the second week after birth, symptomatic 2:1 AVB developed when sinus rate exceeded 140 bpm. Treatment with propranolol was instituted $(3 \times 3 \mathrm{mg} /$ day) in order to slow the sinus rhythm to allow $1: 1$ AV conduction. Continuous ECG recording (Holter) performed on day 10 after birth confirmed frequency-dependent conduction anomalies with episodes of 2:1 AVB (FIGURE 6.1B), and intermittent pre-excitation without documented episodes of supraventricular tachycardias. A clinical challenge with mexiletine had no effect on the QTc interval. Digoxin therapy was initiated in order to prevent development of cardiac failure in anticipation of the closure of the ventricular septal defect. Patient was discharged on beta-blocker and 
FICURE 6.1

(A) Leads $V_{2}$ and $V_{3}$ of a 12 -lead electrocardiogram at day one after birth showing 1-to-1 strioventricular conduction, delta. waves (arrow) indicative of pre. excitation, and QT-interval prolongation. (B) Two lead electrocardiogram from 24-hour recording at 10 days of age, showing 2:1 atrioventricular conduction. (C) Analysis of the QT versus $R-R$ interval relationship in the L619F carrier flead II during Holter recording at different heart rates) revealed $Q T / R-R$ slopes of 0.703 and 0.407 for the proband and an age-matched control subject, respectively.
A

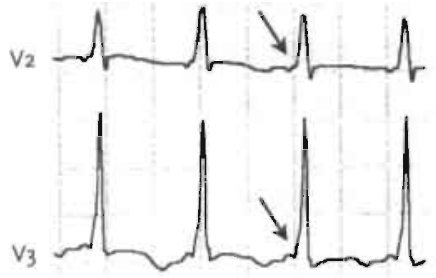

B

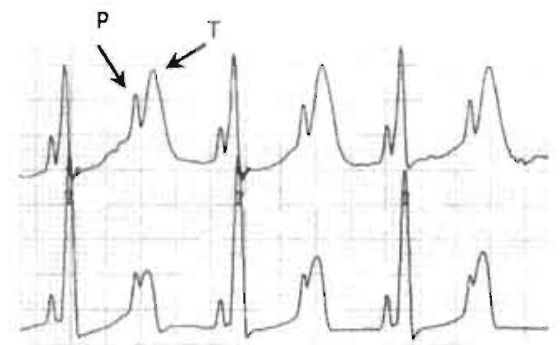

C

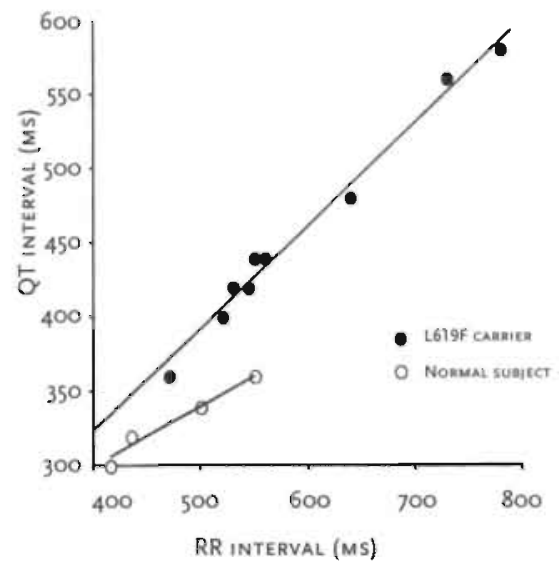

digoxin therapy in combination with cardiac home monitoring. Two weeks later, while temporarily disconnected from the monitor for breast feeding, patient underwent a period of paleness and hypotonia, which could be rapidly reversed by mouth-to-mouth resuscitation by the father. Evaluation in hospital showed sinus rhythm, prolonged QTintervals, and intermittent episodes of 2:1 AVB, which were clinically well tolerated. Breast feeding was discontinued and propranolol increased to $4 \times 3 \mathrm{mg} /$ day. Subsequent follow-up until 11 months of age is uneventful, with QTc values ranging between 481 and $657 \mathrm{~ms}^{1 / 2}$. Despite several weeks of continuous monitoring, and multiple Holter and ECC recordings, no ventricular ectopy has ever been observed in the first year of life. At the age of 5 months, digoxin therapy was discontinued and the ventricular septal defect was surgically closed.

FICURE 6.IC, which compares the relationship between QT and R-R intervals for the proband and an age-matched non-carrier indicates almost a doubling of the QT/R-R slope for the proband. These data show an increased propensity to excessive QT prolongation at slow heart rate for the carrier of the L61gF mutation and suggest increased risk of arrhythmia during bradycardia. This abnormal adaptation of the QT-interval has been reported in carriers of LQT-3 mutations $(13.15)$, but not in carriers of LQT-1 or LQT-2 mutations or in control subjects (15). Thus, the clinical phenotype suggests the possibility of an LQT-3 lesion. 
None of the family members had experienced any symptoms related to LQTS. The father has normal QTc intervals, the mother has a borderline positively prolonged QTC interval of $450 \mathrm{~ms}^{1 / 2}$, and information for the older sibling is lacking.

\section{Identification of the SCN5A Mutation}

Bidirectional sequencing analysis of the $S C N 5 A$ gene revealed a single nucleotide transition (C-T) at position 1855 , which is expected to cause a change from a leucine (L) to a phenylalanine $(F)$ at codon 619 within the cytoplasmic linker between domains I and II (FIGURE 6.2). In addition, D-HPLC analysis of the proband revealed a heteroduplex fragment with abnormal elution profile in the KCNE2 gene, and subsequent sequence analysis revealed the common polymorphism T8A-MiRP 7 in the KCNE2 gene (16).

The L619F mutation in SCN5A and polymorphism in KCNE2 were also present in the mother, but not in the father. No mutations were identified within the KCNQ1, KCNH2, and KCNE7 genes.

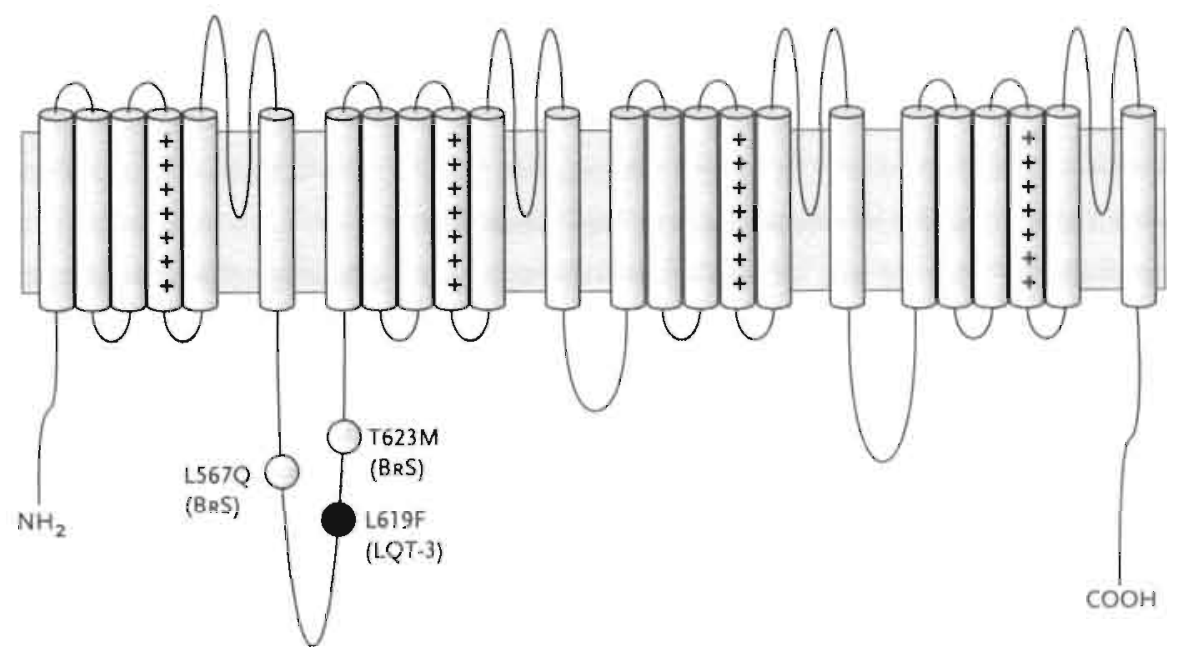

FIGURE 6.2

Arrhỵthmogenic SCNSA mutations in the domain I=11 linker of the cardiac sodium channel protein. Topological model of the shannel is illustrated with location of 2 Brugada syndrome mutations $(2567 Q$. T632M), and the LQT.3 mutation L619F of the present study. 
FIGURE 6.3

(A) Representative $\mathrm{Na}^{+}$currents in

HEK293 cells transiently transfected with WT or $\mathrm{L}_{619} \mathrm{~F}$ cDNA. Currents in $30 \mathrm{mmol} / \mathrm{L}$ $\mathrm{Na}^{+}$extracellular solution were evoked by $25 \mathrm{~ms}$ pulses from a holding potential of $-100 \mathrm{mV}$ to

$-60,-25,-10$, and $+20 \mathrm{mV}$, respectively. (B) $\Pi \mathrm{XX}$-sensitive current $(30 \mu \mathrm{mol} / \mathrm{L})$ in $130 \mathrm{mmol} / \mathrm{L} \mathrm{Na}^{+}$extracellular solution evoked by a test pulse from-100 $\mathrm{mV}$ to - $10 \mathrm{mV}$ (traces are average of 10 sweeps).
WT

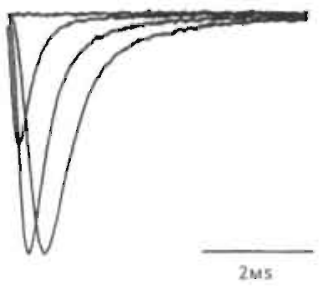

L619F

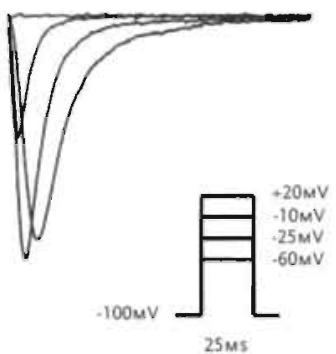

8

CURRENT WT

DENSITY

$(\mathrm{PA} / \mathrm{PF})$

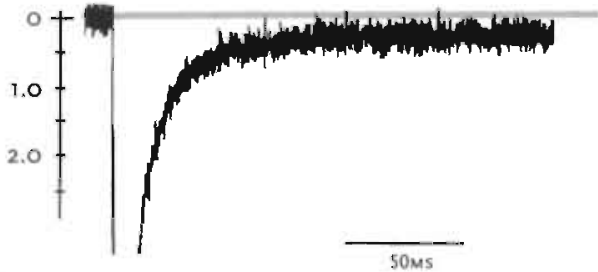

CURRENT DENSITY $(P A / P F)$

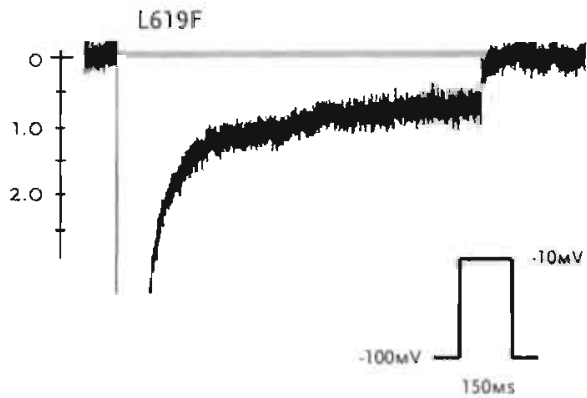

\section{Biophysical Properties of L6ıgF Mutant $\mathrm{Na}^{+}$Channels}

Macroscopic $\mathrm{Na}^{+}$current was recorded from HEK 293 cells expressing wild-type $\left(h_{1} \mathrm{H}_{7} / \mathrm{WT}\right)$ and mutant channels ( $h H_{1} / L_{619 F}$. Peak current density was not affected by the $\mathrm{L}_{619} \mathrm{~F}$ mutation (WT: $362 \pm 40 \mathrm{pA} / \mathrm{pF}(\mathrm{n}=12)$; L619F: $301 \pm 33 \mathrm{pA} / \mathrm{pF}(n=10)$; $\mathrm{P}=\mathrm{NS})$ ). At low recording gain, there is no marked difference between the waveforms of WT and L61gF channels (FICURE 6.3A), but at higher gain, recordings reveal a mutation-induced increase in sustained channel activity (FIGURE 6.3B). Assayed as the tetrodotoxin (TTX)-sensitive current at $-10 \mathrm{mV}$ and $150 \mathrm{~ms}$, this mutation-induced increase in sustained current is significant (WT: $0.26 \pm 0.06 \mathrm{pA} / \mathrm{pF}(n=9) ; \mathrm{L} 61 \mathrm{FF} 0.79 \pm 0.17 \mathrm{pA} / \mathrm{pF}(n=9) ; P<0.01)$.

The L619F mutation does not affect the kinetics of the onset of inactivation (FIGURE 6.4A), but almost halves the time for recovery from inactivation (RFI) (FIGURE 6.4B). $T_{1 / 2}$ (time to half recovery from inactivation) was $2.78 \pm 0.19 \mathrm{~ms}$ for WT $(n=12) ; 1.45 \pm 0.12 \mathrm{~ms}$ for $\mathrm{L}_{1 \mathrm{~g}} \mathrm{~F}(\mathrm{n}=10) ; \mathrm{P}<0.001$. Similar speeding of the RFI for L61gF was measured when the holding potential was $-60 \mathrm{mV},-80 \mathrm{mV}$, or $-120 \mathrm{mV}$ (data not shown).

$\mathrm{L} 6.9 \mathrm{~F}$ also results in $\mathrm{a}+5.8 \mathrm{mV}$ shift in the voltage-dependence of channel availability (WT: $-64.0 \pm 0.8 \mathrm{mV}(n=8)$; L619F: $-58.2+1.1 \mathrm{mV}(\mathrm{n}=10)$; P<0.0.5) (FIGURE 6.5.A). 
A

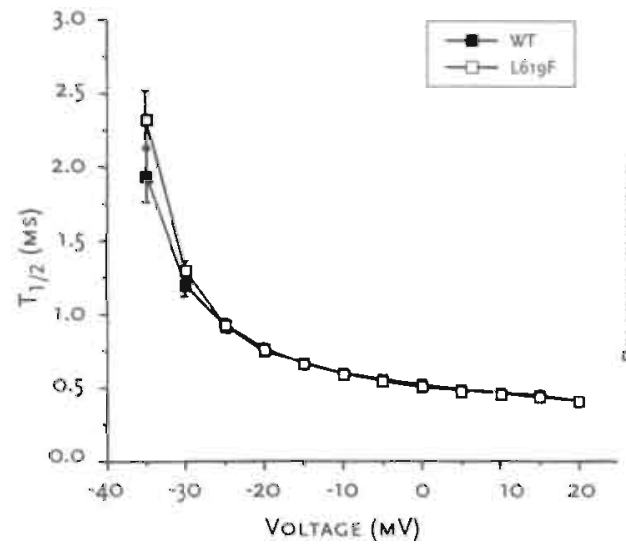

B

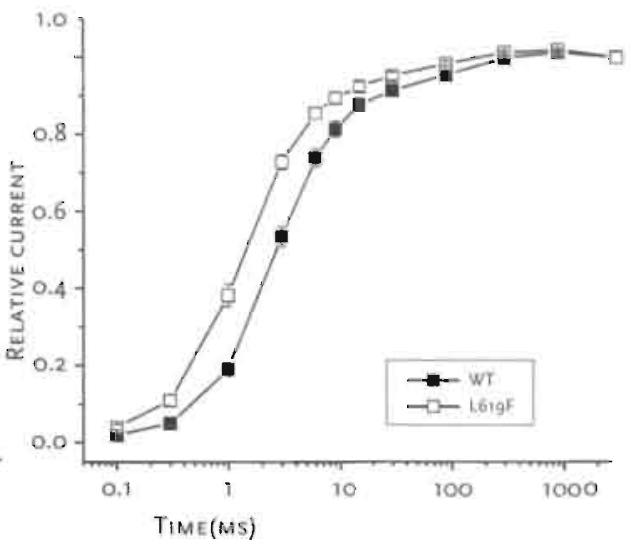

FIGURE 6.4

(A) The L619F mutation does not affect the onset of inactivation kinetics. Time to $50 \%$ inactivation was similar for WT and L619F channels. (B) The L6rgF mutation speeds recovery from inactivation (RFI). RFi was fitted with a bi-exponential function for each individual experiment: the time constants and relative weights on the averaged data are: WT: Tfost $=3.21 \mathrm{~ms}, a_{\text {fast }}=0.87$, $\tau_{\text {slow }}=79.2 \mathrm{~ms}, a_{\text {slow }}=0.13$; and for L61gF: Tfost $=1.75 \mathrm{~ms}, a_{\text {fart }}=0.88$, $\tau_{\text {slow }}=42.5 \mathrm{~ms}, a_{\text {slow }}=0.12$.

A positive shift in the voltage-dependence of channel availability, in the absence of a change in the voltage-dependence of activation, would be expected to change the window of voltages where non-inactivating (window) current can be measured (17). In combination with the mutation-induced increase in sustained current at voltages outside of this window of activation/inactivation overlap (FIGURE 6.3B), the data predict that the L619F mutation should cause marked changes in the voltage-dependence of steady-state (non-inactivating) $\mathrm{Na}^{+}$channel current. We used a ramp voltage protocol for which voltage-changes are imposed at a sufficiently slow rate to reveal steady-state $\mathrm{Na}^{+}$channel currents as a function of membrane potential (13). The L619F mutation increases the current density of the peak window current (WT: $0.58 \pm 0.12 \mathrm{pA} / \mathrm{pF}(n=7)$; L619F: $1.09 \pm 0.17 \mathrm{pA} / \mathrm{pF}(n=7)$ : $P<0.05)$, and shifts the voltage at which the maximum window current occurs by $+3.6 \mathrm{mV}$ (WT: $-44.3 \pm 0.7 \mathrm{mV}(n=7)$; L619F: $-40.7 \pm 0.9 \mathrm{mV}(n=7) ; P<0.01)$ (F!GURE 6.58), consistent with the effects of the mutation on the voltage-dependence of activation and inactivation. In addition, the window current waveform also indicates the presence of non-inactivating channels over a broad voltage-range as evidenced by the 'shoulder' in the curve (see the arrow in FICURE 6.5B). Thus, the voltage-dependence of the non-inactivating component of L619F channel activity is due to both the overlap in steady-state activation and channel availability (FIGURE. 6.5A) as well as to mutation-induced sustained $\mathrm{Na}^{+}$current (FIGURE 6.3B). 
FICURE 6.5

(A) Vohage-dependence of inactivation but not activation is modified by the L619F mutation.

For octivation measurements, peak currents were normalized to driving force to determine conductance. $\#$ P $<0,001$. (B) Currents with WT and L6rgF channels elicited with a ramp protocol ranging from $-100 \mathrm{mV}$ to

$+50 \mathrm{mV}$ in 25 . The presented recordings are normalized to capacitance, and are TTX. subtracted (30 $\mathrm{mmol} / \mathrm{L})$. Averaged L619F window current was larger.

The arrow indicates non. inactivating channels over a broad voltage-range as evidenced by the 'showider' in the curve.
A

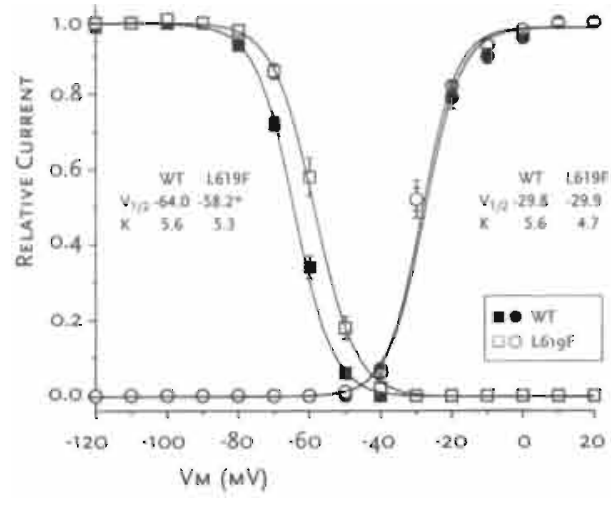

CURRENT

DENSITY

$(\mathrm{PA} / \mathrm{PF})$

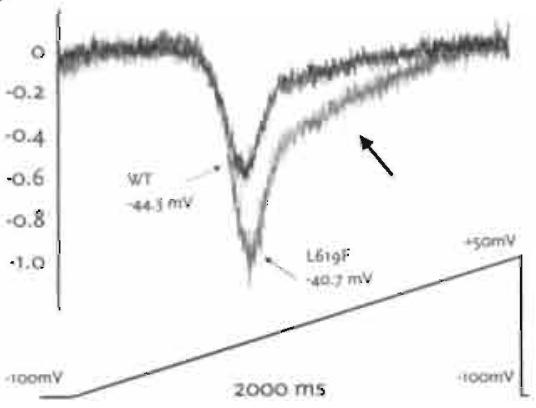

\section{Discussion}

Previous studies have reported the association of homozygous mutations in the SCN5A and $\mathrm{KCNH}_{2}$ genes with congenital long-QT syndrome and 2:1 atrioventricular block (8-10). In the present study, we describe a novel heterozygous LQT-3 missense mutation, L61gF, identified in a neonate with prolonged QT-intervals and episodes of 2:1 AVB.

\section{Long-QT Syndrome and 2:1 Atrioventricular Block}

Long-QT syndrome with 2:1 AVB is rare, with an incidence of $4 \%$ reported in pediatric series of long-QT syndrome patients (6), and to the best our knowledge 64 cases reported so far in the world literature $\left(1,4^{-10}, 18-30\right)$. Electrophysiological studies have revealed that during $2: 1$ atrioventricular conduction, AVB may occur within the His bundle $(24,28)$, or more distal in the Purkinje system and/or ventricular myocardium $(4,7,23)$. In $95 \%$ of the reported cases of LQTS with 2:1 AVB, QTc prolongation exceeded $500 \mathrm{~ms}^{1 / 2}$, and despite the usual treatment regime of beta-blockers with or without a pacemaker, infant mortality approximated $50 \%$.

In only three previous cases, the genotype of the patient with LQTS and 2:1 AVB was assessed (8-10). Two separate cases of homozygous mutations in HERG (8,9), and one case of a homozygous mutation in SCN5A were responsible for this severe phenotype. Our case is unique, as it represents the first case of a heterozygous $\mathrm{Na}^{+}$channel mutation 
associated with LQTS and 2:1 AVB. In addition to the SCN5A mutation, our patient was carrier of the amino acid polymorphism T8A-MiRP in the $\beta$-ancillary subunit accessory of the $I_{K r}$ channel (31), which is a relatively common polymorphism with an allelic frequency of $1.6 \%$ in the general population. We believe that this polymorphism probably did not. contribute to the clinical phenotype, as T8A-MiRP1 does. not significantly affect $l_{\mathrm{Kr}}$ channel properties in the absence of QT prolonging drugs (16). Interestingly, the mother of the index patient, who also carried both the $S C_{5} A$ mutation and the MiRP1 polymorphism, displayed only borderline QTc interval prolongation, and did not experience any long-QT syndrome-related symptoms.

\section{Association long-QT syndrome, 2:1 AVB, and VSD}

The complex cardiac phenotype of long-QT syndrome with functional 2:1 AVB, in combination with a ventricular septal defect has been reported in 6 cases so far (TABLE 6.1). Most cases were identified prenatally because of fetal bradycardia or (supra)ventricular tachycardia. Neonatal QTc iritervals were usually very long

TABLE 6.1

Characteristics of long. QT syndrome patients with 2:1 atrioventricular conduction, and a ventricular septal defect.

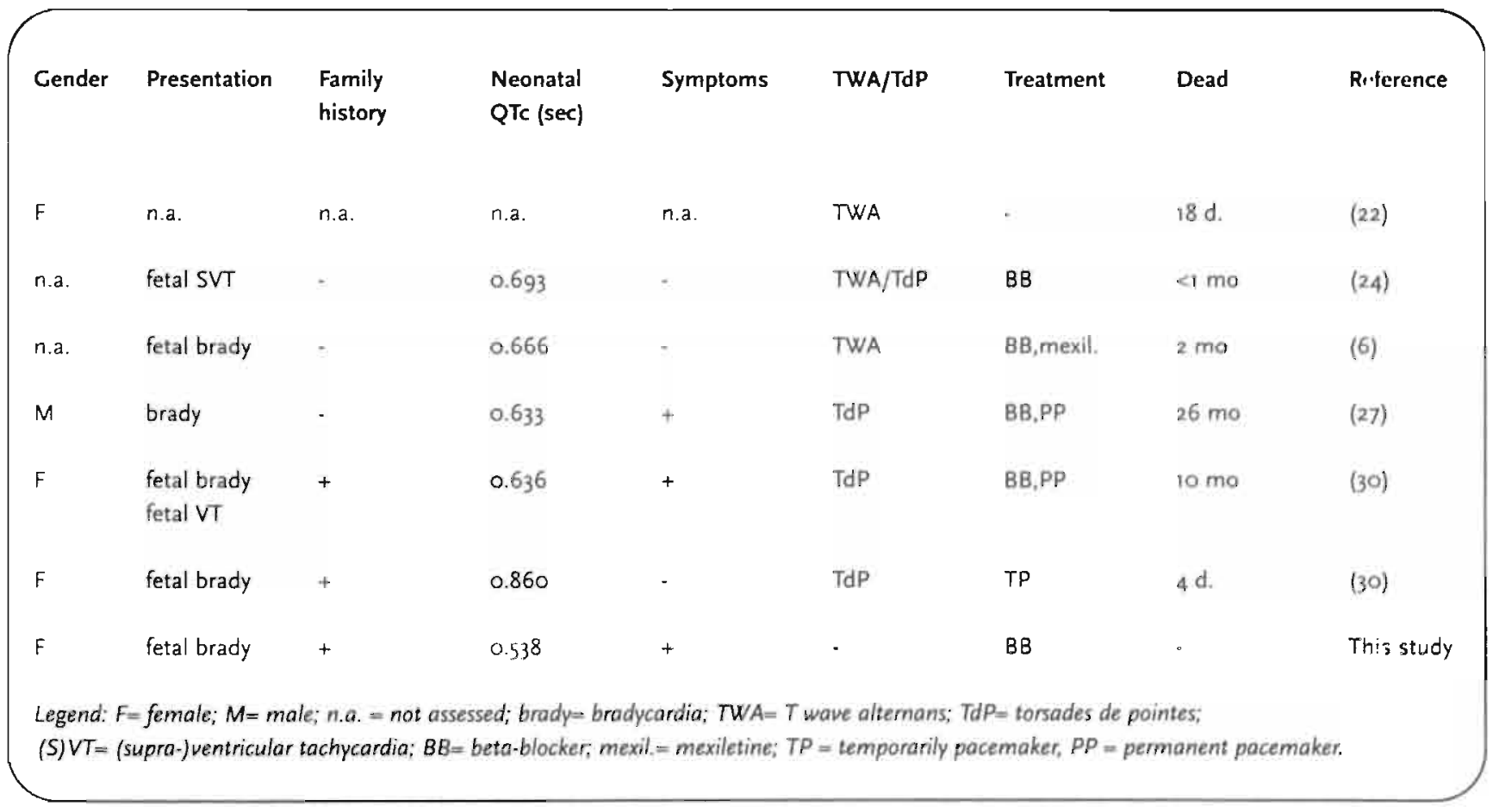


(538-860 $\left.\mathrm{ms}^{1 / 2}\right)$, and all 6 previously reported infants died before the age of 2 years $(6,22,24,27,30,31)$, despite treatment with beta-blockers $(n=4)$ or pacemakers $(n=3)$.

It is possible that the presence of long-QT syndrome and VSD in our patient occurred by chance, but the recognition of seven patients with an association of two uncommon disorders may suggest otherwise (TABLE 6.1). Although it is attractive to assume that the association is not random, and that a genetic mechanism may be responsible, our data suggest that this may not be the case. Importantly, the proband and mother carry the same SCN5A mutation and MiRP1 polymorphism, but only the infant had a VSD and experienced severe QT-interval prolongation. Since proband and mother are of the same sex, the distinction in clinical presentation strongly suggests that other factors likely contribute both to the structural and electrical dysfunction. In terms of the electrical problem, it is possible that the developmentally distinct modifier gene activity may, in combination with the detected $\mathrm{Na}^{+}$channel defect, produce severe changes in QT prolongation seen in the proband.

\section{Novel Biophysical Phenotype of the L619F Mutation}

Functional analysis shows that the biophysical phenotype of the $\mathrm{L}_{619} \mathrm{~F}$ mutation is novel, as it combines increased non-inactivating sodium current as reported previously for several other LQT-3 mutations $(33,34)$, with an increase in the magnitude of window current as first reported by Abriel et a!. (13,35). Using a single channel based model of the ventricular action potential, Clancy and Rudy (11) showed that an increased sustained sodium current can prolong ventricular repolarization, which may cause arrhythmogenic early afterdepolarization (11). The increase in $\mathrm{Na}^{+}$channel window current is most likely sufficient to cause prolongation of the QT-interval by itself, as two previous studies $(13,35)$ reported such channel defect in SCN5A mutants associated with the long.QT syndrome. Neither of these mutations, however, caused non-inactivating sodium current as well. An increase in $\mathrm{Na}^{+}$channel window current is expected to offset the delicate balance between inward and outward membrane currents during the final phase of repolarization (13), which may lead to prolongation of the ventricular action potential. Thus, the biophysical changes caused by the L619F mutation are consistent with the expected cellular phenotype: action potential prolongation.

We also observed a speeding of the recovery from inactivation kinetics in L619F mutant $\mathrm{Na}^{+}$channels. Although faster recovery kinetics are observed in the majority of LQT-3 mutants $(13,14,34,35)$, it is currently not fully understood whether or not this change in gating contributes to action potential prolongation, but this change in recovery kinetics 
will certainly shorten refractory periods in the ventricle and predispose the heart to premature excitation. Interestingly, the mother of the index patient, who also carried the SCN5A mutation, displayed only borderline QTC interval prolongation, and did not experience any long-QT syndrome-related symptoms. This suggests that other (genetic) factors, in combination with the channel defect, may be necessary to induce the long-QT syndrome phenotype.

First LQTS Mutation in the Cytoplasmic Linker Between Domain I and II of SCN5A The L619F mutation is the first LQTS mutation in SCN5A to occur in the cytoplasmic loop, connecting domains $I$ and II. This mutation causes the substitution from an evolutionary conserved leucine to phenylalanine, which is likely to change the protein secundary structure. Previously, two SCN5A mutations linked to Brugada syndrome have been reported in the same domain of the $\mathrm{Na}^{+}$channel. Gulcheney et al. (36) reported the missense mutation T632M, and Priori et al. (37) reported the $L 567 \mathrm{Q}$ mutation in a 14 month old girl that died of ventricular fibrillation due to Brugada syndrome. Wan et al. (38) studied the biophysical properties of $L 567 \mathrm{Q} \mathrm{Na}{ }^{+}$channels in HEK cells, and demonstrated that $L 567 \mathrm{Q}$ channels accelerate fast inactivation, and enhance closed-state inactivation. The resulting decrease in $\mathrm{Na}^{+}$channel availability is believed to be responsible for idiopathic ventricular fibrillation (38).

Together with our results, the data of Wan et al. (38) implicate a role of the intracellular I-II linker in the control of $\mathrm{Na}^{+}$channel inactivation. The $1619 \mathrm{~F}$ mutation speeds the recovery from inactivation, which suggests that the fast inactivated state of

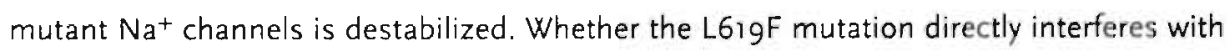
the fast inactivation particle $(39)$, or its docking sites $(40,41)$, or whether this phenomenon is due to allosteric interactions, remains to be determined. 


\section{Summary}

In summary, we have identified a novel heterozygous mutation in the SCN5A gene in an infant with congenital long-QT syndrome and 2:1 atrioventricular block. The clinical presentation and the electrophysiological findings make this mutation very likely to be the cause of the disease. The L61gF mutation causes a unique biophysical phenotype, as it combines increased non-inactivating $\mathrm{Na}^{+}$current with a larger window current. The defective inactivation imposed by the $\mathrm{L}_{619 \mathrm{~F}}$ mutation implicates a novel role for the domain I-II linker in the $\mathrm{Na}^{+}$channel inactivation process.

\section{Acknowledgments}

X.H.T.W. was a recipient of a Hein Wellens Fund travel grant; T.R. is a research assistant of the Fund for Scientific Research- Flanders (FWO Belgium); M.G. was supported in part by the Belgium Foundation for Research in Pediatric Cardiology. This work was supported in part by grant HL-56810 awarded to RSK from the USPHS. We thank Drs. Colleen Clancy and Michihiro Tateyama for helpful discussion. 


\section{References}

1. Mache C], Beitzke A, Haidvoggl M Ir, Gamillscheg A, Suppan C., Stein JI. Perinatal manifestations of idiopathic long-QT syndrome. Pediatr Cardiol 1996;17:118-21.

2. Schwartz PJ. Idiopathic long-QT syndrome: progress and questions. Am Heart J 1985:109:399-411.

3. Schwartz PJ, Priori SG, Dumaine R, Napolitano C, Antzelevitch C, Stramba-Badiale M, Richard TA, Berti MR, Bloise R. A molecular link between the sudden infant death syndrome and the long-QT syndrome. N Engl] Med 2000;343:262-67.

4. Van Hare GF, Franz MR, Roge C, Scheirman MM. Persistent functional atrioventricular block in two patients with prolonged QT-intervals: elucidation of the mechanism of block.

Pacing Clin Electrophysiol 1990;13:608-18.

5. Pruvot E, De Torrente A, De Ferrari GM, Schwartz PI, Goy JJ. Two-to-one AV block associated with the congenital long-QT syndrome. J Cardiovasc Electrophysiol 1999:10:108-13.

6. Trippel DL, Parsons MK, Gillette PC. Infants with long-QT syndrome and 2:1 atrioventricular block. Am Heart J 1995:130:1130-34.

7. Gorgels AP, Al Fadley F, Zaman L, Kantoch MI, Al Halees, Z. The long-QT syndrome with impaired atrioventricular conduction: a malignant variant in infants. J Cardiovasc Electrophysiol 1998;9:1225-32.

8. Hoorntje T, Alders M, Van Tintelen P, Van der Lip K, Sreeram N, Van der Wal A, Mannens M, Wilde A. Homozygous premature truncation of the HERG protein: the human. HERG knockout. Circulation 1999;700:1264.6\%.

9. Piippo $K$, Laitinen $P$, Swan $H$, Toivonen L, Viitasalo $M$, Pasternack $M$, Paavonen $K$, Chapman $H$,

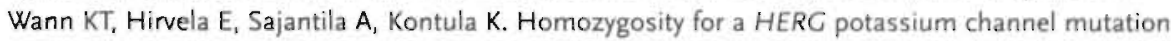
causes a severe form of long-QT syndrome: identification of an apparent founder mutation in the. Finns. J Am Coll Cardiol 2000;35:1919-25:

10. Lupoglazoff JM, Cheav T, Baroudi G, Berthet $M$, Denjoy I, Cauchemez B, Extramiana $F_{\text {s }}$ Chahine M, Guicheney P. Homozygous SCN5A mutation in long-QT syndrome: with functional two-to-one atrioventricular block. Circ Res 2001;89:E76-21.

11. Clancy CE, Rudy Y. Linking a genetic defect to its cellular phenotype in a cardiac arrhythmia. Nature 1999;400:566-69.

12. An RH, Wang XIL, Kerem B, Benhorin ), Medina A, Goldmit M, Kass RS. Novel LQT-3 mutation affects $\mathrm{Na}^{*}$ channel activity through interactions between alpha.- and betal-subunits. Circ Res 1998;83:141-46.

13. Abriel H, Cabo C. Wehrens XHT, Rivolta I. Motoike HK, Memmi M, Napolitano C, Priori SG, Kass RS. Novel arrhythmegenic mechanism revealed by a long-QT syndrome mutation in the cardiac Na. channel. Circ Res 2007;88:740-45.

14. Wehrens XHT, Abriel H, Cabo C, Benhorin J, Kass RS. Arrhythmogenic mechanism of an LQT-3 mutation of the human heart $\mathrm{Na}^{+}$channel alpha-subunit: $\mathrm{A}$ computational analysis.

Circulation 2000;102:584-90.

15. Schwartz PJ, Priori SG, Locati EH, Napolitano C, Cantu F, Towbin JA, Keating MT, Hammoude $H$, Brown AM, Chen LS. Long-QT syndrome patients with rnutations of the SCN5A and HERG genes have differential responses to $\mathrm{Na}^{+}$channel blockade and to increases in heart rate. Implications for gene-specific therapy. Circulation 1995; 92:3381-86.

16. Sesti F, Abbott CW, Wei J, Murray KT: Saksena S. Schwartz PJ, Priori SC, Roden DM, George AL, Goldstein SA. A common polymorphism associated with antibiotic-induced cardiac arrhythmia. Proc Nati Acad Si U S A 2000;97:10613-18. 
17. Attwell D, Cohen I, Eisner D, Ohba M, Ojeda C. The steady state TTX-sensitive ("window") sodium current in cardiac Purkinje fibres. Pflugers Arch 1979;379:137-42.

18. Kernohan RJ, Froggatt P. Atrioventricular dissociation with prolonged QT-interval and syncopal attacks in a 10-year old boy. Br Heart J 1974;36:576-19.

19. Di Segni E, David D, Katzenstein M, Klein HO, Kaplinsky E, Levy MI. Permanent overdrive pacing for the suppression of recurrent ventricular tachycardia in a newborn with long-QT syndrome. $J$ Electrocardiol 1980;13:189-92.

20. Batisse A, Belloy $C_{n}$ Fermont L, Piechaud JF, Kachaner f. Allongement de l'espace QT avec bloc auriculo-ventriculaire functionnel chez le nouveau-né et le jeune nourrisson.

Arch. Fr Pediatr 1981;38:657-62.

21. Morville P, Mauran P, Motte J, Digeon B, Coffin R. Torsades de pointe foetales et syndrome du QT long. Arch Mal Coeur Vaiss 1985;78:781-84.

22. Pellegrino A, Ho \$Y, Anderson RH, Hegerty $A_{2}$ Godman M], Michaelsson M. Prolonged QT-interval and the cardiac conduction tișues. Am $j$ Cardiol 1986;58:1112-13.

23. Case $\mathrm{CL}$, Gillette PC. Conduction system disease in a child with long-QT syndrome. Am Heart J 1990;120:984-86.

24. Saoudi N, Bozio A, Kirkorian G, Atallah G, Normand ), Touboul P. Prolonged QT, atrigventricular block, and sudden death in the newborn: an electrophysiologic evaluation. Eur Heart J 1991;12:838-41.

25. Garson A J, Dick M, Fournier A, Gillette PC, Hamilton R, Kugler JD, van Hare GF $3^{\text {rd }}$, Vetter V, Vick GW $3^{\text {rd }}$. The long-QT syndrome in children. An international study of 287 patients.

Circulation 1993;87:1866-72.

26. Perticone F, Canepa SA, Ceravolo R, Cloro C, Mattioli PL. A case of torsades de pointes occurring in a newborn with persistent 2:1 atrioventricular block. Cardiology 1993:83:134-40.

27. Marks ML, Whișler SL, Clericuzio C, Keating M. A new form of long-QT syndrome associated with syndactyly. J Am Coll Cardiol 1995;25:59-64.

28. Tanel RE, Triedman JK, Walsh EP, Epstein MR, DeLucca JM, Mayer JE Jr, Fishberger SB, Saul JP. High-rate atrial pacing as an innovative bridging therapy in a neorate with congenital long.QT syndrome. J Cardiovasc Electrophysiol 1997;8:812-17.

29. Donofrio MT, Gullquist SD, O'Connell NG, Redwine FO. Fetal presentation of congenital long-QT syndrome. Pediatr Cardio! 1999;20:441-44.

30. Wu MH, Hsieh FC, Wang JK, Kau ML. A variant of long-QT syndrome manifested as fetal tachycardia and associated with ventricular septal defect. Heart 1999:82:386-88.

31. Abbott GW, Sesti F, Splawski I, Buck: ME, Lehmann MH, Timothy KW, Keating MT, Goldstein SA.

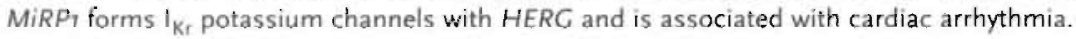
Cell 1999;97:175-8\%.

32. Lin MT, Wu MH, Hsieh Fl, Wang JK, Teng R!, Tscu KI, Lue HC. Long-QT syndrome manifested as fetal ventricular tachycardia and intermittent AV block. Am J Perinatol 1998:15:145-4\%.

33. Bennett: PB, Yazawa K. Makita N. George AL Jr. Molecular mechanism for an inherited cardiac arrhythmia. Nature 1995:376:683-85.

34. Wang DW, Yazawa K. George AL Jr, Bennett PB. Characterization of human cardiac $\mathrm{Na}^{+}$charnel mutations in the congenital long-QT syndrome. Proc Natl Acad Sci U S A 1996;93:13200-05.

35. Wedekind $H$, Smits JP, Schulze-Bahr E, Arnold R, Veldkamp MW, Bajanowski T, Borggrefe M, Brinkmann B, Warnecke! I, Funke $H$, Bhuiyan ZA, Wilde AA, Breithardt $G$, Haverkamp W. De novo mutation in the $5 \mathrm{CN}_{5} \mathrm{~A}$ gene associated with early onset of sudden infant death.

Circulation 2001;104:1158-64. 
36. Guicheney P, Deschenes I, Nicolas L, Berthet M, Chalvidan T, Davy JM, Leenhardt A, Coumel P, Denjoy 1, Chahine M. Novel mutation in the cardiac Na ${ }^{+}$channel $\alpha$-subunit gene (SCNSA) in patients with Brugada syndrome. Eur Heart J 1999:20:465 (abstract).

37. Priori SG, Napolitano C, Giordano U, Collisani G, Memmi M. Brugada syndrome and sudden cardiac death in children. Lancet 2000;355:808-og (letter).

38. Wan X, Chen S, Sadeghpour A, Wang Q, Kirsch CE. Accelerated inactivation in a mutant $\mathrm{Na}^{+}$channel associated with idiopathic ventricular fibrillation. Am J Physiol Heart. Circ Physiol 2001;280: $\mathrm{H}_{354}-6 \mathrm{a}$.

39. West JW, Patton DE, Scheuer T, Wang Y, Goldin AL, Catterall WA. A cluster of hydrophobic amino acid residues required for fast $\mathrm{Na}^{+}$channel inactivation. Proc Nat Acad Sci U SA 1992;89:10910-14.

40. Tang L, Kallen RG, Horn R. Role of an $\mathrm{S}_{4}-\mathrm{S}_{5}$ linker in sodium channel inactivation probed by mutagenesis and a peptide blocker. J Gen Physial 1996;108:89-104.

41. McPhee JC, Ragsdale DS, Scheuer T, Catterall WA. A critical role for the $S_{4}-S_{5}$ intracellular loop in domain IV of the sodium channel alpha-subunit in fast inactivation.J Biol Chem 1998;273:1121-29. 
Novel insights in the Congenital Long QT.3 Syndrome | PACE 138 


\section{Chapter 7}

General Discussion 


\section{Overview of Cardiac Ion Channelopathies}

In 1995, it became clear that the congenital long-QT syndrome resulted from mutations in cardiac ion channels (1). Mutations in cardiac potassium channels, followed by the cardiac sodium channel, and auxiliary $\beta$-subunits of potassium channels have all been linked to the long-QT syndrome (1-7). At present time, a molecular genetic diagnosis can be made in about $80-90 \%$ of all patients with familial long-QT syndrome (P. Doevendans, personal communication), implicating that mutations in proteins not yet identified may also underlie this disease. It is in the line of expectation that other ion channels, as well as auxiliary subunits, and proteins involved in the regulation of cardiac ion channels, will be linked to

TABLE 7.1 Overview of genes causing cardiac ion channelopathies.

\section{$\begin{array}{lll}\text { Syndrome } \quad \text { Gene } & \text { Reference }\end{array}$}

\begin{tabular}{|c|c|c|c|}
\hline LQT-1 & KCNQ & $I_{K s ̦}$ & (3) \\
\hline LQT-2 & $\mathrm{KCNH} 2$ & $\mathrm{I}_{\mathrm{Kr}}$ & (2) \\
\hline LQT-3 & SCNSA & $I_{\mathrm{Na}}$ & (1) \\
\hline LQT-4 & $\cdot$ & - & (4) \\
\hline LQT-5 & KCNET & $I_{\mathrm{Ks}}$ & (5) \\
\hline LQT.6 & KCNE2 & $I_{K r}$ & (6) \\
\hline Brs & $S C N_{5} A$ & $I_{\mathrm{Na}}$ & (11) \\
\hline PCCD & SCNSA & $\mathrm{I}_{\mathrm{Na}}$ & (12) \\
\hline$I C C D$ & $S C N_{5} A$ & $I_{\mathrm{Na}}$ & (13) \\
\hline Andersen's syndrome & $K C N / 2$ & $I_{\text {Kirz.1. }}$ & $(14)$ \\
\hline CPVT & RYR2 & Ryanodine receptor & (15) \\
\hline$A_{R V D}$ & $R Y R_{2}$ & Ryanodine receptor & (16) \\
\hline
\end{tabular}


the long-QT syndrome in the near future (8). Alterations of any of these components may interfere with normal function of ion channels, and thus lengthen ventricular repolarization.

The congenital long-QT syndrome was the first cardiac ion "channelopathy" to be identified. Since then, a whole spectrum of inherited arrhythmias based on cardiac: ion channel mutations has emerged (TABLE 7.1). Although familial arrhythmic syndromes are relatively uncommon, they can provide significant insight into the mechanisms underlying more general conduction and repolarization abnormalities. (9). The understanding of the genetic basis, or the molecular origin, of inherited cardiac arrhythmias is likely to have major impact on the diagnostic approach, prevention and treatment of these disorders (10).

\section{Biophysical Phenotypes of Congenital Long-QT Syndrome $\mathrm{Na}^{+}$Channel Mutations}

As reviewed in CHAPTERS 1 and 2 of this thesis, congenital long-QT syndrome type 3 (LQT-3) is caused by mutations in the SCN5A gene, which encodes the cardiac sodium channel. After the first mutations were discovered in 1995 ( 1 ), the function of recombinant sodium channels encoded by mutated SCN5A genes were studied in heterologous expression systems, in particular Xenopus laevis oocytes and human embryonic kidney (HEK) cells (17-19). From these early studies, it became clear that most of the LQT-3 mutant sodium channels failed to completely inactivate, which leads to so-called 'noninactivating current' visible during prolonged depolarizing pulses $(17,19)$. In addition to 'destabilizing' the inactivated state of the sodium channel (i.e. allowing reopenings of inactived channels) $(17,19-22)$, an allied mechanism has been described for R1623 channels, which exhibit a slowed rate of entry into the fast-inactivated state; causing a net 'gain of function' by prolonging $\mathrm{Na}^{+}$current decay $(23,24)$.

In 1998, An et al. (25) reported the Di79oG mutation, located in the early C-terminal part of the sodium channel, which does not lead to incomplete inactivation of the sodium channel. In CHAPTER 3 of this thesis, we have extended the finding that noninactivating current is absent (26), and used the Luo-Rudy computer model of the ventricular action potential to get a better idea how this mutation might evoke action 
potential prolongation (26). In short, the changes in D1790G $\mathrm{Na}^{+}$channel kinetics reduce $\mathrm{Na}^{+}$current during the action potential upstroke, which is predicted to produce a less positive overshoot of the action potential (CHAPTER 3). The computational model predicts an increased $\mathrm{Ca}^{2+}$ entry via L-type $\mathrm{Ca}^{2+}$ channels, leading to an augmented subsequent $\mathrm{Ca}^{2+}$ transient. Two important ionic pathways, the $\mathrm{Na}^{+} / \mathrm{Ca}^{2+}$ exchanger (27) and slowly activating delayed $\mathrm{K}^{+}$channel current $\mathrm{I}_{\mathrm{Ks}}(28)$, are affected, which is predicted to cause a net increase of inward plateau current and corresponding increase in action potential duration. Because the Luo-Rudy computer model may oversimplify intracellular calcium handling, future studies using transgenic mice harboring the D $1790 \mathrm{C}$ mutation are needed to confirm that action potential prolongation is indeed dependent on $\mathrm{Ca}^{2+}$-sensitive ionic pathways. Recently, Baroudi et al. (98) measured noninactivating $\mathrm{Na}^{+}$current in HEK cells expressing Di79oG channels. Other parameters also differed from those measured in our study (26), in particular $V_{1 / 2}$ values for steady-state activation and inactivation, which might reflect differences in experimental conditions. Additional studies are required to further investigate these interesting observations.

The E1295K mutation, described in CHAPTER 5, is another example of an LQT-3 mutation that does not promote sustained sodium channel activity during prolonged depolarizations (29). This mutation prolongs the ventricular action potential in a distinctly different way. The mutation-induced gating changes shift the window of voltages over which $\mathrm{Na}^{+}$channels do not completely inactivate, and this causes marked changes in action potential duration because of the unique voltage-dependent rectifying properties of cardiac $\mathrm{K}^{+}$channels that underlie the plateau and terminal repolarization phases of the action potential. Because the peak of the E $1295 \mathrm{~K} \mathrm{Na}^{+}$channel window current occurs at more positive potentials, it is likely to have a greater effect on net membrane current because total $\mathrm{K}^{+}$channel conductance is lower at these more positive potentials (29). The same biophysical phenotype has been reported for LQT-3 mutation A133OP (30).

Interestingly, the novel L619F mutation, described in CHAPTER 6, is the first LQT-3 mutation that combines both noninactivating sodium current and an increase in window current. These data clearly demonstrate that there are at least four different mutationinduced gating changes in LQT-3 sodium channels. Although distinctly different. and not always associated with noninactivating sodium current during sustained depolarization, all of these biophysical phenotypes seem to result from mutation-induced defects in the inactivated conformational state of the sodium channel. The first combination of such gating changes has been described for the $6_{619} \mathrm{~F}$ mutation, and it is likely that in the near future even more variations in biophysical phenotypes will be described. 


\section{Correlating $\mathrm{Na}^{+}$Channel Structure and Gating Function}

\section{in LQT-3 Mutations}

The functional characterization of sodium channels containing LQT-3 mutations revealed the biophysical mechanisms causing aberrant conduction of sodium current. Based on the knowledge that has been obtained from mutagenesis experiments over the past decade, a picture of the structure-function relationship of the different domains in the sodium channel has emerged (for review, see CHAPTER 2, and $(31,32)$ ). In the following paragraphs, we try to integrate the LQT-3 mutations into the latest insights in the structure of the sodium channel (FICURE 7.1).

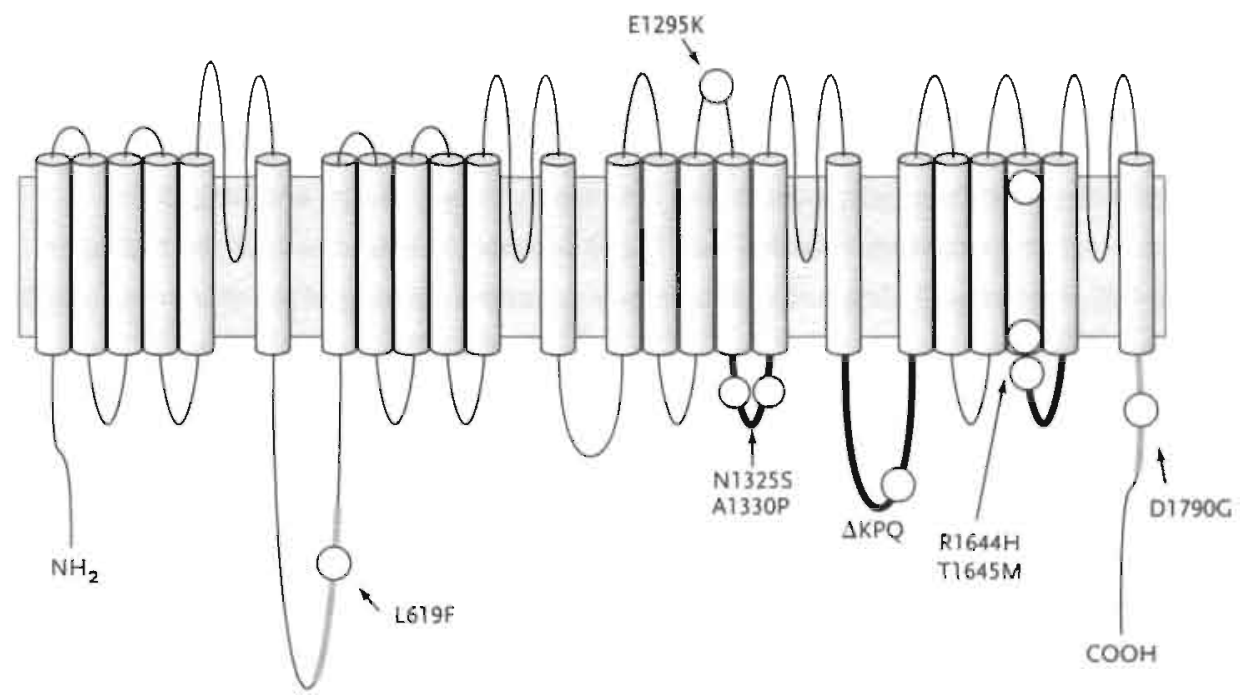

\section{Fast Inactivation Particle: Domain III-IV Linker}

The finding that the $\triangle K P Q$ deletion in the loop between domain III and IV reduces fast inactivation of $\mathrm{Na}^{+}$currents was not unexpected (17). It was already recognized that this region serves as the inactivation particle of the $\mathrm{Na}^{+}$channel (33.34). A cluster of three hydrophobic amino acids $\left(11485, \mathrm{~F}_{1486}, \mathrm{M}_{1487}\right)$ is thought to bind to a receptor region on the cytoplasmic surface of the channel protein. It is therefore likely that the $\triangle K P Q$ deletion due to its close proximity to the IFM motif may disrupt the inactivation particle, hereby interfering with fast inactivation.
SIGURE 7.1

Structure of the cardiac $\mathrm{Na}^{+}$

channel $\alpha$-subunit. Indicated with the circles are long-QT syndrome mutations with the respective amino-acid substitutions. The: domain II-IV linker, as well as the $S_{4}$-S5 loops of domain III and IV (thick black lines) are known to be involved in fast inactivation. Data presented in this thesis implicate that the domain $|-1|$ linker and C-terminus might be involved in this process as well (thick grey lines). 
Rohl et al. (35) determined the three-dimensional structure of the central portion of the inactivation gate as a peptide in a phosphate buffer using multidimensional NMR methods. The experiments revealed a rigid $\alpha$-helix flanked on its $\mathrm{N}$-terminal side by two turns, the second of which contains the IFM motif. They found that M1487 (residue number in the cardiac isoform) of the IFM motif hydrophobically interacts with $Y_{1494}$ and $Y_{1495}$, consistent with a three-dimensional structure of the IFM motif itself. The structure of the inactivation gate peptide in solution suggests that the rigid helix serves as a scaffold to present the IFM motif and the adjacent T1488 to a receptor in the mouth of the pore as the gate closes (hinged lid model).

Since the interaction of the inactivation particle with its receptor is considered to be mediated by the hydrophobic forces (36), the conformation Rohl et al. (35) determined in phosphate buffer seems to represent the IFM motif at a resting or open state of the channels, but not in an inactivated state. Miyamoto et al. (37) determined the solution structure of the III-IV linker in sodium dodecyl sulfate (SDS) micelles (a relevant environment at the inactivated state of the channels), and confirmed the presence of a large hydrophobic cluster composed of the IFM motif, $Y_{1494}, Y_{1495}$, and M1498. In addition, a subsequent study revealed that $T 1488$ probably is bound to 11485 by hydrogen bounds (38). This large hydrophobic cluster may assist the docking of the IFM motif within its receptor regions.

\section{Docking Stations for the Inactivation Particle: Domain III-S4/S5 and Domain IV.S4/S5}

The $\mathrm{S}_{4}$-S5 linkers of domain III and IV are thought to form the docking stations for the inactivation particle (39-42). Recent data from Miyamoto et al. (43) extended these electrophysiological data, and it now seems reasonable to assume that after initial depolarization, two hydrophobic clusters in DIV-S4/S5 interact with the III-IV linker. This hydrophobic interaction would then reduce polarity around the IFM motif, allowing 11485-F1486 to meet the hydrophobic cluster as a result of a conformational change $(37,44)$. The inactivation gate then closes by interacting with $\mathrm{A} 1326$ in domain $111-54 / 55$ and/or with $\mathrm{N}_{16} 69$ in DIV-S4/S5 (43) (FIGURE 7.2).

Several naturally occurring long-QT syndrome mutation occur in the DIII-S4/S5 (N1325S, A $1330 \mathrm{P})$, and DIV-S4/S5 loops (R $\left.644 \mathrm{H}_{2} \mathrm{~T}_{1645} \mathrm{M}\right)$, and it seems tempting to reconcile them with the discussed structural picture of fast inactivation (FICURE 7.1 and 7.2). Whereas the $\mathrm{N} 1325 \mathrm{~S}$ and $\mathrm{R} 1644 \mathrm{H}$ mutations show persistent inward current consistent with disrupted fast inactivation, the Ai33oP (30) and T1645 M (Wehrens et al., 
A

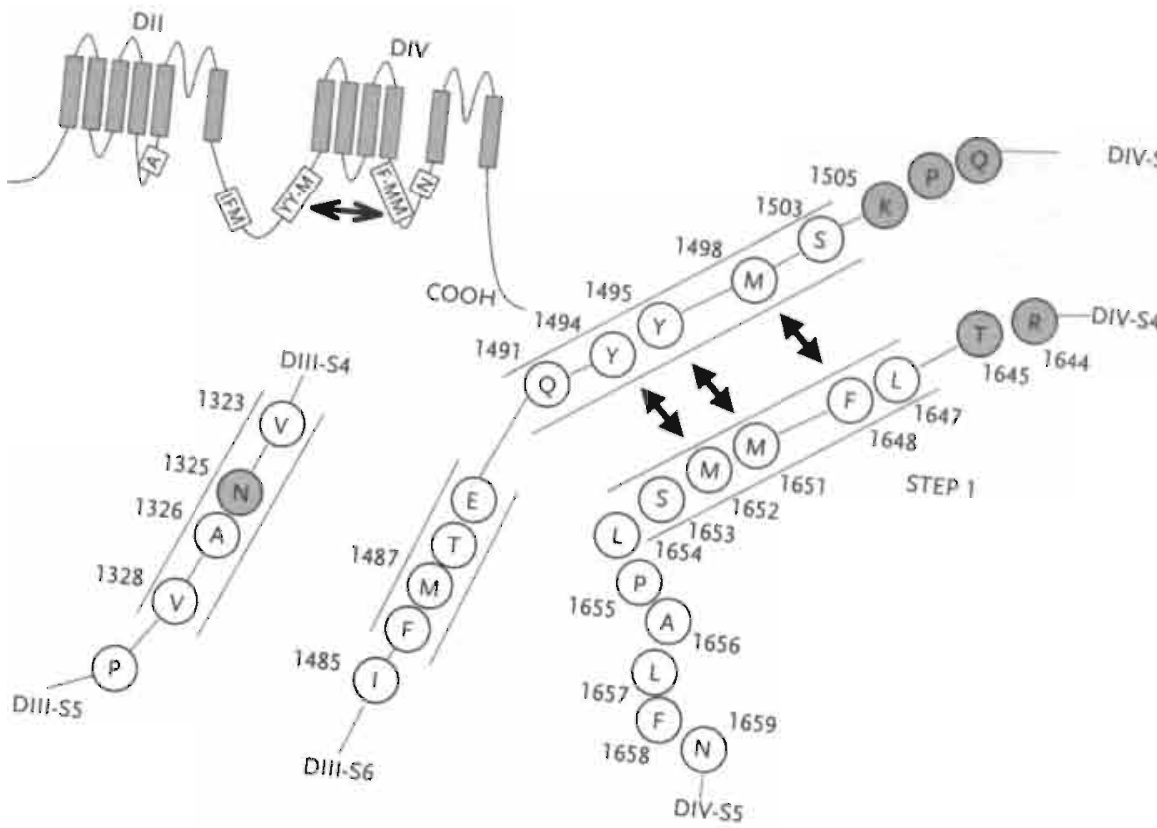

B

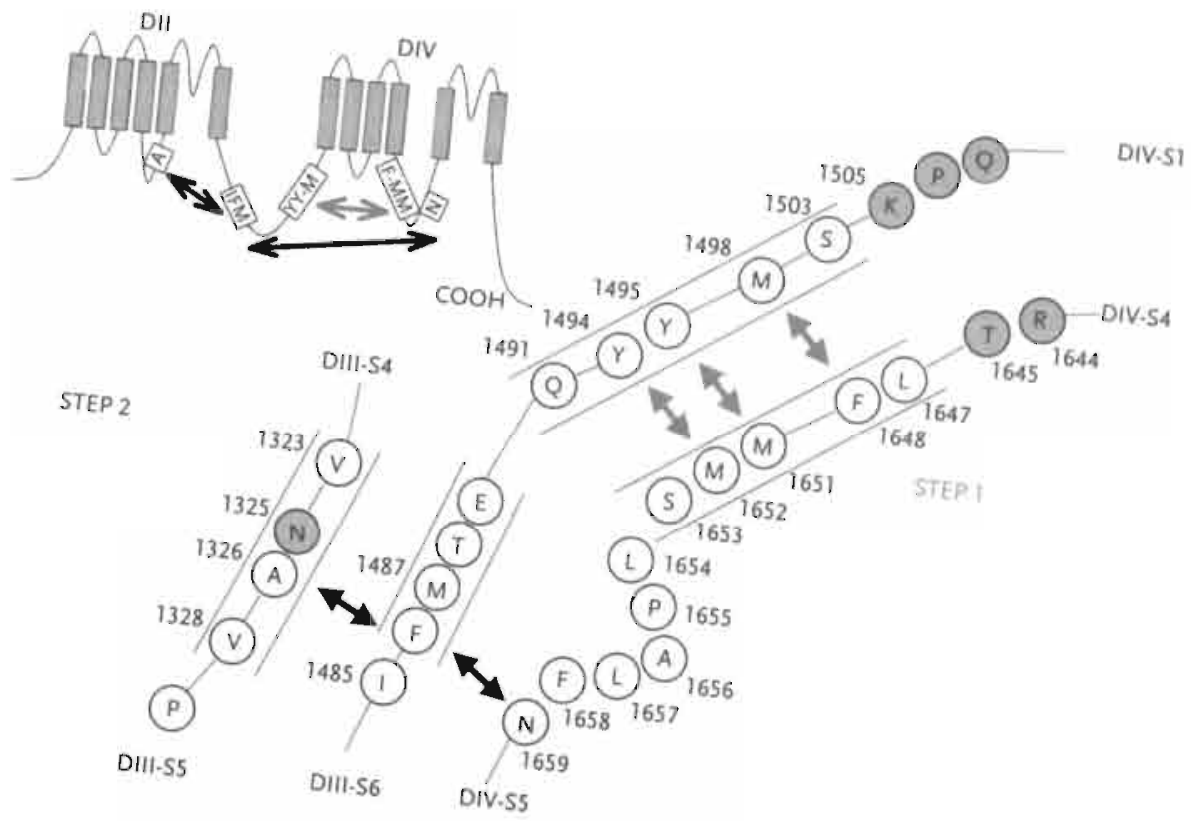

Chapter? I PACE 145 
unpublished data) do not show these electrophysiological properties. The $\mathrm{N}_{1325}$ residue is directly adjacent to $A_{1326}$, which is believed to interact with the phenylalanine of the IFM motif $(40,43)$. For now, it remains unclear how the other long-QT syndrome mutations cause structural changes directly affecting channel gating, and it is more likely that allosteric changes are responsible for impaired channel inactivation.

\section{Role of the C-Terminus in Channel Inactivation}

Little is known about the function of the C-terminal region of the voltage-gated sodium channels. Recently, the study of long-QT syndrome mutations in the C-terminus of the human cardiac sodium channel implicated a role possible of this channel region in fast inactivation (see also CHAPTER 3) $(20,22,26,45)$. Using chimeric channels between the human heart isoform $\left(h^{H} \mathrm{H}_{1}\right)(46)$ and the human skeletal muscle isoform ( $\left.h \mathrm{SkM}_{1}\right)(47)$, Deschenes et al. (48) showed that the first 100 amino acids of the $\mathrm{C}$-terminal region of the $\alpha$-subunit of the sodium channel are responsible for differences in current decay kinetics between heart and skeletal muscle channels. These results together with the modeling study by Sato et al. (49) link the C-terminus to fast inactivation, along with the inactivation gate.

Considerable heterogeneity consists in the biophysical properties of the four longQT syndrome mutations reported so far in the first 23 amino acids of the C-terminus $(20,22,25,45)$. All but one, $1790 \mathrm{G}$, promote non-inactivating $\mathrm{Na}^{+}$current during prolonged depolarizations. On the other hand, whereas three mutations cause a large negative shift in the steady-state inactivation curve, consistent with increased close-state inactivation, the $Y_{1795 C}$ mutation does not alter this parameter (TABLE 7.2). Based on computer model predictions of the sodium channel structure, it is believed that the negatively charged proximal C-terminus might interact with the positively charged III-IV, and possibly also the II-III cytoplasmic linker regions of the $\mathrm{Na}^{+}$channel (49). More comprehensive structural analysis of the carboxy-terminus will be essential to better comprehend the biophysical changes imposed by long-QT syndrome mutations in this region of the channel.

\section{A Role for the Domain I-II Linker in Channel Inactivation?}

In CHAPTER 6, we reported that the L619F mutation in the cytoplasmic loop connecting domain I and II speeds recovery from inactivation, and is thus likely to destabilize the inactivated state of the sodium channel. The intracellular domain between domain I and II is relatively unconserved between sodium channel isoforms $(50,51)$. In the cardiac isoform, 


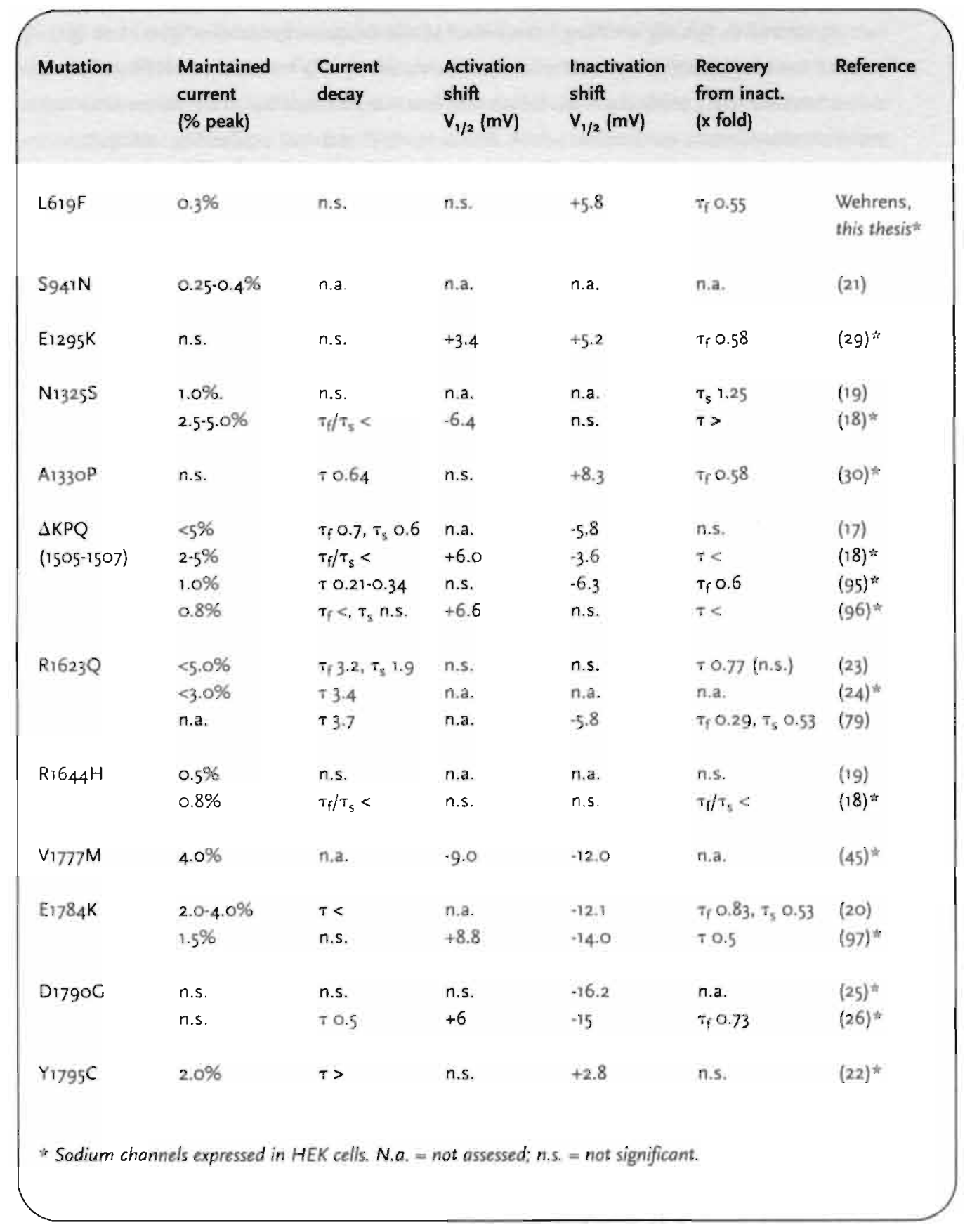


two mutations in this region have been linked to the Brugada syndrome. Wan et al. (52) studied the biophysical properties of one of these, the L567Q mutation, in HEK cells and demonstrated that $\mathrm{L}_{5} 67 \mathrm{Q}$ channels accelerate fast inactivation, but at the same time enhance closed-state inactivation which decreases $\mathrm{Na}^{+}$channel availability, which is believed to cause idiopathic ventricular fibrillation (52).

Our data from CHAPTER 6 along with the data from Wan et al. (52), suggest that the $\mathrm{I}-\mathrm{Il}$ linker region is involved in $\mathrm{Na}^{+}$channel inactivation (FIGURE 7.1). However, it is impossible to conclude whether these mutations in the I-II linker directly interfere with the fast inactivation particle $(17,36)$, or its docking sites $(39,42,53,54)$, or whether this phenomenon is due to allosteric interactions.

\section{Conclusions Regarding LQT-3 Biophysical Phenotypes}

In the last couple of years, it has become apparent that $L^{T}-3$ mutations over a fairly wide range of the sodium channel $\alpha$-subunit can destabilize the inactivated state of the channel, directly or through possible allosteric effects. This suggests that the structural requirements for normal inactivation are fairly precise, and depend upon complex ensemble interactions among many structural domains (31).

Some biophysical properties occur commonly in LQT.3 mutations, most notably a speeding of the onset of inactivation, and a faster recovery from inactivation (TABLE 7.2). Whereas some features such as increased bursting (noninactivating current) and increased window current are easily correlated to a cellular phenotype $(29,55)$, other kinetic properties may also contribute to action potential prolongation in subtle, as yet unexplored, ways.

\section{Molecular Pharmacology of LQT-3 Mutations}

\section{Local Anesthetic Action is Gating-dependent}

In CHAPTER 2, we described that local anesthetic/ class I antiarrhythmic drug activity is gating-dependent (the 'modulated receptor theory') (56-59). Indeed, mutagenesis experiments have revealed that amino acid residues critical to drug binding and channel gating overlap to some degree. For example, alanine substitution of residues $\mathrm{F}_{17} 60$ and $\mathrm{Y}_{1767}$ (in $\mathrm{SCN}_{5} \mathrm{~A}$ ) in $\mathrm{D}_{4} \mathrm{~S} 6$ increase the $\mathrm{IC}_{50}$ for depolarization-dependent block by lidocaine up to two orders of magnitude $(60,61)$. In addition, mutations in DiS6 
( $\mathrm{N}_{406}$ and $\mathrm{L}_{409}$ in the cardiac isoform) also reduce drug affinity $(62,63)$. Interestingly, channels with the mutation $\mathrm{F}_{17} 60 \mathrm{~A}$ show impaired fast inactivation $(64,65)$, and substitution of the residue $\mathrm{N}_{4} \mathrm{O} 6$ alters both fast and slow inactivation (62). Current conceptualization predicts that the channel inactivation process may alter the orientation of amino acid side chains in $\mathbf{S 6}$ domains in a manner that facilitates drug binding $(62,66)$.

\section{Proximity of the Local Anesthetic Receptor Site and the Pore Segments}

A pore-plugging motif for LA molecules is well supported by evidence that permanently charged lidocaine derivatives (i.e. QX-314) move deeply (50-70\%) into the pore from the cytoplasmic site (67-69). This implies that the putative LA binding residues in S6 lie intracellular to the selectivity filter, which is formed by the 'DEKA' ring contributed by the

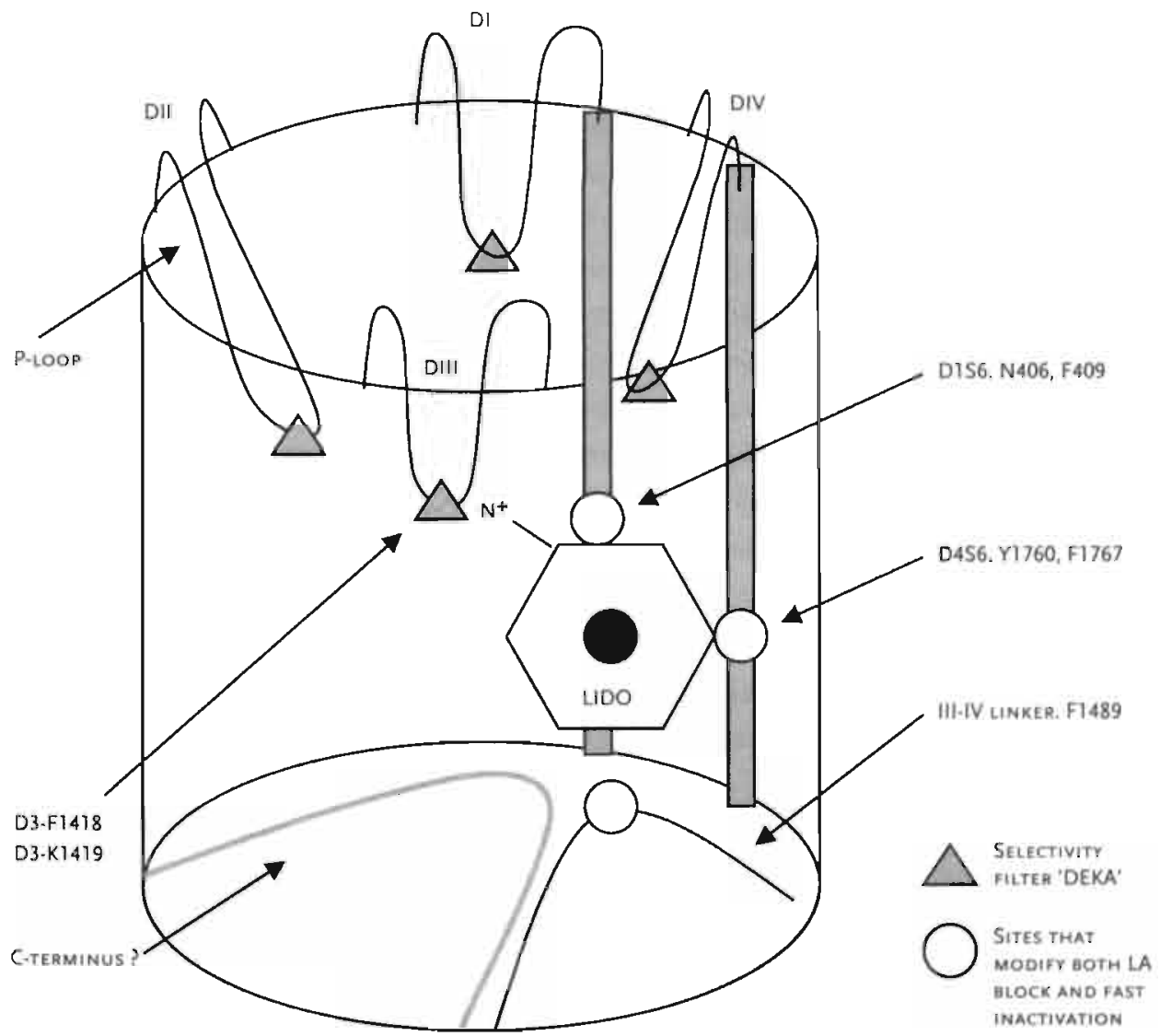

FICURE 7.3

Schematic view of the $\mathrm{Na}^{+}$ channel pore (cylinder), with a fidocaine, residing in the pore (LDO). The outer pore region is formed by the pore-loops of the four homologous domains (I-IV). while the 56 segments line the inner pore. The P-segment selectivity filter residues bridge the outer and inner pore regions. As described in the text, residues in the selectivity filter (i,e. K1419) and the domains I and IV, SG segments interact with local anesthetics. Residue numbers correspond to the human cardiac isoform (46). Adapted from Baiser, J Mol Cell Cardiol 2001:33:599-613 
P-loops of each domain (CHAPTER 2). P-loop residues in domains I, II, and IV limit external access (and escape) of hydrophilic LAs, and the domain III lysine residue repels the LA through an electrostatic interaction with the ionizable amino group $(70,71)$. These findings suggest proximity between the S6 segments of domains I and IV and the P-loop selectivity filter regions $(70,71)$, which could provide a rationale for LA induced conformational changes involving the outer P-loops (FIGURE 7.3).

\section{Tonic Block of Sodium Channels: Interaction of Local Anesthetics with} the Fast-inactivated State

The earliest modulated-receptor schemes for LA and class I antiarrhythmic drug action assigned a high affinity for the drugs to the open channel state (57). However, experiments that disabled the inactivation gate by replacing the hydrophobic triplet IFM by QQQ in the cytoplasmic III-IV linker suggested an interaction between $\mathrm{Na}^{+}$channel blockers and the inactivated conformational state $(69,72)$. However, more recent studies suggest that $L A$ block can occur without affecting the inactivation gate directly (73). Although lidocaine accelerates depolarization-dependent binding of the inactivation particle to its receptors, it does not 'trap' the fast-inactivation gate as proposed in earlier studies (73), and therefore seems to function as an allosteric effector.

Studies by Hanck et al. $(74,75)$ examined the $S_{4}$ voltage sensors during lidocaine block, and revealed that the maximum gating charge $\left(\mathrm{I}_{\mathrm{g}}\right)$ associated with channel depolarization is reduced by lidocaine. Moreover, site-3 toxins (that specifically inhibit movement of the voltage-sensor associated with inactivation) have an additional effect with lidocaine to suppress the maximum gating charge, further suggesting that lidocaine does not 'stabilize' the $\mathrm{Na}^{+}$channel in the fast-inactivated state (75). These studies suggest that lidocaine may alter closed-state inactivation by influencing the voltage sensors coupled to inactivation gating.

\section{Differential Pharmacological Effects of $\mathrm{Na}^{+}$Channel Blockers in LQT-3 Patients} From clinical studies, it became clear that $\mathrm{Na}^{+}$channel blockers may be particularly useful in managing patients with LQT-3 mutations $(76,77)$. The noninactivating inward current conducted by certain LQT-3 mutations is potentially inhibited by lidocaine and its analogous $(19,78)$. The selective blockade of the late current probably accounts for the QT-interval shortening without QRS prolongation in these patients (76).

However, the class IB antiarrhythmics lidocaine and mexiletine may not have beneficial effects on all LQT-3 mutations. Enhanced sensitivity of the R1623Q peak sodium 
current to lidocaine raised concerns regarding the pro-arrhythmic potential of $\mathrm{Na}^{+}$channel blockade in these patients (79). The pro-arrhythmic consequences of $\mathrm{Na}^{+}$channel blockade are well known from the CAST trial (80). In addition, lidocaine did not correct repolarization abnormalities in carriers of the D1790G mutation (77), a mutation that does not enhance late $\mathrm{Na}^{+}$current $(25,26)$. Interestingly, the class IC antiarrhythmic drug flecainide did correct QT-intervals in DI790G mutation carriers (77). Furthermore, there are now clinical data that flecainide might also be effective in carriers of the $\triangle K P Q$ mutation (81).

\section{Molecular Pharmacology of Sodium Channel Blockers and LQT-3 Mutations}

Certain LQT-3 mutations reduce stability of the inactivated state, inducing a small noninactivating plateau of inward current during depolarization $(17,19)$. When exposed to very low concentrations of the class $\mathrm{IB}$ antiarrhythmic agents lidocaine or mexiletine, $\triangle K P Q$ channels exhibit gating behavior that approaches the wild-type phenotype $(78,82)$. At the single channel level, lidocaine suppresses the bursting mode (82) and isolated late channel openings (83) of $\triangle \mathrm{KPQ}$ mutant channeis.

Studies of the $R_{1} 623 \mathrm{Q}$ sodium channel mutation exposed an alternative mechanism for lidocaine action on sustained current (79). This study revealed that not only the sustained current component, but also the peak sodium current was unusually sensitive to lidocaine. Further studies revealed that 'closed-state inactivation' (as evidenced by a hyperpolarizing shift in the steady-state inactivation curve) in drug-free conditions was increased (79), in contrast to the more obvious mutation-induced disruption in open-state inactivation (as evidenced by a slowed onset of inactivation) (23). Using a quantitative Markovian model, it was demonstrated that state-dependent lidocaine affinity could further augment closed-state inactivation through an allosteric effector mechanism (79). The same model was also sufficient to reproduce observed effects of lidocaine on sustained current induced by the $\triangle K P Q$ mutation, suggesting that an allosteric interaction between lidocaine and the closed-state inactivation state may be more generally applicable. Although the complete picture is still emerging, it is increasingly clear that interactions among multiple mutation-induced gating processes influence local anesthetic action, thereby affording tremendous pharmacologic diversity.

\section{Use-dependent Sodium Channel Block}

The previous paragraphs discussed the sensitivity of $\mathrm{Na}^{+}$channels to blockade that ensues immediately upon depolarization ('first-pulse' or 'tonic' block), which correlates primarily 
to block that develops during a stimulus delivered after a long diastolic pause. Additional mechanisms may be involved in modulating drug activity that develops during repetitive depolarizations ('use-dependent' block) $(84,85)$. A recent study $(70,86)$ revealed that slow recovery of drug-bound channels between depolarizing stimuli may involve an interaction between local anesthetics and slow-inactivated conformational states. Ong et al. (86) showed that an electrostatic interaction between the domain III P-loop residue $\mathrm{K}_{14} 19 / \mathrm{F}_{14} 18$ and the lidocaine amino terminus might induce structural rearrangements associated with slow inactivation that move $\mathrm{Na}^{+}$channel P-loops into positions that stabilize the interaction between lidocaine and the pore (FIGURE 7.3). Therefore, 'use-dependent' block may occur when lidocaine induces sodium channels to occupy a slow inactivating state (86). However, further evidence is required before definite conclusions may be drawn regarding the role of slow inactivation in use-dependent local anesthetic block.

\section{LQT-3 Mutations that Alter Use-dependent Block of Sodium Channels}

Flecainide, which is thought to preferentially block open but not inactivated channels, is effective in correcting DG-induced QT prolongation in patients carrying the DG gene defect, while lidocaine has no effect (77). Using, heterologously expressed Di790G channels, we showed that this dis.parity is based on markedly increased use-dependent block. sensitivity to flecainide (compared to wild-type channels), but not to lidocaine (87). It was already known that fiecainide, as other type IC agents, dissociates relatively slowly after it binds primarily to activated sodium channels (88), and is capable of producing strong use-dependent block of sodium channels (89). From our study (CHAPTER 4), however, it is not clear how a mutation in the C-terminal part of the sodium channel may selectively alter channel sensitivity to use-dependent flecainide block.

Interestingly, the specific alteration of the sensitivity to use-dependent block by flecainide is not a general property of all LQT-3 mutant channels. Recently, Nagatomo et al. (90) found that L.QT-3 $\triangle K P Q$ mutant channels have an intrinsically higher affinity than wild-type channels to flecainide, but in the case of $\triangle K P Q$, sensitivity to both TB and UDB is increased $(90,91)$. These results implicate that $\triangle \mathrm{KPQ}$ channels are susceptible to enhanced tonic flecainide block as a resuit of increased closed-state inactivation gating (91). Thus, our data indicate that the D1790G point mutation causes a unique pharmacological response, which is distinct not only from wild-type but also from $\triangle K P Q$ mutant channels. 
Conclusions Regarding Mutation-specific Pharmacotherapy for LQT-3 Patients Present knowledge suggests that fast and slow inactivation gating play important roles in sodium channel blockade. Inherited LQT-3 mutations can alter these gating processes, which may substantially influence the response to antiarrhythmic drugs. On the basis of molecular pharmacological studies in combination with current concepts regarding the interactions of local anesthetic with the sodium channel, the clinical usefulness of particular antiarrhythmic drugs may be predicted.

Carriers of the $\triangle K P Q$ mutation, and other mutations that cause late $\mathrm{Na}^{+}$current during the action potential plateau phase, may benefit from treatment with lidocaine/ mexiletine $(76,78,82,83,92)$, or flecainide/ pilsicainide $(81,83,90)$. In contrast, patients with the $\operatorname{Ri}_{123} \mathrm{Q}$ mutations may experience pro-arrhythmic consequences of lidocaine treatment $(79,80)$. Finally, our studies revealed that LQT-3 patients with the D1790G mutation benefit from treatment with flecainide, but not from lidocaine $(77,87)$.

\section{Novel Developments in Mutation-specific Pharmacotherapy and Tailor-made Drugs}

A critical aspect of the development of gene- or mutation-specific therapeutic approaches is the functional study of disease-related mutations. Whereas in the past, cardiovascular drug discovery often depended on serendipity, more recently, drugs have arise from more logical scientific approaches. Comprehensive understanding of the biophysical mechanisms underlying ion channel dysfunction, ideally in combination with a detailed picture of the protein structure and channel gating, will enable tailor-made design of drugs that may prevent cardiac arrhythmias; in a subset of patients with a particular genetic susceptibility $(93,94)$. 


\section{References}

1. Wang Q, Shen ), Splawski I, Atkinson D, Li Z, Robinson IL, Moss A], Towbin |A, Keating MT. SCN5A mutations associated with an inherited cardiac arrhythmia, long-QT syndrome. Cell 1995;80:805-11.

2. Curran ME, Splawski I, Timothy KW, Vincent GM, Green ED, Keating MT. A molecular basis for cardiac arrhythmia: HERG mutations cause long-QT syndrome. Cell 1995;80:795-803.

3. Wang Q, Curran ME, Splawski I, Burn TC, Millholland JM, VanRaay TJ, Shen J, Timothy KW, Vincent GM, de jager T, Schwartz PJ, Toubin JA, Moss A), Atkinson DL, Landes GM, Connors TD, Keating MT. Positional cloning of a novel potassium channel gene: KVLQT1 mutations cause cardiac arrhythmias. Nat Genet 1996:12:17-23.

4. Schott 1], Charpentier F, Peltier S, Foley P, Drouin E, Bouhour JB, Donnelly P, Vergnaud C, Bachner L, Moisan JP. Mapping of a gene for long-QT syndrome to chromosome 4925-27.

Am J Hum Genet 1995:57:1114-22.

5. Splawski I, Tristani-Firouzi M, Lehmann MH, Sanguinetti MC, Keating MT. Mutations in the hminK gene cause long-QT syndrome and suppress $I_{\mathrm{Ks}}$ function. Nat Genet 1997;17:338-40.

6. Abbott CW, Sesti F, Splawski I, Buck ME, Lehmann MH, Timothy KW, Keating MT, Goldstein SA. MiRP! forms $I_{\mathrm{Kr}}$ potassium channels with HERG and is associated with cardiac arrhythmia. Cell 1999:97:775-87.

7. Geelen [L, Doevendans PA, Jongbloed RJ, Wellens HJ, Geraedts JP. Molecular genetics of inherited long.QT syndromes. Eur Heart J 1998;19:1427-33.

8. Kuo HC, Cheng CF, Clark RB, Lin J], Lin JL, Hoshijima M, Nguyen-Tran VT, Gu Y, Ross J, Giles WR, Chien KR. A defect in the Kv channel-interacting protein $2\left(K C h I P_{2}\right)$ gene leads to a complete loss of transient outward potassium current (ITO) and confers genetic susceptibility to ventricular tachycardia. Cel! 2001;107:801-13.

9. Cardiovascular Genetics. Doevendans PA, Wilde AAM (eds)

Dordrecht, Netherlands: Kluwer Academic Publisher, 2001.

10. Wẹrens $\mathrm{XH}$, Vos MA, Doevendans PA, Wellens HJ. Novel insights in the congenital long.QT syndrome. Ann Intern Med 2002;in press.

11. Chen Q, Kirsch GE, Zhang D, Brugada R, Brugada J, Brugada P, Potenza D, Moya A, Borggrefe M, Breithardt C, Ortiz-Lopez R, Wang Z, Antzelevitch C, O'Brien RE, Schulze-Bahr E, Keating MT, Towbin JA, Wang $Q$. Genetic basis and molecular mechanism for idiopathic ventricular fibrillation. Nature 1998;392:293-96.

12. Schott J]. Alshinawi C, Kyndt F, Probst V, Hoorntje TM, Hulsbeek M, Wilde AA, Escande D, Mannens $M ! M$, Le Marec H. Cardiac conduction defects associate with mutations in SCNSA.

Nat Genet 1999;23:20-21.

13. Tan $H L$, Bink-Boelkens MT, Bezzina $C R$, Viswanathan PC, Beaufort-Krol GC, Van Tintelen P], Vạn den Berg MP. Wilde AA. Balșer JR. A șodium-channel mutation causes isolated cardiac conduction disease. Nature 2001;409:1043-47.

44. Plastē NM, Tawil R: Tristani-Firouzi M, Canun $S$, Bendahhou 5 , Tsunoda $A$, Donaldson MR, lannaccone ST, Brunt E, Barohn R, Clark J, Deymeer F, George AL Jr., Fish FA, Hahn A, Nitu A, Ozdemir C, Serdaroglu P, Subramony SH, Wolfe G. Fu YH, Ptacek L]. Mutations in $K_{\text {ir } 2,1}$ cause the developmental and episodic electrical phenotypes of Andersen's syndrome. Cell 2001;105:511-19. 


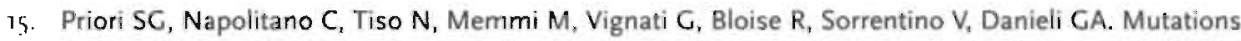
in the cardiac ryanodine receptor gene ( $h R \psi R 2)$ underlie catecholaminergic polymorphic ventricular tachycardia. Circulation 2001;103:196-200.

16. Tiso N, Stephan DA, Nava A, Bagattin A, Devaney JM, Stanchi F, Larderet G, Brahmbhatt B, Brown K, Bauce B, Muriago M, Basso C, Thiene G, Danieli GA, Rampazzo A. Identification of mutations in the cardiac ryanodine receptor gene in families affected with arrhythmogenic right ventricular cardiomyopathy type 2 (ARVD2). Hum Mol Cenet 2001;10:189-94.

17. Bennett PB, Yazawa K, Makita N, George AL Jr. Molecular mechanism for an inherited cardiac arrhythmia. Nature 1995; 376:683-85.

18. Wang DW, Yazawa K, George AL Jr, Bennett PB. Characterization of human cardiac. $\mathrm{Na}^{+}$channel mutations in the congenital long-QT syndrome. Proc Natl Acad Sci U S A 1996;93:13200-05.

19. Dumaine R, Wang Q, Keating MT, Hartmann HA, Schwartz PJ, Brown AM, Kirsch GE. Multiple mechanisms of $\mathrm{Na}^{+}$channel-linked long-QT syndrome. Circ Res 1996;78:216-24.

20. Wei J, Wang DW, Alings M, Fish F, Wathen M, Roden DM, George AL Jr. Congenital long-QT syndrome caused by a novel mutation in a conserved acidic domain of the cardiac $\mathrm{Na}^{+}$channel. Circulation 1999;99:3765-71.

21. Schwartz PJ, Priori SG, Dumaine R, Napolitano C, Antzelevitch C, Stramba-Badiale M, Richard TA, Berti MR, Bloise R. A molecular link between the sudden infant death syndrome and the long-QT syndrome. N EnglJ Med 2000;343:262-67.

22. Rivolta I, Abriel H, Tateyama M, Liu H, Memmi M, Vardas P, Napolitano C, Priori SG, Kass RS. Inherited Brugada and LQT-3 syndrome mutations of a single residue of the cardiac sodium channel confer distinct channel and clinical phenotypes. J Biol Chem 2001;276:30623-30.

23. Makita N, Shirai N, Nagashima M, Matsuoka R, Yamada $Y$, Tohse N, Kitabatake A. A de novo missense mutation of human cardiac $\mathrm{Na}^{+}$channel exhibiting novel molecular mechanisms of long. QT syndrome. FEBS Lett 1998;423:5-9.

24. Kambouris NG, Nuss HB, Johns DC, Tomaselli GF, Marban E. Balser JR. Phenotypic characterization of a novel long-QT syndrome mutation (R1623Q) in the cardiac sodium channel.

Circulation 1998;97:640-44.

25. An RH, Wang XL, Kerem B, Benhorin J, Medina A, Goldmir M, Kass RS. Nove! LQT-3 mutation affects. $\mathrm{Na}^{*}$ channel activity through interactions between alpha- and beta1-5ubunits. Cirt Res 1998;83:741-46.

26. Wehrens XH, Abriel H, Cabo C, Benhorin ), Kass RS. Arrhythmogenic mechanism of an LQT-3 mutation of the human heart $\mathrm{Na}^{+}$channel alpha-subunit: $\mathrm{A}$ computational analysis.

Circulation 2000;102:584-90.

27. Blaustein MP, Lederer Wj. Sodium/calcium exchange: its physiological implications. Physiol Rev 1999:79:763-854.

28. Tohse N. Calcium-sensitive delayed rectifier potassium current in guinea pig ventricular cells. Am J Physiol 1990;258:H1200-07.

29. Abriel H, Cabo C, Wehrens XH, Rivolta I, Motoike HK, Memmi M, Napolitane C, Priori SC, Kass RS. Novel arrhythmogenic mechanism revealed by a long-QT syndrome mutation in the cardiac $\mathrm{Na}^{*}$ channel. Circ Res 2001;88:740-45.

30. Wedekind H, Smits JP, Schulze-Bahr E, Arnold R, Veldkamp MW, Bajanowski T, Borggrefe M, Brinkmann B, Warnecke I, Funke H, Bhuiyan ZA, Wilde AA, Breithardt G, Haverkamp W. De novo mutation in the SCN5A gene associated with early onset of sudden infant death.

Circulation 2001;104:1158-64.

3i. Balser JR. Structure and function of the cardiac sodium channels. Cardiovasc Res 1999:42:327-38. 
32. Bezzina CR, Rook MB, Wilde AA. Cardiac sodium channel and inherited arrhythmia syndromes. Cardiovasc Res 2001;49:257-71.

33. Vassilev P, Scheuer T, Catterall WA. Inhibition of inactivation of single sodium channels by a sitedirected antibody. Proc Natl Acad Sci U S A 1989;86:8147-51.

34. Patton DE, West IW' Catterall WA, Goldin AL. Amino acid residues required for fast $\mathrm{Na}^{+}$channel inactivation: charge neutralizations and deletions in the III-IV linker.

Proc Natl Acad Sci U S A 1992;89:10905-09.

35. Rohl CA, Boeckman FA, Baker C, Scheuer T, Catterall WA, Klevit RE. Solution structure of the sodium channel inactivation gate. Biochemistry 1999:38:855-61.

36. West JW, Patton DE, Scheuer T, Wang Y, Goldin AL, Catterall WA. A cluster of hydrophobic amino acid residues, required for fast $\mathrm{Na}^{+}$channel inactivation. Proc Natl Acad Sci U S A 1992;89:10910-14.

37. Miyamoto K, Nakagawa T, Kuroda Y. Solution structure of the cytoplasmic linker between domain III-S6 and domain IV-S1 (III-IV linker) of the rat brain sodium channel in SDS micelles. Biopolymers 2001:59:380-93:

38. Miyamoto K, Kanaori K, Nakagawa T, Kuroda Y. Solution structures of the inactivation gate particle peptides of rat brain type-IIA and human heart sodium channels in SDS micelles.

f Pept Res 2001;57:203-14.

39. Tang $\mathrm{L}$, Kallen RG, Horn R. Role of an $\mathrm{S}_{4}$-S s linker in sodium channel inactivation probed by mutagenesis and a peptide blocker. J Gen Physiol 1996;108:89-104.

40. Smith MR, Goldin AL. Interaction between the sodium channel inactivation linker and domain III S4-S5. Biophys J 1997;73:1885-95.

41. Filatov GN, Nguyen TP, Kraner SD, Barchi RL. Inactivation and secondary structure in the $\mathrm{D}_{4} / \mathrm{S}_{4}-5$ region of the SkM1 sodium channel. J Gen Physiol 1998;11:703-15.

42. McPhee JC, Ragsdale DS, Scheuer T, Catterall WA. A critical role for the S4-S5 intracellular loop in domain IV of the sodium channel alpha-subunit in fast inactivation. J Biol Chem 1998;273:1121-29.

43. Miyamoto K, Nakagawa $T$, Kuroda $Y$. Solution structures of the cytoplasmic linkers between segments $\mathrm{S}_{4}$ and $\mathrm{S}_{5}\left(\mathrm{~S}_{4}-\mathrm{S}_{5}\right)$ in domains III and IV of human brain sodium channels in SDS micelles.

I Pept Res 2001;58:193-203.

44. Kellenberger S, Scheuer T; Catterall WA. Movement of the $\mathrm{Na}^{+}$channel inactivation gate during inactivation. J Biol Chem 1996;273:3097\%-79.

45. Lupoglazoff /M, Cheav T, Baroudi G, Berthet M, Denjoy I, Cauchemez B, Extramiana F, Chahine M, Guicheney P. Homozygous SCN5A mutation in long-QT syndrome with functional two-to-one atrioventricular block. Circ Res 2001;89:E16-21.

46. Ge!lens ME, George AL Ix, Chen LQ, Chahine M, Horn R, Barchi RL, Kallen RG. Primary structure and functional expression of the human cardiac tetrodotoxin-insensitive voltage-dependent sodium channel, Proc Natl Açad Sci U S A 1992;89:554-58.

47. George AL, Komisarof 1, Kallen RC, Barchi RL. Primary structure of the adult human skeletal muscle voltage-dependent sodium channel. Ann Neurol 1992;31:131-37.

48. Deschenes 1, Trottier $E_{1}$ Chahine M. Implication of the C-terminal region of the $\alpha$-subunit of voltagegated sodium channels in fast inactivation. J Membr Biol 2001;183:103-14.

49. Sato $C$, Matsumoto G. Sodium channel functioning based on an octagonal structure model. $J$ Membr Biol 1995:147:45-70.

50. Wang Q, Li Z, Shen J, Keating MT. Genomic organization of the human SCN5A gene encoding the cardiac sodium channel. Genomics 1996;34:9-16.

51. Goldin AL. Diversity of mammalian voltage-gated sodium channels.

Ann N Y Acad Sci 1999; 868:38-50. 
52. Wan X, Chen S, Sadeghpour A, Wang Q, Kirsch GE. Accelerated inactivation in a mutant $\mathrm{Na}^{+}$channel associated with idiopathic ventricular fibrillation. Am J Physiol Heart Circ Physiol 2001;280: $\mathrm{H}_{354}-60$.

53. Lerche $H_{8}$ Peter W, Fleischhauer R, Pika-Hartlaub U, Malina T, Mitrovic N, Lehmann-Horn F. Role in fast inactivation of the IV/ $/ \mathrm{S}_{4}-\mathrm{S}_{5}$ loop of the human muscle: $\mathrm{Na}^{+}$channel probed by cysteine mutagenesis. J Physiol 1997:505:345-52.

54. Tang L, Chehab N, Wieland SJ, Kallen RG. Glutamine substitution at alanine 1649 in the S4-S5. cytoplasmic loop of domain 4 removes the voltage sensitivity of fast inactivation in the human heart sodium channel. J Gen Physiol 1998;117:639-52.

55. Clancy CE, Rudy $Y$. Linking a genetic defect to its cellular phenotype in a cardiac arrhythmia. Nature 1999;400:566-69.

56. Hille B. Local anesthetics: hydrophilic and hydrophobic pathways for the drug-receptor reaction. I Gen Physiol 1977:69:497-515.

57. Hondeghem LM, Katzung BG. Time- and voltage-dependent interactions of antiarrhythmic drugs with cardiac sodium channels. Biochim Biophys Acta 1977:472:373-98.

58. Bean BP, Cohen $C_{j}$, Tsien RW. Lidocaine block of cardiac sodium channels. $J$ Gen Physiol 1983;81:613-42.

59. Starmer CF, Grant AO, Strauss HC. Mechanisms of use-dependent block of sodium channels in excitable membranes by local anesthetics. Biophys J 1984;46:15-27.

6o. Ragsdale DS, McPhee JC, Scheuer T, Catterall WA. Molecular deterrninants of state-dependent block of $\mathrm{Na}^{+}$channels by local anesthetics. Science 1994;265:1724-28.

61. Ragsdale DS, MCPhee JC, Scheuei T, Catterall WA. Common molecular determinants of local anesthetic, antiarrhythmic, and anticonvulsant block of voltage-gated $\mathrm{Na}^{+}$channels.

Proc Natl Acad Sci U S A 1996:93:9270-75.

62. Nau C, Wang SY, Strichartz GR, Wang GK. Point mutations at N434 in D1-S6 of mut $\mathrm{Na}^{+}$channels modulate binding affinity and stereoselectivity of local anesthetic enantiomers.

Mol Pharmacol 1999;56:404-13.

63. Wang GK, Quan C, Wang SY. Local anesthetic block of batrachotoxin-resistant muscle $\mathrm{Na}^{+}$channels: Mol Pharmacol 1998;54:389-96.

64. MCPhee IC, Ragsdale DS, Scheuer T, Catterall WA. A mutation in segment IVS6 disrupts fast inactivation of sodium channels. Proc Natl Acad Sci U S A 1994;91:12346-50.

65. McPhee IC, Ragsdale DS, Scheuer T, Catterall WA. A critical role for transmembrane segment IVS6 of the sodium channel $\alpha$-subunit in fast inactivation. J Biol Chem 1995;270:12025-34.

66. Li HL, Galue A, Meadows L, Ragsdale DS. A molecular basis for the different local anesthetic affinities of resting, versus open and inactivated states of the sodium channel.

Mol Pharmacol 1999:55:134-4\%.

67. Strichartz, GR. The inhibition of sodium currents in myelinated nerve by quaternary derivatives of lidocaine. J Gen Physiol 1973:62:37-57.

68. Gingrich KJ, Beardsley D, Yue DT. Ultra-deep biockade of $\mathrm{Na}^{+}$channèls by a quaternary ammonium ion: catalysis by a transition-intermediate state? J Physiol 1993:471:319-41.

69. Balser JR, Nuss HB, Orias DW, Johns DC, Marban E, Tomaselli GF, Lawrence \H. Local anesthetics as effectors of allosteric gating. Lidocaine effects on inactivation-deficient rat skeletal muscle $\mathrm{Na}^{+}$ channels. I Clin Invest 1996;98:2874-86.

70. Sunami A, Dudley SC, Fozzard HA. Sodium channel selectivity filter regulates antiarrhythmic drug binding. Proc Natl Acad Sci U S A 1997;94:14126-31. 
71. Sunami A, Glaaser IW, Fozzard HA. A critical residue for isoform difference in tetrodotoxin affinity is a molecular determinant of the external access path for local anesthetics in the cardiac sodium channel. Proc Noti Acad Sci U S A 2000;97:2326-31.

72. Bennett PB, Valenzuela C, Chen LQ, Kallen RG. On the molecular nature of the lidocaine receptor of cardiac $\mathrm{Na}^{+}$channels. Modification of block by alterations in the alpha-subunit III-IV interdomain.

Circ Res 1995;77:584-92.

73. Vedantham V, Cannon SC. The position of the fast-inactivation gate during lidocaine block of voltagegated $\mathrm{Na}^{+}$channels. J Gen Physiol 1999;113:7-16.

74. Hanck DA, Makielski JC, Sheets MF. Kinetic effects of quaternary lidocaine block of cardiac sodium channels: a gating current study. J Gen Physiol 1994:103:79-43.

75. Hanck DA, Makielski JC, Sheets MF. Lidocaine alters activation gating of cardiac $\mathrm{Na}^{+}$channels. Pflugers Arch 2000;439:814-21.

76. Schwartz PJ, Priori SG, Locati EH, Napolitano C, Cantu F, Towbin JA, Keating MT, Hammoude $H$, Brown AM, Chen LS. Long.QT syndrome patients with mutations of the SCNSA and HERG genes have differential responses to $\mathrm{Na}^{+}$channel blockade and to increases in heart rate. Implications for gene-specific therapy. Circulation 1995:92:3381-86.

77. Benhorin I, Taub R, Goldmit M, Kerem B, Kass RS, Windman I, Medina A. Effects of flecainide in patients with new SCN 5 A mutation: mutation-specific therapy for long-QT syndrome?

Circulation 2000;101:1698-706.

78. An RH, Bangalore R, Rosero SZ, Kass RS. Lidocaine block of LQT-3 mutant human $\mathrm{Na}^{+}$channels. Circ Res 1996;79:103-08:

79. Kambouris NG, Nuss HB, Johns DC, Marban E, Tomaselli CF, Balser JR. A revised view of cardiac sodium channel "blockade" in the long-QT syndrome. J Clin invest 2000;105:1133-40.

80. Echt DS, Liebson PR, Mitchell LB, Peters RW, Obias-Manno D, Barker AH, Arensberg D, Baker A, Friedman L, Greene HL. Mortality and morbidity in patients receiving encainide, flecainide, or placebo. The Cardiac Arrhythmia Suppression Trial. N EnglJ Med 1991;324:781-88.

81. Windle JR, Geletka RC, Moss AJ, Zareba W, Atkins DL. Normalization of ventricular repolarization with flecainide in long.QT syndrome patients with SCN5A-JKPQ mutation.

Ann Noninvasive Electrocardiol 2001:6:153-58.

82. Dumaine $\mathrm{R}$, Kirsch GE. Mechanism of lidocaine block of late current in long-QT mutant $\mathrm{Na}^{+}$ channels. Am J Physiol 1998;274:H477-87.

83. Ono K, Kaku T, Makita N, Kitabatake A, Arita M. Selective block of late currents in the $\triangle K P Q N^{+}$ channel mutant by pilsicainide and lidocaine with distinct mechanisms.

Mol Pharmacol 2000;57:392-400.

84. Courtney KR. Mechanism of frequency-dependent inhibition of sodium currents in frog myelinated nerve by the lidocaine derivative GEA. J Pharmacol Exp Ther 1975:195:225-36.

85. Kambouris NG, Hastings LA, Stepanovic S, Marban E, Tomaselli GF, Balser JR. Mechanistic link between lidocaine block and inactivation probed by outer pore mutations in the rat $\mu$ s seletal muscle sodium channel. J Physiol 1998;512:693-705.

86. Ong BH, Tomaselli $\mathrm{C}$, Balser JR. A structural rearrangement in the sodium channel pore linked to slow inactivation and use dependence. J Gen Physiol 2000;116:653-61.

87. Abriel H, Wehrens $X H_{*}$, Benhorin J, Kerem B, Kass RS. Molecular pharmacology of the sodium channel mutation Di79oG linked to the congenital long-QT syndrome. Circulation 2000;102:921-25.

88. Anno T, Hondeghem LM. Interactions of flecainide with guinea pig cardiac sodium channels. Importance of activation unblocking to the voltage dependence of recovery. Circ Res 1990;66:789.803 
89. Campbell TJ, Vaughan Williams EM. Voltage- and time-dependent depression of maximum rate of depolarization of guinea pig ventricular action potentials by 2 new antiarrhythmic drugs, flecainide and lorcainide. Cardiovasc Res 1983:17:251-58,

90. Nagatomo T, January CT, Makielski JC. Preferential block of late sodium current in the LQT-3 $\triangle K P Q$ mutant by the class IC antiarrhythmic fiecainide. Mol Pharmacol 2000;57:101-07.

91. Viswanathan $P C$, Bezzina $C R$, George $A L$, Roden DM, Wilde AA, Balser JR. Gating-dependent mechanisms for flecainide action in SCNSA-linked arrhythmia syndromes.

Circulation 2001;104:1200-05.

92. Wang DW, Yazawa K, Makita N, George AL Jr, Bennett PB. Pharmacological targeting of long-QT mutant sodium channels. J Clin Invest 1997;99:1714-20.

93. Li RA, Tsushima RG, Himmeldirk. K, Dime DS, Backx PH. Local anesthetic anchoring to cardiac sodium channels. Implications into tissue-selective drug targeting. Circ Res 1999:85:88-98.

94. De Luca A, Natuzzi F, Desaphy JF, Loni G, Lentini G, Franchini C, Tortorella V, Camerino DC. Molecular determinants of mexiletine structure for potent and use-dependent block of skeletal muscle sodium channels. Mol Pharmacol 2000;57:268-77.

95. Chandra R, Starmer CF, Grant AO. Multiple effects of $\triangle K P Q$ deletion mutation on gating of human Cardiac $\mathrm{Na}^{*}$ channels expressed in mammalian cells. Am J Physiol $1998 \mathrm{May} ; 274: \mathrm{H}_{7} 643-54$.

96. Nagatomo T, Fan Z, Ye B. Tonkovich CS, January CT, Kyle JW, Makielski JC. Temperature dependence of early and late currents in human cardiac wild-type and long-QT $\triangle K P Q ~ N a *$ channels.

Am J Physiol 1998;275:H2016-24.

97. Deschenes I, Baroudi G, Berthet M, Barde I, Chalvidan T, Denjoy I, Guicheney P, Chahine M. Electrophysiological characterization of SCN5A mutations causing long-QT (E1784 K) and Brugada (R1512W and R1432G) syndromes. Cardiovasc Res 2000;46:55-65.

98. Baroudi $G$, Chahine M. Biophysical phenotype of SCN5A mutations causing long-QT and Brugada syndrome. FEBS Lett 2000;487:224-28. 


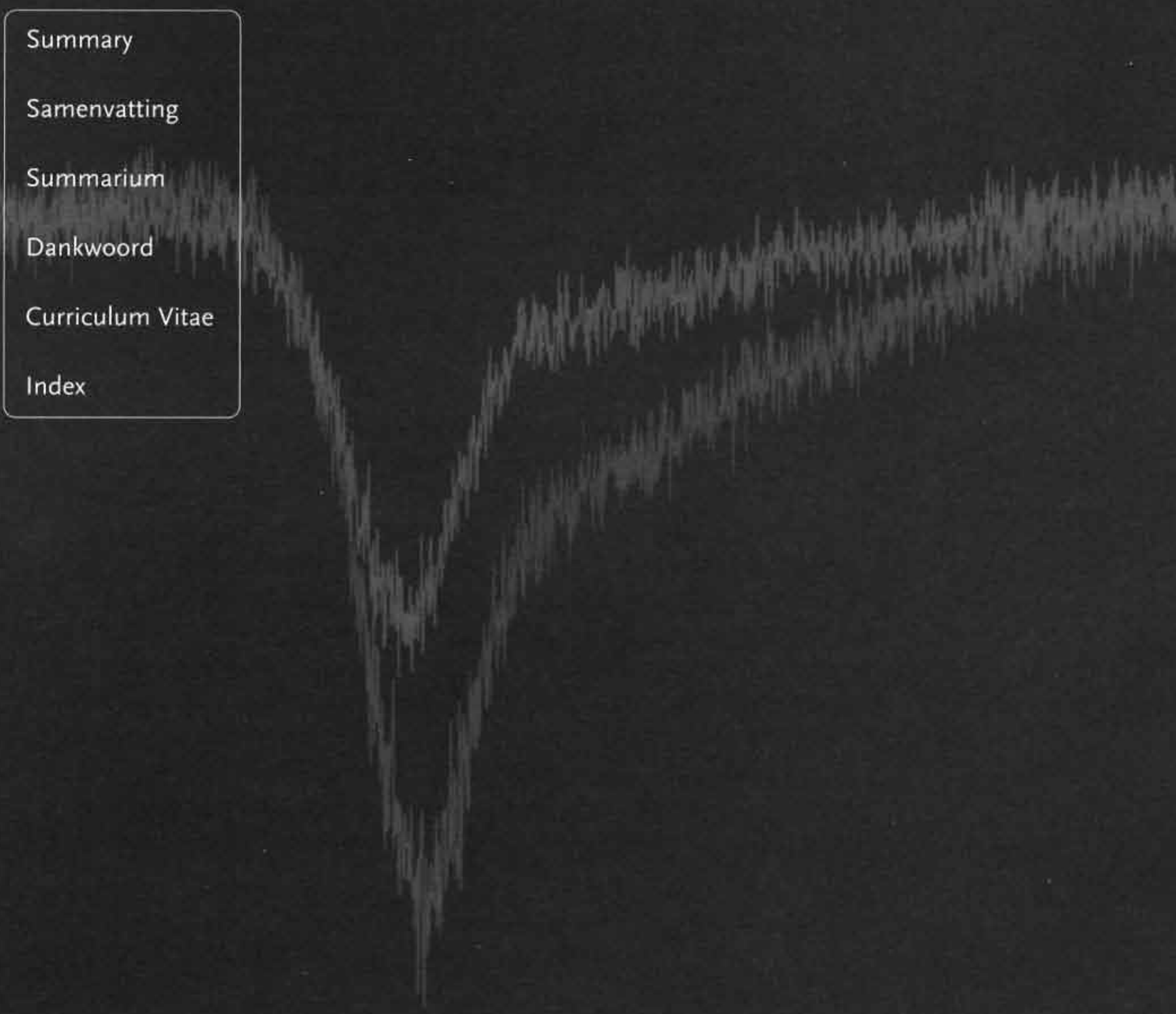




\section{Summary}

in recent years, important breakthroughs in the understanding of the congenital long-QT syndrome have followed the linkage to mutations in genes encoding cardiac ion channels. It became clear that what had been classified under the name 'congenital long-QT syndrome' actually represents a variety of different conditions caused by ion channel mutations, most of which produce alterations in ionic currents, leading to the same end result: prolonged ventricular repolarization. From both clinical and biophysical studies, it gradually became evident that heterogeneity exists, even among ion channel mutation in the same gene, which has important implications for both the comprehension of the pathophysiologic mechanisms, and perhaps even more promising, for mutation-specific therapeutic approaches.

In CHAPTER 1, the background of the present thesis is provided. Manifestations of the congenital long.QT syndrome include prolonged ventricular repolarization (QT-interval on the ECG), a propensity for life-threatening ventricular tachyarrhythmias, syncope, and sudden cardiac death. Current estimates suggest that this condition causes 3000-4000 sudden deaths in children and young adults each year in the US only. On the basis of the genetic transmission pattern, two major clinical syndromes are recognized: the autosomaldominant form (Romano-Ward syndrome) with a pure cardiac phenotype, and the rarer autosomal-recessive form (Jervell and Lange-Nielsen syndrome) characterized by the association with congenital neuronal deafness. Strategies to identify individuals with the congenital long-QT syndrome, with particular attention for the genotype-specific manifestations, and treatment options for different categories of these patients, are discussed in depth.

In CHAPTER 2, the physiology, molecular biology, biophysics, pharmacology, modulation, and regulation of the cardiac sodium channel are reviewed. This review focuses particularly on SCN5A mutations that cause congenital long-QT syndrome. Some sodium channel mutations may cause action potential prolongation by inducing sustained sodium channel activity during the action potential plateau phase. However, for several other mutations the arrhythmogenic mechanisms have not been elucidated.

In order to investigate the biophysical phenotypes of $\mathrm{Na}^{+}$channel mutations linked to the congenital long-QT syndrome, we expressed recombinant cardiac $\mathrm{Na}^{+}$ channels in human embryonic kidney (HEK 293) cells. Properties of the voltage-gated 
$\mathrm{Na}^{+}$channels were measured using whole-cell patch-clamp analysis. In CHA.PTER 3, the biophysical phenotype of the D1790G mutation was investigated. This mutation in the carboxy-terminus of the $\mathrm{Na}^{+}$charinel can prolong the ventricular action potential despite the absence of mutation-induced sustained $\mathrm{Na}^{+}$channel current. Using the Luo-Rudy model, computations of the ventricular action potential predicted that Di79oG-induced changes in $\mathrm{Na}^{+}$channel activity prolong action potentials in a steeply heart rate-dependent manner. This lengthening is not directly due to changes in $\mathrm{Na}^{+}$entry through bursting mutant channels but instead to alterations in the balance of net plateau currents by modulation of calcium-sensitive exchange and ion channel currents.

A clinical study in carriers of the Di790G mutation revealed that the class IB antiarrhythmic drug lidocaine was ineffective, whereas flecainide, a class iC sodium channel blocker, corrected repolarization parameters in these patients. In CHAPTER 4, we investigated the molecular basis of this divergence. The results of this study demonstrate that the Di79oG mutation confers a unique pharmacological res.ponse on expressed channels. The therapeutic effect in carriers of this mutation is probably the result of enhanced flecainide use-dependent block of Di790G channels. Furthermore, these data suggest a role of the $\mathrm{Na}^{+}$channel $\alpha$-subunit $\mathrm{C}$-terminus in the flecainide/ channel interaction.

In CHAPTER 5, the functional consequences of the novel E1295K mutation were described. Biophysical analysis of the mutant channels indicated that the E1295K mutation changes channel activity in a manner distinct from previously investigated LQT-3 mutations. The changes in gating shift the window of voltages at which $\mathrm{Na}^{+}$channels do not completely inactivate. The altered window current is likely to affect net membrane current during terminal repolarization, which is most likely the mechanism for action potential prolongation.

In CHAPTER 6, we describe the first case of a congenital long.QT syndrome patient with functional 2:1 atrioventricular block due to a heterozygcus mutation of the SCN5A gene. The L619F mutation promotes an increase in sustained (non-inactivating) current as well as an increase in $\mathrm{Na}^{+}$channel window-current, two mechanisms, which are expected to delay ventricular repolarization. Importantly, the defective inactivation imposed by the L619F mutation implicates a novel role for the domain I-II linker in the $\mathrm{Na}^{+}$channel inactivation process.

In the final CHAPTER of this thesis (CHAPTER 7), the major findings are discussed in the perspective of biophysical mechanisms underlying congenital long-QT syndrome caused by SCN5A mutations. In addition, new insights in the complex interrelationship 
between channel gating, antiarrhythmic block, and long-QT syndrome $\mathrm{Na}^{+}$channel mutations are discussed. Finally, the implications for the development of mutation-specific therapy for the long-QT syndrome are discussed.

In short, this thesis deals with the complex functional changes that occur in cardiac sodium channels in patients afflicted by the congenital long-QT syndrome. The data presented contribute to the comprehension that multiple, distinct gating defects in sodium channels may cause long-QT syndrome through discrete arrhythmogenic mechanisms.

This notion is likely to increasingly contribute to the design of mutation-specific pharmacotherapy based on unique gating features of long-QT syndrome-associated sodium channels. 


\section{Samenvatting}

Het aangeboren lange QT-tijd syndroom is de meest voorkomende ocrzaak van plotse hartdood in mensen zonder structureel hartlijden. De elektrische stroomvoorziening van het hart regelt de synchrone samentrekking van de hartspier. Als gevolg van deze samentrekking wordt het bloed door het lichaam rondgepompt. Bij het lange QT-tijd syndroom is er sprake van een normaal hart, maar de stroomvoorziening van het hart kan ineens verstoord raken. De naam van de ziekte verwijst naar het tijdsinterval tussen de Q- en T-golf op het electrocardiogram (ECG). In deze QT-tijd herstelt het hart zich van een samentrekking, om zo een volgende hartslag mogelijk te maken. Een afwijking in deze herstelperiode kan een ontsporing van het hartritme veroorzaken. Hierdoor gaat het hart chaotisch en ongecontroleerd kloppen, en kan daardoor geen bloed meer rondpompen, waardoor mensen bewusteloos kunnen raken of snel kunnen overlijden.

Recentelijk is ontdekt dat het aangeboren lange QT-tijd syndroom wordt veroorzaakt door een verandering in het erfelijk materiaal. Dergelijke DNA afwijkingen (mutaties) treden op in genen, die de informatie bevatten voor ionkanalen in het hart. Een goede functie van deze ionkanalen is essentieel voor een nauwkeurige alansturing van de electrische activiteit in het hart.

In HOOFDSTUK 1 worden de klinische kenmerken van het lange QT-tijd syndroom beschreven. Symptomen zijn onder andere een verlengd QT-interval op het ECG, een verhoogde kans op hartritmestoornissen, en plotselinge dood. Op basis van het overervingspatroon worden twee klinische syndromen onderscheiden: de autosomaal dominant-overervende vorm, Romano-Ward syndroom genaamd, en het autosomaal recessief-overervende fervell-Lange Nielsen syndroom, hetgeen vaak met doofheid gepaard gaat. In dit hoofdstuk worden de strategièen besproken hoe deze patiènten opgespoord kunnen worden en wat de beste behandeling is voor elke subgroep van lange QT-tiijd syndroom patiënten.

Het proefschrift biedt specifiek aandacht aan het lange QT-tijd syndroom type 3 . hetgeen veroorzaakt wordt door mutaties in het natriumkanaal. In HOOFDSTUK 2 wordt derhalve de fysiologie, moleculaire biologie, biofysica, farmacologie, modulatie en regulatie van het cardiale natriumkanaal besproken. In het bijzonder worden mutaties in het natriumkanaalgen besproken, die het lange QT-tijd syndroom veroorzaken. Voor een aantal mutaties is aangetoond dat ze het $\mathrm{QT}$-interval kunnen verlengen door een soort lekstroom 
te veroorzaken in de zieke natriumkanalen. Echter, er wordt ook geconcludeerd dat voor een aantal mutaties nog niet duidelijk is hoe ze het lange QT-tijd syndroom veroorzaken.

Om de biofysische eigenschappen van natriumkanaalmutaties te kunnen onderzoeken, werd een celsysteem gebruikt waarin mutante kanalen tot expressie gebracht werden. Middels de 'whole-ceil patch-clamp' techniek konden de biofysische eigenschappen van het voltage-afhankelijke natriumkanaal in detail onderzocht worden. In HOOFDSTUK 3 werd de Di79oG mutatie onderzocht. Deze mutatie bevindt zich in het carboxy-terminale uiteinde van het, natriumkanaal en kan de duur van het QT-interval verlengen zonder de prototypische lekstroom te veroorzaken. Door gebruik te maken van het Luo-Rudy computer model van de hartspiercel, werd aangetoond dat de Dı79oGgeinduceerde veranderingen in de natriumkanaalactiviteit verlenging van het QT-interval kunnen veroorzaken. Deze verlenging is waarschijnilijk het gevolg van indirecte veranderingen die optreden in de functie van andere ionkanalen in het hart, hetgeen het hart gevoeliger maakt voor hartritmestoornissen.

In een klinische studie in patiënten met de D1790G mutatie is aangetoond dat het klasse IB antiaritmicum lidocaine geen effect heeft, terwijl flecainide, een klasse IC natriumkanaalblokker, juist wel het QT-interval effectief kan verkorten. In HOOFDSTUK 4 werd de oorzaak van deze verrassende bevinding nader onderzocht. De resultaten van deze studie tonen aan dat de $\mathrm{D} 1790 \mathrm{G}$ mutatie unieke farmacologische eigenschappen geeft aan de natriumkanalen. Het therapeutische effect in de mutatiedragers is waarschijnlijk het gevolg van een versterkte 'gebruiks-afhankelijke' blokkade van Di7goC kanalen door flecainide. Tevens suggereren deze data dat het carboxy-terminale uiteinde van het natriumkanaal een rol kan hebben in de interactie met flecainide.

In HOOFDSTUK 5 worden de functionele eigenschappen beschreven van de E1295K mutatie. Een biofysische analyse toonde aan dat de E1295K mutatie de activiteit van de natriumkanalen op een unieke manier verandert. Deze veranderingen in de natriumkanaalgeleiding veranderen het gebied van voltages waarin het natriumkanaal niet volledig sluit. Deze veranderde zgn. 'window' natriumstroom verandert waarschijnlijk de totale hoeveelheid stroom in de hartspiercel aan het einde van de electrische herstelfase na een hartslag, hetgeen de totale duur van het $\mathrm{QT}$-interval kan verlengen.

In HOOFDSTUK 6 beschreven we voor het eerst een pasgeboren patiënt met het aangeboren lange QT-tijd syndroom en 2:l boezem-naar-kamer geleiding ten gevolge van een heterozygote mutatie in het natriumkanaalgen. Biofysische analyse van de $\mathrm{L}_{619} \mathrm{~F}$ mutatie toonde aan dat er sprake was van natriumkanaal lekstroom, in combinatie met een toegenomen 'window' natriumstroom. De functionele veranderingen ten gevolge van de 
L619F mutatie duiden waarschijnlijk op een niet eerder onderkende rol van het gebied tussen domein I en II in de sluiting van het natriumkanaal.

In het laatste hoofdstuk van dit proefschrift (HOOFDSTUK 7) worden de belangrijkste bevindingen bediscussieerd in de context van de biofysische mechanismen die het lange QT-tijd syndroom kunnen veroorzaken. Tevens worden de nieuwste inzichten op het gebied van de natriumkanaal functie en farmacologie samengevat. Tenslotte worden de implicaties voor de ontwikkeling van een mutatie-specifieke behandeling van lange QT-tijd patiënten besproken.

Concluderend kan worden gesteld dat de resultaten van de studies beschreven in dit proefschrift hebben geleid tot meer inzicht in de ontstaanswijze van het lange QT-tijd syndroom. Zo werd onder andere duidelijk dat hele subtiele veranderingen in de functie van het natriumkanaal verantwoordelijk kunnen zijn voor potentieel dodelijke hartritmestoornissen. Deze kennis kan bijdragen aan het totstandkomen van een mutatie-specifieke behandeling van patiënten met deze ziekte. Zo zullen sommige mensen meer prafijt hebben van een pacemaker om een trage hartslag te voorkomen, terwijl andere mensen (met andere natriumkanaal mutaties) beter beschermd worden tegen ritmestoornissen met behulp van bepaalde medicijnen. Door een adequate behandeling van deze patiënten kan de incidentie van hartritmestoornissen, flauwvallen, en plotselinge dood worden teruggedrongen. 


\section{Summarium}

LONGO QT CONGENITA SYNDROMA MAIOR CAUSA EST MORTIS SUBITAE CARDIACAE ALIOQUI SANORUM HOMINUM. AESTIMATIONES HODIERNAE CENSENT ISTAM CONDITIONEM QUOTANNIS CAUSAM ESSE MORTIS SUBITAE CARDIACAE MMM-MMMM PUERORUM ET iUvenum solum in Civitatibus Americae Unitis. Aegroti affiecti esse possunt PROLONGATIONE QT-INTERVALLI, SYNCOPA, VEL MORTE SUBITA CARDIACA. HIS TEMPORIBUS, NOVISSIMA REPERTA IN ARTE GENETICA COMPREHENSIONEM MELIORAVERUNT LONGO QT CONGENITAE SYNDROMAE. MANIFESTUM EST MUTATIONES IN GENIS DEPOSITORIIS INFORMATIONUM DE CANALIBUS IONICIS CARDIACIS CAUSAS ESSE HUIUS MORBI. RECTA FUNCTIO HORUM CANALIUM IONICORUM ESSENTIALIS EST AD NORMALEM RECTIONEM CONTRATIONUM CORDIS.

HAC THESIS DISSERAT DE LONGO QT SYNDROMA TYPO III (LQT-III), A MUTATIONIBUS CANAIIS CARDIACI SODII CAUSATA. UTENDO SYSTEMATE CELLULARI EMBRYONIS RENIS HUMANI (HEK- CCXCIII), DIVERSAE LQT-III MUTATIONES EXHIBITA

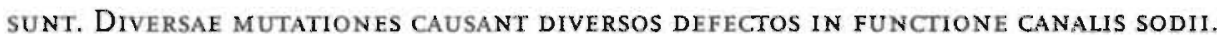
ETIAM MANIFESTUM EST, INTER ALIA, TARDOS RHYTHMOS CARDIACOS MAGNA PERICULA ESSE

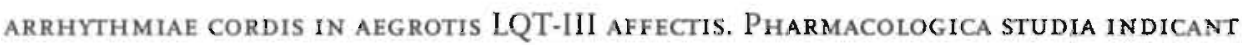
QUOD SINGULAE MUTATIONES EXHIBENT SENSIBILITATEM SINGULAREM DIVERSORUM MEDICAMENTORUM.

REPERTA DESCRIPTA IN HAC THESI PRAEBENT NOVAS COGNITIONES CIRCA diversttatem inter LQT-III Canalis sodit mutationes. Pluri mechanismi Canalis SODII DISFUNCTIONIS DESCRIPTI SUNT, ET APPARENS EST QUOD PARVI DEFECTI FUNCTIONAIES PROVOCARE POSSUNT RHYTHMOS IRREGULARES ATQUE MORTEM SUBTTAM CARDIACAM. NOVAE COGNITIONUM ACQUISITIONES CIRCA EXACTOS DEFECTOS A MUTATIONIBUS CANALIS SODII CAUSATOS, ETIAMQUE CIRCA EARUM SENSIBILITATEM PECUIIARUM MEDICAMENTORUM, MELIUS DIRIGENT THERAPIAM LONGO QT-III SYNDROMA AFFLICTORUM. 


\section{Acknowledgments}

LABOR VOLUPTASQUE, DISSIMILLIMA NATURA, SOCIETATE QUADAM INTER SE NATURAII SUNT IUNCTA. The research leading to my thesis was initiated by Dr. P.A. Doevendans, who asked me to become his first PhD student in 1997. We had actually first met 4 years before, when I was in the second year of medical school. Pieter and I carried out two clinical studies together, and he managed to convince me that cardiology is more interesting than surgery. Now, 7 years later, Pieter has been an excellent mentor civer a!l these years, allowing a lot of freedom for own initiative, but also providing guidance: at important moments. SUPERFLUA NON NOCENT! His incredible zest for work has been a great inspiration.

Much of the experimental work described in this thesis has been performed under the guidance of Prof. R.S. Kass at Columbia University (New York). Rocky managed to transform an illiterate student into a patch-clamp fanatic: EXERCITIO ARTUM. PARAT. His hospitality has been unlimited, his scientific mentorship exemplary. Rocky always managed to transform some crude observations into novel scientific concepts, and deserves great credit for the fast pace at which this thesis could be completed.

Dr. M.A. Vos is greatly acknowledged for his guidance and motivation for thorough reflection of my experimental data. DOLORES CAPITIS NON FERO, EOS DO. My passionate style of working may have intimidated you at: first, but I believe working together was a great learning experience for both of us. Now that I will change focus from congenital to acquired cardiac disease, I will benefit a lot from your lessons in the past.

When I was in medical school, few of my fellow students at the time were aware that one of the 'godfathers' of cardiology, Prof. H.J.J. Wellens, taught at our university. Being a young doctor, it was a dream coming true when I got the opporturity to wark for this eminent clinician, scientist, and teacher. RATIO ET CONCIIIUM PROPRIAE DUCIS ARTIS. His knowledge of the cardiology field is incredible, and his clear vision on the fiuture of cardiology helped to make choices for my future career:

The members of the thesis assessment committee, Professors H.A.l. Struijker Boudier, E. Carmeliet, H.). Crijns, I.P. Geraedts, and A.A.M. Wilde, are gratefully acknowledged for critically reading this thesis. I am also indebted to the following mentors from the past: Drs. J.P.M. Offermans, G.J.J.M. van Eys, F.R.C. Rannaekers, I.V. Small (Austrian Academy of Sciences), M.G.A. oude Egbrink, D.W. Slaaf, and G. Ramsay. Also, I would like to thank the following collaborators who contributed importantly to this 
thesis: Drs. R. Jongbloed, and H. Smeets (Dept of Genetics, Maastricht); Dr. J. Benhorin (Jerusalem, Israel); Drs. C. Cabo, H. Abriel, I. Rivolta, and H. Motoike (Columbia University, New York); Drs. C. Napolitano, and S.G. Priori (Pavia, Italy); Drs. T. Rossenbacker, M. Gewillig, and H. Heidbuchel (Leuven, Belgium).

I would like to express my gratitude to the Departments of Physiology and Cardiology (Maastricht University), in particular the members of the molecular cardiology group (Leon, Alexandra, Bianca, Chiel, Daan, Denny, Els, Eva, Ewald, Fawzi, Jordie, Meindert, Reinier, Roger, Sara, Sigmund, Vanessa, Victor), and the cardiac electrophysiology group (Cora, Chris, Dirk, Elke, Jérôme, Jet, Jurren, Marieke, Milan, Morten, Paul, Roel), Drs. de Muinck, Gorgels, and Hofstra, the secretaries (in particular Nicolle and Vivian), and the research nurses (Suzanne, Aimee, Margaret, Moniek, and Mireille). I am also very greatful to the members of the Kass lab (Columbia University): Allan, Badru, Colleen, Huajun, Jay, Jenny, Jing, Josh, Junko, Levi, Mary, Michihiro, and Tsedan. A very special thanks goes out to my friends Ellen, Esther, Ronald, and Ruben, for lots of motivation and encouragement. My sister Kim Wehrens and Luciano Nardonne are acknowledged for their help with the translation of the Latin summary. Oscar Toebosch, Romain Groenen, and in particular Paul Maas and Suzanne van den Homberg were essential to transform this text into a wonderful book.

I am grateful to my friends Dr. H. Schulten en Dr. T. Leiner, who will provide moral support during my thesis defense as 'paranymphs'. Tim, best friend since medical school, I hope that we will continue to develop novel ideas on research and medical education being on the other continent. IN TERRA INCOGNATA VINCEMUS! Finally, I am forever indebted to my parents and sister for their understanding, endless patience and encouragement when it was most required.

TEMPUS EST ETIAM MAIORA CONARI. 


\section{Curriculum Vitae}

The author of this thesis was born February 4, 1975 in Heerlen, the Netherlands. He attended the Bernardinus College in Heerlen, where he obtained two first-prize awards in the National Mathematics team Olympiads. In 1993, he graduated valedictorian (summa cum laude), with several distinctions for academic excellence.

The same year, he started his medical training at the Faculty of Medicine, Maastricht University. During the pre-clinical years, he served as a research assistant in the departments of Molecular Cell Biology, Physiology, and Surgery. With an E. Dekker-grant from the Netherlands Heart Foundation, he spent three months at the Austrian Academy of Sciences, Institute of Molecular Biology. He was the founding president of the 'Maastricht Medical Students Research Conference Foundation', and served as chairman on its First Annual Conference. In 1997, he graduated cum laude, after receiving the Maastricht University 'Student Research Prize 1997' for his MSc thesis.

His clinical training commenced with an internship at the department of General Surgery at the Royal Infirmary of Edinburgh (UK). After completion of the first year of clinical internships, he enrolled in the MD/PhD program at the Cardiovascular Research Institute Maastricht, Department of Cardiology. The year 1999 was spent at the department of Pharmacology, College of Physicians and Surgeons of Columbia University in New York City, with a stipend from 'De Drie Lichten Foundation'. Back in the Netherlands, he graduated as a Medical Doctor (cum laude), after receiving the National 'Hippokrates Award' for the best research project performed by a Dutch medical student (CHAPTERS 3 and 4 of this thesis). During his PhD training, he served as secretary of the PhD student Association of Maastricht University (ProVUM).

Dr. Wehrens has accepted a position as postdoctoral research scieritist at the department of Cardiology of the Columbia Presbyterian Medical Center in New York City. 
1. WEHRENS XHT, Doevendans PA, Dantzig van JM, Snoep G, Wellens HJJ. Infected sternal fracture hematoma after cardiopulmonary resuscitation presenting as pericarditis. Am Heart J 1996; $132: 685-86$.

2. Wehrens XHT, Mies B, Gimona M, Ramaekers FCS, Eys van GJjM, Small JV. Localization of smoothelin in avian smooth muscle and identification of a vascular-specific isoform. FEBS Lett 1997;405:315-20.

3. Eys van GJJM, Völler MCW, Timmer EDJ, WEHRENS XHT, Small JV, Schalken JA, Ramaekers FCS, Van der Loop FTL. Smoothelin expression characteristics: development of a smooth muscle cell in vitro system and identification of a vascular variant. Cell Struct Funct 1997;22:65-72.

4. WEHRENS XHT, Leiner T, Dammers R. Research performed by medical students [Interesse voor wetenschappelijk onderzoek bij medisch studenten].

Ned Tijdschr Geneeskd 1998; 1(2):1-2.

5. WEHRENS XHT, Leiner T, Dammers R, Stockbrügger RW. Participation of students in medical research at Maastricht University Medical School [Participatie in wetenschappelijk onderzoek door studenten. Een inventarisatie aan de medische faculteit Maastricht]. Bull Med Ondenw 1998;17:13-17.

6. WEHRENS XHT, Kirchhoff S, Doevendans PA. Mouse electrocardiography: an interval of thirty years [review]. Cardiovasc Res 2000;45:231-37.

7. WeHRENS XHT, Doevendans PA, Oude Ophuis TJ, Wellens HJJ. A comparison of electrocardiographic changes during reperfusion of acute myocardial infarction by thrombolysis or PTCA. Am Heart J 2000;139:430-36.

8. WeHrens XHT, Abriel H, Cabo C, Benhorin J, Kass RS. Arrhythmogenic mechanism of an LQT-3 mutation of the human heart $\mathrm{Na}^{+}$channel $\alpha$-subunit: a computational analysis. Circulation 2000;102:584-90.

9. Abriel H*, WEHRENS XHT*, Benhorin J, Kass RS. Molecular pharmacology of the sodium channel mutation D179oG linked to the long-QT syndrome.

Circulation 2000; 102:921-25. [* contributed equally].

10. WeHrens XHT, Breda van $E_{1}$ Velzen van IS, oude Egbrink MCA, Slaaf DW. Use of an intact mouse skeletal muscle preparation for endocrine vascular studies: evaluation of the model. Horm Metab Res 2000;32:378-80. 
17. Abriel H, Cabo C, Wehrens XHT, Rivolta I, Motoike HK, Memmi M, Napolitano C, Priori SC, Kass RS. Novel arrhythmogenic mechanism revealed by a long-QT syndrome mutation in the cardiac $\mathrm{Na}^{+}$channel. Circ Resi 2001;88:740-45.

12. WEHRENS XHT, Doevendans PA. Primary osteomyelitis of the sternum.

[Primaire osteomyelitis van het sternum] [letter]. Ned Tijdschr Geneesk 2001;145:245-46.

13. Dammers R, WEHRENS XHT, oude Egbrink MGA, Slaaf DW, Kurvers HAJM, Ramsay G. Microcirculatory effects of experimental acute limb ischaemia-reperfusion. Br J Surg 2001;88:816-24.

14. Wehrens XHT, Doevendans PA, Widdershoven JWMC, Dassen WRM, Prenger K, Wellens HJJ, Gorgels APM. Usefulness of sinus tachycardia and ST-segment elevation in $V_{5}$ to identify impending left ventricular wall rupture in inferior wall myocardial infarction. Am J Cardiol 2001;88:414-17.

15. WeHrens XHT, Leiner T. Publications from extracurricular research [letter]. Lancet 2007;358:846.

16. WeHrens XHT, Offermans JPM, Snijders M, Peeters LHH. Fetal cardiovascular response to large cardiovascular chorioangiomata.

Obstet Cynaecol Comm 2002, in press.

17. oude Egbrink MGA, Janssen CHCW, Ookawa K, Reneman RS, WEHRENS XHT, Maaijwee C, Ohshima N, Struijker Boudier HAJ, Tangelder G). Especially polymorphonuclear, but also monomorphonuclear leukocytes roll spontaneously in venules of intact rat skin: involvement of E-selectin. J Invest Dermotol 2002, in press.

18. Wehrens XHT, Rouwet EV, oude Egbrink MCA, Slaaf DW, Ramsay G. The effect of lower limb ischaemia-reperfusion injury on mesenteric microcirculation. BrJ Surg 2002, in press.

19. WeHRENS XHT, Doevendans PA, Vos MA, Wellens HJ. Novel insights in the congenital long-QT syndrome [review]. Ann Intern Med 2002, in press. 


\section{Index}

Acquired long-QT syndrome, 11

Andersen's syndrome, 140

Ankyrin, 51

Antiarrhythmic drug, 47, 100, 148

Arrhythmogenic mechanism, 14, 58

Arrhythmogenic right ventricular dysplasia, 140

Asymptomatic patient, 21

Atrioventricular block, 20, 60, 123

Autosomal-dominant, 11

Autosomal-recessive, 11

Ball-and-chain model, 46

Beta-blocker, 16, 116, 125

Beta-subunit, 13, 49

Bradycardia, 20, 86, 110,125

Brugada syndrome, 21, 40, 101, 133

Bursting channels, 55

Calcium channel, 76

Calcium transient, 75

Catecholaminergic polymorphic ventricular

tachycardia, 140

Channel gating: 45, 106, 125, 146

Channel modulation, 93

Channelopathy, 140

Chromosome, 13, 41, 75

Closed-state inactivation, 47, 133, 148

Compound heterozygosity, 13

Computational model, 58, 76, 142

Congenital deafness, 12

C-terminus, 57, 93, 146

Di790G mutation, $57,75,93,141$

DEKA ring, 149

Diagnostic criteria, 15

Diggoxin, 125

Dominant-negative effect, 14

E1295K mutation, 107, 142

Early after-depolarization, 81, 132

Effective refractory period, 123

Epileptic seizure, 16, 123
EP study, 23

Exercise test, 23

Fast inactivation, 46, 115, 133, 143

Flecainide, 21, 47, 93, 150

Genotype, 11, 130

Glycosylation, 52

Guarded receptor model, 48

Hinged-lid, 46

Hodgkin-Huxley model, 43, 76

Holter, 25, 110, 125

Human embryonic kidney cell, 55, 141

Idiopathic ventricular fibrillation, 21, 133

IFM motiv, 46, 143

Implantable cardioverter defibrillator, 20

Jervell Lange-Nielssen syndrome, 12

L619F, 54, 123, 142

Lev-Lenegre syndrome, 60

Lidocaine, 21, 47, 93, 148

Local anesthetic: 47,148

Luo-Rudy model, 6r, 76, 141

Markov model, 58, 151

Mexiletine, 17, 52, 117, 125, 150

Modulated receptor model, 48,148

Molecular pharmacology, 58, 101, 148

Nicorandil, 21

Noișe, 17

Pacemaker, 10, 117, 130

Permeation, 43

Penetrance, 26

Pharmacotherapy, 18, 58, 152

Plateau current, 40, 75, 142

P-loop, 43, 150

Polymorphism, 11, 127 
Post-translational modification, 52

Pre-excitation, 125

Pregnancy, 16

Progressive cardiac conduction defect, 60, 140

Protein kinase A, 52

Protein kinase C, 52

QT-interval dispersion, 22, 10 1

QT-interval prolongation, 11, 59, 107, 132

Quinidine, 26, 47

Recombinant DNA, 77, 94, 108, 124, 14t

Recovery from inactivation, $55,77,112,128,146$

Romano-Ward syndrome, 11

Ryanodine receptor, 140

Saxitoxin (STX), 44

Sinus pause, 23

Slip-mode conductance, 54

Slow inactivation, 46, 77, 147

Stellate ganglionectomy, 20

ST-segment elevation, 21

Sudden cardiac death, $11,60,123$

Sudden infant death syndrome, 56, 123

Syncope, 11, 60, 75, 93, 107, 123
Tetrodotoxin (TTX), 47, 111, 128

Tocainide, 21, 58

Tonic block 4, 48, 94, 150

Torsades de pointes, 14, 75, 93, 123

Transcriptional regulation, 51

Transgenic: mice, 61, 142.

Transient outward current, 87

Triggers, 16

T wave alternans, 14, 131

T wave dispersion, 22, 87

T wave morphology, 22, 110

Use-dependent block, 48, 92, 152

Ventricular fibrillation, 14, 56, 133

Ventricular repolarization, $11,75,93,108,123$

Ventricular septal defect (VSD), 125

Voltage--dependent activation, 45

Voltage-dependent inactivation, 46

Voltage-sensor, 45,150

Whole-cell patch-clamp, 55, 76, 94, 109, 124.

Window current, $41,108,123,142$

Xenopus oocytes, 13,50

Picture of COСомAMA, the Incan goddess of health and happiness. Originally a promiscuous woman cut in half by jealous lovers; her body grew into the first coca bush. 

ISBN 90-9015/470-1 